\author{
Universidade de São Paulo \\ Instituto de Astronomia, Geofísica e Ciências Atmosféricas \\ Departamento de Ciências Atmosféricas
}

\title{
Avaliação da previsão sazonal de precipitação do projeto North America Multi Model Ensemble (NMME) para o Brasil
}

José Paulo de Oliveira Flores

São Paulo

2021 



\title{
José Paulo de Oliveira Flores
}

\section{Avaliação da previsão sazonal de precipitação do projeto North America Multi Model Ensemble (NMME) para o Brasil}

\author{
Dissertação de mestrado apresentado no Instituto \\ de Astronomia, Geofísica e Ciências Atmosféricas \\ da Universidade de São Paulo (IAG-USP), para a \\ obtenção do título de Mestre em Meteorologia. \\ Versão Corrigida. $\mathrm{O}$ original encontra-se \\ disponível na Unidade.
}

Departamento: Ciências Atmosféricas

Orientador(a): Prof. ${ }^{a}$ Dr. ${ }^{a}$ Rosmeri Porfírio da Rocha

São Paulo 

"Pouco conhecimento faz com que as pessoas se sintam orgulhosas.

Muito conhecimento, com que se sintam humildes."

\section{Leonardo Da Vinci}




\section{Agradecimentos}

A Deus por todo amor, apoio emocional e psicológico necessários para a minha vida.

Aos meus pais Ivan e Natércia e irmãos João Pedro e Maria Clara, que foram os pilares da minha formação como pessoa e como aluno, me apoiando, aconselhando e incentivando em todos os momentos.

A minha noiva Luísa Zucchi, pelo amor, carinho e companheirismo, sempre me confortando, aconselhando e incentivando durante todas as etapas desse trabalho.

A minha orientadora, Prof. ${ }^{a}$ Dr $^{\mathrm{a}}$ Rosmeri Porfírio da Rocha, por todo apoio pessoal e acadêmico, os quais foram essenciais para a minha formação e pela oportunidade de realização desse trabalho.

Aos professores do Departamento de Ciências Atmosféricas da Universidade de São Paulo, que foram essenciais para o conhecimento adquirido ao longo do curso.

Ao meu amigo e colega de trabalho Marcio Oliveira, por todo companheirismo, conselhos pessoais e acadêmicos necessários para a minha formação.

Aos meus amigos de graduação e pós-graduação pelo apoio e companheirismo durante a minha jornada. 



\section{RESUMO}

FLORES, J. P. O. Avaliação da previsão sazonal de precipitação do projeto North America Multi-Model Ensemble (NMME) sobre o Brasil. 2021. Dissertação de Mestrado - Instituto de Astronomia, Geofísica e Ciências Atmosféricas, Universidade de São Paulo, São Paulo, 2021.

Esse estudo avaliou a previsão sazonal de precipitação dos modelos acoplados (oceanoatmosfera) que compõem o projeto North America Multi Model Ensemble (NMME). A fim de identificar e corrigir erros sistemáticos nas previsões de cada modelo, foram considerados dois períodos: hindcasting (1981/1982 - 2010) e forecasting (2011 - 2018). Para os dados observados considerou-se a análise de precipitação mensal do Climate Predicition Center (CPC), que foi interpolada bilinearmente para o mesmo espaçamento de grade dos modelos do NMME. Em função de atualizações do projeto NMME, foram avaliadas previsões dos modelos NCEPCFSv2, ECC-CanCM4i, ECC-GEMNEMO, GFDL-aer04, GFDL-FLORa06, GFDL-FLORb01, NASA-GEOS5v2 e a respectiva média linear entre eles (MME). As avaliações concentraram-se nas regiões Amazônica (AMZ), Centro-Oeste (BC), Nordeste (NE), Sudeste (SE) e Sul (SUL) do Brasil. As correlações de anomalias (e outros índices estatísticos) entre a chuva prevista e observada mostram que nas regiões AMZ e NE há uma maior habilidade de previsão dos modelos principalmente nas estações de DJF, MAM e JJA. Para a região SUL, há uma maior habilidade de previsão sobre áreas do PR para as estações MAM e JJA, e um deslocamento das maiores correlações para áreas do RS entre SON e DJF. As previsões de precipitação nas regiões SE e BC apresentam baixas correlações com as observações, indicando baixa previsibilidade sazonal dos modelos do NMME. As chuvas nas regiões AMZ, NE e SUL apresentam uma maior dependência, em termos de correlação, com o padrão de anomalia de temperatura da superfície do mar do Oceano Pacífico Equatorial, resultando em maior correlação dos modelos sobre essas regiões. Essa dependência com os padrões oceânicos não ocorre nas regiões SE e BC. Apesar do MME apresentar erros climatológicos mais suavizados em algumas estações do ano e LEADs de previsão, previsões individuais de modelos se destacam como melhores previsores de chuva do que o MME para todas as estações do ano. Essas informações estão sintetizadas neste estudo e poderão auxiliar os centros de previsão climática do país.

Palavras-chave: NMME, correlação de anomalia, índices estatísticos, Previsão Sazonal, chuva, Brasil. 


\begin{abstract}
FLORES, J. P. O. Evaluation of the seasonal precipitation of the North America Multi-Model Ensemble (NMME) over Brazil. 2021. Dissertação de Mestrado - Instituto de Astronomia, Geofísica e Ciências Atmosféricas, Universidade de São Paulo, São Paulo, 2021.
\end{abstract}

This study evaluated the seasonal precipitation forecast of the coupled models (oceanatmosphere) of the North America Multi Model Ensemble (NMME) project. In order to identify and correct systematic errors in the predictions of each model, two periods were considered: hindcasting (1981/1982 - 2010) and forecasting (2011 - 2018). For the observed data, monthly precipitation analysis from the Climate Predicition Center (CPC) were used, which were interpolated bilinearly to the same grid spacing of the NMME models. Due to updates of the NMME project, were evaluated the forecasts of the models NCEP-CFSv2, ECC-CanCM4i, ECCGEMNEMO, GFDL-aer04, GFDL-FLORa06, GFDL-FLORb01, NASA-GEOS5v2 and their linear average (MME). The evaluations concentrated in the regions Amazônica (AMZ), Centro-Oeste (BC), Nordeste (NE), Sudeste (SE) e Sul (SUL) of Brazil. The anomalies correlations (and other statistical indices) of the predicted and observed rain show that in the AMZ and NE regions there is a greater forecast ability of the models, mainly in the DJF, MAM and JJA. For the SUL region, there is a greater forecast ability in PR areas for MAM and JJA, which shifts to RS areas between SON and DJF. The rainfall forecasts in the SE and BC regions show low correlations with the observations, indicating low seasonal predictability of the NMME models. The precipitation in the $A M Z, N E$ and SUL regions have a greater dependence, as indicated by correlation patterns, with the sea surface temperature anomaly pattern of the Equatorial Pacific Ocean, resulting in a greater correlation of the models over these regions. This dependence on oceanic patterns does not occur in the SE and BC regions. Although in MME the biases are smoothed in some seasons and forecasting LEADs, individual model forecasts stand out as better precipitation forecasting than MME for all seasons. This information is synthesized in this study and may be useful to the Brazilian climate forecast centers.

Keywords: NMME, anomaly correlation, statistical indices, seasonal forecast, rain, Brazil. 


\section{Sumário}

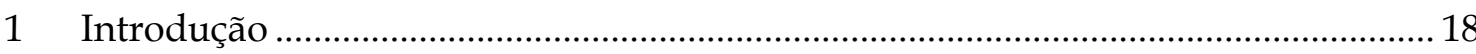

1.1 Evolução temporal da modelagem climática ........................................................ 19

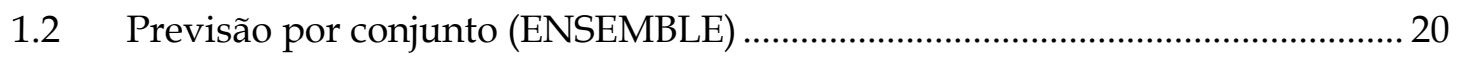

1.3 Previsões sazonais para o Brasil.......................................................................... 23

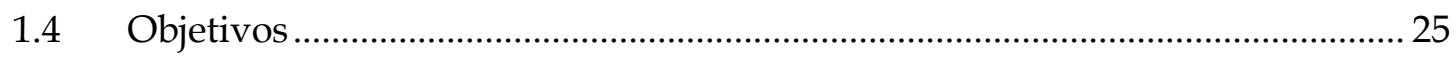

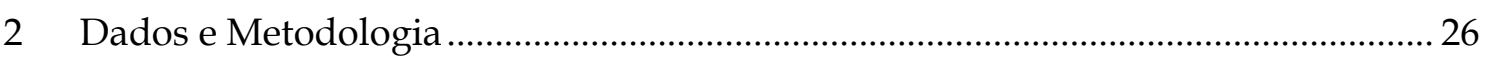

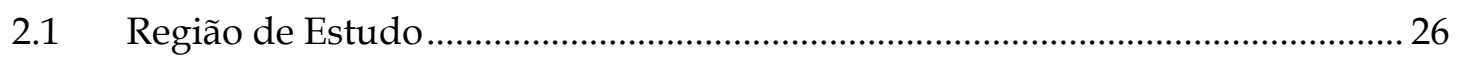

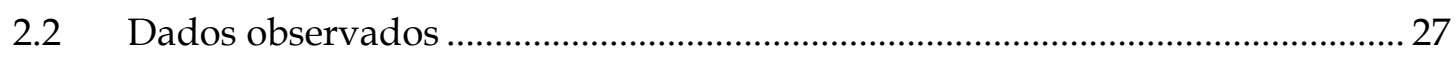

2.3 Previsões climáticas do North America Multi-Model Ensemble - NMME...... 29

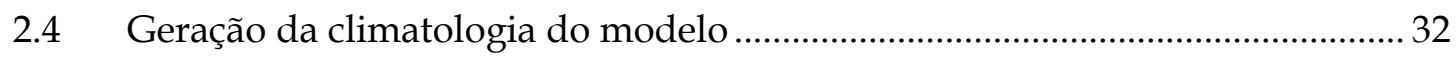

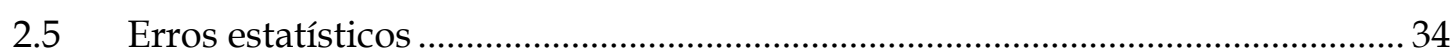

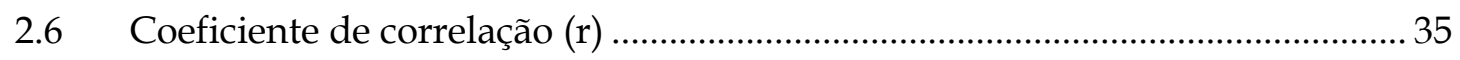

$2.7 \quad$ Teste de significância estatística (T-Student)...................................................... 37

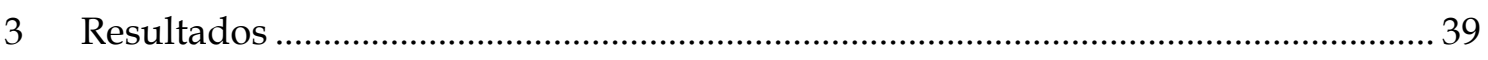

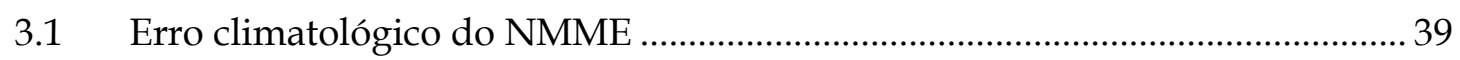

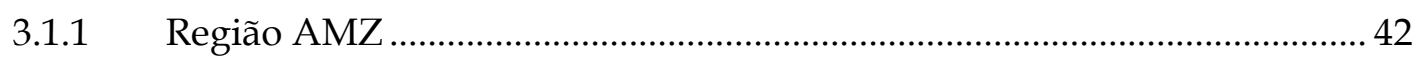

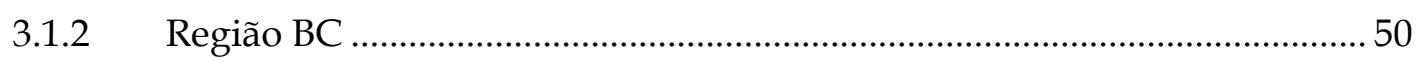

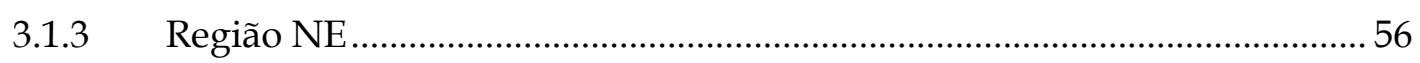

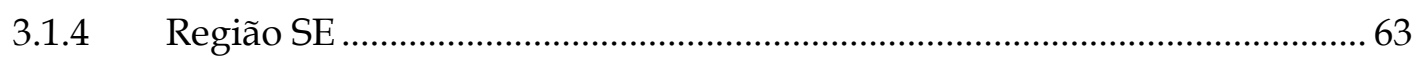

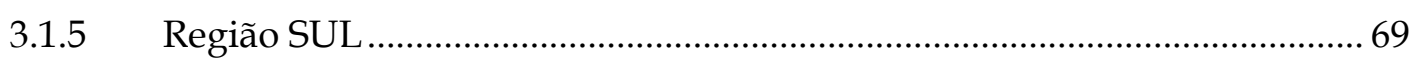

3.2 Correlação entre as anomalias de precipitação previstas e observadas. ........... 75

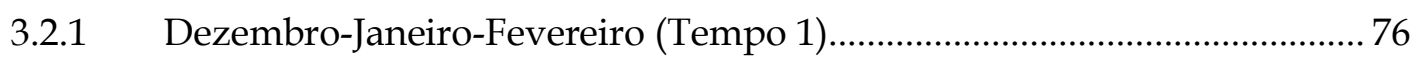

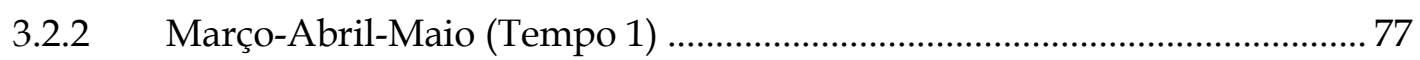

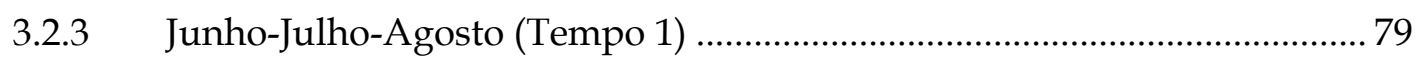

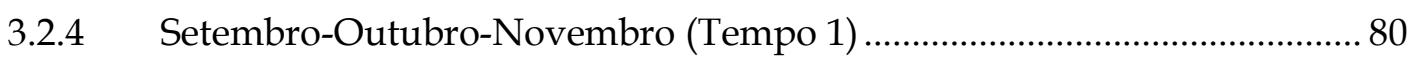

3.3 Correlação entre as anomalias de precipitação previstas e a Temperatura da

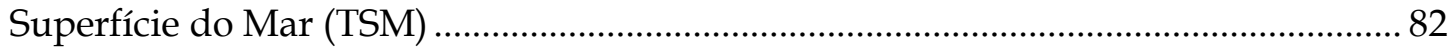

3.3.1 Dezembro-Janeiro-Fevereiro (Tempo 1) ………............................................. 83

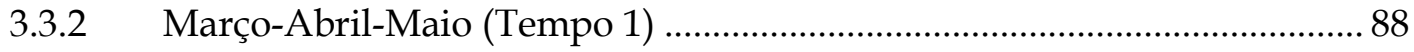

3.3.3 Junho-Julho-Agosto (Tempo 1) …………........................................................ 94

3.3.4 Setembro-Outubro-Novembro (Tempo 1) …............................................... 100

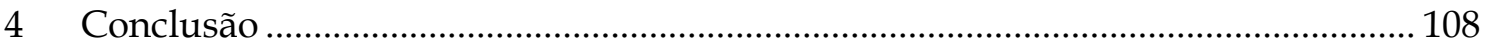

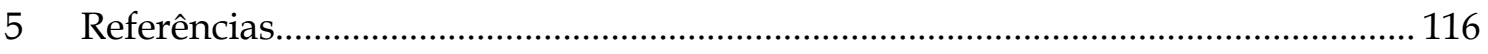




\section{Lista de Figuras}

Figura 1 - Comparação da Matriz hidrelétrica mundial (a esquerda) e brasileira (a direita). Fonte: EPE

Figura 2 - Evolução da modelagem climática ao longo dos anos. Fonte: Danabasoglu (2020).

Figura 3 - Ilustração esquemática para o conceito da divergência da previsão por ensemble. A linha sólida representa a evolução de uma simulação que possui uma melhor representação da condição inicial. As linhas tracejadas representam a evolução da simulação com condições iniciais dos demais membros do modelo com diferentes condições iniciais. No começo as condições iniciais são próximas (elipse pequena), porém com resultados podendo ser totalmente diferentes e dispersos (elipse maior). Dado a proximidade das condições iniciais, todos são resultados possíveis e não há um melhor modo de se escolher a melhor simulação. $O$ tamanho da elipse no estado final também representa a incerteza do modelo. Fonte: Adaptado Wilks, página 233........... 21

Figura 4 - Figura esquemática para a representação das componentes básicas da previsão por ensemble ao longo do tempo. A partir de uma condição perturbada, observa-se que há uma maior probabilidade de representar o real estado da atmosfera quando comparado a uma simulação em que não há perturbação. Fonte: Cheung, 2001........... 22

Figura 5 - Regiões do Brasil para realizar a verificação das previsões do NMME. ........ 26

Figura 6 - Comparação entre os dados de chuva do CPC após (esquerda) e antes (direita) a interpolação para a mesma grade para validação das previsões do NMME. O mapa é um exemplo de representação da interpolação referente a climatologia da precipitação entre 1981 e 2010 para o mês de Janeiro em mm.

Figura 7 - Esquema para a composição dos períodos de hindcast para cada modelo. As setas vermelhas representam os membros de cada modelo e M sua média (ensemble). CI: Condição Inicial. Clim representa o hindcast como sendo a média de M para o período de hindcast do modelo. 33 
Figura 8- Esquema para a correção da previsão pelo erro médio climatológico. O índice de asterisco (“*”) representa que diferentes climatologias foram utilizadas em função de modelos com períodos climatológicos diferentes (ver tabela 3)

Figura 9 - Ciclo anual da taxa de precipitação (mm/dia) para o tempo 1 de previsão para os hindcastings dos modelos do NMME para as regiões: (a) AMZ, (b) BC, (c) NE, (d) SE, (e) SUL

Figura 10 - Ciclo anual do erro climatológico (mm/dia) em módulo (erro absoluto), para o tempo 1 de previsão dos modelos do NMME para as regiões: (a) AMZ, (b) BC, (c) NE, (d) SE, (e) SUL 40

Figura 11 - Erro climatológico entre a climatologia observada e o tempo 1 de previsão do termo médio (MME), em mm/dia, para as estações de DJF (a), MAM (b), JJA (c) e SON (d). 42

Figura 12 - Diagramas de Taylor da região AMZ para (a) DJF, (b) MAM, (c) JJA, (d) SON. Em azul é mostrada a correlação, vermelho o RSME ( $\mathrm{mm} /$ dia) e em roxo o desvio padrão (mm/dia).

Figura 13 - Série temporal da chuva média sazonal (mm/dia) utilizada nas estatísticas do diagrama de Taylor para a região AMZ: (a) DJF, (b) MAM, (c) JJA, (d) SON. 44 Figura 14 - Erro climatológico relativo (\%) do NMME para a chuva média trimestral na região AMZ. O eixo Y representa os tempos de previsão (de 0 a 6), e o eixo X os trimestres alvos. 46

Figura 15 - Média dos erros relativos (\%) dos melhores modelos (menores erros em módulo) para as previsões entre as estações entre 2011 e 2018 para a região AMZ. O símbolo “*” indica que o modelo foi corrigido pelo viés climatológico (figura 13)........ 47 Figura 16 - Média dos erros relativos (\%) dos piores modelos (maiores erros em módulo) e para as previsões entre as estações entre 2011 e 2018 para a região AMZ. O símbolo “*” indica que o modelo foi corrigido pelo viés climatológico (figura 13). 48 Figura 17 - Diagramas de Taylor da região BC para (a) DJF, (b) MAM, (c) JJA, (d) SON. Em azul é mostrada a correlação, vermelho o RSME (mm/ dia) e em roxo o desvio padrão (mm/dia). 50

Figura 18 - Série temporal da chuva média sazonal (mm/dia) utilizada nas estatísticas do diagrama de Taylor para a região $B$ : (a) DJF, (b) MAM, (c) JJA, (d) (d) SON. 51 
Figura 19 - Erro climatológico relativo (\%) do NMME para a chuva média trimestral na região BC. O eixo Y representa os tempos de previsão (de 0 a 6), e o eixo X os trimestres alvos.

Figura 20 - Média dos erros relativos (\%) dos melhores modelos (menores erros em módulo) para as previsões entre as estações entre 2011 e 2018 para a região BC. O símbolo “*” indica que o modelo foi corrigido pelo viés climatológico (figura 19). 54

Figura 21 - Média dos erros relativos (\%) dos piores modelos (maiores erros em módulo) e para as previsões entre as estações entre 2011 e 2018 para a região BC. O símbolo “*” indica que o modelo foi corrigido pelo viés climatológico (figura 19). 55 Figura 22 - Diagramas de Taylor da região NE para (a) DJF, (b) MAM, (c) JJA, (d) SON. Em azul é mostrada a correlação, vermelho o RSME ( $\mathrm{mm} /$ dia) e em roxo o desvio padrão (mm/dia). .56

Figura 23 - Série temporal da chuva média sazonal (mm/dia) utilizada nas estatísticas do diagrama de Taylor para a região NE: (a) DJF, (b) MAM, (c) JJA, (d) SON. 57 Figura 24 - Erro climatológico relativo (\%) do NMME para a chuva média trimestral na região NE. O eixo $Y$ representa os tempos de previsão (de 0 a 6 ), e o eixo $X$ os trimestres alvos.

Figura 25 - Média dos erros relativos (\%) dos melhores modelos (menores erros em módulo) para as previsões entre as estações entre 2011 e 2018 para a região NE. O símbolo "*" indica que o modelo foi corrigido pelo viés climatológico (figura 24)........ 61 Figura 26 - Média dos erros relativos (\%) dos piores modelos (menores erros em módulo) para as previsões entre as estações entre 2011 e 2018 para a região NE. O símbolo “*” indica que o modelo foi corrigido pelo viés climatológico (figura 24).

Figura 27 - Diagramas de Taylor da região SE para (a) DJF, (b) MAM, (c) JJA, (d) SON. Em azul é mostrada a correlação, vermelho o RSME ( $\mathrm{mm} /$ dia) e em roxo o desvio padrão (mm/dia).

Figura 28 - Série temporal da chuva média sazonal (mm/dia) utilizada nas estatísticas do diagrama de Taylor para a região SE: (a) DJF, (b) MAM, (c) JJA, (d) SON.

Figura 29 - Erro climatológico relativo (\%) do NMME para a chuva média trimestral na região SE. O eixo Y representa os tempos de previsão (de 0 a 6), e o eixo X os trimestres alvos. 
Figura 30 - Média dos erros relativos (\%) dos melhores modelos (menores erros em módulo) para as previsões entre as estações entre 2011 e 2018 para a região SE. O símbolo “*” indica que o modelo foi corrigido pelo viés climatológico (figura 29).

Figura 31 - Média dos erros relativos (\%) dos piores modelos (menores erros em módulo) para as previsões entre as estações entre 2011 e 2018 para a região NE. O símbolo “*” indica que o modelo foi corrigido pelo viés climatológico (figura 29).

Figura 32 - Diagramas de Taylor da região SE para (a) DJF, (b) MAM, (c) JJA, (d) SON. Em azul é mostrada a correlação, vermelho o RSME ( $\mathrm{mm} /$ dia) e em roxo o desvio padrão (mm/dia).

Figura 33 - Série temporal da chuva média sazonal (mm/dia) utilizada nas estatísticas do diagrama de Taylor para a região SE: (a) DJF, (b) MAM, (c) JJA, (d) SON. 70

Figura 34 - Erro climatológico relativo (\%) do NMME para a chuva média trimestral na região SUL. O eixo Y representa os tempos de previsão (de 0 a 6), e o eixo X os trimestres alvos. .73

Figura 35 - Média dos erros relativos (\%) dos melhores modelos (menores erros em módulo) para as previsões entre as estações entre 2011 e 2018 para a região SUL. O símbolo "*" indica que o modelo foi corrigido pelo viés climatológico (figura 34)........ 74 Figura 36 - Média dos erros relativos (\%) dos piores modelos (menores erros em módulo) para as previsões entre as estações entre 2011 e 2018 para a região SUL. O símbolo “*” indica que o modelo foi corrigido pelo viés climatológico (figura 34).

Figura 37 - Correlação de anomalia da taxa de precipitação prevista e observada para DJF- Tempo 1 com foco sobre o Brasil. Condição Inicial da previsão: Novembro. Áreas em branco não possuem significância estatística para a CA. 77 Figura 38 - Correlação de anomalia da taxa de precipitação prevista e observada para MAM- Tempo 1 com foco sobre o Brasil. Condição Inicial da previsão: Fevereiro. Áreas em branco não possuem significância estatística para a CA .78 Figura 39 - Correlação de anomalia da taxa de precipitação prevista e observada para JJA- Tempo 1 com foco sobre o Brasil. Condição Inicial da previsão: Maio. Áreas em branco não possuem significância estatística para a CA. 
Figura 40 - Correlação de anomalia da taxa de precipitação prevista e observada para SON- Tempo 1 com foco sobre o Brasil. Condição Inicial da previsão: Agosto. Áreas em branco não possuem significância estatística para a CA. 81

Figura 41 - Índices de teleconexão em diferentes bacias Oceânicas. ENOS: El Niño Oscilação Sul; ODP: Oscilação Decadal do Pacífico; IOBW: Indian Ocean Basin Warming; DOI: Dipolo do Oceano Índico; TSA e TNA: Dipolo do Oceano Atlântico; OAN: Oscilação do Atlântico Norte.

Figura 42 - Correlação temporal entre a anomalias de chuva previstas e anomalias de TSM para o tempo 1 de previsão para o hindcast de DJF para região AMZ: (a) CanCM4i, (b) CFSv2, (c) CCSM4, (d) GEMNEMO, (e) GFDLAER04, (f) GFDLFLORA06, (g) GFDLFLORB01, (h) NASA, (i) MME. Os valores em branco não apresentam significância estatística.

Figura 43 - Correlação temporal entre a anomalias de chuva previstas e anomalias de TSM para o tempo 1 de previsão para o hindcast de DJF para região BC: (a) CanCM4i, (b) CFSv2, (c) CCSM4, (d) GEMNEMO, (e) GFDLAER04, (f) GFDLFLORA06, (g) GFDLFLORB01, (h) NASA, (i) MME. Os valores em branco não apresentam significância estatística. 84

Figura 44 - Correlação temporal entre a anomalias de chuva previstas e anomalias de TSM para o tempo 1 de previsão para o hindcast de DJF para região NE: (a) CanCM4i, (b) CFSv2, (c) CCSM4, (d) GEMNEMO, (e) GFDLAER04, (f) GFDLFLORA06, (g) GFDLFLORB01, (h) NASA, (i) MME. Os valores em branco não apresentam significância estatística.

Figura 45 - Correlação temporal entre a anomalias de chuva previstas e anomalias de TSM para o tempo 1 de previsão para o hindcast de DJF para região SE: (a) CanCM4i, (b) CFSv2, (c) CCSM4, (d) GEMNEMO, (e) GFDLAER04, (f) GFDLFLORA06, (g) GFDLFLORB01, (h) NASA, (i) MME. Os valores em branco não apresentam significância estatística. .86

Figura 46 - Correlação temporal entre a anomalias de chuva previstas e anomalias de TSM para o tempo 1 de previsão para o hindcast de DJF para região SUL: (a) CanCM4i, (b) CFSv2, (c) CCSM4, (d) GEMNEMO, (e) GFDLAER04，(f) GFDLFLORA06, (g) GFDLFLORB01, (h) NASA, (i) MME. Os valores em branco não apresentam significância estatística. 
Figura 47 - Padrões de correlação para as anomalias de TSM e chuva observada para as regiões de estudo e para a estação de DJF. Os valores em branco não apresentam significância estatística.

Figura 48 - Correlação temporal entre a anomalias de chuva previstas e anomalias de TSM para o tempo 1 de previsão para o hindcast de MAM para região AMZ: (a) CanCM4i, (b) CFSv2, (c) CCSM4, (d) GEMNEMO, (e) GFDLAER04, (f) GFDLFLORA06, (g) GFDLFLORB01, (h) NASA, (i) MME. Os valores em branco não apresentam significância estatística. 89

Figura 49 - Correlação temporal entre a anomalias de chuva previstas e anomalias de TSM para o tempo 1 de previsão para o hindcast de MAM para região BC: (a) CanCM4i, (b) CFSv2, (c) CCSM4, (d) GEMNEMO, (e) GFDLAER04, (f) GFDLFLORA06, (g) GFDLFLORB01, (h) NASA, (i) MME. Os valores em branco não apresentam significância estatística. 90

Figura 50 - Correlação temporal entre a anomalias de chuva previstas e anomalias de TSM para o tempo 1 de previsão para o hindcast de MAM para região NE: (a) CanCM4i, (b) CFSv2, (c) CCSM4, (d) GEMNEMO, (e) GFDLAER04, (f) GFDLFLORA06, (g) GFDLFLORB01, (h) NASA, (i) MME. Os valores em branco não apresentam significância estatística. .91

Figura 51 - Correlação temporal entre a anomalias de chuva previstas e anomalias de TSM para o tempo 1 de previsão para o hindcast de MAM para região SE: (a) CanCM4i, (b) CFSv2, (c) CCSM4, (d) GEMNEMO, (e) GFDLAER04, (f) GFDLFLORA06, (g) GFDLFLORB01, (h) NASA, (i) MME. Os valores em branco não apresentam significância estatística. 92

Figura 52 - Correlação temporal entre a anomalias de chuva previstas e anomalias de TSM para o tempo 1 de previsão para o hindcast de MAM para região SUL: (a) CanCM4i, (b) CFSv2, (c) CCSM4, (d) GEMNEMO, (e) GFDLAER04, (f) GFDLFLORA06, (g) GFDLFLORB01, (h) NASA, (i) MME. Os valores em branco não apresentam significância estatística. .93

Figura 53 - Padrões de correlação para as anomalias de TSM e chuva observada para as regiões de estudo e para a estação de MAM. Os valores em branco não apresentam significância estatística. 94 
Figura 54 - Correlação temporal entre a anomalias de chuva previstas e anomalias de TSM para o tempo 1 de previsão para o hindcast de JJA para região AMZ: (a) CanCM4i, (b) CFSv2, (c) CCSM4, (d) GEMNEMO, (e) GFDLAER04, (f) GFDLFLORA06, (g) GFDLFLORB01, (h) NASA, (i) MME. Os valores em branco não apresentam significância estatística. 95

Figura 55 - Correlação temporal entre a anomalias de chuva previstas e anomalias de TSM para o tempo 1 de previsão para o hindcast de JJA para região BC: (a) CanCM4i, (b) CFSv2, (c) CCSM4, (d) GEMNEMO, (e) GFDLAER04, (f) GFDLFLORA06, (g) GFDLFLORB01, (h) NASA, (i) MME. Os valores em branco não apresentam significância estatística. 96

Figura 56 - Correlação temporal entre a anomalias de chuva previstas e anomalias de TSM para o tempo 1 de previsão para o hindcast de JJA para região NE: (a) CanCM4i, (b) CFSv2, (c) CCSM4, (d) GEMNEMO, (e) GFDLAER04, (f) GFDLFLORA06, (g) GFDLFLORB01, (h) NASA, (i) MME. Os valores em branco não apresentam significância estatística.. 97

Figura 57 - Correlação temporal entre a anomalias de chuva previstas e anomalias de TSM para o tempo 1 de previsão para o hindcast de JJA para região SE: (a) CanCM4i, (b) CFSv2, (c) CCSM4，(d) GEMNEMO, (e) GFDLAER04，(f) GFDLFLORA06，(g) GFDLFLORB01, (h) NASA, (i) MME. Os valores em branco não apresentam significância estatística. 98

Figura 58 - Correlação temporal entre a anomalias de chuva previstas e anomalias de TSM para o tempo 1 de previsão para o hindcast de JJA para região SUL: (a) CanCM4i, (b) CFSv2, (c) CCSM4, (d) GEMNEMO, (e) GFDLAER04, (f) GFDLFLORA06, (g) GFDLFLORB01, (h) NASA, (i) MME. Os valores em branco não apresentam significância estatística.

Figura 59 - Padrões de correlação para as anomalias de TSM e chuva observada para as regiões de estudo e para a estação de MAM. Os valores em branco não apresentam significância estatística. 100

Figura 60 - Correlação temporal entre a anomalias de chuva previstas e anomalias de TSM para o tempo 1 de previsão para o hindcast de SON para região AMZ: (a) CanCM4i, (b) CFSv2, (c) CCSM4，(d) GEMNEMO, (e) GFDLAER04，(f) GFDLFLORA06，(g) 
GFDLFLORB01, (h) NASA, (i) MME. Os valores em branco não apresentam significância estatística.

Figura 61 - Correlação temporal entre a anomalias de chuva previstas e anomalias de TSM para o tempo 1 de previsão para o hindcast de SON para região BC: (a) CanCM4i, (b) CFSv2, (c) CCSM4, (d) GEMNEMO, (e) GFDLAER04, (f) GFDLFLORA06, (g) GFDLFLORB01, (h) NASA, (i) MME. Os valores em branco não apresentam significância estatística. 102

Figura 62 - Correlação temporal entre a anomalias de chuva previstas e anomalias de TSM para o tempo 1 de previsão para o hindcast de SON para região NE: (a) CanCM4i, (b) CFSv2, (c) CCSM4, (d) GEMNEMO, (e) GFDLAER04, (f) GFDLFLORA06, (g) GFDLFLORB01, (h) NASA, (i) MME. Os valores em branco não apresentam significância estatística. 103

Figura 63 - Correlação temporal entre a anomalias de chuva previstas e anomalias de TSM para o tempo 1 de previsão para o hindcast de SON para região SE: (a) CanCM4i, (b) CFSv2, (c) CCSM4, (d) GEMNEMO, (e) GFDLAER04, (f) GFDLFLORA06, (g) GFDLFLORB01, (h) NASA, (i) MME. Os valores em branco não apresentam significância estatística. 104

Figura 64 - Correlação temporal entre a anomalias de chuva previstas e anomalias de TSM para o tempo 1 de previsão para o hindcast de SON para região SUL: (a) CanCM4i, (b) CFSv2, (c) CCSM4, (d) GEMNEMO, (e) GFDLAER04, (f) GFDLFLORA06, (g) GFDLFLORB01, (h) NASA, (i) MME. Os valores em branco não apresentam significância estatística. 105

Figura 65 - Padrões de correlação para as anomalias de TSM e chuva observada para as regiões de estudo e para a estação de MAM. Os valores em branco não apresentam significância estatística. 106

Figura 66 - Relação de até quatro melhores (a esquerda) e piores (a direita) modelos do NMME para previsão, considerando os valores de correlação entre a precipitação prevista e observada estatisticamente significativa. A ordem dos modelos (letras) indica a ordem das maiores para as menores correlações. A cor das letras mostra se determinado modelo possui correlação negativa (azul) ou positiva (vermelho) com a região do Pacífico Equatorial 


\section{Lista de tabelas}

Tabela 1 - Delimitações (latitudes e longitudes) das áreas indicadas na figura 4. 27

Tabela 2 - Precipitação média sazonal (mm/ dia) no período 1981-2010 da análise CPC em cada área considerando resolução horizontal original $(0.5 \times 0.5)$ e interpolada $(1.0 \mathrm{x}$ $1.0)$.

Tabela 3 - Modelos participantes do projeto NMME. Em azul temos os modelos utilizados atualmente em modo operacional. Em vermelho os modelos que já foram descontinuados/substituídos. 31

Tabela 4 - Relação do tempo de previsão e estação alvo para diferentes combinações de condições iniciais. O mês em cada célula representa a condição inicial da previsão para cada estação alvo.

Tabela 5 - Coeficiente de correlação (r), Desvio Padrão (STD) e RMSD para os hindcasts (1982-2010) modelos para estações do ano da região AMZ. Em negrito temos as correlações que possuem significância estatística para um valor de $\alpha=0.05$.

Tabela 6 - Coeficiente de correlação (r), Desvio Padrão (STD) e RMSD para os hindcasts (1982-2010) modelos para estações do ano da região BC. Em negrito temos as correlações que possuem significância estatística para um valor de $\alpha=0.05$. 52

Tabela 7 - Coeficiente de correlação (r), Desvio Padrão (STD) e RMSD para os hindcasts (1982-2010) modelos para estações do ano da região NE. Em negrito temos as correlações que possuem significância estatística para um valor de $\alpha=0.05$. 59

Tabela 8 - Coeficiente de correlação (r), Desvio Padrão (STD) e RMSD para os hindcasts (1982-2010) modelos para estações do ano da região SE. Em negrito temos as correlações que possuem significância estatística para um valor de $\alpha=0.05$.

Tabela 9 - Coeficiente de correlação (r), Desvio Padrão (STD) e RMSD para os hindcasts (1982-2010) modelos para estações do ano da região SUL. Em negrito temos as correlações que possuem significância estatística para um valor de $\alpha=0.05$.

Tabela 10 - Média na área da região Equatorial do Pacífico das correlações entre as anomalias de TSM e precipitação previstas para as estações do ano e regiões de estudo. (a) CanCM4i, (b) CFSv2, (c) CCSM4, (d) GEMNEMO, (e) GFDLaer04, (f) GFDLFLORa06, 
(g) GFDLFLORb01, (h) NASA, (i) MME e observação. Em vermelho temos as correlações positivas e em azul as negativas. Em branco temos as correlações sem significância estatística. 


\section{Lista de abreviaturas}

EPE - Empresa de Pesquisa Energética do Brasil.

GrEC - Grupo de Estudos Climáticos da Universidade de São Paulo

NMME - North America Multi-Model Ensemble

NCEP - National Centers for Environmental Prediction

GFDL - Geophysical Fluid Dynamics Laboratory

ECCC - Environment and Climate Change Canada

NCAR - National Center for Atmospheric Research

NASA - National Aeronautics and Space Administration

ENOS - El Niño Oscilação Sul

IOBW - Indian Ocean Basin Warming

OMJ - Oscilação de Madden-Julian

ODP - Oscilação Decadal do Pacífico

TSA e TNA - Dipolo do Oceano Atlântico Sul e Norte

DOI - Dipolo do Oceano Índico

MMP - Modo Meridional do Pacífico

TSM - Temperatura da Superfície do Mar

CI - Condição Inicial

Leads - Tempo de previsão a partir da condição inicial 


\section{Introdução}

A precipitação é uma das variáveis meteorológicas que rege boa parte da vida cotidiana das pessoas e contribui para o desenvolvimento energético e econômico de um país. Segundo a Empresa de Pesquisa Energética do Brasil (EPE), cerca de 65.2\% da matriz energética do país (figura 1) é proveniente da matriz hidráulica que por sua vez utiliza as águas da chuva para a geração de energia. Dessa forma, o estudo dessa variável, bem como o melhoramento de técnicas utilizadas para a sua previsão, principalmente sobre áreas do continente, favorece o planejamento futuro de várias atividades (agricultura, produção de energia, prevenção de desastres naturais etc.) da sociedade.

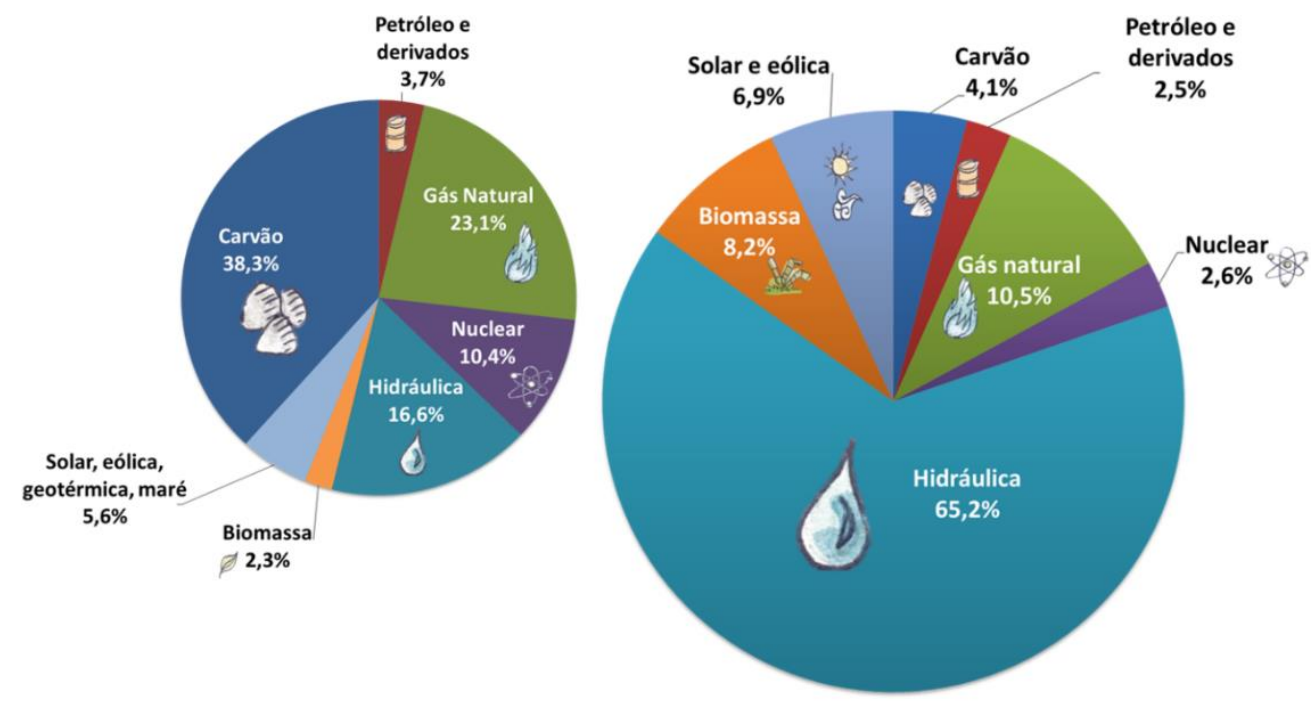

Figura 1 - Comparação da Matriz hidrelétrica mundial (a esquerda) e brasileira (a direita). Fonte: EPE.

Atualmente, há uma vasta quantidade de modelos numéricos atmosféricos que geram previsões de chuva em diferentes escalas temporais e espaciais. Contudo, nem sempre a qualidade das previsões é boa o suficiente quando comparado aos dados observados. Para Gimeno (2013), a assimilação de dados, parametrizações e a representação dos processos de pequena escala, por exemplo, são desafios que, se aprimorados e bem selecionados, podem gerar previsões com menores erros. Além disso, segundo Kalnay (2002), a utilização de 
condições iniciais e de fronteira mais acuradas e métodos numéricos sofisticados, proporcionam uma representação mais realista da atmosfera. No entanto, vale destacar que os modelos numéricos têm como objetivo resolver os processos físicos que governam os movimentos da atmosfera, mas devido ao seu estado caótico não há uma previsão que seja totalmente correta.

No caso das previsões de tempo (entre 1 e 15 dias), as condições iniciais para a inicialização das simulações numéricas são de extrema importância para garantir a qualidade da previsão. Estas condições podem ser obtidas através sistema de assimilação de dados que incorporam observações de estações meteorológicas de superfície, satélites, sondagens e boias oceânicas disponíveis ao longo do globo. Além dos dados coletados já possuírem erros intrínsecos, não há uma total sincronia entre a assimilação de dados e a data inicial da simulação dos modelos, o que também acarreta erros nas previsões. Dessa forma, ao integrar esses erros em um intervalo de tempo futuro, eles se acumulam, aumentando sistematicamente cada vez mais os erros nas previsões.

Em relação à previsão de escala temporal climática, há diversas escalas temporais de interesse: intrasazonal (entre 10 e 45 dias), sazonal (aproximadamente 90 dias) e de longo período (menor que 1 ano). Para períodos maiores de previsão é necessário um melhor entendimento do oceano, visto que a temperatura da superfície do mar (TSM) interage com a atmosfera atuando como moduladora do clima global.

Como enunciado por Grimm e Ambrizzi (2009), o termo “teleconexão” denota anomalias climáticas relatadas a uma distância típica da ordem de $10^{3} \mathrm{~km}$, foi utilizado para descrever influências nas características da circulação atmosférica em regiões remotas e seus efeitos em variáveis atmosféricas, tais como precipitação e temperatura. Dessa forma a utilização de modelos dinâmicos acoplados (oceano-atmosfera) são extremamente necessários para previsões na escala climática e da variabilidade climática.

\subsection{Evolução temporal da modelagem climática}


Ao longo dos anos, várias mudanças ocorreram em relação ao crescimento da modelagem climática. De acordo com Danabasoglu (2020), entre as décadas de 1960 e 1970, apenas duas fontes eram consideradas de forma separada: Oceano e Atmosfera. Entre 1980 a 1990, começaram a ser considerados modelos acoplados oceano-atmosfera, bem como modelos que resolvem toda a complexidade do gelo marinho. Entre 1990 a 2000, características como aerossóis, ciclos bioquímicos, ciclo do carbono e interações com a vegetação foram adicionados. Entre 2000 até os dias atuais, os modelos já estão resolvendo processos de níveis mais altos da atmosfera e sua interação química, sendo os ecossistemas marinhos também considerados (figura 2).

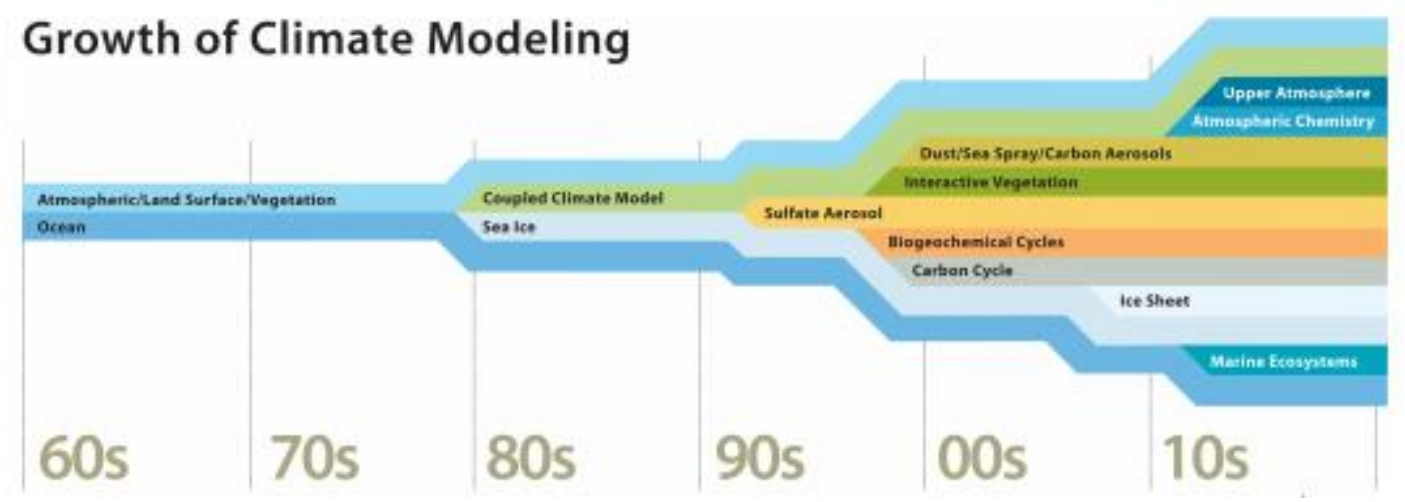

Figura 2 - Evolução da modelagem climática ao longo dos anos. Fonte: Danabasoglu (2020).

De acordo com Edwards (2010), a utilização da modelagem acoplada (com início aproximadamente a partir de 1980), possibilitou uma melhor representação física das respostas atmosféricas e oceânicas que, além de contribuírem com melhores previsões, também favoreceram uma melhor comunicação e evolução entre os centros de modelagem.

\subsection{Previsão por conjunto (ENSEMBLE)}

Segundo Kirtman et al, (2014), o desenvolvimento de modelos climáticos também inspirou duas notáveis mudanças na estratégia de previsão. A primeira é a inclusão de informações quantitativas a respeito das incertezas nas previsões, ou seja, criou-se um conceito de previsões probabilísticas (Goddard et al, 2000; Palmer et al, 2004; DeWitt, 2005). A segunda 
corresponde à utilização da previsão por conjunto ("Ensembles”), ou seja, utilizar vários modelos para aumentar as chances de acerto e resolver, em partes, as incertezas correspondentes a cada previsão individual. Os Ensembles são analisados pelo resultado médio de simulações inicializadas com diferentes condições iniciais (ensemble temporal) ou parametrizações físicas dos modelos (ensemble físico), com intuito de buscar uma representação mais realística do estado da atmosfera (figura 3).

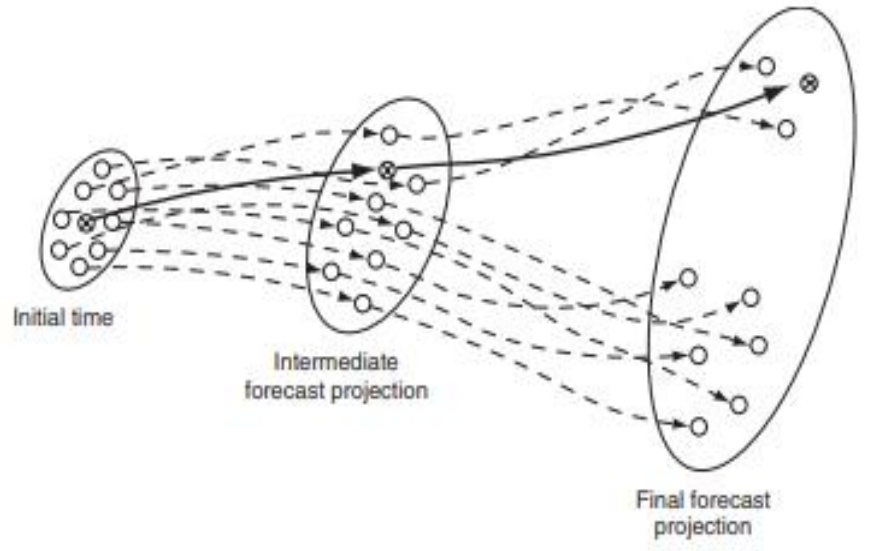

Figura 3 - Ilustração esquemática para o conceito da divergência da previsão por ensemble. A linha sólida representa a evolução de uma simulação que possui uma melhor representação da condição inicial. As linhas tracejadas representam a evolução da simulação com condições iniciais dos demais membros do modelo com diferentes condições iniciais. No começo as condições iniciais são próximas (elipse pequena), porém com resultados podendo ser totalmente diferentes e dispersos (elipse maior). Dado a proximidade das condições iniciais, todos são resultados possíveis e não há um melhor modo de se escolher a melhor simulação. O tamanho da elipse no estado final também representa a incerteza do modelo. Fonte: Adaptado Wilks, página 233.

Para a geração de previsões probabilísticas, geralmente trata-se os membros do ensemble como um evento, e, a partir de limiares como precipitações abaixo ou acima de um determinado valor, calcula-se determinada chance de que o evento ocorra. Dois principais atributos relacionados às previsões probabilísticas são a confiabilidade e a resolução, que dependem dos campos previstos e observados (Toth et al, 2003).

Dessa forma, a utilização da previsão por conjunto tem principal motivação de gerar melhores previsões com maiores possibilidades de acerto das mesmas, quando comparado com apenas a previsão de um único modelo (Palmer et al, 2004; Smith et al, 2013). Contudo, 
existem limitações e desafios em relação a utilização dessa técnica, como a necessidade de mais recursos computacionais por exemplo.

Segundo Cheung (2001), geralmente divide-se a previsão por ensemble em uma componente controle (estado básico) e uma componente perturbada (estado perturbado), como descrito pela equação (1). A simulação controle parte de uma análise, que por sua vez é considerada a melhor estimativa da atmosfera real em dado instante, com base nas observações disponíveis. Nos demais membros são adicionados pequenos erros aleatórios à essa análise:

$$
v=\bar{v}+v^{\prime}
$$

Cheung (2001) ainda ressalta que se as deficiências dos membros que compõe o ensemble foram negligenciadas, todos os membros possuem a mesma probabilidade de representar o real estado do atmosfera. Pela figura 4, observa-se que o rápido crescimento dos erros presentes nas condições iniciais da previsão leva a uma má representação do estado real da atmosfera (previsão controle). Contudo, ao se utilizar perturbações nessas condições iniciais, pode ser que pelo menos uma previsão perturbada consiga simular melhor o real estado da atmosfera.

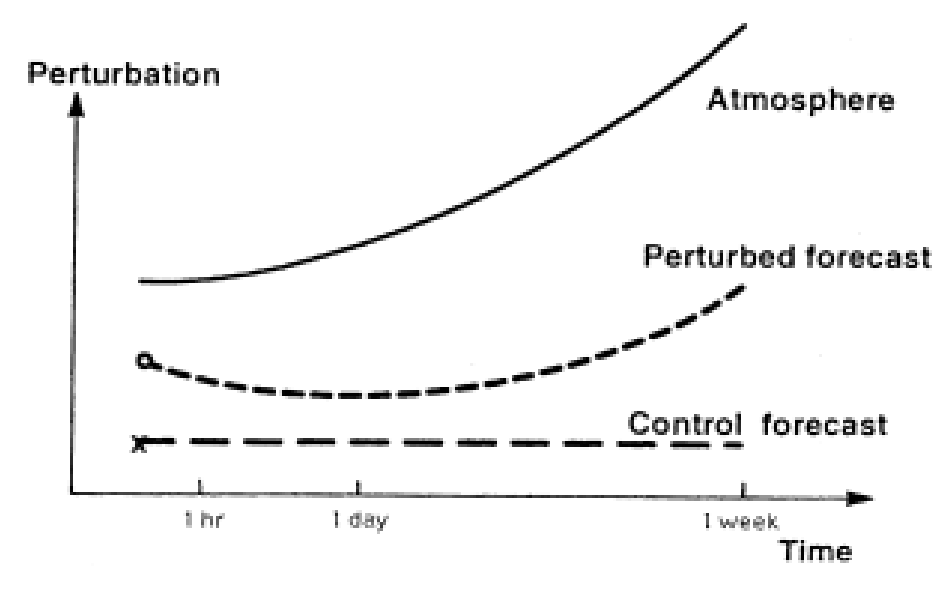

$x$ Analysis o Perturbed Initial Condition

Figura 4 - Figura esquemática para a representação das componentes básicas da previsão por ensemble ao longo do tempo. A partir de uma condição perturbada, observa-se que há uma maior probabilidade de representar o real estado da atmosfera quando comparado a uma simulação em que não há perturbação. Fonte: Cheung, 2001. 
Visto que a base para a realização da previsão por ensemble é a utilização de perturbações na condição inicial, Toth e Kalnay (1993) argumentam que há dois métodos para gerar tais perturbações. O primeiro foi introduzido por Leith (1974) e diz respeito ao método de Monte Carlo, no qual a condição inicial da previsão controle é perturbada adicionando-se pequenos números aleatórios e o segundo tem como base a utilização de "lags", no qual são utilizadas previsões realizadas anteriormente para o mesmo evento.

\subsection{Previsões sazonais para o Brasil.}

Em função da grande utilização dos recursos naturais, o Brasil possui uma forte dependência da previsão sazonal de clima. Evento como a grave seca que ocorreu na região Sudeste do Brasil entre os anos de 2014/2015 (Herring et al, 2015; Coelho et al, 2015) é um exemplo de como a previsão poderia ajudar na prevenção e remediação dos prejuízos associados ao evento. Dessa forma, a avaliação da qualidade e dessas previsões tem importância fundamental.

Chou et al (2020) estudaram 10 anos de previsões do modelo regional ETA sobre a América do Sul, discutindo os erros de superestimação e subestimação da precipitação sazonal em áreas do Brasil, e mostrando que esse modelo apresentou uma maior habilidade de previsão sobre áreas ao norte e nordeste do Brasil e menor habilidade em áreas do sudeste do Brasil.

No trabalho realizado por Reboita et al. (2018) também foi avaliado a habilidade de previsão de chuva e de temperatura do ar para regiões do Brasil através do modelo regional (RegCM4) e global (CFSv2 e CPTEC/INPE). Assim como Chou et al. (2020), as regiões norte e nordeste do Brasil apresentaram uma maior habilidade de previsão, principalmente para o modelo regional. Contudo, na região sul do Brasil, o modelo global CFSv2 forneceu melhores previsões para a chuva sazonal.

Anochi et al. (2019) utilizaram modelos de previsão que consideram redes neurais artificiais (RNA) para simular a condição observada para a chuva durante o ano de seca na região sudeste do Brasil em 2015. Dentre os resultados, mostraram que apesar das dificuldades de previsão da chuva, o modelo que utiliza inteligência artificial (que engloba o RNA) 
conseguiu reproduzir de forma satisfatória o padrão de chuva observado, mostrando a viabilidade da utilização de tecnologias mais modernas para a análise e previsão da chuva.

Bombardi et al. (2018), avaliaram a previsibilidade da chuva sobre a América do Sul durante o período de verão (DJF) através da modelagem acoplada oceano-atmosfera (IFS_NEMO). Dentro os resultados de Bombardi et al. (2018), destaca-se a maior habilidade de previsão sazonal em áreas ao norte da América do Sul e uma habilidade moderada na região da bacia do Prata. Além disso, a utilização da modelagem acoplada também permitiu representar mais realisticamente os padrões de circulação de larga escala, o que resultou em previsões de chuva com erros menores para o período de verão da América do Sul.

Sampaio e Dias (2014) identificaram que a América do Sul possui regiões com baixa, média e alta previsibilidade sazonal de chuva. Devido às variabilidades dos Oceanos Atlântico e Pacífico, áreas ao norte das regiões norte e nordeste possuem uma alta previsibilidade de chuva, enquanto nas regiões centro-oeste e sudeste a previsibilidade diminui devido a menor dependência oceânica e maior variabilidade dos sistemas meteorológicos que atuam sobre essas áreas. Para a região sul, a previsibilidade da chuva sazonal foi considerada como média por Sampaio e Dias (2014).

Além de previsões sazonais, previsões nas escalas sazonais-para-intrasazonais (SPS ou S2S em inglês) de chuva, ou seja, previsões para até quatro semanas a frente podem ter boas performances durante períodos de verão (de Andrade, 2019) e outono (Coelho et al, 2018). Contudo, Klingaman et al, (2021) avaliou as previsões na escala SPS para quatro diferentes modelos (ECMWF, NCEP, BAM e UKMO) e quatro semanas à frente, mostrando que as previsões com menores erros ocorrem principalmente entre as semanas 1 e 2 de previsão. Resultados de correlação de anomalia e raiz quadrada do erro médio quadrático (RMSE) para previsões de chuva encontrados por Guimarães et al, (2019), também mostraram previsões com menores erros entre as duas primeiras semanas de previsão. 


\subsection{Objetivos}

Dada a importância da previsão sazonal de chuva, o objetivo do presente estudo é avaliar a qualidade da previsão de chuva sazonal para o Brasil dos modelos numéricos acoplados que compõem o North America Multi-Model Ensemble (NMME). Os objetivos específicos deste estudo são:

- realizar uma avaliação objetiva (através de índices estatísticos) de cada um dos modelos do NMME e da média do conjunto desses modelos (ensemble);

- avaliar em que regiões do Brasil e estações do ano as previsões de chuva do NMME apresentam menores e maiores erros de previsão;

- selecionar os modelos com as melhores e piores previsões sazonais de chuva para determinada estação do ano e região do Brasil;

- correlacionar as previsões de chuva dos modelos com as anomalias de TSM presentes no globo; 


\section{Dados e Metodologia}

Este capítulo descreve os dados observados, as previsões numéricas e as metodologias utilizadas para avaliar as previsões sazonais.

\subsection{Região de Estudo}

Como o Brasil possui diferentes regimes pluviométricos ao longo do seu território, foram escolhidas 5 regiões, delimitadas na (figura 5) onde serão realizadas verificações objetivas das previsões considerando valores médios na área. Essas regiões correspondem ao norte (AMZ), nordeste (NE), sul (SUL), sudeste (SE) e centro-oeste (BC) do Brasil.

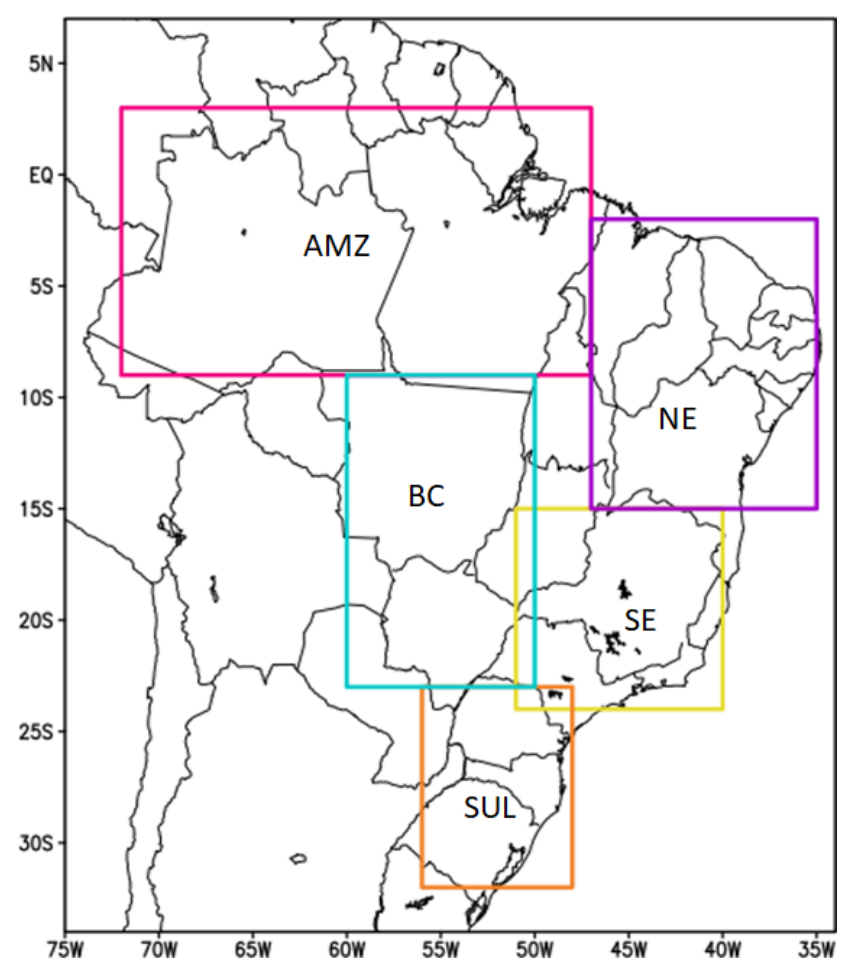

Figura 5 - Regiões do Brasil para realizar a verificação das previsões do NMME.

A tabela 1 informa as latitudes e longitudes utilizadas para cada das regiões área mostradas na figura 1 . As delimitações dessas áreas tiveram como base a metodologia utilizada 
nas análises e previsões climáticas do metodologia do Grupo de Estudos Climáticos da Universidade de São Paulo (GrEC - http://www.grec.iag.usp.br/data/index_BRA.php).

Tabela 1 - Delimitações (latitudes e longitudes) das áreas indicadas na figura 4.

\begin{tabular}{ccccc}
\hline Área de estudo & Lat Inicial $\left({ }^{\circ}\right)$ & Lat Final $\left({ }^{\circ}\right)$ & Lon Inicial $\left({ }^{\circ}\right)$ & Lon Final $\left({ }^{\circ}\right)$ \\
\hline \hline AMZ & 3 & -9 & 288 & 313 \\
BC & -23 & -9 & 300 & 310 \\
$\mathbf{N E}$ & -15 & -2 & 313 & 325 \\
$\mathbf{S E}$ & -24 & -15 & 309 & 320 \\
$\mathbf{S E}$ & -32 & -23 & 304 & 312 \\
\hline \hline
\end{tabular}

\subsection{Dados observados}

Para realizar a verificação das previsões climáticas foram utilizados os dados de precipitação observada do CPC (Climate Prediction Center) - Unified Gauge Based para o período de 1981 a 2018. Outros estudos (Xie et al, 2007; Chen et al, 2008; Becker et al, 2014) também já utilizaram essa base dados como referência, sendo que para áreas do Brasil Machado (2011) encontrou correlações altas ao comparar esses dados com estações meteorológicos in "situ".

De acordo com Xie et al (2007), a base de dados do CPC agrega muitas estações meteorológicas e tem como propósito disponibilizar análise de chuva acumulada diariamente ao longo do globo e sobre áreas do continente. O controle de qualidade desses dados é feito através de comparações de registros históricos e informações externas próximas às estações, como a utilização de informações de satélite, radar, observações e resultados de modelos numéricos de previsão.

Os dados do CPC são disponibilizados publicamente (https:/ / psl.noaa.gov /) e possuem uma extensão temporal desde 1979 até os dias atuais. Segundo (Chen et al, 2008) entre os anos de 1979 até 2005 foram utilizadas 30 mil estações por dia, enquanto entre 2006 até o presente estão sendo utilizadas 15 mil. Os dados são disponibilizados originalmente em uma resolução espacial de $0.5^{\circ} \times 0.5^{\circ}$ e foram interpolados bilinearmente para a resolução de $1.0^{\circ} \times 1.0^{\circ}$ para 
a validação dos modelos que compõe o projeto NMME. Como essa tipo de interpolação utiliza pontos de grade "vizinhos", pontos de grade próximos ao Oceano Atlântico não apresentam valores de chuva observada e são substituídos como indefinidos nas previsões do NMME (figura 6).
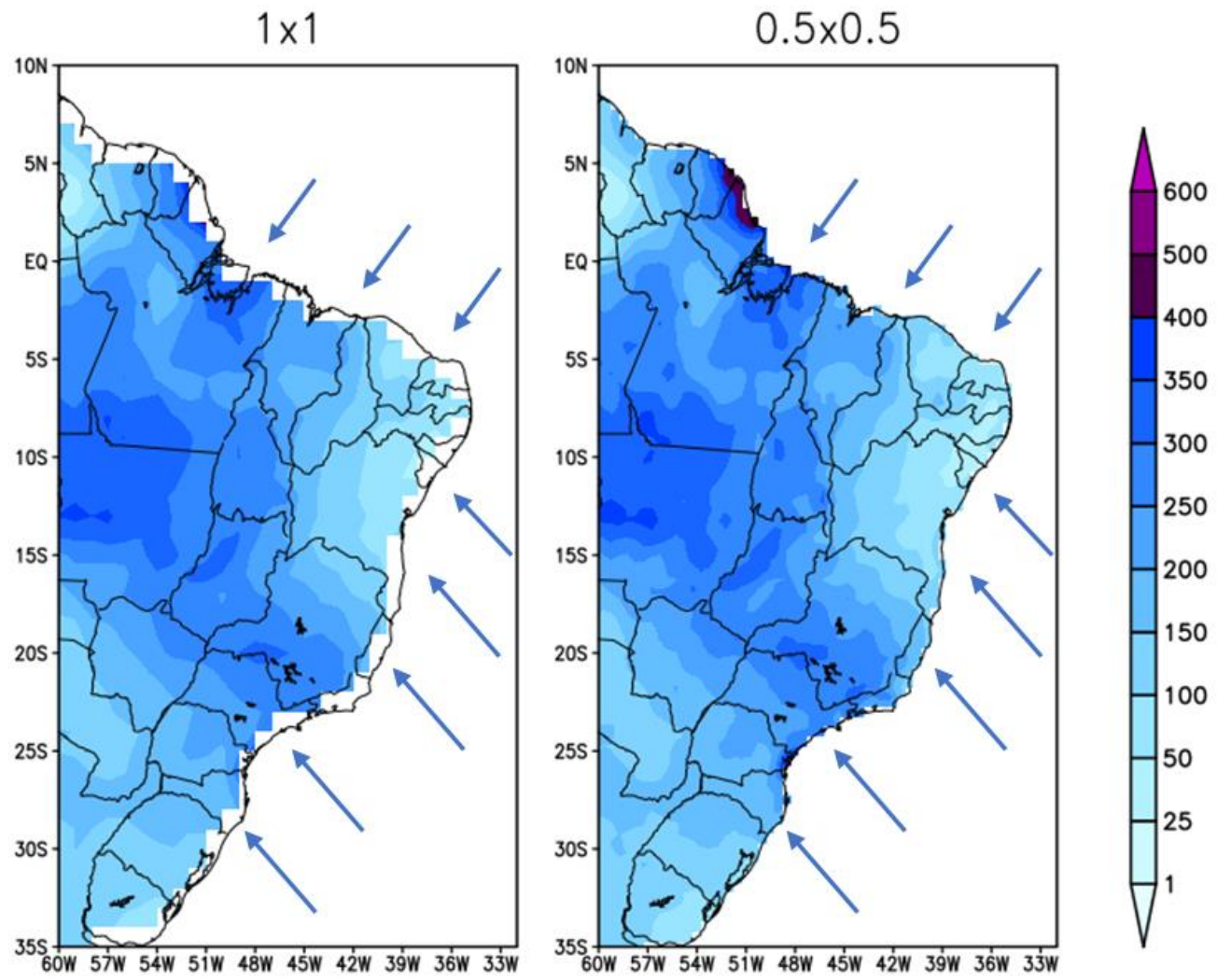

Figura 6 - Comparação entre os dados de chuva do CPC após (esquerda) e antes (direita) a interpolação para a mesma grade para validação das previsões do NMME. O mapa é um exemplo de representação da interpolação referente a climatologia da precipitação entre 1981 e 2010 para o mês de Janeiro em mm.

A precipitação média para quatro estações do ano em cada região estudada antes e após a interpolação é mostrada na tabela 2. Observa-se que interpolação tem pequeno impacto nos valores médios para cada região já que os valores são iguais, com poucos casos nos quais às diferenças não são significativas. 
Tabela 2 - Precipitação média sazonal (mm/dia) no período 1981-2010 da análise CPC em cada área considerando resolução horizontal original $(0.5$ x 0.5) e interpolada $(1.0 \mathrm{x}$ 1.0).

\begin{tabular}{ccccccccc}
\hline Área de & \multicolumn{4}{c}{$\mathbf{0 . 5} \times \mathbf{0 . 5}$} & \multicolumn{4}{c}{$\mathbf{1 . 0} \times \mathbf{1 . 0}$} \\
\cline { 2 - 9 } estudo & DJF & MAM & JJA & SON & DJF & MAM & JJA & SON \\
\hline \hline AMZ & $\mathbf{8 . 2}$ & 8.8 & 4.2 & 4.5 & $\mathbf{8 . 0}$ & 8.8 & 4.1 & 4.6 \\
BC & $\mathbf{8 . 1}$ & 4.2 & 0.6 & 4.2 & $\mathbf{8 . 1}$ & 4.2 & 0.6 & 4.2 \\
NE & $\mathbf{4 . 2}$ & 4.3 & 1.1 & 1.5 & $\mathbf{4 . 2}$ & 4.3 & 0.9 & 1.5 \\
SE & $\mathbf{7 . 0}$ & 3.1 & 0.7 & 3.7 & $\mathbf{7 . 0}$ & 3.1 & 0.7 & 3.7 \\
SUL & $\mathbf{5 . 4}$ & 4.4 & 3.6 & 5.1 & $\mathbf{5 . 3}$ & 4.4 & 3.6 & 5.1 \\
\hline
\end{tabular}

\subsection{Previsões climáticas do North America Multi-Model Ensemble - NMME}

Dentro os projetos de previsão climática disponíveis atualmente, destaca-se o North America Multi Model Ensemble - NMME - conforme descrito por Kirtman et al (2014). Esse projeto é composto por modelos numéricos de diferentes centros de modelagem climática e teve início em 2010, contando com previsões atualizadas mensalmente desde agosto de 2011 até o presente. Além disso, a frequente atualização dos modelos também tende a gerar melhores resultados em relação as previsões (Becker et al, 2020).

A atualização mensal, a disponibilidade pública dos dados desses modelos, também é um atrativo para serem estudados, sendo encontrados online pelo website do Climate Prediction Center (ftp://ftp.cpc.ncep.noaa.gov/NMME). Atualmente, o projeto NMME é divido em duas fases, a primeira com foco na previsão sazonal e interanual e a segunda com foco nas previsões intrasazonais e que ainda está em desenvolvimento.

De acordo com Kirtman et al. (2014) os diferentes centros de modelagem atmosférica que compõe o NMME concordam em seguir os seguinte protocolos:

a. Os procedimentos para a geração das previsões intrasazonais-sazonais-interanuais (ISI) deverão ser idênticos àqueles de geração da climatologia de cada modelo.

b. A climatologia de cada modelo deverá ter uma condição inicial para cada mês do ano, porém, cada modelo poderá escolher um dia específico para a inicialização.

c. O número necessário é de pelo menos 9 meses à frente de previsão (tempos ou leads). 
d. A climatologia do modelo (hindcast) precisa de um período mínimo de 29 a 30 anos (tipicamente entre 1981-2010).

e. A quantidade de membros de cada modelo é livre.

f. As configurações do modelo, tais como a resolução espacial, versão, estratégias de inicialização e estratégias de geração da média dos membros são livres.

g. Campos que necessariamente deverão ser gerados mensalmente são o de temperatura a 2 metros ( $\mathrm{t} 2 \mathrm{~m})$, taxa de precipitação (prate) e temperatura da superfície do mar (TSM).

h. A rotina de geração da previsão mensal deverá ser disponibilizada todo dia 08 de cada mês.

Como um dos objetivo do trabalho é avaliar e verificar as previsões do NMME e disponibilizar uma base de apoio para possíveis consultas e análises de previsões operacionais, para esse estudo foram utilizados os modelos que são atualizados até o presente trabalho, ou seja, modelos que foram descontinuados, como o NCEP-CFSv1 e CMC1-CanCM3 por exemplo, não possuem atualização e então não foram utilizados para a realização do estudo. Com base na tabela 3, os modelos disponíveis atualmente são:

- NCEP-CFSv2

- GFDL-CM2p1 (AER04)

- GFDL-CM2p5 (FLORa06 e FLORb01)

- ECCC-GEMNEMO

- ECCC-CanCM4i

- NCAR-CCSM4

- NASA-GEOS5v2

Vale ressaltar que os modelos ECC-GEMNEMO e ECC-CanCM4i apresentam um intervalo de previsão entre setembro de 2019 até o presente e o modelo NASA-GEOS5v2 entre fevereiro de 2018 até o presente, o que prejudica em relação às suas verificações devido aos poucos dados referentes a esses modelos. Contudo, a análise, principalmente no período de hindcast desses modelos, é importante para identificar as erros sistemáticos em suas previsões. 
Tabela 3 - Modelos participantes do projeto NMME. Em azul temos os modelos utilizados atualmente em modo operacional. Em vermelho os modelos que já foram descontinuados/substituídos.

\begin{tabular}{|c|c|c|c|c|c|c|c|c|}
\hline Modelo & Organização & $\begin{array}{l}\text { Periodo de } \\
\text { Climatologia }\end{array}$ & Membros & Tempos & $\begin{array}{c}\text { Módulo } \\
\text { atmosférico }\end{array}$ & $\begin{array}{l}\text { Módulo } \\
\text { Oceânico }\end{array}$ & $\begin{array}{l}\text { Periodo de } \\
\text { utilização }\end{array}$ & Referência \\
\hline CFSv2 & NCEP & $1982-2010$ & 24 & 10 & GFS T126L64 & $\begin{array}{c}\text { MOM4 L40 } \\
0.25^{\circ} \mathrm{Eq}\end{array}$ & $\begin{array}{c}2011 \text { - } \\
\text { presente }\end{array}$ & $\begin{array}{l}\text { Saha et al, } \\
2014\end{array}$ \\
\hline CM2.1 (AER04) & GFDL & $1982-2010$ & 10 & 12 & $\begin{array}{c}\text { CM2.1 } 2 \times 2.5^{\circ} \\
\text { L24 }\end{array}$ & $\begin{array}{c}\text { MOM4 L50.3 } \\
\text { Eq }\end{array}$ & $\begin{array}{c}2011 \text { - } \\
\text { presente }\end{array}$ & $\begin{array}{l}\text { Delworth, } \\
2006\end{array}$ \\
\hline $\begin{array}{c}\text { CM2.5 } \\
\text { (FLORA06+B01) }\end{array}$ & GFDL & $1982-2010$ & 10 & 12 & $\begin{array}{c}\text { CM2.5 C18L32 } \\
(50 \mathrm{~km})\end{array}$ & $\begin{array}{l}\text { MOM5 L50 0.3 } \\
\text { Eq } 1^{\circ} \text { Polar1.5 }\end{array}$ & $\begin{array}{c}2014 \text { - } \\
\text { presente }\end{array}$ & $\begin{array}{l}\text { Delworth, } \\
2012\end{array}$ \\
\hline CanCM4i & ECCC & $1981-2010$ & 10 & 12 & $\begin{array}{c}\text { CanAMA4 } \\
\text { T63L31 }\end{array}$ & $\begin{array}{l}\text { CanOM4 } \\
\mathrm{L} 40.94^{\circ} \mathrm{Eq}\end{array}$ & $\begin{array}{c}2019 \text { - } \\
\text { presente }\end{array}$ & $\begin{array}{c}\text { Marryfield et } \\
\text { al, } 2020\end{array}$ \\
\hline CCSM4 & NCAR & $1982-2010$ & 10 & 12 & $\begin{array}{c}\text { CAM4 } 0.9 \times 1.25^{\circ} \\
\text { L26 }\end{array}$ & POPL60.25 Eq & $\begin{array}{c}2014 \text { - } \\
\text { presente }\end{array}$ & $\begin{array}{c}\text { Em } \\
\text { preparação }\end{array}$ \\
\hline GEMNEMO & $\mathrm{ECCC}$ & $1981-2010$ & 10 & 12 & GEM 256x128 & $\begin{array}{c}\text { NEMO } 1 \times 1 \\
1 / 3 \mathrm{Eq}\end{array}$ & $\begin{array}{c}2019 \text { - } \\
\text { presente }\end{array}$ & $\begin{array}{c}\text { Marryfield et } \\
\text { al, } 2020\end{array}$ \\
\hline GEOS5v2 & NASA & $1981-2010$ & 10 & 10 & $\begin{array}{c}\text { GEOS5 AGCM } \\
0.5^{\circ} \mathrm{L} 72\end{array}$ & $\begin{array}{c}\text { MOM5 L40 } 0.5^{\circ} \\
\text { Eq }\end{array}$ & $\begin{array}{c}2018 \text { - } \\
\text { presente }\end{array}$ & Molod, 2020 \\
\hline CFSv1 & NCEP & $1982-2009$ & 15 & 9 & T62L64 & $\begin{array}{c}\text { MOM3 L40 } \\
0.30^{\circ} \mathrm{Eq}\end{array}$ & $2011-2012$ & $\begin{array}{l}\text { Saha et al, } \\
2006\end{array}$ \\
\hline CCSM3 & NCAR & $1982-2010$ & 6 & 12 & T83L26 & $\begin{array}{c}\text { POPL42 } 0.3^{\circ} \\
\text { Eq }\end{array}$ & $2011-2014$ & $\begin{array}{c}\text { Kirtman and } \\
\text { Min, } 2007\end{array}$ \\
\hline ECHAM4f & IRI & $1982-2010$ & 12 & 8 & T42L19 & $\begin{array}{c}\text { MOM3L25 } \\
1.5 \times 0.5\end{array}$ & $2011-2012$ & DeWitt, 2005 \\
\hline ECHAM4a & IRI & $1981-2010$ & 12 & 8 & T42L19 & $\begin{array}{c}\text { MOM3L25 } \\
1.5 \times 0.5\end{array}$ & $2011-2012$ & DeWitt, 2005 \\
\hline CESM1 & NCAR & $1982-2010$ & 11 & 12 & $0.9 \times 1.25^{\circ} \mathrm{L} 30$ & POPL60.25 Eq & 2016 & $\begin{array}{l}\text { Vernieres et } \\
\text { al, } 2012\end{array}$ \\
\hline CanCM3 & $\mathrm{CMC}$ & $1981-2010$ & 10 & 12 & CanAM3 T63L31 & $\begin{array}{c}\text { CanOM4 } \\
\mathrm{L} 40.94^{\circ} \mathrm{Eq}\end{array}$ & $2012-2019$ & $\begin{array}{c}\text { Marryfield et } \\
\text { al, } 2013\end{array}$ \\
\hline CanCM1 & $\mathrm{CMC}$ & $1981-2010$ & 10 & 12 & CanAM3 T63L35 & $\begin{array}{c}\text { CanOM4 } \\
\text { L40.94 } \mathrm{Eq}\end{array}$ & $2012-2019$ & $\begin{array}{c}\text { Marryfield et } \\
\text { al, } 2013\end{array}$ \\
\hline GEOS5 & NASA & $1981-2010$ & 10 & 10 & $\begin{array}{c}\text { GEOS5 AGCM } \\
1 \times 1.25^{\circ} \mathrm{L} 72\end{array}$ & $\begin{array}{c}\text { MOM4 L40 } 0.5^{\circ} \\
\text { Eq }\end{array}$ & $2011-2017$ & $\begin{array}{l}\text { Borovick et } \\
\text { al, } 2017\end{array}$ \\
\hline
\end{tabular}

Os modelos que compõe o NMME já foram utilizados em diferentes regiões do globo, porém, a maioria dos trabalhos tem com foco principal a América do Norte (Li et al 2011; Infanti et al, 2014; Mo et al, 2014; Tian et al, 2014; Wang et al, 2014; Becker et al, 2014; Shukla et al, 2015; entre outros), o que também é um incentivo adicional para a realização deste trabalho.

A utilização de modelos acoplados também induz ao estudo de módulos oceânicos para entender possíveis padrões de teleconexão, como o fenômeno ENOS (El Niño Oscilação Sul). Larson et al. (2014) avaliou que o MMP (Modo Meridional do Pacífico) poderia ser 
caracterizado como precursor do fenômeno ENOS para um conjunto de modelos do NMME. A partir destes resultados, notou-se que, de uma forma independente, principalmente com antecedências (tempos de previsão) entre 1 e 3, a variabilidade do MPP é capturada pelas previsões do NMME, destacando-se frequentemente como um precursor dos eventos de ENOS nos modelos.

Para previsões probabilísticas, Becker et al (2016) estudou a TSM, temperatura a 2 m e taxa de precipitação para as regiões do Niño $3.4\left(5^{\circ} \mathrm{N}-5^{\circ} \mathrm{S}, 190^{\circ}-240^{\circ} \mathrm{E}\right)$, Hemisfério Norte $\left(23^{\circ}\right.$ $\left.75^{\circ} \mathrm{N}\right)$ e região tropical $\left(23^{\circ} \mathrm{S}-23^{\circ} \mathrm{N}\right)$, dividindo os modelos estudados em três conjuntos em função do número de membros que compõe o ensemble. Dentro os resultados, destaca-se que em todas as regiões e variáveis estudadas, o conjunto que apresenta o maior número de membros possui uma frequência de probabilidade de previsão mais próxima da frequência observada, o que contribui para aumentar a confiabilidade de previsão desse conjunto.

\subsection{Geração da climatologia do modelo}

Sabendo que a modelagem atmosférica não representa de forma totalmente precisa as condições atmosféricas reais, a comparação com as climatologias observadas permite identificar erros sistemáticos das previsões dos modelos. Neste estudo, são analisados tanto os valores médios como as anomalias previstas. As anomalias previstas pelos modelos são obtidas fazendo a diferença entre a climatologia do modelo (hindcast) e a previsão (do mesmo modelo) para determinado período. A climatologia é definida pela média aritmética dos membros para determinado mês ou estação alvo ao longo dos anos disponíveis para cara modelo (1981/ 82 - 2010), como esquematizado pela figura 7. 

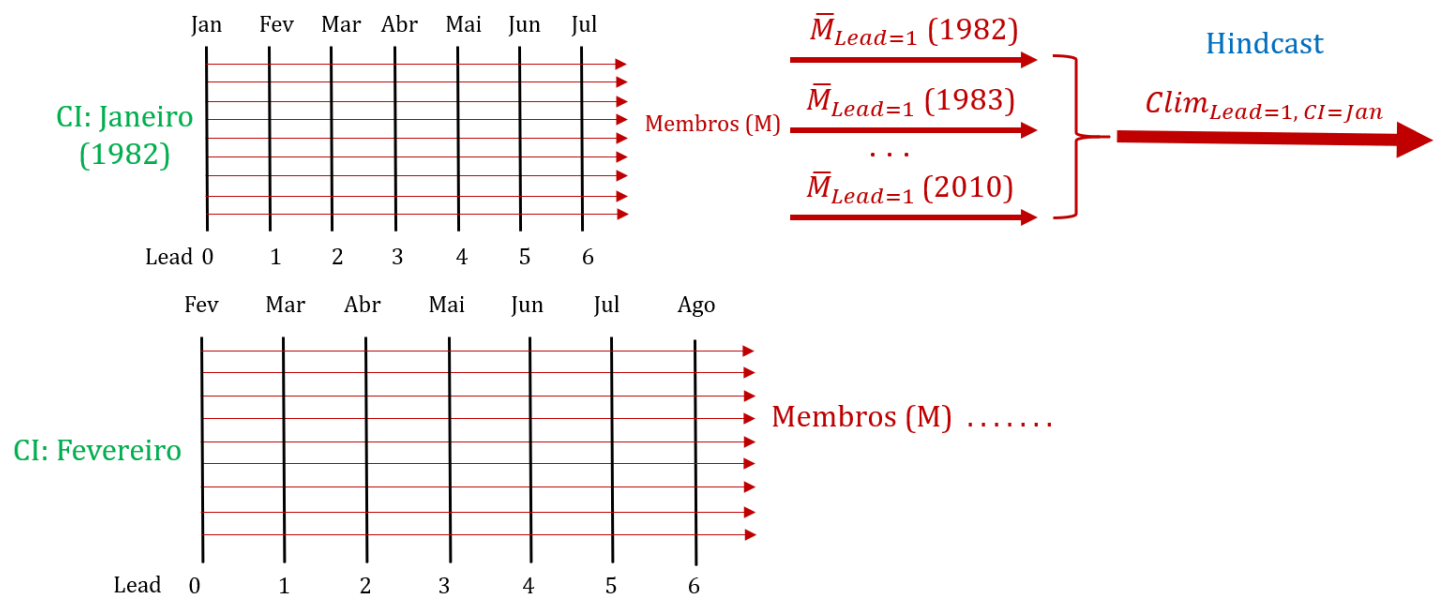

Figura 7 - Esquema para a composição dos períodos de hindcast para cada modelo. As setas vermelhas representam os membros de cada modelo e $\mathrm{M}$ sua média (ensemble). CI: Condição Inicial. Clim representa o hindcast como sendo a média de $\mathrm{M}$ para o período de hindcast do modelo.

Tendo em vista que determinada estação ou mês alvo pode estar em diferentes tempos de previsão, considerou-se que para as previsões sazonais de tempo 0, a condição inicial será a do primeiro mês da estação. Para o tempo 1, será o mês anterior ao primeiro mês da estação, e assim sucessivamente. Por exemplo, para a estação de DJF, a condição inicial do tempo 0 será dezembro, a do tempo 1 será novembro, a do tempo 2 será outubro, e assim sucessivamente. A tabela 4 mostra a relação das condições iniciais para o tempo de previsão versus estação do ano alvo.

Tabela 4 - Relação do tempo de previsão e estação alvo para diferentes combinações de condições iniciais. O mês em cada célula representa a condição inicial da previsão para cada estação alvo.

\begin{tabular}{lclllllllllll}
$\mathbf{6}$ & JUN & JUL & AGO & SET & OUT & NOV & DEZ & JAN & FEV & MAR & ABR & MAI \\
$\mathbf{5}$ & JUL & AGO & SET & OUT & NOV & DEZ & JAN & FEV & MAR & ABR & MAI & JUN \\
$\mathbf{4}$ & AGO & SET & OUT & NOV & DEZ & JAN & FEV & MAR & ABR & MAI & JUN & JUL \\
$\mathbf{3}$ & SET & OUT & NOV & DEZ & JAN & FEV & MAR & ABR & MAI & JUN & JUL & AGO \\
$\mathbf{2}$ & OUT & NOV & DEZ & JAN & FEV & MAR & ABR & MAI & JUN & JUL & AGO & SET \\
$\mathbf{1}$ & NOV & DEZ & JAN & FEV & MAR & ABR & MAI & JUN & JUL & AGO & SET & OUT \\
$\mathbf{0}$ & DEZ & JAN & FEV & MAR & ABR & MAI & JUN & JUL & AGO & SET & OUT & NOV \\
\hline \hline & DJF & JFM & FMA & MAM & AMJ & MJJ & JJA & JAS & ASO & SON & OND & NDJ
\end{tabular}

Estação Alvo 


\subsection{Erros estatísticos}

Para quantificar a diferença entre a climatologia prevista $\left(\right.$ Clim $\left._{\text {prev }}\right)$ do modelo numérico (prev) e a climatologia observada $\left(\operatorname{Clim}_{\text {obs }}\right)$, foi calculado o erro climatológico para cada condição inicial (CI) e mês/estação alvo de previsão (L) do modelo (2).

$$
\operatorname{Erro}_{\text {clim }}(C I, L)=\operatorname{Clim}_{\text {prev }}(C I, L)-\operatorname{Clim}_{\text {obs }}(L)
$$

Visto que a climatologia de precipitação em cada estação do ano para cada região de estudo é bastante diferente, também se calculou os erros relativos, dados por:

$$
\operatorname{Erro}_{\text {clim }_{\text {relativo }}}(C I, L)=\frac{\operatorname{Clim}_{\text {prev }}(C I, L)-\operatorname{Clim}_{\text {obs }}(L)}{\operatorname{Clim}_{\text {obs }}(C I)} * 100
$$

Com o valor do erro obtido, a correção da previsão foi obtida subtraindo o valor previsto para estação do erro climatológico (ou viés) do hindcast de acordo com:

$$
P_{\text {corr }}(C I, L)=P(C I, L)-\text { Erro }_{\text {clim }}(C I, L)
$$

Para medir a habilidade das previsões em reproduzir eventos extremos, calculou-se a raiz quadrada do erro médio quadrático (RMSD):

$$
R M S D=\frac{\sqrt{\sum_{n=1}^{N}(P(C I, L)-o b s(L))^{2}}}{N}
$$

O desvio padrão (uma medida da habilidade das previsões capturarem a variabilidade temporal observada) entre as previsões dos modelos e as observações foi calculado como: 


$$
\operatorname{Desv}_{p a d}=\frac{\sum_{n=1}^{N}(P(C I, L)-\overline{P(C I, L)})}{N-1}
$$

Onde $\mathrm{N}$ representa a quantidade de eventos.

Para a validação do processo de correção da climatologia do modelo, foi realizada uma validação cruzada para o período entre 2011 e 2018 (período de previsão). Essa validação considerou apenas os modelos que ainda estão sendo atualizados e que estavam disponíveis entre 2011 e 2018 (tabela 3). Esquematicamente, o processo de obtenção da previsão corrigida pelo viés do hindcast está representado na figura 8.

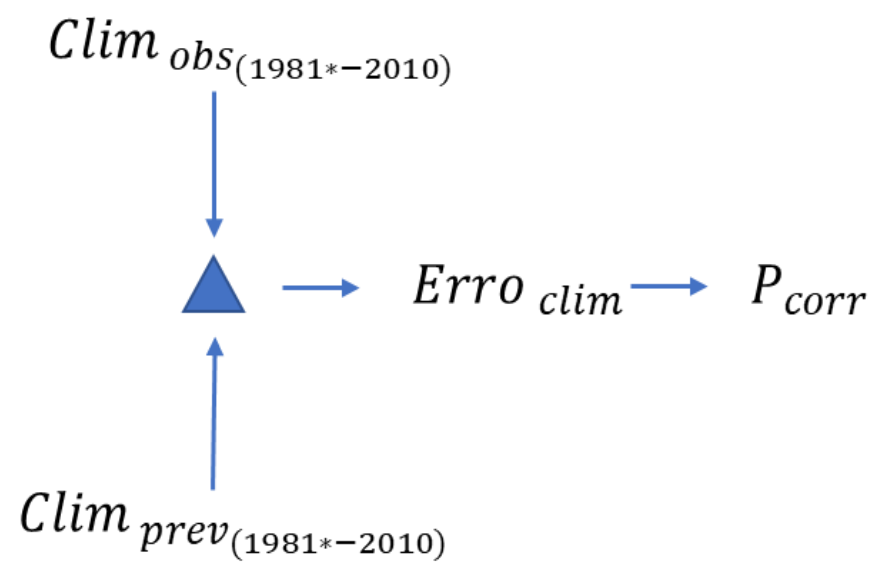

Figura 8- Esquema para a correção da previsão pelo erro médio climatológico. O índice de asterisco (“*”) representa que diferentes climatologias foram utilizadas em função de modelos com períodos climatológicos diferentes (ver tabela 3).

\subsection{Coeficiente de correlação (r)}

Visto que o coeficiente de correlação de Pearson (8) quantifica a relação entre duas variáveis, sua análise é essencial na avaliação de previsões sazonais. Porém, em variáveis meteorológicas, como no caso da precipitação, a presença do ciclo anual é muito evidente sobre o Brasil e pode mascarar os valores de correlação encontrados devido às fases da onda. Dessa forma, para avaliação de previsões sazonais foi retirado o ciclo anual de cada modelo, resultando no campo de anomalia. O mesmo procedimento foi adotado para as observações, resultando nas anomalias observadas. A correlação entre as anomalias previstas e observadas, 
indica locais de maior habilidade (skill) de previsão (Becker et al, 2014). O coeficiente de correlação de Pearson foi calculado como:

$$
r=\frac{\sum_{i=1}^{n}\left(x_{i}-\bar{x}\right) *\left(y_{i}-\bar{y}\right)}{\sqrt{\left[\sum_{i=1}^{n}\left(x_{i}-\bar{x}\right)^{2}\right] *\left[\sum_{i=1}^{n}\left(y_{i}-\bar{y}\right)^{2}\right]}}
$$

onde $\mathrm{x}$ e y indicam, respectivamente, as anomalias previstas e observadas.

Matematicamente, é possível definir o campo observado como $\mathrm{O}(\mathrm{g}, \mathrm{t}, \mathrm{CI})$, no qual " $\mathrm{g}$ " representa o ponto de grade $\mathrm{e}$ " $\mathrm{t}$ " o tempo (anos). Para a previsão, tem-se que o campo previsto é definido como $\mathrm{P}(\mathrm{g}, \mathrm{t}, \mathrm{CI}, \mathrm{L})$, ou seja, há uma dependência com a estação/mês alvo de previsão (L). Como as previsões dos modelos utilizados possuem diferentes quantidades de membros (n), uma nova variável também é necessária para definir a previsão $P$. ou seja, $P=P$ $(\mathrm{g}, \mathrm{t}, \mathrm{CI}, \mathrm{L}, \mathrm{n})$. Dessa forma, a média dos valores previstos é dada por:

$$
P_{\text {médio }}=\frac{1}{N} \sum_{i=1}^{n} P(g, t, C I, L, n)
$$

Sendo que $\mathrm{N}$ representa a quantidade total de membros de cada modelo. Vale destacar que todos os membros possuem o mesmo peso para o cálculo de $P_{\text {médio }}$, o que caracteriza uma média aritmética simples. A escolha dessa média simples condiz com a metodologia oficial do órgão responsável pelos dados operacionais dos dados do NMME (Kirtman et al, 2014).

A partir do $P_{\text {médio }}$ e de $\mathrm{O}$, é possível calcular os campos de anomalia previstas e observadas, calculados como:

$$
\begin{gathered}
\text { Anom }_{\text {observada }}(g, t, C I)=O(g, t, C I)-\overline{O(g, C I)} \\
\text { Anom }_{\text {prevista }}(g, t, C I, l)=P_{\text {médio }}(g, t, C I, l)-\overline{P_{\text {médio }}(g, C I, l)}
\end{gathered}
$$


Sendo $\overline{O(g, C I)}$ e $\overline{P_{\text {médıo }}(g, C I, l)}$ as médias, respectivamente, observadas e previstas para todo o período $(t)$. Vale lembrar que como há modelos com períodos diferentes de climatologia (tabela 3), também foram utilizadas diferentes climatologias observadas (uma para cada período) correspondentes aos modelos.

A correlação entre anomalia previstas e observadas, em função do mês (condição inicial) e do tempo de previsão é dado por:

$$
\begin{aligned}
& C A(m, l)=\frac{\sum \text { Anom }_{\text {observada }} * \text { Anom }_{\text {prevista }}}{\sqrt{\sum\left(\text { Anom }_{\text {observada }}\right)^{2} *\left(\text { Anom }_{\text {prevista }}\right)^{2}}}=
\end{aligned}
$$

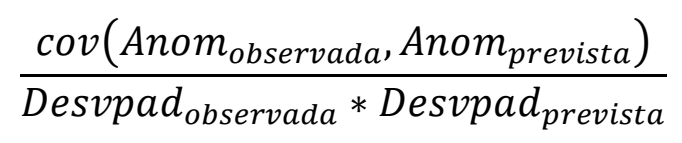

\subsection{Teste de significância estatística (T-Student)}

A significância estatística do coeficiente de correlação (r) foi avaliada utilizando o teste tStudent bicaudal e considerando a hipóteses como:

- $\mathrm{H}_{0}: \mathrm{r}=0$ (hipótese nula)

- $\mathrm{H}_{1}: \mathrm{r} \neq 0$

Dessa forma, com nível de significância $\alpha=0.05$, considerou-se os seguintes passos a seguir para a rejeição, ou não, de $\mathrm{H}_{0}$ :

1. Calcula-se a variável t pela equação (13),

$$
t=r \sqrt{\frac{n-2}{1-r^{2}}}
$$

Sendo n o número de eventos. 
2. Se $t>t$ (tabela) ou $t<-t$ (tabela), rejeita-se $\mathrm{H}_{0}$. Caso contrário, aceita-se $\mathrm{H}_{0}$.

a. Caso $\mathrm{H}_{0}$ for rejeitada, há correlação estatisticamente significativa com um nível de significância $\alpha$.

b. Caso $\mathrm{H}_{0}$ não for rejeitada, não há correlação estatisticamente significativa com um nível de significância $\alpha$. 


\section{Resultados}

A seguir serão mostrados os resultados obtidos no trabalho. Visto que os modelos foram inicializados com diferentes condições iniciais, foi considerado o tempo (lead) 1 para a análise dos resultados.

\subsection{Erro climatológico do NMME}

A figura 9 apresenta os ciclos anuais médios no período 1981-2010 de chuva do CPC e do tempo 1 de previsão para cada um dos modelos do hindcast do NMME para as diferentes subregiões da figura 1. Considerando os meses de verão do Hemisfério Sul (Dezembro, Janeiro e Fevereiro, DJF), observa-se que as regiões $\mathrm{AMZ}, \mathrm{SE}$, NE e BC possuem o máximo de precipitação observada nessa estação que decresce à medida em que se aproxima dos meses de inverno (Junho, Julho e Agosto, JJA). Em relação a região SUL, nota-se chuvas igualmente distribuídas ao longo de todo o ano, sendo isso devido à frequência sazonal praticamente constante de sistemas frontais que atuam na região (Reboita et al., 2010).

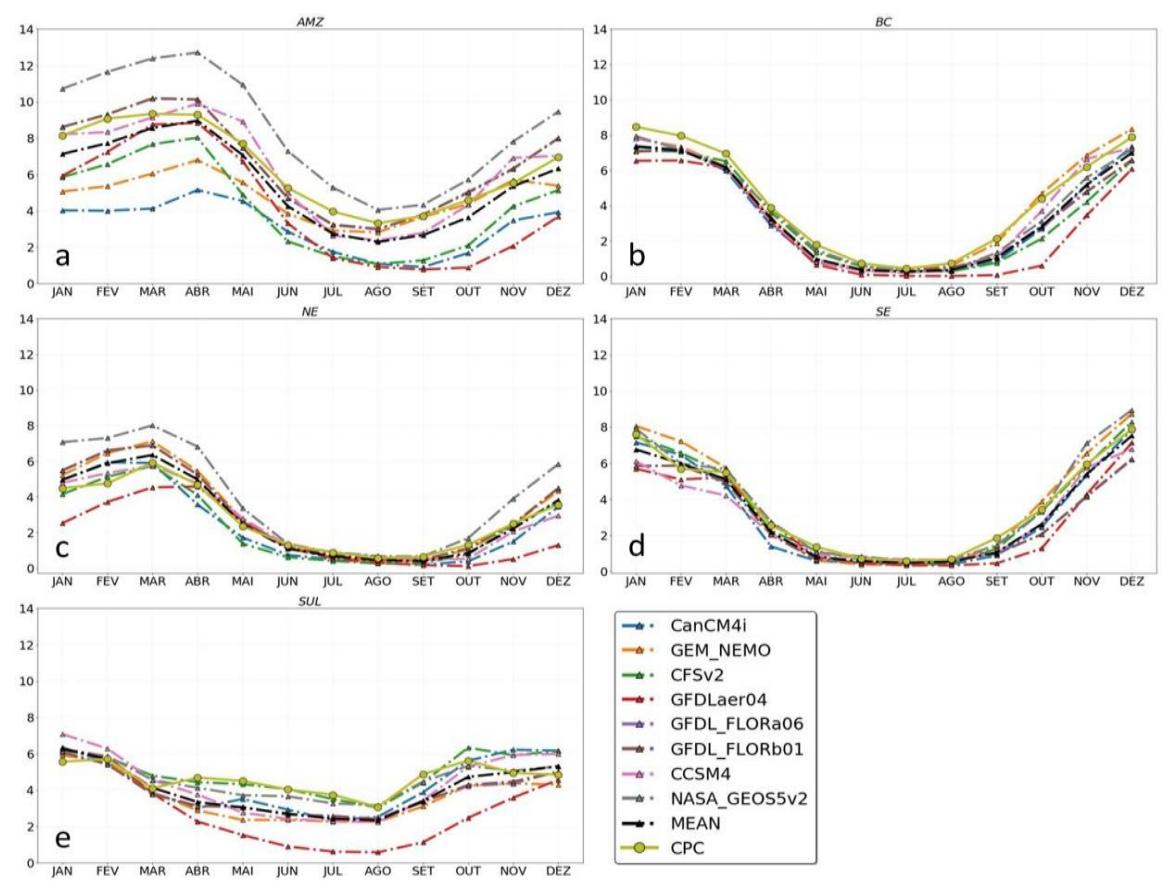

Figura 9 - Ciclo anual da taxa de precipitação (mm/dia) para o tempo 1 de previsão para a climatologia dos modelos do NMME para as regiões: (a) AMZ, (b) BC, (c) NE, (d) SE, (e) SUL. 
Como representado na figura 8 , os modelos possuem certa habilidade em reproduzir os ciclos anuais observados (CPC), sendo as regiões BC e SE as que apresentam ciclos previstos mais próximos do observado em todos os modelos estudados. Para a região NE, o modelo GFDLaer04 tende a subestimar a chuva observada principalmente entre outubro e abril. Sobre a região AMZ, os modelos GFDLFLORa06 e GFDLFLORb01 apresentam curvas climatológicas mais próximas à do CPC e para a região SUL os menores erros médios mensais ocorrem na simulação do modelo CFSv2.

De uma forma geral, para a região $\mathrm{AMZ}$ a tendência é que a maioria dos modelos subestimam a chuva observada ao longo dos anos, o que se reflete numa subestimação também quando se considera a média das previsões (MME).

A relação do erro médio climatológico (viés) para o tempo 1 de previsão é mostrada na figura 10. Os maiores erros estão representados por uma maior altura da barra.

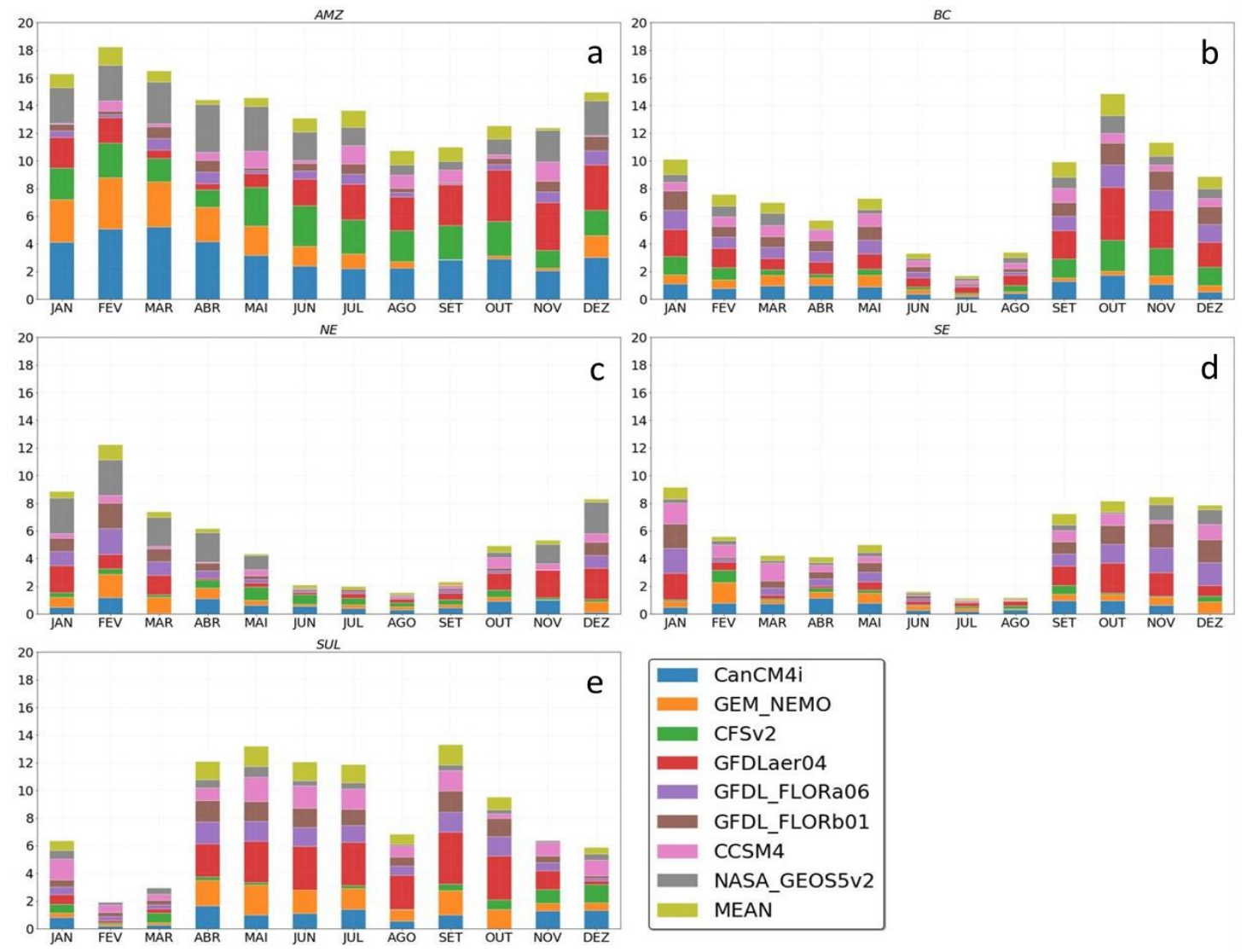

Figura 10 - Ciclo anual do erro climatológico (mm/dia) em módulo (erro absoluto), para o tempo 1 de previsão dos modelos do NMME para as regiões: (a) AMZ, (b) BC, (c) NE, (d) SE, (e) SUL. 
Em geral, o erro é maior na região AMZ e principalmente nos modelos CanCM4i e GEMNEMO para os primeiros meses do ano, e para o modelo GFDLaer04 entre outubro e dezembro (Figura 10a). De acordo com Souza e Cavalcanti et al. (2009), a variabilidade interanual do início e fim das estações chuvosas na Amazônia, bem como os volumes de chuva que podem ocorrer na região, dependem da variação da anomalia da temperatura da superfície do mar (ATSM), o que pode ser um indicativo para os maiores erros de previsão por alguns modelos nesta região.

Comparando as regiões, nota-se que entre as estações de outono e inverno, há um relativo decréscimo nos volumes de chuva nas regiões $\mathrm{AMZ}, \mathrm{NE}, \mathrm{BC}$ e SE, a região SUL apresenta maiores erros climatológicos para alguns modelos do NMME, sendo o GFDLaer04 o modelo com maior erro e o NASA_GEOS5v2 o com menor erro absoluto (Figura 10e).

Para a região NE a dispersão entre os modelos e os erros absolutos são maiores entre outubro-maio e decrescem entre junho-setembro (Figuras 9c, 10c). Nas regiões BC e SE, a climatologia do modelo também apresenta maior dispersão entre os modelos, com maiores erros absolutos e aumento da dispersão entre os membros, no período mais úmido do ano (Figuras 9b, 10b).

Para a evolução do erro climatológico da chuva nas estações do ano a previsão do MME (figura 11), temos uma superestimação sobre áreas a leste dos Andes. Em relação à estação de verão (figura 11a), há uma tendência do MME em superestimar a chuva no norte da região NE e de subestimar sobre grande parte da região $A M Z$ e norte da região BC. Para as regiões SE e SUL, nota-se o predomínio de valores entre -1 e $1 \mathrm{~mm} /$ dia de erro do MME comparado com a climatologia observada.

Em relação a estação de outono (figura 11b), há uma superestimação da chuva pelo MME que é maior sobre o oeste da região SUL e com as demais regiões de estudo não apresentando erros significativos de chuva.

No inverno (figura 11c), há o predomínio de valores negativos para o erro climatológico do MME, principalmente no norte da região AMZ e áreas litorâneas da região NE. Valores negativos do erro climatológico da chuva também são encontrados sobre o oeste da região SUL, mais especificamente no sudoeste dos estados do PR, SC e RS. 
Já na primavera (figura 11d), na região do BC o MME subestima a chuva observada com valor máximo próximo às áreas entre o MT, TO e PA. Para áreas da região SUL, o MME segue subestimando a chuva principalmente a oeste da região.
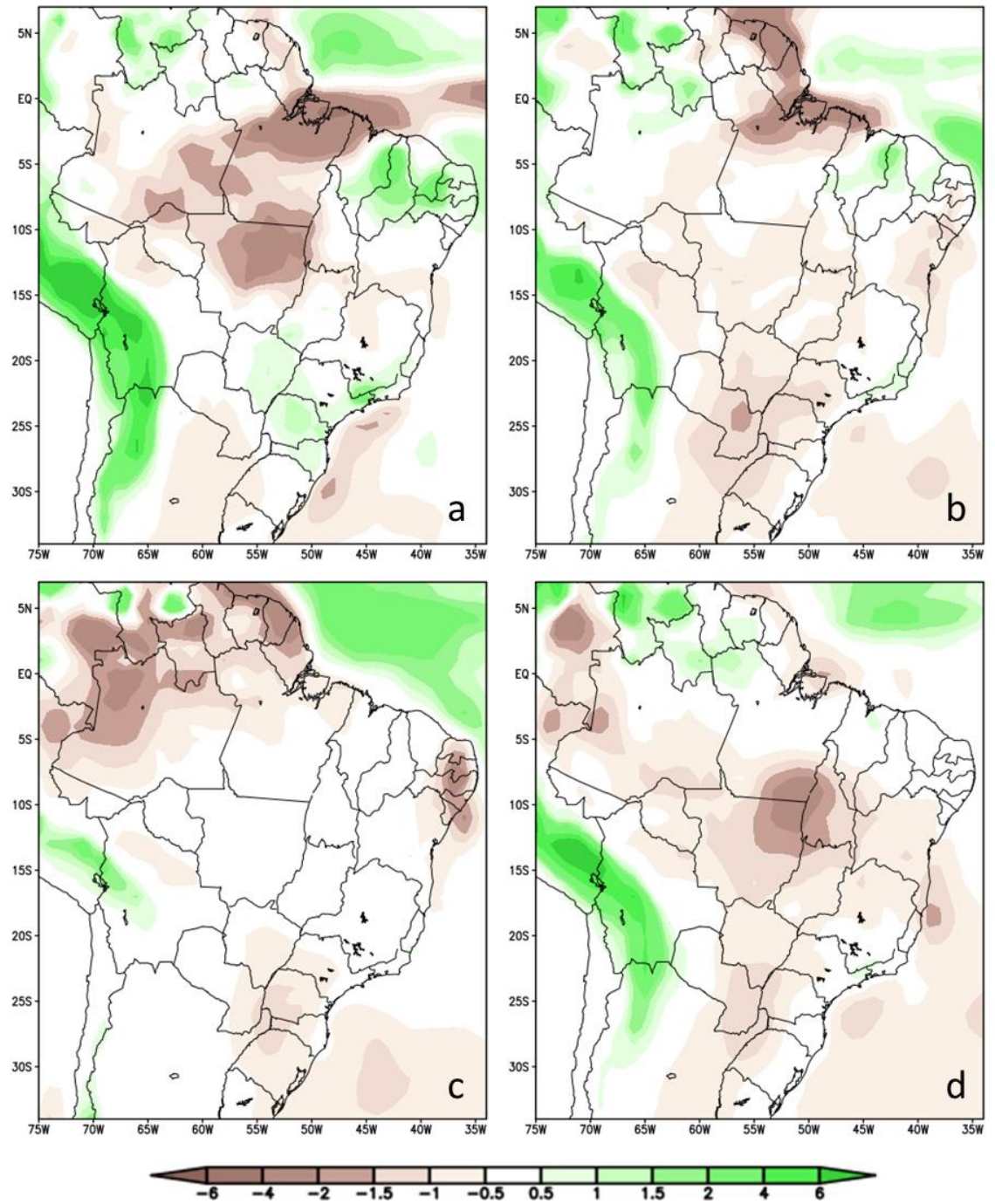

Figura 11 - Erro climatológico entre a climatologia observada e o tempo 1 de previsão do termo médio (MME), em mm/ dia, para as estações de DJF (a), MAM (b), JJA (c) e SON (d).

\subsubsection{Região AMZ}

A utilização do diagrama de Taylor (Taylor, 2001) possibilita sumarizar vários índices estatísticos, tais como, a correlação, RMSE e o desvio padrão (STD) em um único diagrama. Isso facilita a comparação entre os diversos modelos no período de climatologia. Para a 
construção dos diagramas, séries temporais e avaliação objetiva, foi considerado o tempo 1 de previsão em todas as regiões de estudo.
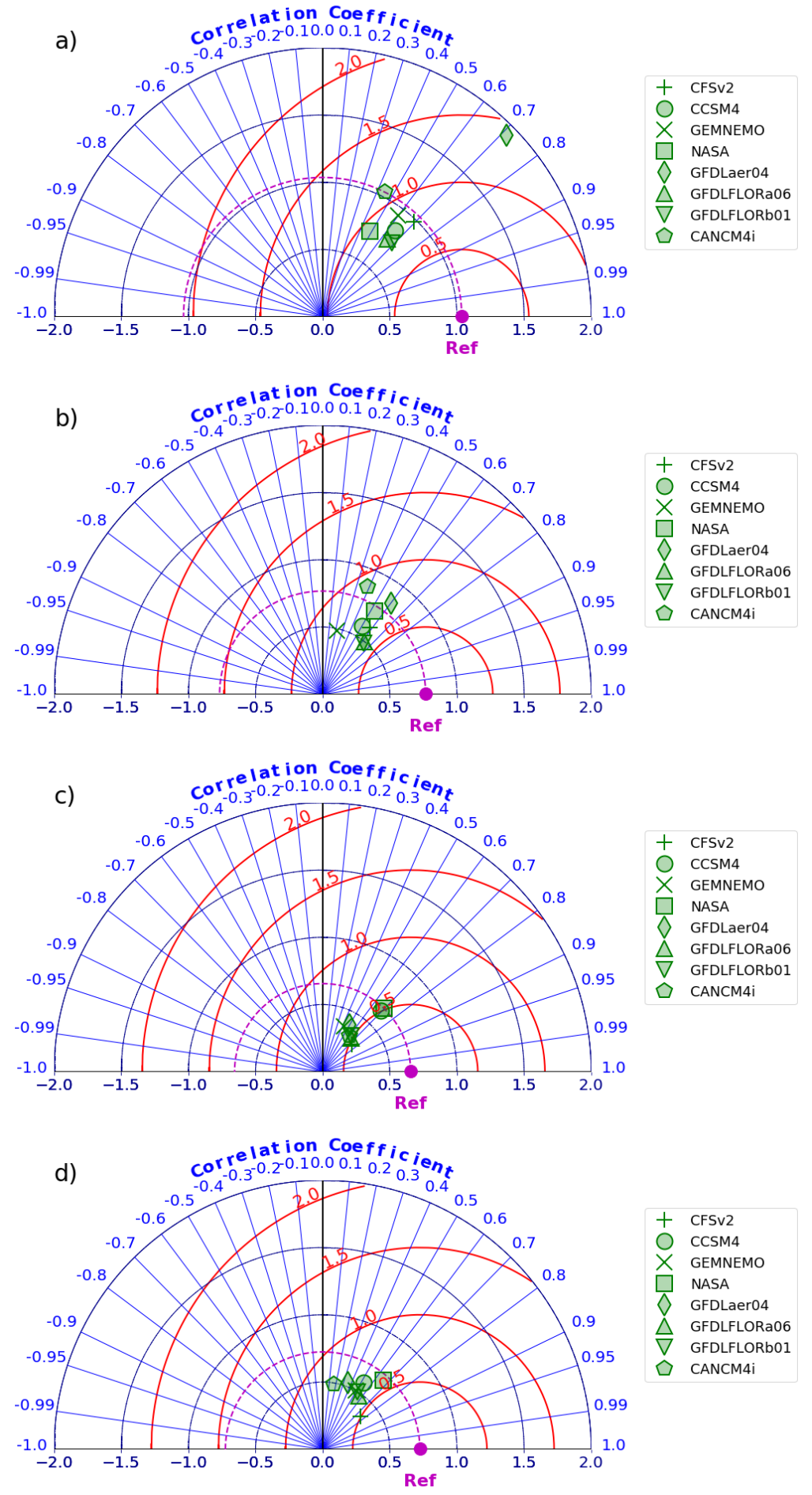

Figura 12 - Diagramas de Taylor da região AMZ para (a) DJF, (b) MAM, (c) JJA, (d) SON. Em azul é mostrada a correlação, vermelho o RSME (mm/ dia) e em roxo o desvio padrão (mm/dia). 

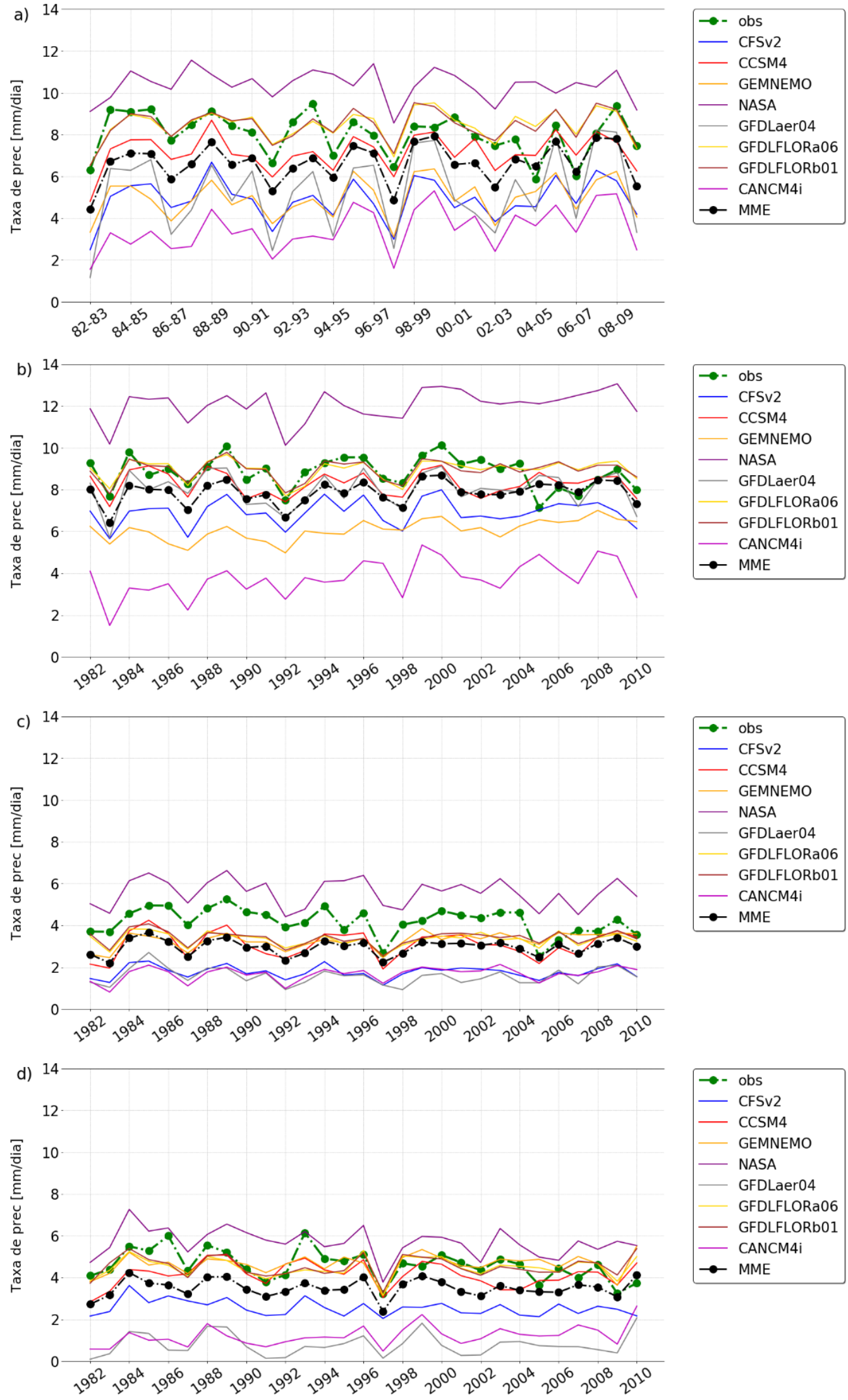

Figura 13 - Série temporal da chuva média sazonal ( $\mathrm{mm} /$ dia) utilizada nas estatísticas do diagrama de Taylor para a região AMZ: (a) DJF, (b) MAM, (c) JJA, (d) SON. 
As figuras 12 e 13, apresentam, respectivamente, o diagrama de Taylor e a série temporal utilizada para a geração do diagrama de Taylor para a região AMZ e para quatro estações do ano (DJF, MAM, JJA e SON). Nota-se que todas as estações do ano apresentam correlações positivas para a taxa de precipitação observada e prevista, indicando que, de uma forma geral, as previsões possuem fases de onda semelhantes às observadas. Destaca-se, por exemplo, os eventos 14 a 15 (1995-1996), onde o índice ONI (Oceano Nino Index) do CPC/NOAA apresentou valores negativos (indicando La Niña) entre as estações JAS/1995 a FMA/1996 e houve redução na taxa de precipitação observada, o que foi adequadamente previsto por todos os modelos. Em relação ao RMSE, para a estação DJF os erros dos modelos se concentram entre 1,5 e $0,5 \mathrm{~mm} /$ dia e tendem a ser menores do que $1,0 \mathrm{~mm}$ / dia entre as estações MAM e SON. Os maiores valores de RMSDs em DJF e MAM também são evidentes nas séries temporais, onde os modelos apresentam uma forte dispersão em relação à taxa de precipitação observada. Os índices estatísticos mostrados nas figuras 12 e 13 estão sumarizados na tabela 5.

Tabela 5 - Coeficiente de correlação (r), Desvio Padrão (STD) e RMSD para os hindcasts (1982-2010) modelos para estações do ano da região AMZ. Em negrito temos as correlações que possuem significância estatística para um valor de $a=0.05$.

\begin{tabular}{lccccccccccccc}
\hline \multirow{2}{*}{ Modelo } & \multicolumn{4}{c}{ Correlação (r) } & \multicolumn{4}{c}{ Desv. Pad (STD) } & \multicolumn{4}{c}{ RMSD } \\
\cline { 2 - 13 } & DJF & MAM & JJA & SON & DJF & MAM & JJA & SON & DJF & MAM & JJA & SON \\
\hline CFSv2 & $\mathbf{0 , 6 9}$ & $\mathbf{0 , 5 8}$ & $\mathbf{0 , 7 3}$ & $\mathbf{0 , 7 5}$ & 0,98 & 0,60 & 0,30 & 0,37 & 0,77 & 0,63 & 0,47 & 0,49 \\
CCSM4 & $\mathbf{0 , 6 4}$ & $\mathbf{0 , 4 9}$ & $\mathbf{0 , 6 8}$ & $\mathbf{0 , 5 2}$ & 0,84 & 0,58 & 0,63 & 0,58 & 0,80 & 0,68 & 0,49 & 0,64 \\
GEMNEMO & $\mathbf{0 , 5 8}$ & 0,22 & $\mathbf{0 , 4 2}$ & $\mathbf{0 , 6 3}$ & 0,93 & 0,48 & 0,37 & 0,5 & 0,87 & 0,79 & 0,58 & 0,63 \\
NASA & $\mathbf{0 , 4 8}$ & $\mathbf{0 , 5 3}$ & $\mathbf{0 , 6 9}$ & $\mathbf{0 , 5 7}$ & 0,72 & 0,73 & 0,64 & 0,68 & 0,91 & 0,71 & 0,50 & 0,56 \\
GFDLaer04 & $\mathbf{0 , 7 1}$ & $\mathbf{0 , 6 0}$ & $\mathbf{0 , 4 9}$ & $\mathbf{0 , 7 2}$ & 1,92 & 0,84 & 0,40 & 0,53 & 1,36 & 0,71 & 0,57 & 0,72 \\
GFDLFLORa06 & $\mathbf{0 , 6 4}$ & $\mathbf{0 , 6 2}$ & $\mathbf{0 , 6 4}$ & $\mathbf{0 , 5 9}$ & 0,75 & 0,5 & 0,33 & 0,48 & 0,78 & 0,59 & 0,50 & 0,59 \\
GFDLFLORb01 & $\mathbf{0 , 6 8}$ & $\mathbf{0 , 6 3}$ & $\mathbf{0 , 6 1}$ & $\mathbf{0 , 6 2}$ & 0,75 & 0,48 & 0,34 & 0,5 & 0,75 & 0,58 & 0,51 & 0,62 \\
CanCM4i & $\mathbf{0 , 4 4}$ & $\mathbf{0 , 3 9}$ & $\mathbf{0 , 6 0}$ & $\mathbf{0 , 8 0}$ & 1,03 & 0,86 & 0,33 & 0,49 & 1,07 & 0,89 & 0,52 & 0,79 \\
MME & $\mathbf{0 , 6 1}$ & $\mathbf{0 , 5 0}$ & $\mathbf{0 , 6 1}$ & $\mathbf{0 , 6 3}$ & 0,99 & 0,63 & 0,42 & 0,51 & 0,91 & 0,70 & 0,52 & 0,63 \\
OBS & $\mathbf{1 , 0 0}$ & $\mathbf{1 , 0 0}$ & $\mathbf{1 , 0 0}$ & $\mathbf{1 , 0 0}$ & 1,04 & 0,77 & 0,66 & 0,72 & 0,00 & 0,00 & 0,00 & 0,00 \\
\hline
\end{tabular}

Nota-se que os menores erros de previsão, ou seja, maior correlação, menor RMSE e desvio padrão próximo do observado são obtidos pela média do conjunto (MME). Além disso, não indica um único modelo que se destaque por apresentar menores erros de previsão em todas as estações do ano. No entanto, em termos de reprodução da variabilidade interanual, 
para cada estação do ano é possível selecionar 3 modelos que apresentam maior correlação: CFSv2, GFDLaer04 GFDLFLORb01 em DJF; os três membros do GFDL em MAM; CFSv2, CCSM4 e NASA em JJA; CFSv2, GFDLae04 e CanCM4i em SON. Individualmente, o modelo CFSv2 se destaca fornecendo menores erros de previsão como indicado pelas correlações altas e RMSDs menores, exceto em MAM (tabela 5). Também se calculou o erro relativo (\%) da previsão de precipitação a fim de identificar os erros climatológicos sistemáticos em função do tempo de previsão em cada estação do ano (figura 14).

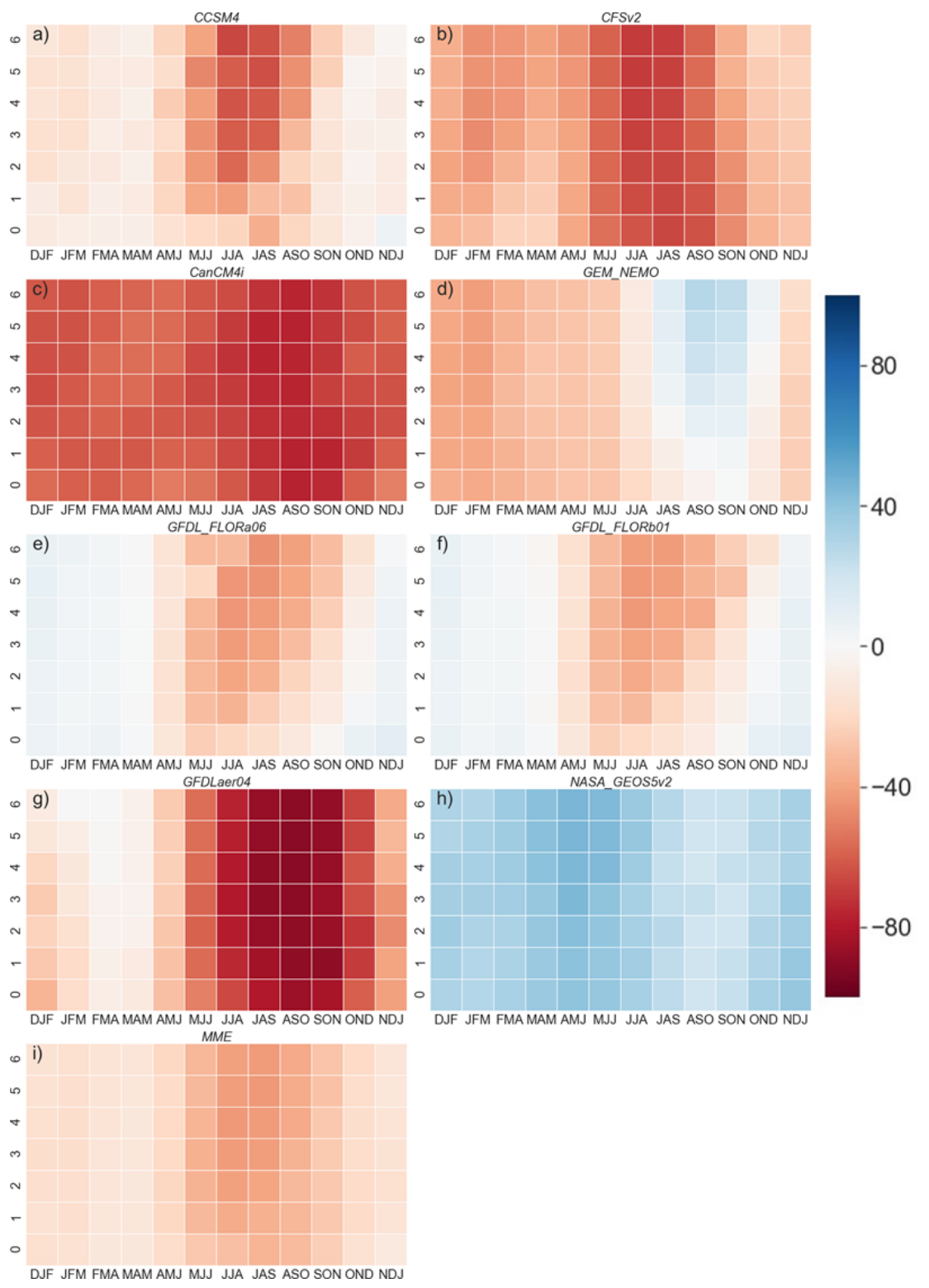

Figura 14 - Erro climatológico relativo (\%) do NMME para a chuva média trimestral na região AMZ. O eixo Y representa os tempos de previsão (de 0 a 6), e o eixo X os trimestres alvos. 
Pela figura 14, nota-se que o MME (figura 14i) apresenta viéses relativos negativos em todas as estações do ano e tempos de previsão. Os maiores erros relativos ocorrem principalmente entre as estações MJJ e ASO e nos modelos CCSM4 (figura 14a), CFSv2 (figura 14b), CanCM4i (figura 14c) e GFDLaer04 (figura 14g). O modelo GEMNEMO (figura 14d), também mostra um erros relativos majoritariamente negativo entre AMJ e SON, mas com valores absolutos menores. Em contrapartida, destaca-se o NASA_GEOS5v2 (figura 14h) que apresenta um viés relativo positivo em todos as estações e tempos de previsão de previsão.

Visto a indicação do viés climatológico mostrado pela figura 15, realizou-se uma correção de cada modelo para o período de previsão (entre 2011 e 2018). Essa correção permite verificar e quantificar em quais estações e tempos de previsão, a remoção do viés climatológico contribuiu para melhorar a qualidade dos resultados. Comparando as previsões dos modelos com correção $\left(^{*}\right)$ e sem correção, obteve-se um diagrama (figura 15) que mostra qual modelo apresentou, na média entre 2011 a 2018, o menor erro relativo. Como os modelos CanCM4i, GEMNEMO e NASA_GEOS5v2 não possuem previsões para toda a série temporal de previsão, eles não foram considerados para essa validação.

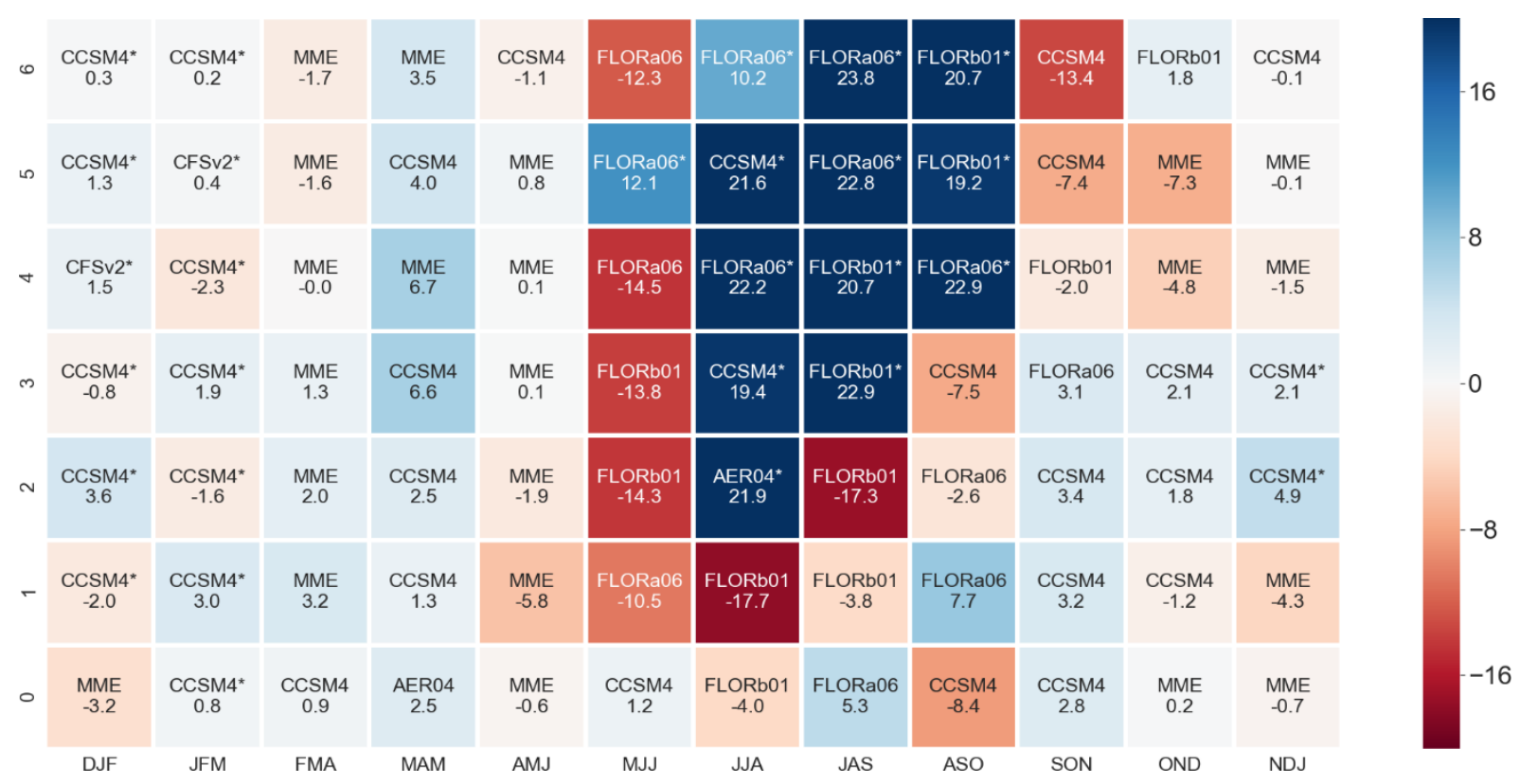

Figura 15 - Média dos erros relativos (\%) dos melhores modelos (menores erros em módulo) para as previsões entre as estações entre 2011 e 2018 para a região AMZ. O símbolo "*" indica que o modelo foi corrigido pelo viés climatológico (figura 13). 
Da figura 15, também se nota um maior valor absoluto do erro relativo entre as estações MJJ e ASO, principalmente entre os tempos 2 e 6 de previsão. Para os tempos 0 e 1 de previsão, os modelos CCSM4 e MME apresentaram uma maior frequência de ocorrência de menores erros entre as estações DJF e NDJ. Considerando todos os tempos de previsão, o MME apresentou uma maior ocorrência de erros relativos menores, mostrando que, em média, a utilização da previsão por conjunto (ENSEMBLE) resultou em menores viéses nessa região durante o período de previsão. Dentre os modelos presentes entre as estações de maiores valores de erro relativo (MJJ e ASO), os modelos GFDLFLORb01 e GFDLFLORa06 apresentaram erros relativamente menores.

Similarmente ao processo de criação do diagrama de melhores modelos, também foi feito o diagrama dos piores modelos (figura 16). Esse diagrama mostra um intervalo entre os menores e maiores erros relativos, em módulo, para a região.

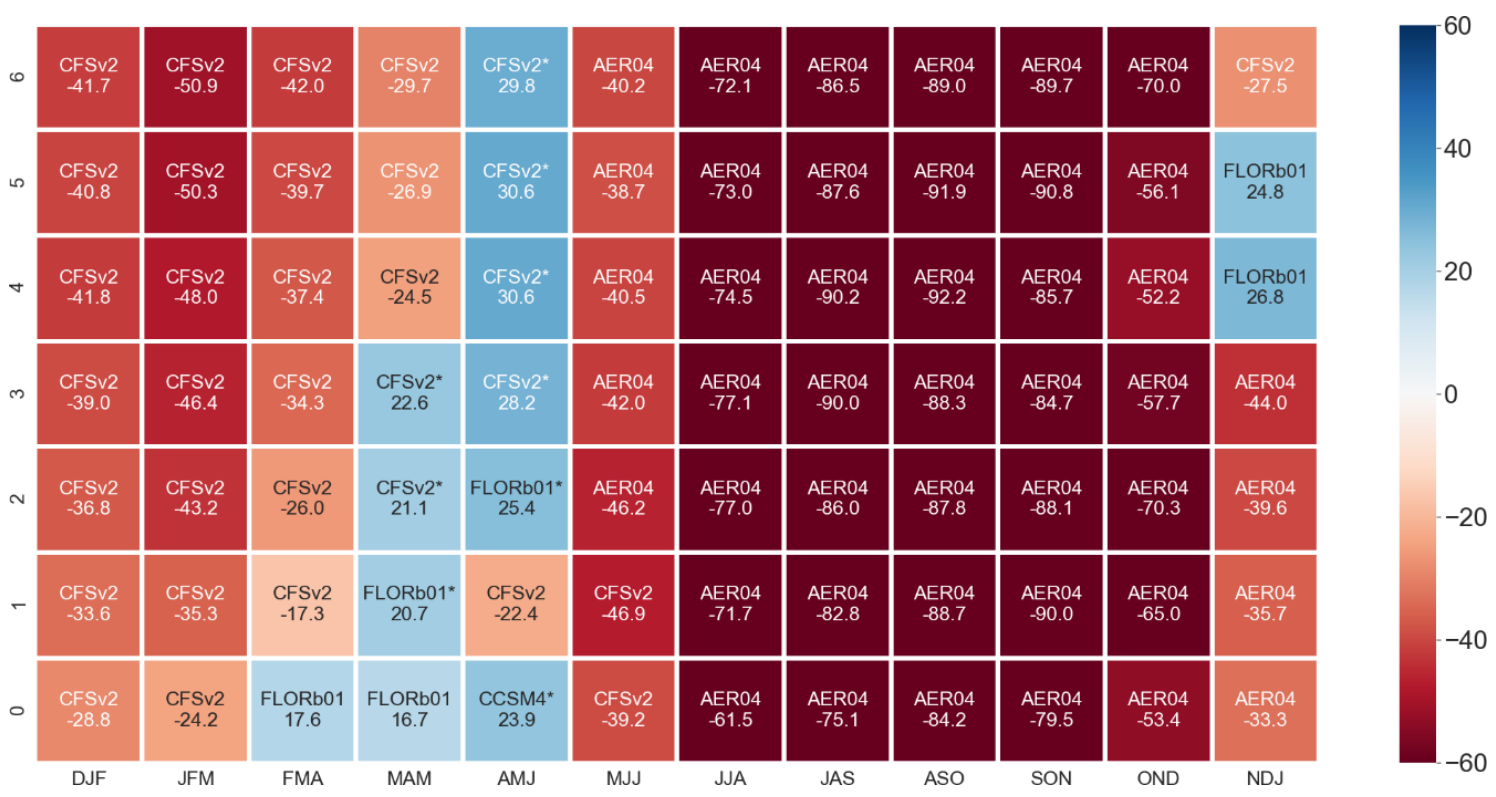

Figura 16 - Média dos erros relativos (\%) dos piores modelos (maiores erros em módulo) e para as previsões entre as estações entre 2011 e 2018 para a região AMZ. O símbolo “*” indica que o modelo foi corrigido pelo viés climatológico (figura 13).

Nesse caso, os maiores erros relativos, em módulo, persistem entre as estações JJA e ASO e avançam também para as estações SON e OND. Dentre os modelos, destacam-se os CFSv2 e GFDLaer04 sem a correção do viés climatológico $\left({ }^{*}\right)$ que apresentaram maiores ocorrências de 
maior erro relativo, indicando a presença de erros sistemáticos nessas previsões. Essas subestimativas da chuva pelo CFSv2 e GFDLaer04 já eram notadas para as quatro estações do ano mostradas na Figura 11. No entanto, como já destacado, ambos modelos apresentam grande habilidade na previsão da variabilidade interanual com correlações maiores em três estações do ano cada um (tabela 5).

Assim, para a região $\mathrm{AMZ}$, os resultados obtidos da comparação da previsão e observação para o período climatológico (1981-2010) mostraram uma tendência de subestimativa da taxa de precipitação do termo médio (MME), havendo uma maior convergência entre os modelos (exceto NASAGEOS5v2 e GEMENMO) principalmente entre as estações de AMJ e ASO. 


\subsubsection{Região BC}

Para a região $\mathrm{BC}$, os diagramas de Taylor e suas respectivas séries temporais são apresentados nas figuras 17 e 18 .
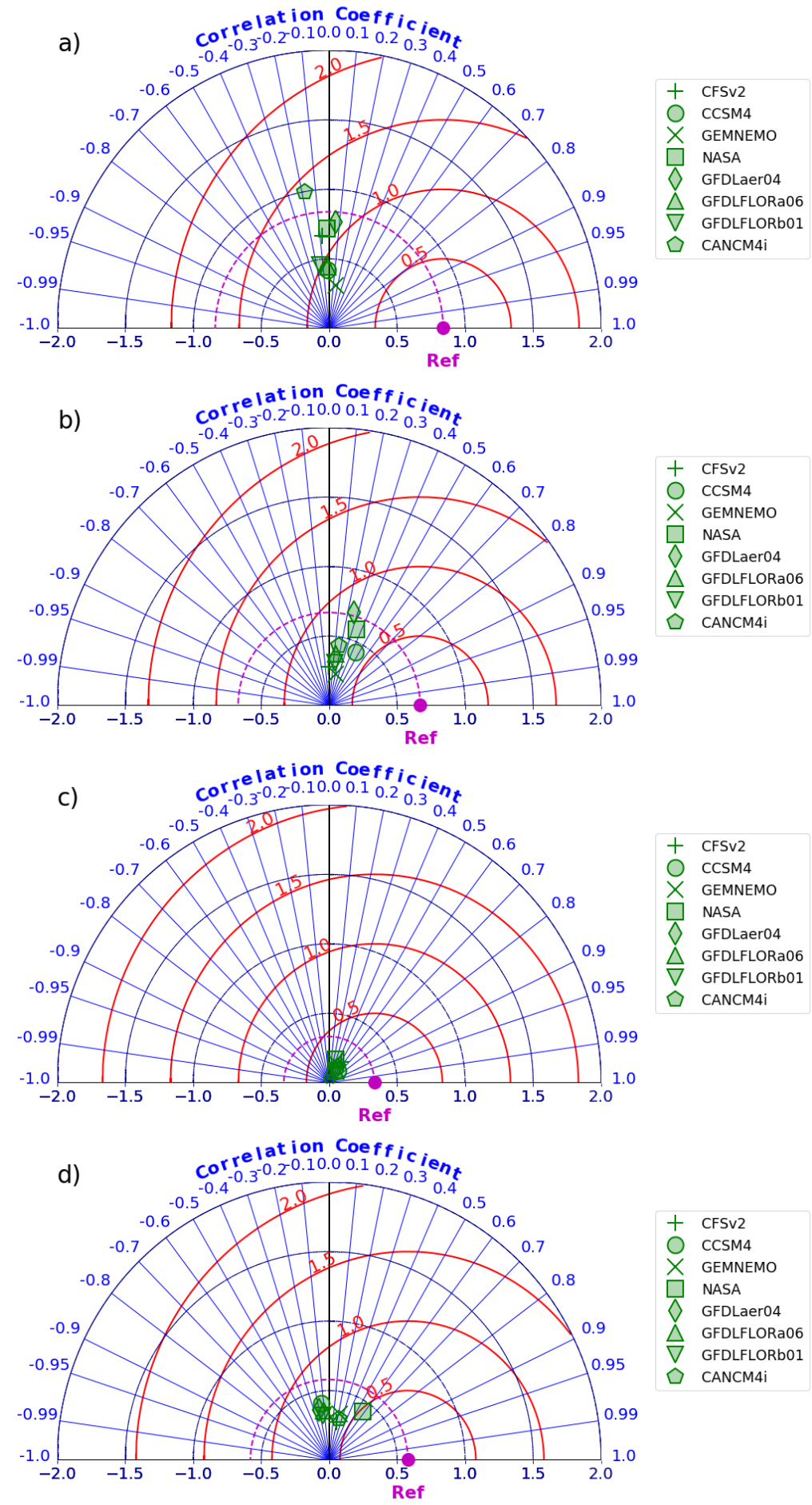

Figura 17 - Diagramas de Taylor da região BC para (a) DJF, (b) MAM, (c) JJA, (d) SON. Em azul é mostrada a correlação, vermelho o RSME ( $\mathrm{mm} /$ dia) e em roxo o desvio padrão (mm/dia). 

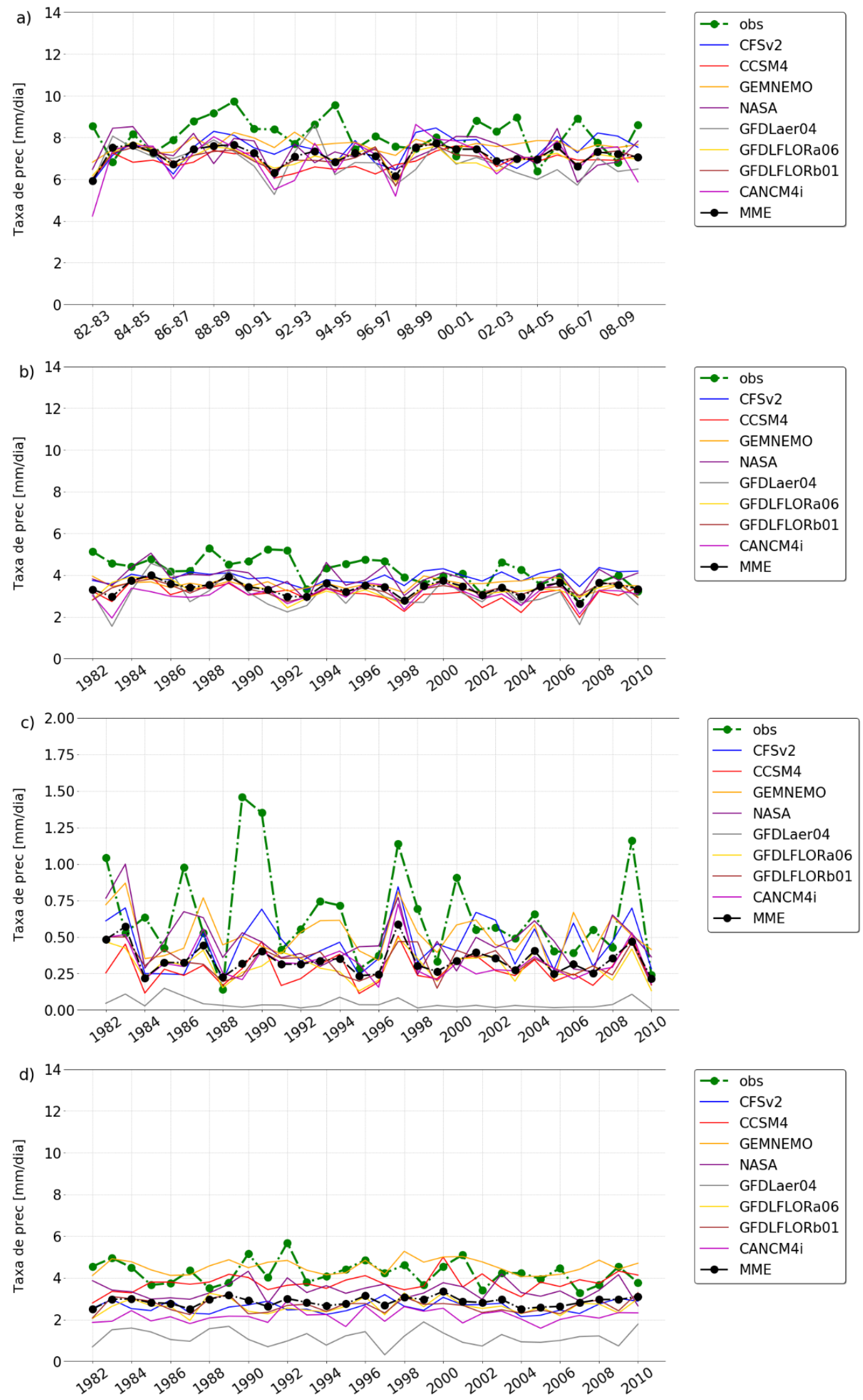

Figura 18 - Série temporal da chuva média sazonal (mm/dia) utilizada nas estatísticas do diagrama de Taylor para a região BC: (a) DJF, (b) MAM, (c) JJA, (d) SON. 
No período chuvoso do BC, que compreende as estações SON à DJF (figuras 17a, 17d, 18a e 18d), há menores valores de correlação que inclusive se aproximam de zero. Durante a estação JJA (figuras 17c e 18c), nota-se uma redução na amplitude da escala (eixo y da figura 18c) em comparação com a região $\mathrm{AMZ}$, já que na região $\mathrm{BC}$ a precipitação é bastante escassa nesse período. Esse ajuste de escala também foi aplicado para as regiões SE, NE e SUL. Apesar desses baixos valores, em anos nos quais foram observados picos na taxa de precipitação, os modelos não previram a amplitude observada (figura 18). No entanto, como destacado na tabela 6, as correlações temporais foram maiores em JJA do que em DJF, com os modelos CCSM4, CFSv2 e GFDLaer04 apresentando maiores correlações temporais em JJA. Nas estações intermediárias (MAM e SON) as correlações continuaram baixas, exceto no modelo da NASA em SON e CCSM4 em MAM. Nas estações de JJA e SON (figuras 18c e 18d), o modelo GFDLaer04 apresentou uma maior subestimação da precipitação, o que se reflete nos maiores valores de RMSD em comparação aos demais modelos para as mesmas estações.

Tabela 6 - Coeficiente de correlação (r), Desvio Padrão (STD) e RMSD para os hindcasts (1982-2010) modelos para estações do ano da região BC. Em negrito temos as correlações que possuem significância estatística para um valor de $\alpha=0.05$.

\begin{tabular}{lcccccccccccc}
\hline \multirow{2}{*}{ Modelo } & \multicolumn{4}{c}{ Correlação (r) } & \multicolumn{4}{c}{ Desv. Pad (STD) } & \multicolumn{4}{c}{ RMSD } \\
\cline { 2 - 12 } & DJF & MAM & JJA & SON & DJF & MAM & JJA & SON & DJF & MAM & JJA & SON \\
\hline CFSv2 & $-0,08$ & $-0,01$ & $\mathbf{0 , 5 0}$ & 0,19 & 0,67 & 0,28 & 0,17 & 0,28 & 1,09 & 0,72 & 0,28 & 0,58 \\
CCSM4 & $-0,03$ & $\mathbf{0 , 4 5}$ & $\mathbf{0 , 6 1}$ & $-0,14$ & 0,42 & 0,43 & 0,11 & 0,41 & 0,93 & 0,60 & 0,28 & 0,74 \\
GEMNEMO & 0,15 & 0,19 & 0,27 & 0,23 & 0,31 & 0,23 & 0,16 & 0,34 & 0,84 & 0,65 & 0,32 & 0,59 \\
NASA & $-0,02$ & $\mathbf{0 , 3 5}$ & 0,25 & $\mathbf{0 , 5 8}$ & 0,72 & 0,58 & 0,18 & 0,43 & 1,10 & 0,71 & 033 & 0,47 \\
GFDLaer04 & 0,06 & 0,26 & 0,20 & $-0,19$ & 0,76 & 0,70 & 0,04 & 0,37 & 1,08 & 0,81 & 0,32 & 0,73 \\
GFDLFLORa06 & $-0,02$ & 0,13 & $\mathbf{0 , 4 9}$ & $-0,12$ & 0,45 & 0,37 & 0,10 & 0,36 & 0,94 & 0,71 & 0,29 & 0,70 \\
GFDLFLORb01 & $-0,15$ & 0,13 & $\mathbf{0 , 5 2}$ & $-0,15$ & 0,46 & 0,31 & 0,10 & 0,33 & 0,99 & 0,69 & 0,29 & 0,69 \\
CanCM4i & $-0,18$ & 0,16 & $\mathbf{0 , 4 5}$ & 0,23 & 1,00 & 0,44 & 0,13 & 0,31 & 1,39 & 0,72 & 0,29 & 0,58 \\
MME & $-0,03$ & 0,21 & $\mathbf{0 , 4 1}$ & 0,08 & 0,60 & 0,42 & 0,12 & 0,35 & 1,05 & 0,70 & 0,30 & 0,64 \\
OBS & $\mathbf{1 , 0 0}$ & $\mathbf{1 , 0 0}$ & $\mathbf{1 , 0 0}$ & $\mathbf{1 , 0 0}$ & 0,84 & 0,67 & 0,33 & 0,58 & 0,00 & 0,00 & 0,00 & 0,00 \\
\hline
\end{tabular}

Na figura 19 o erro relativo (\%) da climatologia do modelo como função do tempo de previsão, nota-se na maioria dos modelos (exceto CFSv2 e GEMNEMO) o predomínio de valores negativos, indicando um viés climatológico de subestimação da taxa de precipitação. Além disso, os maiores valores dessa subestimativa ocorrem principalmente entre as estações 
AMJ e ASO. Em particular, no modelo GFDLaer04 (figura 17d) são encontrados os maiores erros relativos em módulo. Dessa forma, apesar dos baixos volumes acumulados de chuva esperados para essa época do ano (entre AMJ e ASO), há um maior erro relativo nas previsões sazonais. Importante notar que assim como para a região AMZ (figura 14) os erros sazonais relativos apresentam maior dependência da estação do ano (menores nos períodos chuvosos e maiores nos períodos mais secos) do que com a antecedência (tempo de previsão) da previsão.

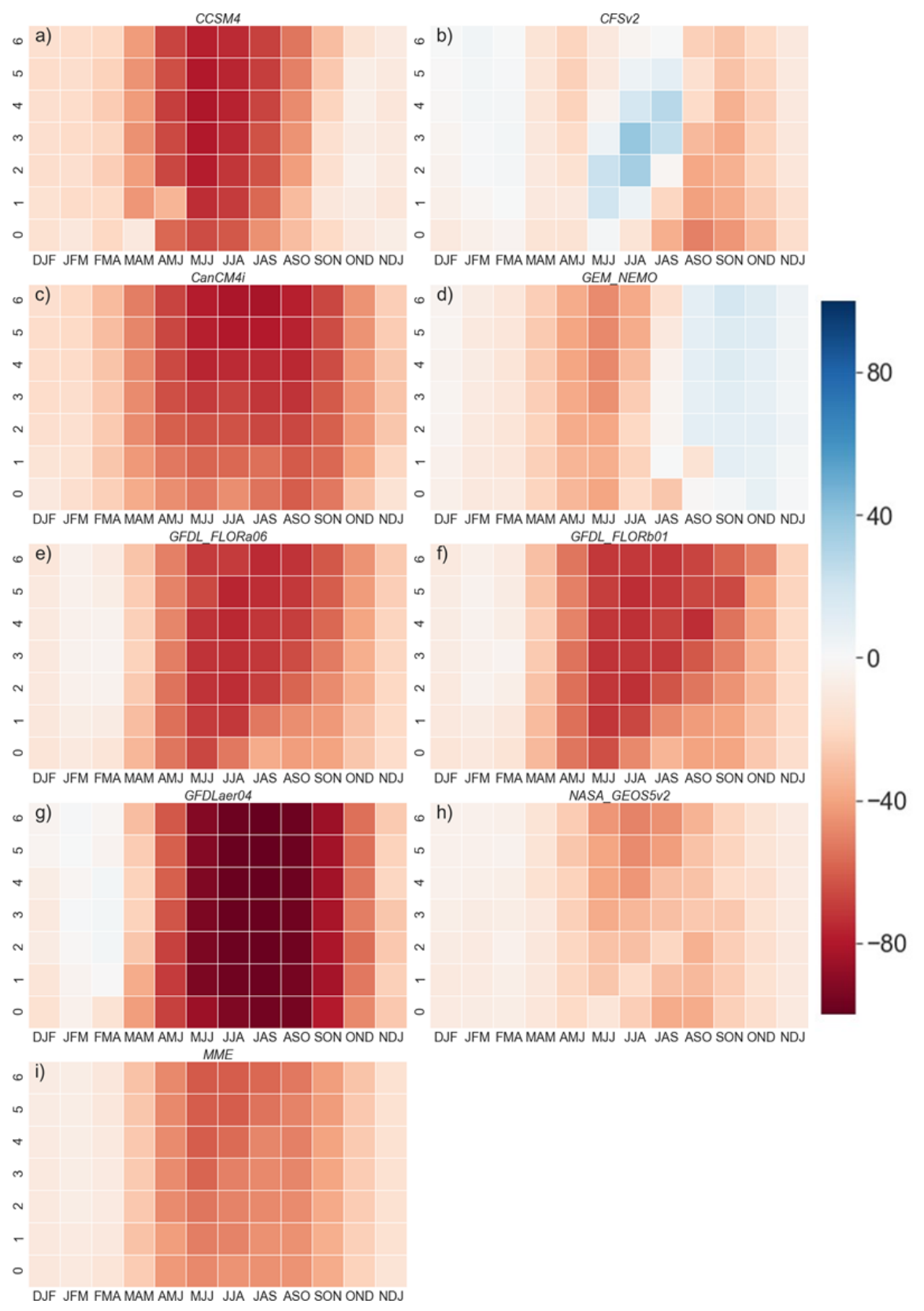

Figura 19 - Erro climatológico relativo (\%) do NMME para a chuva média trimestral na região BC. O eixo $\mathrm{Y}$ representa os tempos de previsão (de 0 a 6), e o eixo $\mathrm{X}$ os trimestres alvos. 
A relação dos modelos que apresentaram o menor erro relativo durante o período de previsão (2011-2018) na região BC é mostrada na figura 20. De uma forma geral e considerando os tempos 0 e 1 de previsão, o modelo GFDLaer04, que apresentou um grande viés climatológico, se destaca como melhor modelo para previsão do volume de chuva após a correção na maioria das estações do ano (apenas para DJF que a correção não foi necessária). Ainda para esses tempos de previsão o modelo CFSv2 também apresentou menores erros relativos de previsão na maioria das vezes. Novamente, para as estações entre JJA e SON, o erro relativo aumenta em comparação com as demais estações do ano. A média dos membros (MME) se mostrou com menor erro relativo principalmente na estação NDJ, onde aparece em praticamente todos os tempos de previsão (exceto para o tempo 5).

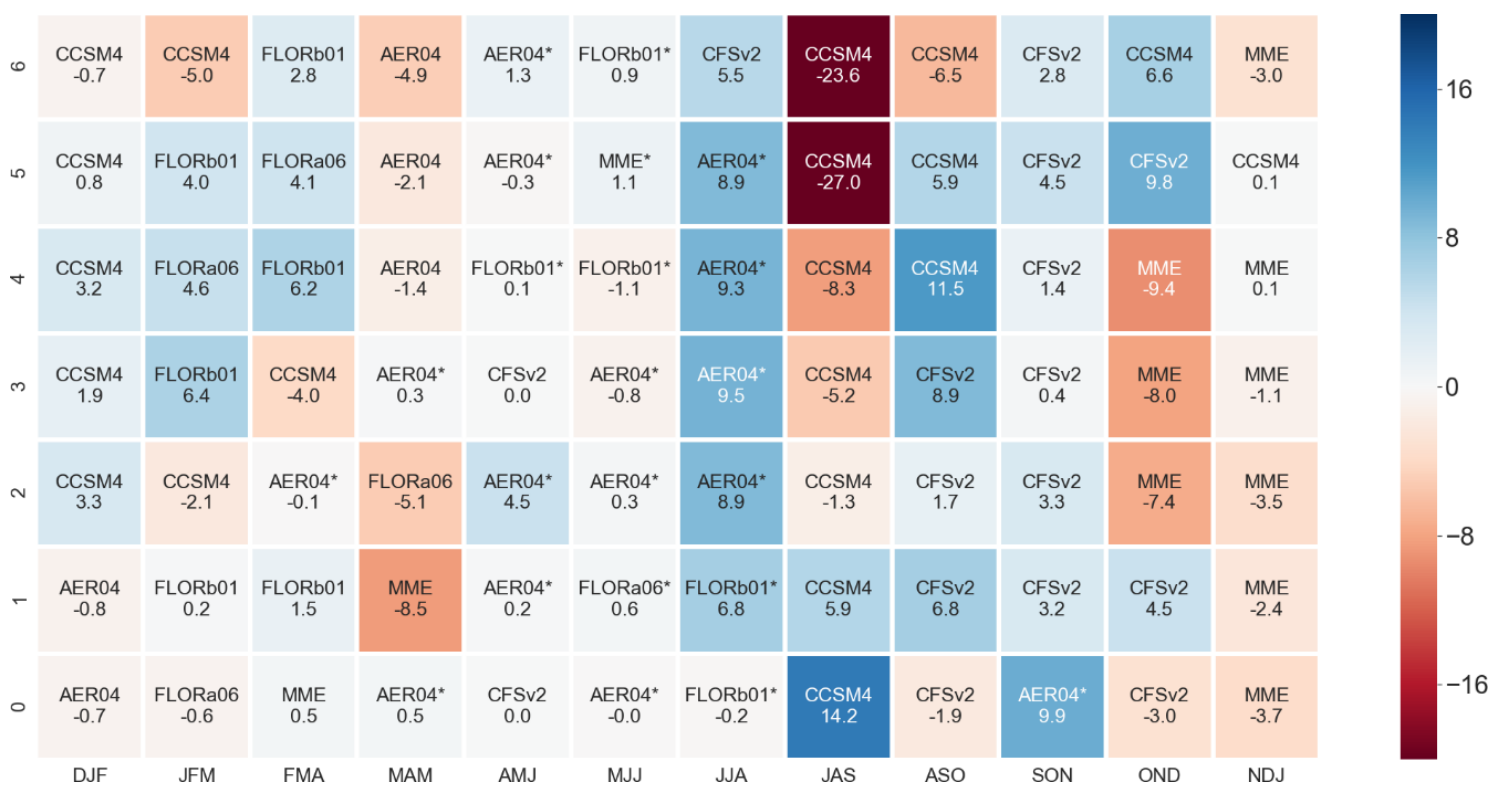

Figura 20 - Média dos erros relativos (\%) dos melhores modelos (menores erros em módulo) para as previsões entre as estações entre 2011 e 2018 para a região BC. O símbolo “*” indica que o modelo foi corrigido pelo viés climatológico (figura 19).

Para os piores modelos (figura 21), comprova-se a presença de um grande viés climatológico do modelo GFDLaer04 que apresentou uma maior frequência de ocorrência principalmente entre as estações AMJ e SON. Além disso, nas estações MJJ e SON o modelo GFDLaer04 também apresentou maiores erros em todos os tempos de previsão. Para as 
estações entre NDJ e FMA, o CFSv2 predominou como pior modelo e mesmo aplicando a correção viés no CFSv2*, o modelo não apresentou uma melhora nos resultados.

O modelo CCSM4 também apresentou maiores valores de erro relativo, principalmente para as estações MAM e AMJ e entre os tempos de previsão 2 e 6. A média dos modelos (MME) não foi classificada como pior modelo em nenhum tempo ou estação alvo de previsão.

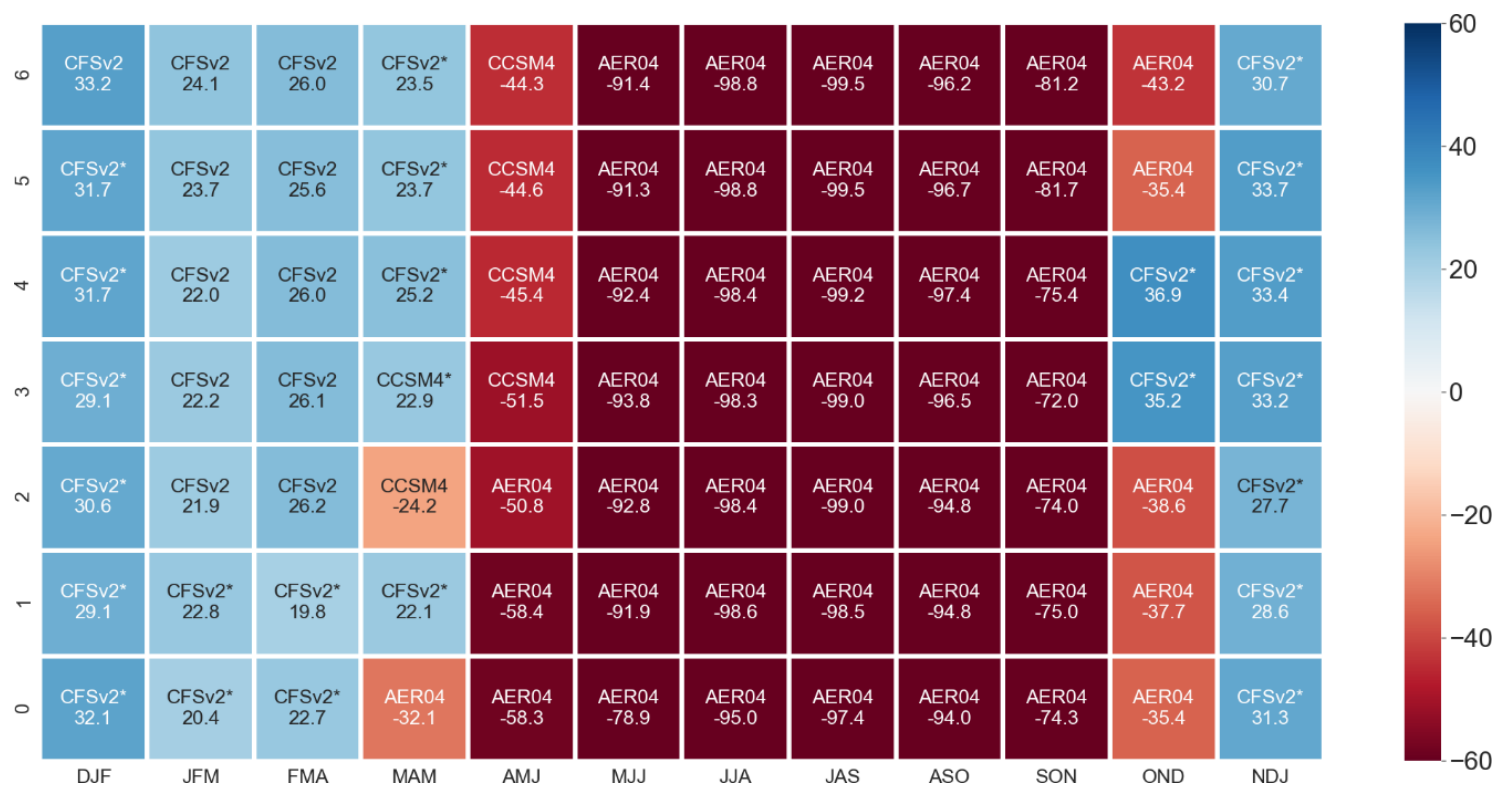

Figura 21 - Média dos erros relativos (\%) dos piores modelos (maiores erros em módulo) e para as previsões entre as estações entre 2011 e 2018 para a região BC. O símbolo “*” indica que o modelo foi corrigido pelo viés climatológico (figura 19).

De uma maneira geral, os resultados para a região BC mostram que não necessariamente a relação de um menor viés climatológico irá gerar melhores previsões, como ocorre com o modelo CFSv2 (figura 19b e figura 21). Contudo, para tempos de previsão/estações onde o modelo simula um maior viés climatológico negativo (positivo), há uma tendência de que a previsão subestime (superestime) a taxa de precipitação. Sendo isso evidenciando principalmente pelo modelo GFDLaer04 e pelas figuras 19g e 21. 


\subsubsection{Região NE}

Para a região NE, os diagramas de Taylor e as respectivas séries temporais são apresentados nas figuras 22 e 23 .
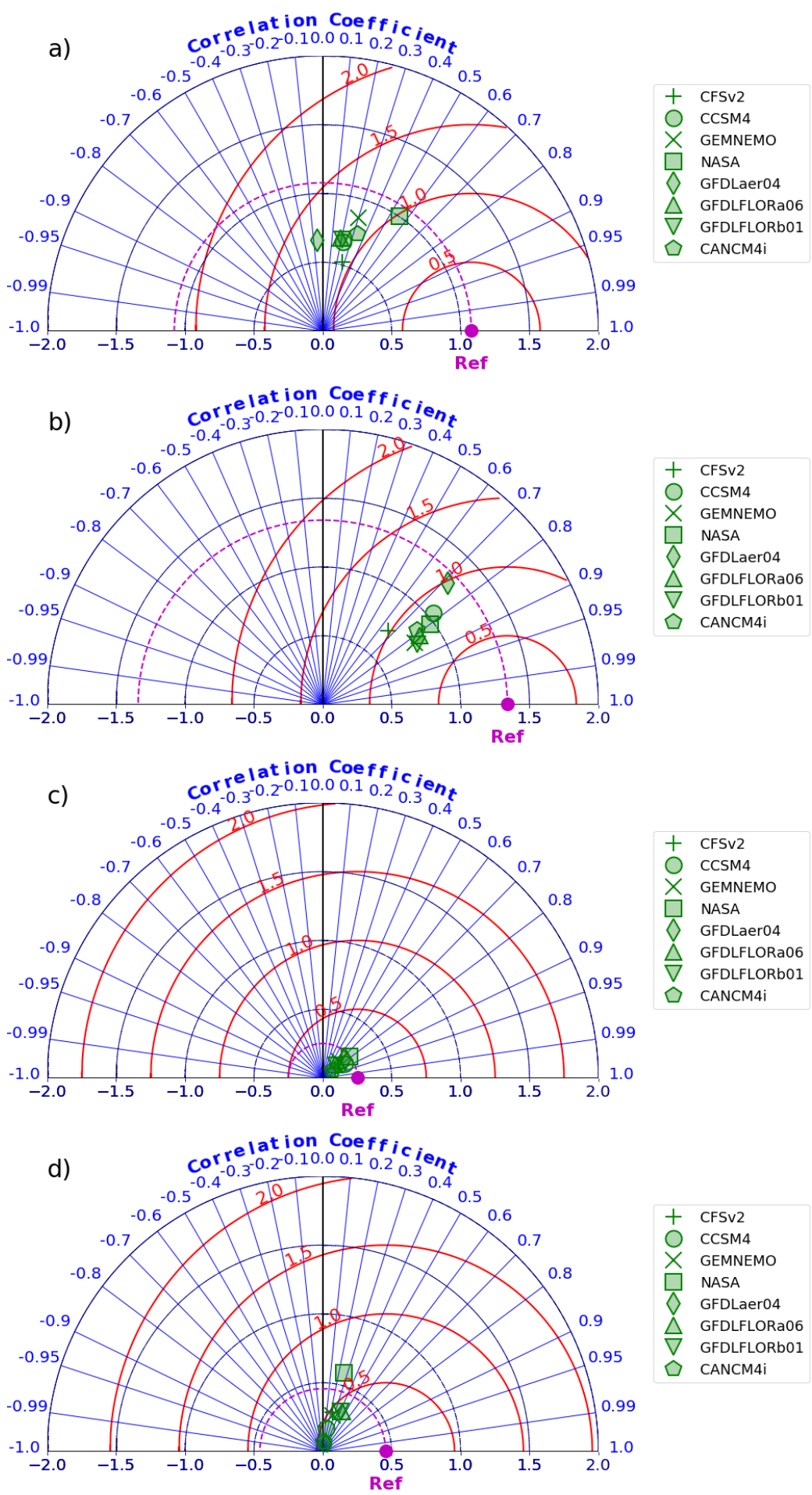

Figura 22 - Diagramas de Taylor da região NE para (a) DJF, (b) MAM, (c) JJA, (d) SON. Em azul é mostrada a correlação, vermelho o RSME (mm/dia) e em roxo o desvio padrão (mm/dia). 


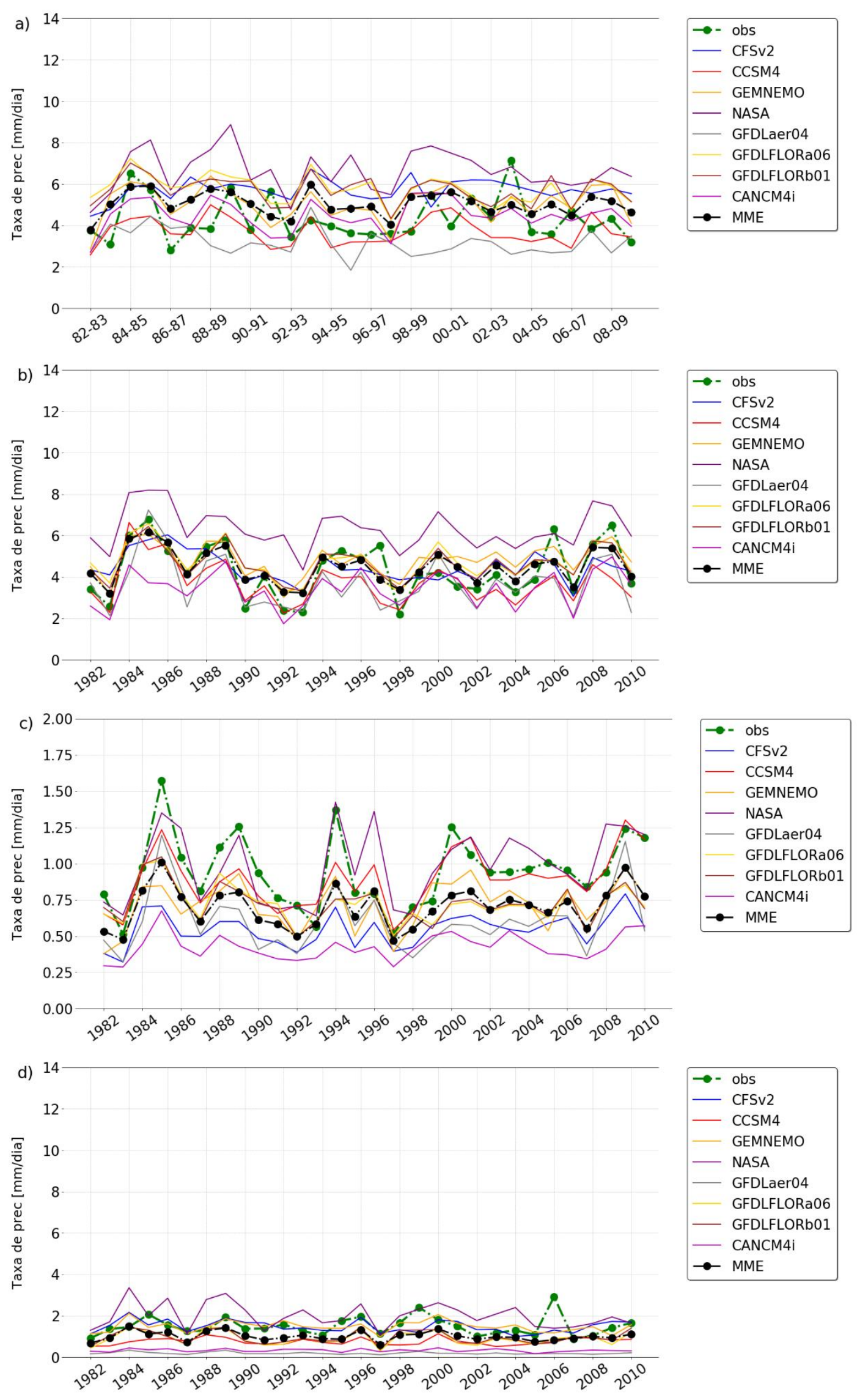

Figura 23 - Série temporal da chuva média sazonal (mm/dia) utilizada nas estatísticas do diagrama de Taylor para a região NE: (a) DJF, (b) MAM, (c) JJA, (d) SON. 
Para a estação de verão (figuras 22a e 23a), destaca-se o modelo da NASA_GEOS5v2 que apresentou durante toda a série temporal um viés positivo (superestimação da chuva). Ainda no verão, os demais modelos também apresentaram superestimativa da taxa de precipitação observada, sendo que isso também reflete no MME.

Para a estação MAM, observa-se que os modelos possuem uma maior correlação e um menor viés em relação a taxa de precipitação observada, contudo, ainda há a presença de um forte erro positivo para o modelo NASAGEOS5v2.

Na estação JJA, os modelos apresentam subestimação da chuva (viés negativo) e, ao contrário das demais estações, o modelo da NASAGEOS5v2 apresenta uma correlação alta indicando habilidade em prever a variabilidade interanual da chuva observada.

Para a estação SON, destacam-se os modelos CanCM4i, GFDLFLORa06, GFDLFLORb01 e GFDLaer04 que subestimam a chuva durante toda a série temporal. Os valores de correlação, desvio padrão e o desvio do erro quadrático médio para a região NE são mostrados na tabela 7.

Nota-se que para essa região as correlações são relativamente altas (acima de 0.70) na maioria dos modelos em MAM e JJA, ou seja, nas estações chuvosas, respectivamente, do centro-norte e leste do NE (Reboita et al., 2010). É bastante conhecida a forte influência tanto do Oceano Pacífico como do Atlântico tropical na variabilidade interanual da estação chuvosa na região nordeste do Brasil (Uvo et al., 1998; Moura et al., 2000; Santo e Silva, 2010.). Isso indicaria uma grande habilidade dos modelos em prever a variabilidade interanual da TSM no setor tropical com consequente boa qualidade de previsão da variabilidade da chuva nas estações MAM e JJA.

Por outro lado, durante DJF e SON nota-se um decréscimo acentuado das correlações entre os modelos e as observações o que indicaria que fenômenos diferentes dos mencionados controlam a variabilidade interanual da chuva e não estariam sendo adequadamente previstos pelos modelos. Para o verão a correlação mais alta é de 0.56 para o modelo NASA, enquanto em SON gira em torno de 0.40 em duas versões do GFDL (GFDLFLORa06 e GFDLFLORb01). 
Tabela 7 - Coeficiente de correlação (r), Desvio Padrão (STD) e RMSD para os hindcasts (1982-2010) modelos para estações do ano da região NE. Em negrito temos as correlações que possuem significância estatística para um valor de $\alpha=0.05$.

\begin{tabular}{lcccccccccccc}
\hline \multirow{2}{*}{ Modelo } & \multicolumn{4}{c}{ Correlação (r) } & \multicolumn{4}{c}{ Desv. Pad (STD) } & \multicolumn{4}{c}{ RMSD } \\
\cline { 2 - 12 } & DJF & MAM & JJA & SON & DJF & MAM & JJA & SON & DJF & MAM & JJA & SON \\
\hline CFSv2 & 0,27 & $\mathbf{0 , 6 6}$ & $\mathbf{0 , 7 8}$ & 0,24 & 0,52 & 0,72 & 0,11 & 0,29 & 1,04 & 1,00 & 0,17 & 0,47 \\
CCSM4 & 0,22 & $\mathbf{0 , 7 7}$ & $\mathbf{0 , 8 4}$ & 0,15 & 0,67 & 1,04 & 0,19 & 0,17 & 1,11 & 0,84 & 0,13 & 0,45 \\
GEMNEMO & 0,30 & $\mathbf{0 , 8 3}$ & $\mathbf{0 , 6 9}$ & 0,27 & 0,86 & 0,81 & 0,17 & 0,27 & 1,14 & 0,79 & 0,18 & 0,46 \\
NASA & $\mathbf{0 , 5 6}$ & $\mathbf{0 , 8 0}$ & $\mathbf{0 , 7 8}$ & 0,26 & 1,00 & 0,97 & 0,25 & 0,59 & 0,97 & 0,80 & 0,16 & 0,64 \\
GFDLaer04 & $-0,06$ & $\mathbf{0 , 7 2}$ & $\mathbf{0 , 7 5}$ & 0,35 & 0,66 & 1,27 & 0,21 & 0,05 & 1,27 & 0,96 & 0,16 & 0,43 \\
GFDLFLORa06 & 0,19 & $\mathbf{0 , 8 2}$ & $\mathbf{0 , 6 8}$ & $\mathbf{0 , 4 3}$ & 0,69 & 0,86 & 0,13 & 0,32 & 1,15 & 0,79 & 0,18 & 0,42 \\
GFDLFLORb01 & 0,21 & $\mathbf{0 , 8 4}$ & $\mathbf{0 , 7 1}$ & $\mathbf{0 , 4 1}$ & 0,68 & 0,81 & 0,13 & 0,32 & 1,13 & 0,77 & 0,18 & 0,43 \\
CanCM4i & 0,34 & $\mathbf{0 , 7 8}$ & $\mathbf{0 , 7 9}$ & 0,11 & 0,75 & 0,88 & 0,09 & 0,07 & 1,06 & 0,84 & 0,18 & 0,45 \\
MME & 0,25 & $\mathbf{0 , 7 8}$ & $\mathbf{0 , 7 5}$ & 0,28 & 0,73 & 0,92 & 0,16 & 0,26 & 1,11 & 0,85 & 0,16 & 0,47 \\
OBS & $\mathbf{1 , 0 0}$ & $\mathbf{1 , 0 0}$ & $\mathbf{1 , 0 0}$ & $\mathbf{1 , 0 0}$ & 1,08 & 1,34 & 0,25 & 0,46 & 0,00 & 0,00 & 0,00 & 0,00 \\
\hline
\end{tabular}

Os erros dos modelos mostrados nas séries temporais da figura 23 estão sintetizados pelos diagramas de cor da figura 24 para todas as estações do ano e tempos de previsão. Vale destacar que os modelos CFSv2 (figura 24b), GEMNEMO (figura 24d), GFDLFLORa06 (figura 24e) e GFDLFLORb01 (figura 24f) apresentam resultados similares entre as estações próximas do período de verão (NDJ a FMA) onde há uma superestimação da chuva média trimestral.

A similaridade ocorre também para as estações próximas ao período de inverno (AMJ e $\mathrm{SON}$ ), onde esses modelos subestimam a taxa de precipitação observada sobre essa região. Além disso, também há um padrão similar ao mencionado para o MME (figura 24i), mas com erros absolutos menores. Os modelos CCSM4 (figura 24a) e CanCM4i (figura 24c) apresentam erros climatológicos predominantemente negativos (subestimação) durante todas as estações do ano e tempos de previsão. 

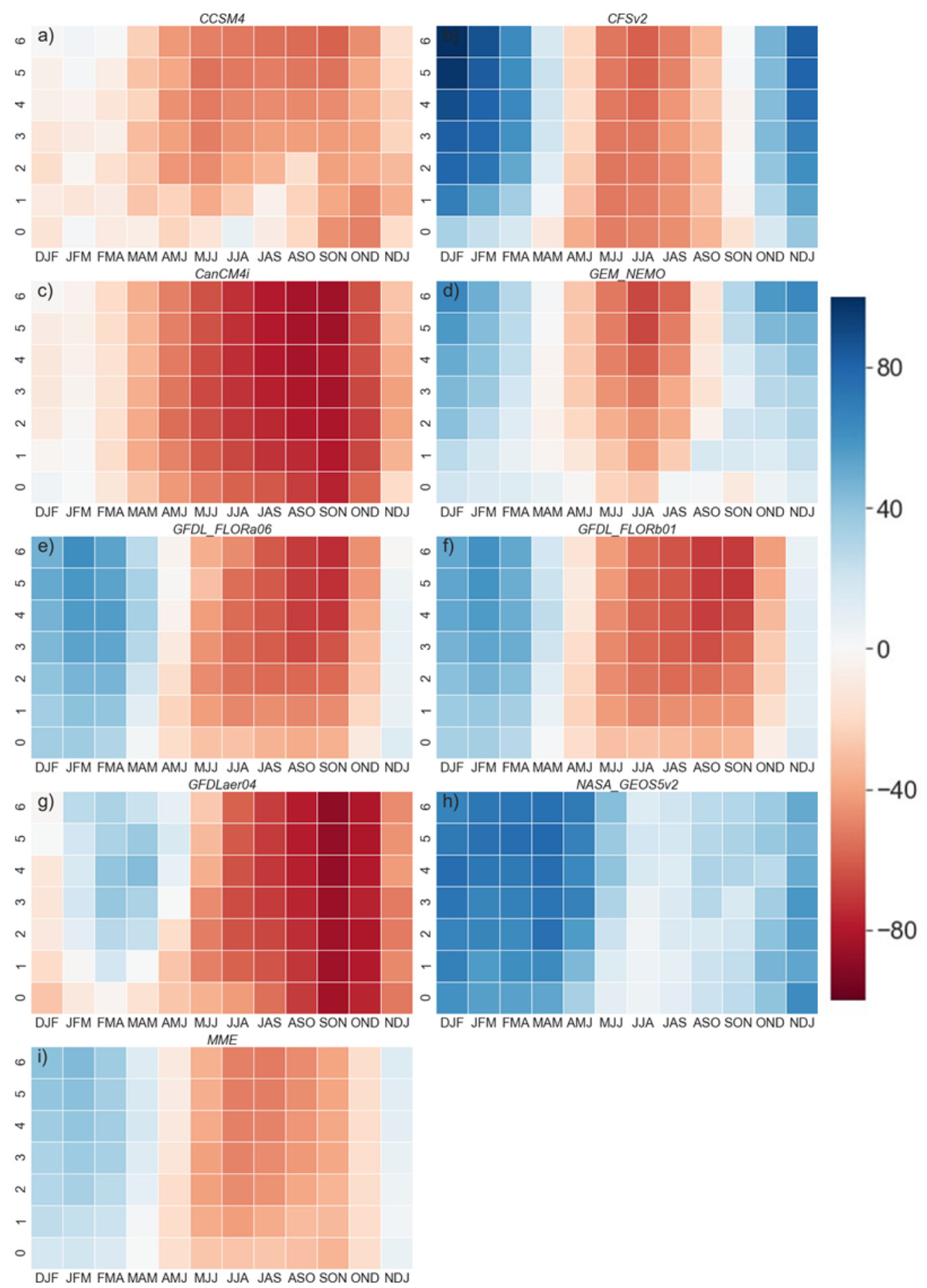

DJF JFM FMA MAM AMJ MJJ JJA JAS ASO SON OND NDJ

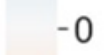

Figura 24 - Erro climatológico relativo (\%) do NMME para a chuva média trimestral na região NE. O eixo Y representa os tempos de previsão (de 0 a 6), e o eixo X os trimestres alvos.

Considerando os melhores modelos para o período de previsão (figura 25), há, em comparação com as demais regiões já apresentadas, maiores erros absolutos mesmo para os modelos que apresentaram os menores erros relativos. Isso torna-se mais evidente 
principalmente em tempos de previsão maiores. Para os tempos 0 e 1 de previsão, os modelos que apresentaram uma maior frequência de ocorrência de menores erros trimestrais relativos foram o CCSM4 e o GFDLaer04. Além disso, também se nota que a média dos modelos (MME) para as estações AMJ e OND dentro do tempo 0 de previsão se destaca com erros relativos menores para a chuva trimestral. Além disso, até tempo 2 os erros relativos para os melhores modelos são pequenos desde que inferiores à $\pm 15 \%$, exceto em dois casos (CCSM4 nos tempos 1 e 2).

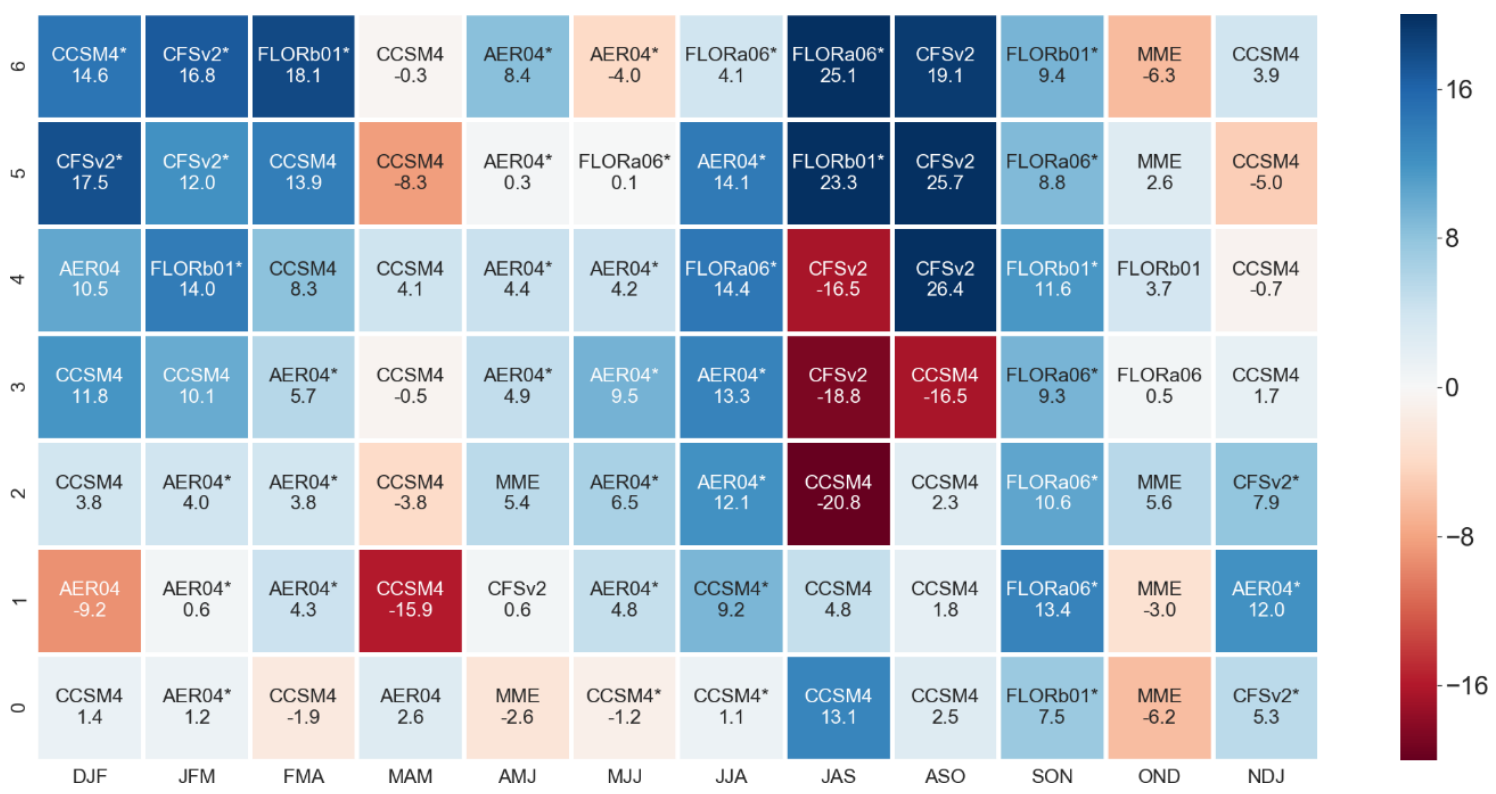

Figura 25 - Média dos erros relativos (\%) dos melhores modelos (menores erros em módulo) para as previsões entre as estações entre 2011 e 2018 para a região NE. O símbolo "*” indica que o modelo foi corrigido pelo viés climatológico (figura 24).

Para os piores modelos de previsão (figura 26), é possível identificar a presença do viés climatológico que resulta em superestimação da chuva nas estações próximas ao verão (DJF) e em subestimação à medida que se aproximam as estações de inverno (JJA). Esse comportamento se destaca nos modelos CFSv2 e o GFDLaer04. Além disso, o aumento do tempo de previsão também tende a aumentar os erros relativos para os piores modelos na região $\mathrm{NE}$. 


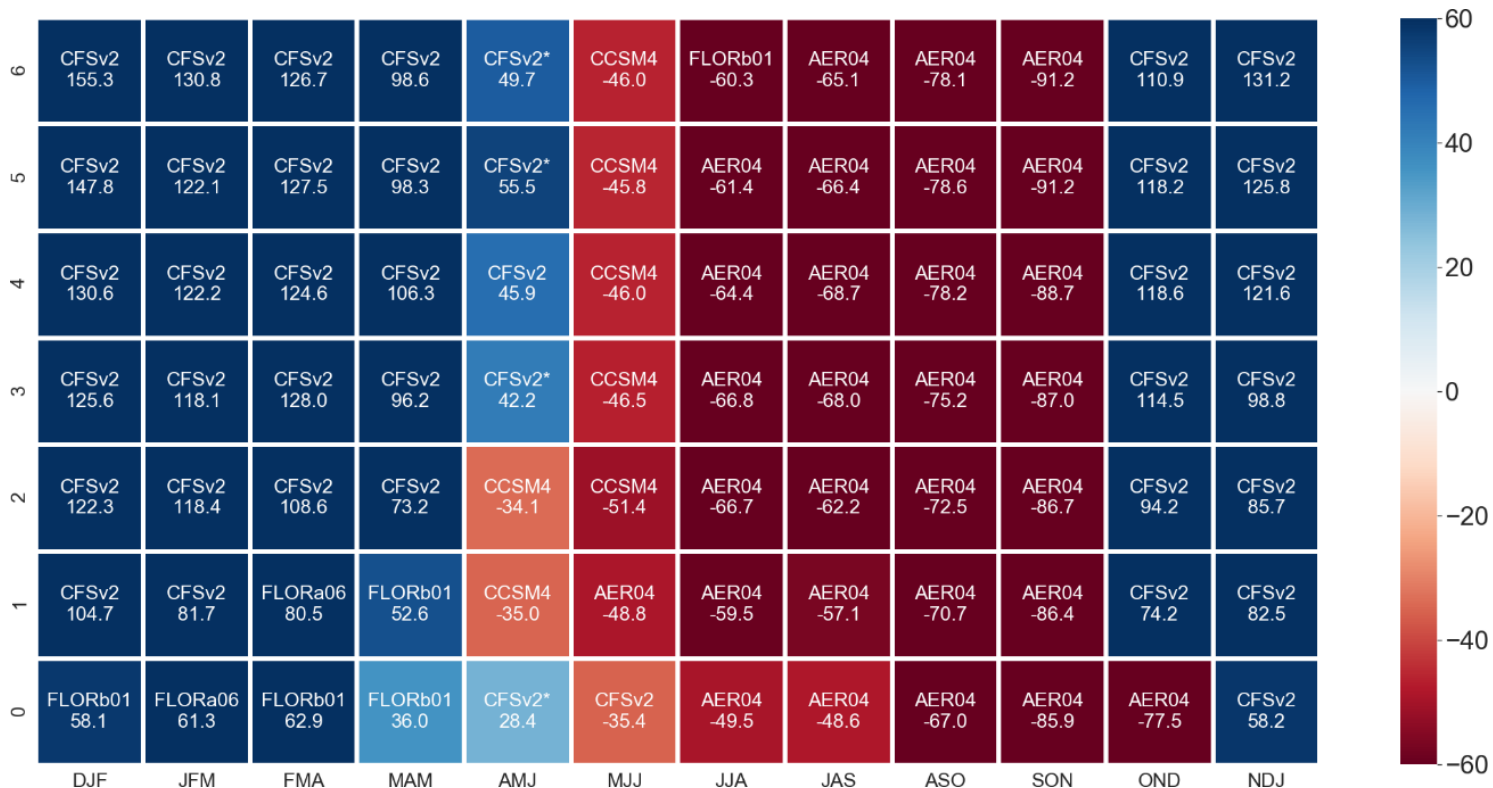

Figura 26 - Média dos erros relativos (\%) dos piores modelos (menores erros em módulo) para as previsões entre as estações entre 2011 e 2018 para a região NE. O símbolo “*” indica que o modelo foi corrigido pelo viés climatológico (figura 24).

De uma forma geral, para a região NE, as figuras 25 e 26 mostram que o processo de correção do viés climatológico é importante para reduzir os erros das previsões. Isso porque nos modelos com melhores desempenhos (figura 25) há uma maior frequência daqueles que foram corrigidos (com asterisco), enquanto entre os piores modelos (figura 26) predominam os que não foram corrigidos (sem asterisco) com o viés climatológico. 


\subsubsection{Região SE}

Em relação a região SE, os diagramas de Taylor e as respectivas séries temporais estão nas figuras 27 e 28 .
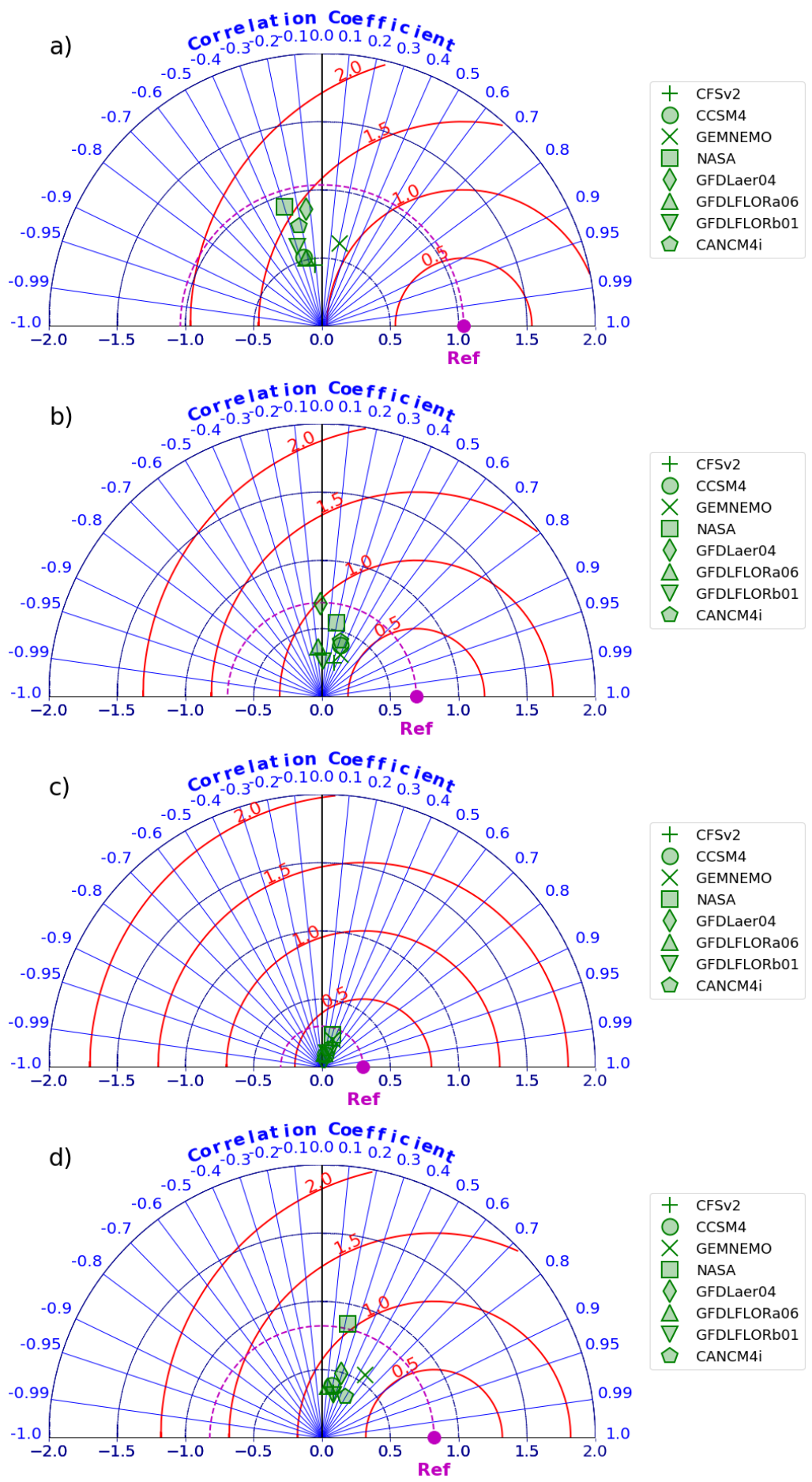

Figura 27 - Diagramas de Taylor da região SE para (a) DJF, (b) MAM, (c) JJA, (d) SON. Em azul é mostrada a correlação, vermelho o RSME (mm/dia) e em roxo o desvio padrão (mm/dia). 
64
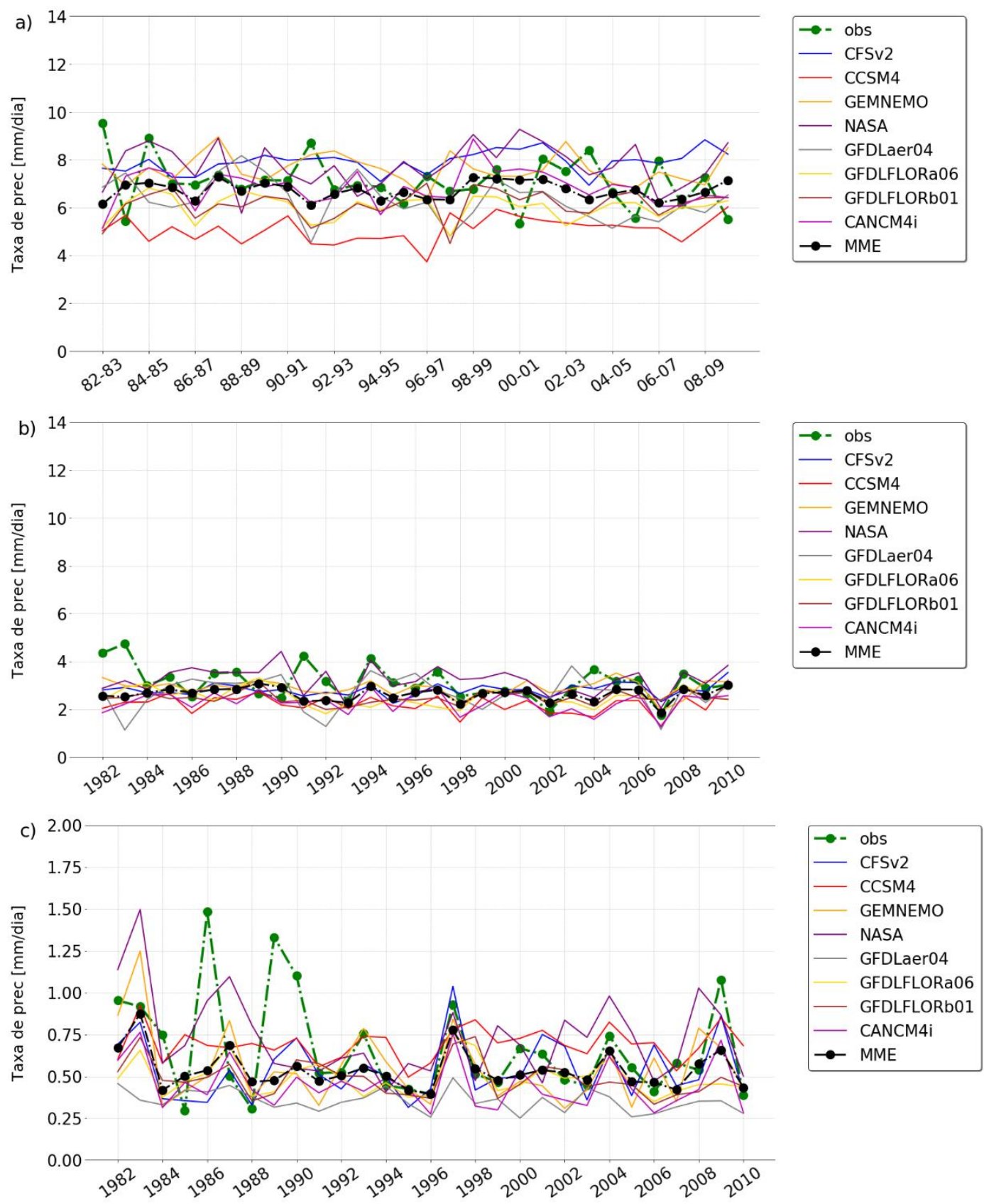

d) 14
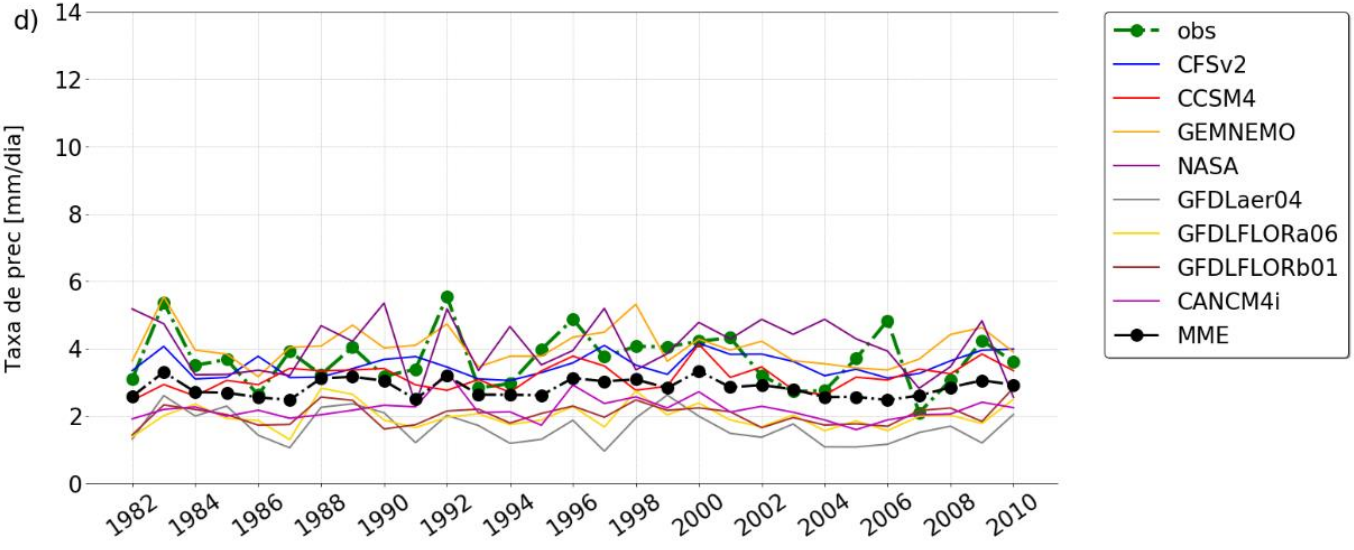

Figura 28 - Série temporal da chuva média sazonal ( $\mathrm{mm} /$ dia) utilizada nas estatísticas do diagrama de Taylor para a região SE: (a) DJF, (b) MAM, (c) JJA, (d) SON. 
A região SE apresenta durante o período de verão (DJF) correlação negativa entre as previsões e observações para todos os modelos, exceto o GEMNEMO. Nessa estação, destacase o modelo CCSM4 que subestima a chuva ao longo de toda a série temporal (figura 28a), enquanto o modelo CFSv2 destaca-se como o que mais superestima a chuva. Além disso, comparado às demais estações do ano, DJF apresenta um maior RMSD e STD, indicando um maior erro e dispersão das previsões. Na estação MAM, os valores de correlação voltam a ser positivos para a maioria dos modelos (exceto GFDLaer04 e GFDLFLORa06), sendo o GEMNEMO o que apresentou o maior correlação $(+0,40)$. Em relação à estação de inverno (JJA), tem-se uma maior correlação das previsões com o padrão de chuva observado. Em especial, destaca-se, por exemplo, a transição entre os anos 1996 e 1998 e entre 2002 e 2004 onde todos os modelos indicaram uma tendência de anomalia positiva de chuva em concordância com as observações.

Tabela 8 - Coeficiente de correlação (r), Desvio Padrão (STD) e RMSD para os hindcasts (1982-2010) modelos para estações do ano da região SE. Em negrito temos as correlações que possuem significância estatística para um valor de $\propto=0.05$.

\begin{tabular}{lcccccccccccc}
\hline \multirow{2}{*}{ Modelo } & \multicolumn{4}{c}{ Correlação (r) } & \multicolumn{4}{c}{ Desv. Pad (STD) } & \multicolumn{4}{c}{ RMSD } \\
\cline { 2 - 13 } & DJF & MAM & JJA & SON & DJF & MAM & JJA & SON & DJF & MAM & JJA & SON \\
\hline CFSv2 & $-0,11$ & 0,34 & $\mathbf{0 , 4 3}$ & 0,24 & 0,45 & 0,27 & 0,18 & 0,34 & 1,15 & 0,64 & 0,27 & 0,80 \\
CCSM4 & $-0,25$ & 0,34 & 0,24 & 0,18 & 0,52 & 0,40 & 0,10 & 0,39 & 1,25 & 0,66 & 0,29 & 0,83 \\
GEMNEMO & 0,21 & $\mathbf{0 , 4 0}$ & 0,35 & $\mathbf{0 , 5 7}$ & 0,62 & 0,34 & 0,22 & 0,56 & 1,07 & 0,63 & 0,30 & 0,67 \\
NASA & $-0,30$ & 0,20 & 0,31 & 0,22 & 0,91 & 0,56 & 0,25 & 0,85 & 1,54 & 0,78 & 0,32 & 1,03 \\
GFDLaer04 & $-0,13$ & $-0,02$ & 0,20 & 0,29 & 0,87 & 0,68 & 0,06 & 0,49 & 1,41 & 0,96 & 0,29 & 0,81 \\
GFDLFLORa06 & $-0,23$ & $-0,07$ & 0,21 & 0,11 & 0,52 & 0,37 & 0,10 & 0,38 & 1,24 & 0,79 & 0,29 & 0,85 \\
GFDLFLORb01 & $-0,29$ & 0,03 & 0,31 & 0,25 & 0,61 & 0,26 & 0,11 & 0,33 & 1,32 & 0,72 & 0,28 & 0,79 \\
CanCM4i & $-0,22$ & 0,32 & 0,35 & $\mathbf{0 , 4 8}$ & 0,76 & 0,43 & 0,14 & 0,35 & 1,39 & 0,67 & 0,28 & 0,71 \\
MME & $-0,17$ & 0,19 & 0,30 & 0,29 & 0,66 & 0,41 & 0,15 & 0,46 & 1,30 & 0,73 & 0,29 & 0,81 \\
OBS & $\mathbf{1 , 0 0}$ & $\mathbf{1 , 0 0}$ & $\mathbf{1 , 0 0}$ & $\mathbf{1 , 0 0}$ & 1,04 & 0,69 & 0,30 & 0,82 & 0,00 & 0,00 & 0,00 & 0,00 \\
\hline
\end{tabular}

Em média, a presença do viés climatológico para a região SE (figura 29) é maior principalmente entre as estações MAM e SON, e tende a ser negativo (subestimativa da chuva). Entre os modelos, o GFDLaer04 (figura 29g) apresenta maior erro, em módulo, neste intervalo de estações. 
Entre as estações de OND e FMA, nota-se que nos modelos CFSv2 (figura 29b), GEMNEMO (figura 29d) e NASA_GEOS5v2 (figura 29h) há uma tendência de superestimativa da chuva, como indicado pelo viés climatológico positivo nessas estações. No MME (figura 29i) nota-se uma predominância de viés positivo na maior parte do ano, mas apresenta viés climatológico muito menor que os modelos individuais principalmente entre MAM e SON.

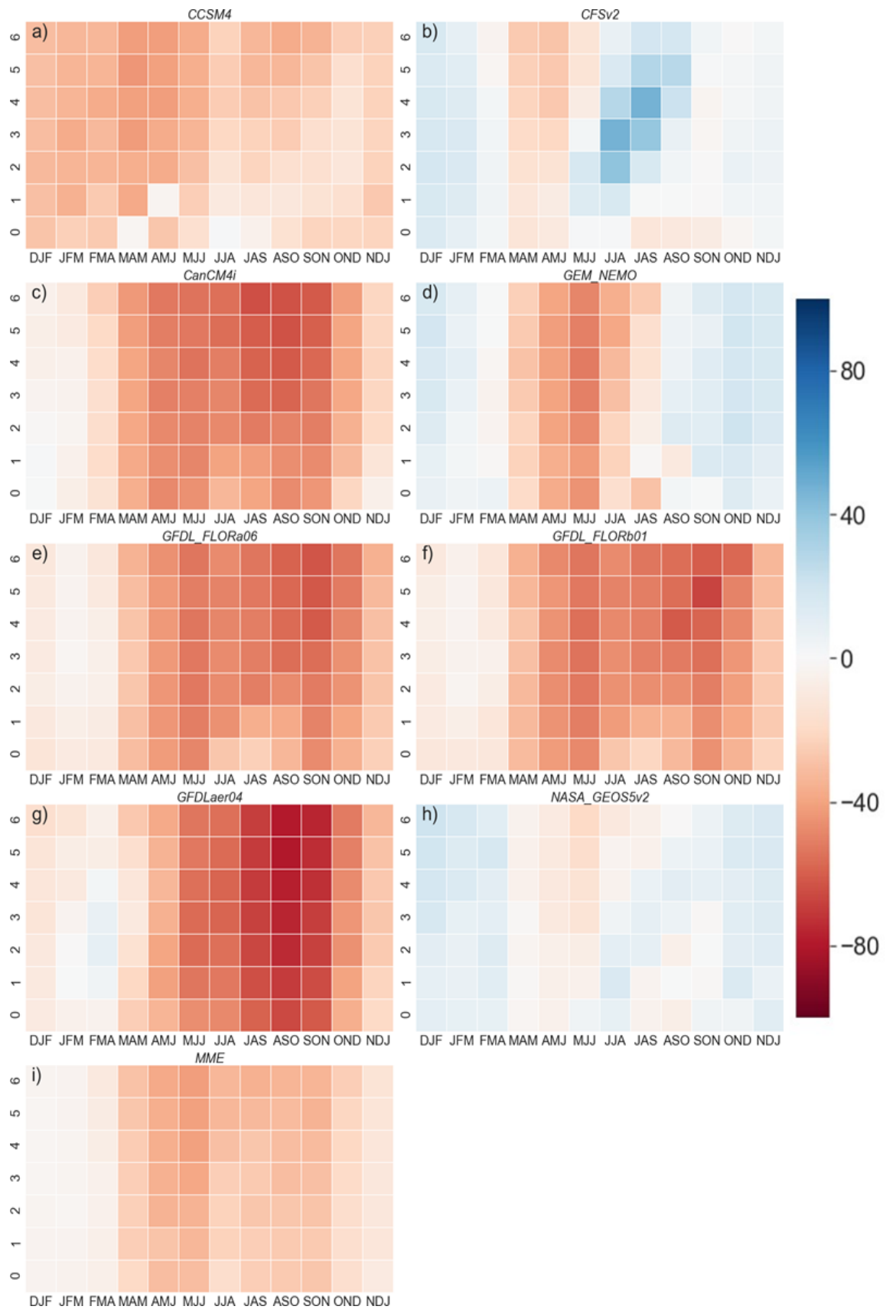

Figura 29 - Erro climatológico relativo (\%) do NMME para a chuva média trimestral na região SE. O eixo Y representa os tempos de previsão (de 0 a 6), e o eixo X os trimestres alvos. 
Considerando os modelos com menores viéses trimestrais (figura 30), nota-se uma maior frequência dos modelos CCSM4, GFDLaer04* e MME ao longo das estações do ano. Vale destacar que na estação SON, o MME aparece com o menor erro relativo em todos os tempos de previsão exceto o tempo 6. Os maiores erros dos melhores modelos ocorrem em maiores tempos de previsão e nas estações JFM, FMA, JAS e SON. Até o tempo 3 de previsão os erros relativos são pequenos desde que em módulo são inferiores +- 15\%.

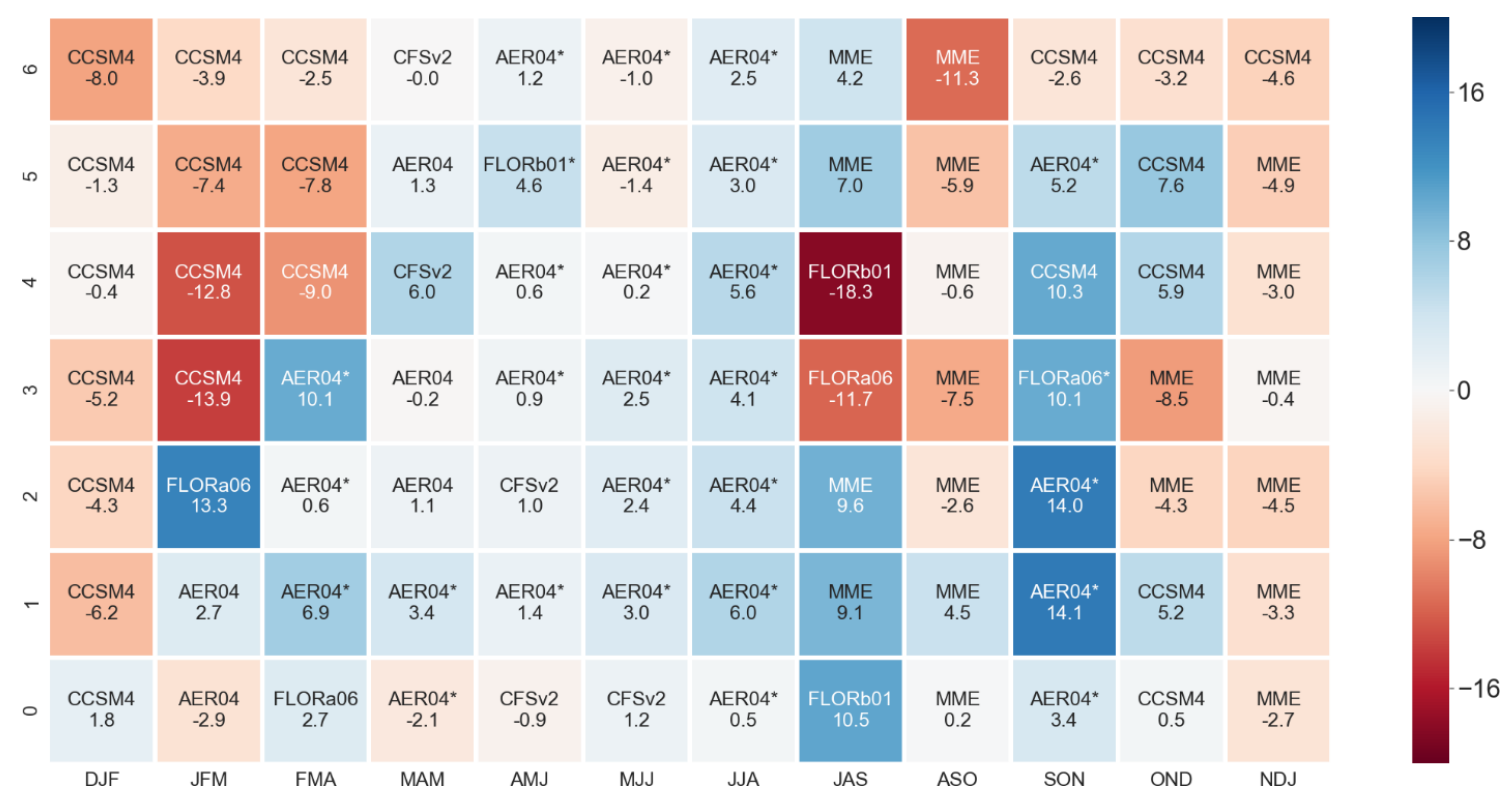

Figura 30 - Média dos erros relativos (\%) dos melhores modelos (menores erros em módulo) para as previsões entre as estações entre 2011 e 2018 para a região SE. O símbolo “*” indica que o modelo foi corrigido pelo viés climatológico (figura 29).

Em relação aos piores modelos (figura 31) nota-se uma maior frequência do modelo CFSv2 para o período próximo ao verão (entre OND e FMA) e entre as estações de JAS e ASO. Nas estações AMJ, MJJ e SON também os modelos GFDLaer04 e GFDLFLORb01 apresentam erros médios sazonais muito grandes. A presença desses maiores valores de erro relativo evidencia os viéses climatológicos desses modelos nessas estações. 


\begin{tabular}{|c|c|c|c|c|c|c|c|c|c|c|c|}
\hline $\begin{array}{c}\text { CFSv2 } \\
62.5\end{array}$ & $\begin{array}{c}\text { CFSv2 } \\
49.3\end{array}$ & $\begin{array}{c}\text { CFSv2 } \\
47.4\end{array}$ & $\begin{array}{c}\text { CFSv2* } \\
25.5\end{array}$ & $\begin{array}{c}\text { FLORb01 } \\
-42.9\end{array}$ & $\begin{array}{c}\text { AER04 } \\
-60.9\end{array}$ & $\begin{array}{c}\text { AER0 } 4 \\
-58.2\end{array}$ & $\begin{array}{c}\text { CFSv2 } \\
104.1\end{array}$ & $\begin{array}{c}\text { CFSv2 } \\
82.0\end{array}$ & $\begin{array}{c}\text { AER0 } 4 \\
-70.0\end{array}$ & $\begin{array}{c}\text { FLORa06 } \\
-45.6\end{array}$ & $\begin{array}{c}\mathrm{CCSM}^{*} \\
27.7\end{array}$ \\
\hline $\begin{array}{c}\text { CFSv2 } \\
56.1\end{array}$ & $\begin{array}{c}\text { CFSv2 } \\
52.6\end{array}$ & $\begin{array}{c}\text { CFSv2 } \\
43.3\end{array}$ & $\begin{array}{c}\text { CFSv2* } \\
27.2\end{array}$ & $\begin{array}{c}\text { FLORb01 } \\
-39.5\end{array}$ & $\begin{array}{c}\text { AER04 } \\
-60.9\end{array}$ & $\begin{array}{c}\text { AER0 } 4 \\
-59.6\end{array}$ & $\begin{array}{c}\text { CFSv2 } \\
123.8\end{array}$ & $\begin{array}{c}\text { CFSv2 } \\
96.0\end{array}$ & $\begin{array}{c}\text { AER0 } 4 \\
-70.0\end{array}$ & $\begin{array}{c}\text { FLORa06 } \\
-41.4\end{array}$ & $\begin{array}{c}\text { CFSv2 } \\
35.3\end{array}$ \\
\hline $\begin{array}{c}\text { CFSv2 } \\
61.3\end{array}$ & $\begin{array}{c}\text { CFSv2 } \\
48.9\end{array}$ & $\begin{array}{c}\text { CFSv2 } \\
49.6\end{array}$ & $\begin{array}{c}\mathrm{CFSv2}^{*} \\
24.4\end{array}$ & $\begin{array}{c}\text { FLORb01 } \\
-41.0\end{array}$ & $\begin{array}{c}\text { AER04 } \\
-61.7\end{array}$ & $\begin{array}{c}\text { CFSv2 } \\
60.8\end{array}$ & $\begin{array}{c}\text { CFSv2 } \\
169.7\end{array}$ & $\begin{array}{c}\text { CFSv2 } \\
109.7\end{array}$ & $\begin{array}{c}\text { AER0 } \\
-63.3\end{array}$ & $\begin{array}{c}\text { FLORa06 } \\
-38.0\end{array}$ & $\begin{array}{c}\text { CFSv2 } \\
32.6\end{array}$ \\
\hline $\begin{array}{c}\text { CFSv2 } \\
56.6\end{array}$ & $\begin{array}{c}\text { CFSv2 } \\
54.1\end{array}$ & $\begin{array}{c}\text { CFSv2 } \\
48.8\end{array}$ & $\begin{array}{c}\mathrm{CCSM}_{2}^{*} \\
24.4\end{array}$ & $\begin{array}{c}\text { CCSM4 } \\
-35.0\end{array}$ & $\begin{array}{c}\text { AER04 } \\
-61.5\end{array}$ & $\begin{array}{c}\text { CFSv2 } \\
100.0\end{array}$ & $\begin{array}{c}\text { CFSv2 } \\
163.9\end{array}$ & $\begin{array}{c}\text { CFSv2 } \\
77.0\end{array}$ & $\begin{array}{c}\text { AER04 } \\
-56.0\end{array}$ & $\begin{array}{c}\text { CFSv2 } \\
34.6\end{array}$ & $\begin{array}{c}\text { CFSv2 } \\
37.2\end{array}$ \\
\hline $\begin{array}{c}\text { CFSv2 } \\
58.6\end{array}$ & $\begin{array}{c}\text { CFSv2 } \\
53.3\end{array}$ & $\begin{array}{c}\text { CFSv2 } \\
48.9\end{array}$ & $\begin{array}{c}\text { CCSM4 } 4 \\
-25.3\end{array}$ & $\begin{array}{c}\text { FLORb01 } \\
-37.9\end{array}$ & $\begin{array}{c}\text { AER04 } \\
-61.6\end{array}$ & $\begin{array}{c}\text { CFSv2 } \\
75.0\end{array}$ & $\begin{array}{c}\text { CFSv2 } \\
103.0\end{array}$ & $\begin{array}{c}\text { CFSv2 } \\
71.6\end{array}$ & $\begin{array}{c}\text { AER0 } 4 \\
-54.5\end{array}$ & $\begin{array}{c}\text { CFSv2 } \\
41.4\end{array}$ & $\begin{array}{c}\text { CFSv2 } \\
30.9\end{array}$ \\
\hline $\begin{array}{c}\text { CFSv2 } \\
56.6\end{array}$ & $\begin{array}{c}\text { CFSv2 } \\
49.5\end{array}$ & $\begin{array}{c}\text { CFSv2 } \\
38.6\end{array}$ & $\begin{array}{c}\text { CCSM4 } \\
-24.9\end{array}$ & $\begin{array}{c}\text { CCSM }^{*}{ }^{*} \\
\end{array}$ & $\begin{array}{c}\text { AER04 } \\
-58.0\end{array}$ & $\begin{array}{c}\text { AER04 } \\
-52.6\end{array}$ & ${ }_{86.0}^{\mathrm{CCSM}_{4}^{*}}$ & $\begin{array}{c}\text { CFSv2 } \\
81.4\end{array}$ & $\begin{array}{c}\text { AER04 } \\
-52.8\end{array}$ & $\begin{array}{c}\text { CFSv2 } \\
31.3\end{array}$ & $\begin{array}{c}\text { CFSv2 } \\
29.6\end{array}$ \\
\hline $\begin{array}{c}\text { CFSv2 } \\
55.3\end{array}$ & $\begin{array}{c}\text { CFSv2 } \\
33.2\end{array}$ & $\begin{array}{c}\text { CFSv2 } \\
34.7\end{array}$ & $\begin{array}{c}\text { CFSv2* } \\
20.1\end{array}$ & $\begin{array}{c}\text { FLORb01 } \\
-40.3\end{array}$ & $\begin{array}{c}\text { FLORb01 } \\
-49.8\end{array}$ & $\begin{array}{c}\text { AER04 } \\
-52.3\end{array}$ & $\begin{array}{c}\mathrm{CFSv2}^{*} \\
86.2\end{array}$ & $\begin{array}{c}\text { CFSv2 } \\
68.0\end{array}$ & $\begin{array}{c}\text { AER04 } \\
-58.3\end{array}$ & $\begin{array}{c}\text { AER04 } \\
-28.2\end{array}$ & $\begin{array}{c}\text { CFSv2 } \\
31.2\end{array}$ \\
\hline
\end{tabular}

Figura 31 - Média dos erros relativos (\%) dos piores modelos (menores erros em módulo) para as previsões entre as estações entre 2011 e 2018 para a região NE. O símbolo “*” indica que o modelo foi corrigido pelo viés climatológico (figura 29). 


\subsubsection{Região SUL}

Em relação a região SUL, as figuras 32 e 33 mostram os diagramas de Taylor e as respectivas séries temporais sazonais.
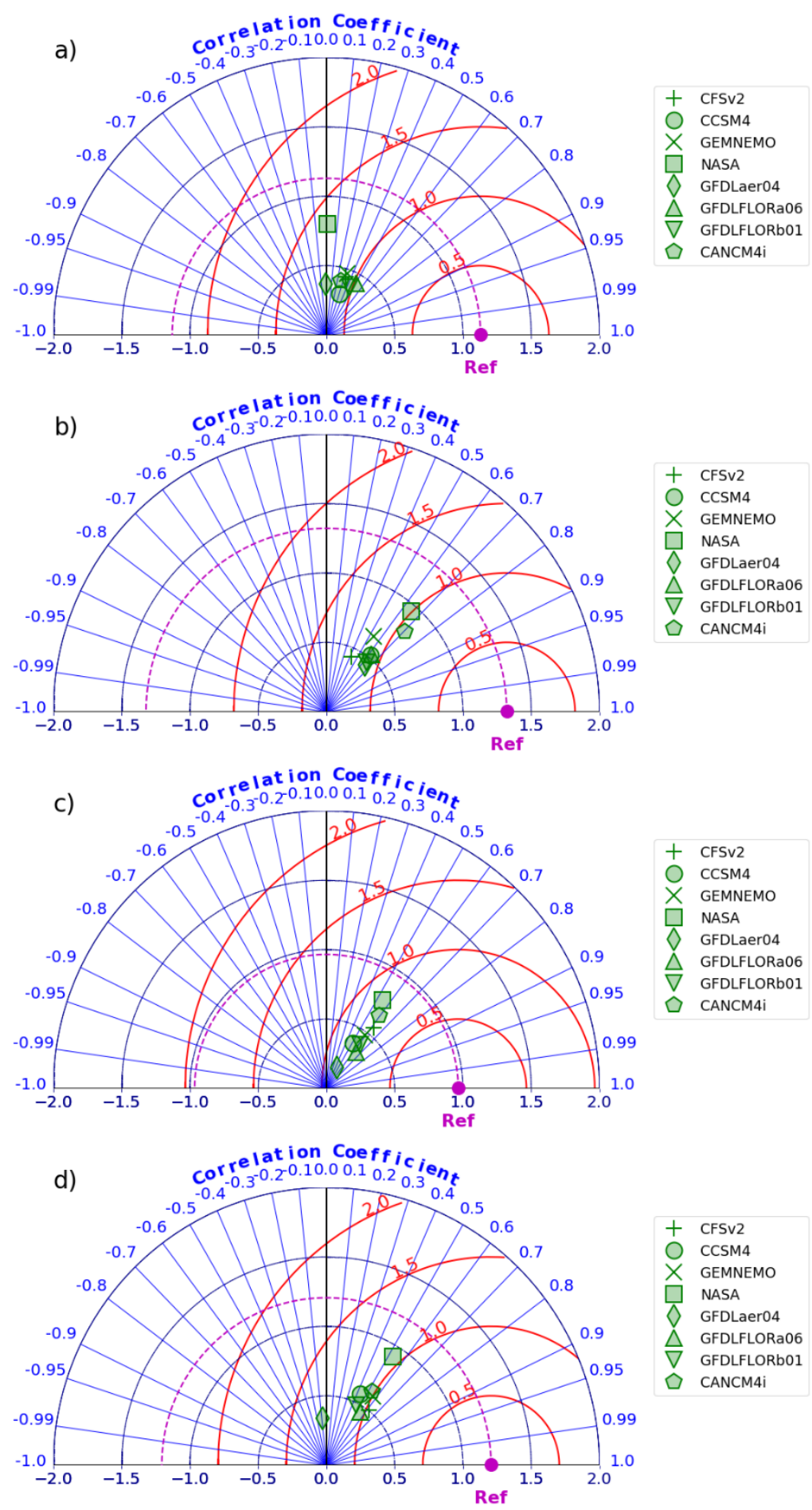

Figura 32 - Diagramas de Taylor da região SE para (a) DJF, (b) MAM, (c) JJA, (d) SON. Em azul é mostrada a correlação, vermelho o RSME (mm/ dia) e em roxo o desvio padrão (mm/dia). 

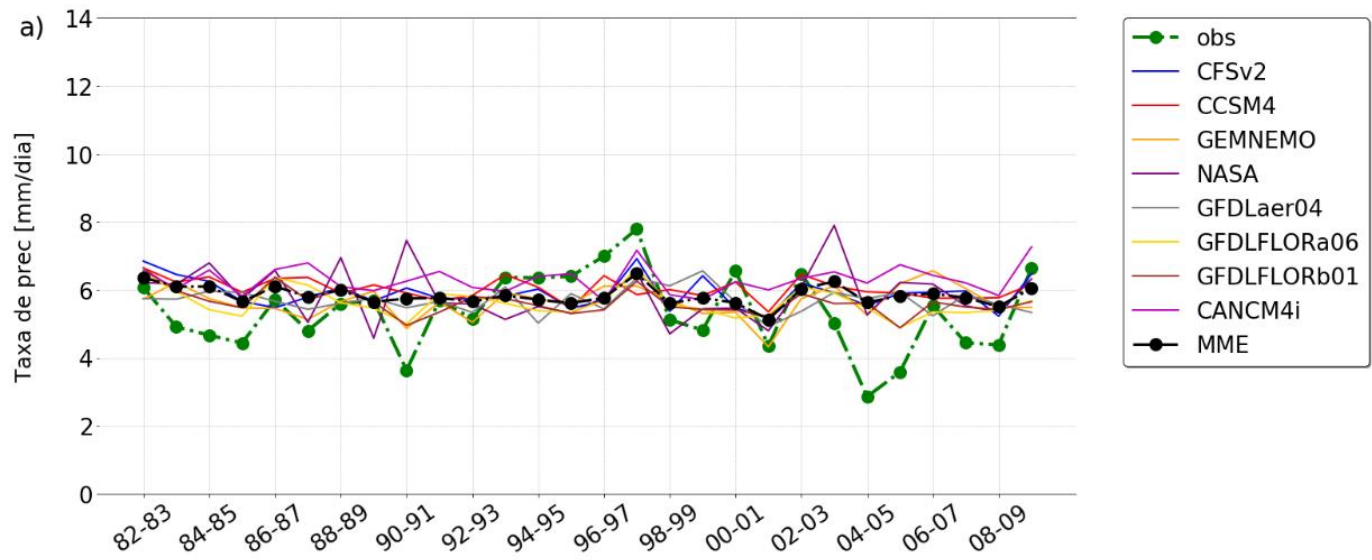

$$
\text { b) }
$$

b) 14
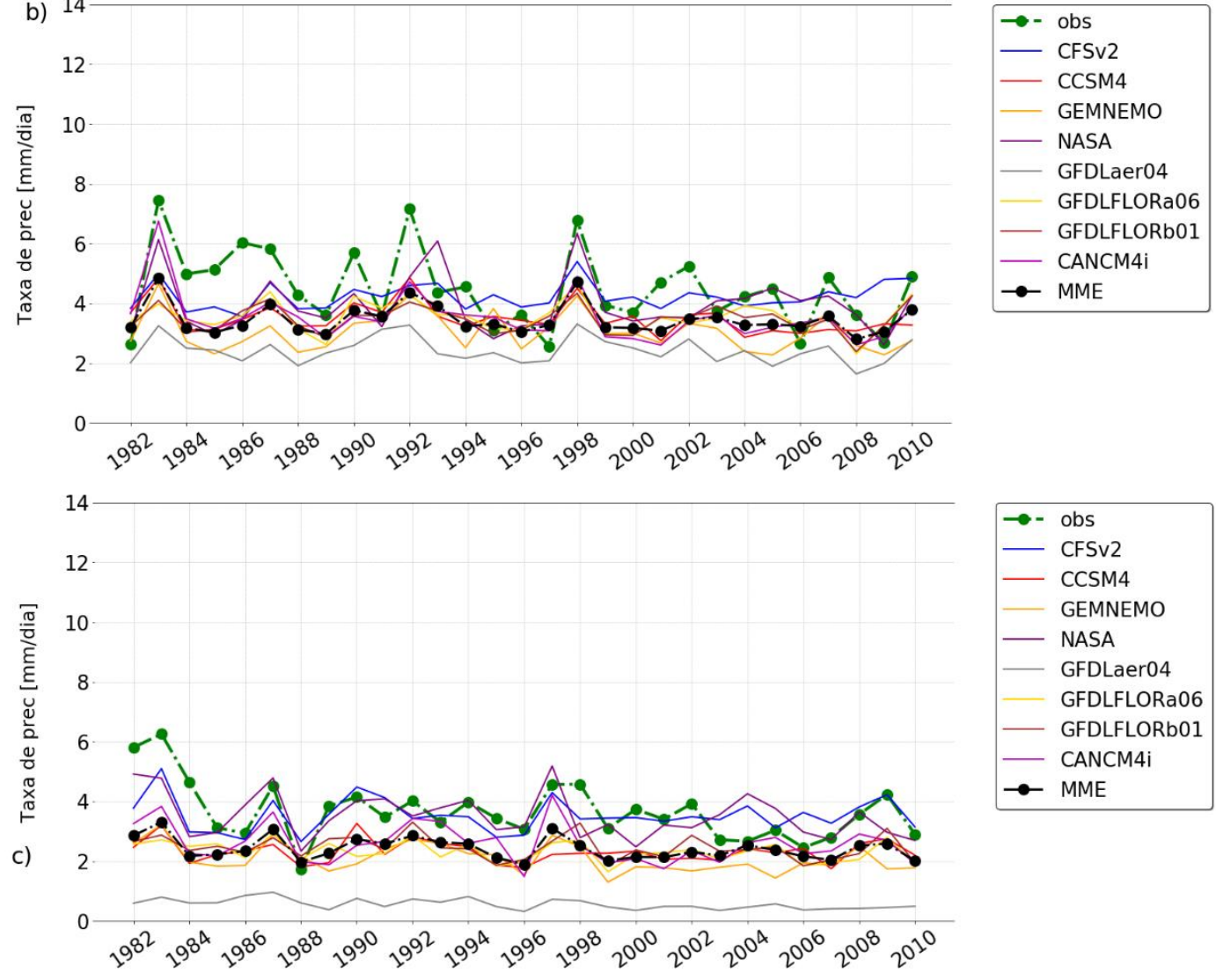

or 1
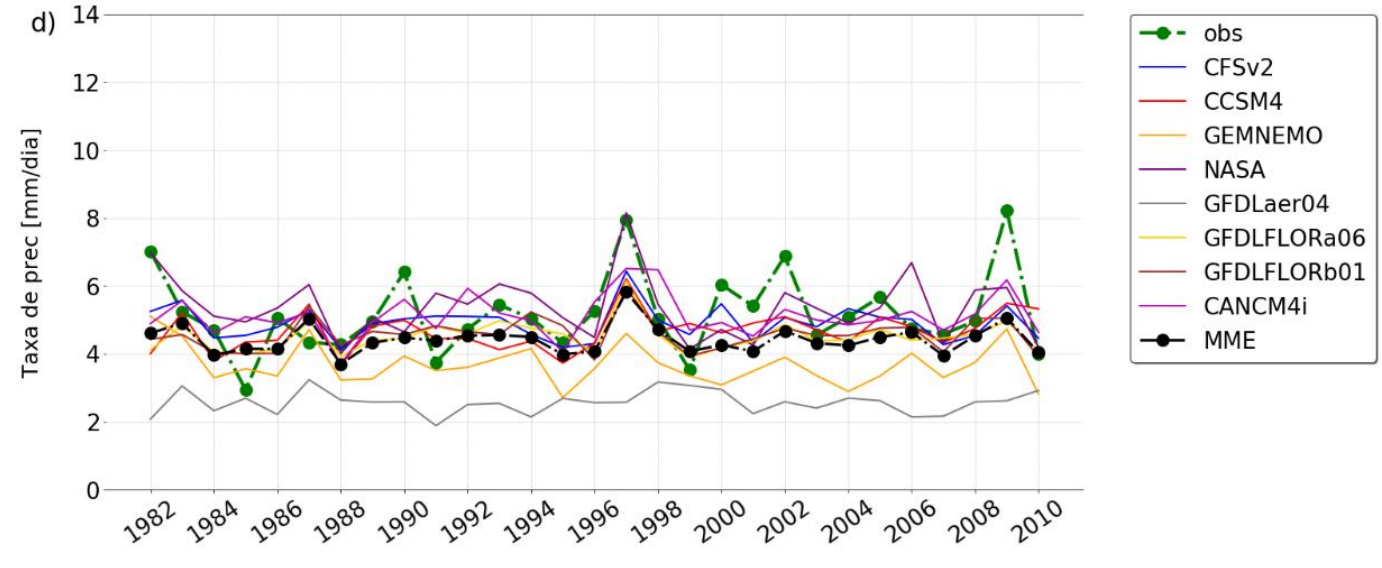

Figura 33 - Série temporal da chuva média sazonal (mm/dia) utilizada nas estatísticas do diagrama de Taylor para a região SE: (a) DJF, (b) MAM, (c) JJA, (d) SON. 
Ao longo do período de verão (figuras 32a e 33a), nota-se maior correlação positiva para os modelos GFDLFLORa06 e GFDLFLORb01 (+0,50 e +0,44 respectivamente), e menor correlação para os modelos GFDLaer04 (-0.01) e NASAGEOS5v2 (+0,01). Além dessa baixa correlação, também há um maior RMSD associado a esses modelos e com valores de 1,17 e 1,36 $\mathrm{mm} /$ dia respectivamente, o que indica que para esse período do ano, esses modelos não possuem uma boa habilidade de previsão de chuva na região.

Para a estação de MAM (figuras 32b e 33b), nota-se que todas as correlações entre as taxas de precipitação previstas e observadas são positivas (figura 32b), sendo o modelo CanCM4i o que apresenta maior correlação positiva $(+0,70)$ e o modelo CFSv2 a menor correlação $(+0,43)$. Em relação ao RMSD, também há uma similaridade com as correlações, sendo o menor valor para o modelo CanCM4i (0,93 mm/dia) e o maior para o modelo CFSv2 (1,18 mm/dia). Nessa estação, também há uma grande subestimativa da taxa de precipitação pelo modelo GFDLaer04 (figura 33b).

Na estação de inverno (figuras 32c e 33c), o modelo GFDLaer04 continua subestimando a taxa de precipitação, evidenciando a presença de forte viés climatológico nessa estação, embora ainda apresente uma habilidade moderada na previsão da fase desde que a correlação é positiva de 0,45 (figura 32c e tabela 9). Além disso, esse modelo também apresenta um maior RMSD (0,89 mm/dia) em comparação aos demais modelos. Dentro os modelos com maiores correlações e menores RMSDs, destacam-se o CFSv2, GFDLFLORa06 e GFDLFLORb01.

Na estação SON (figuras 32d e 33d), o modelo GFDLaer04 permanece subestimando bastante a taxa de precipitação, e apresenta a menor correlação $(-0,08)$ e maior RMSD $(1,26$ $\mathrm{mm}$ / dia) em comparação aos outros modelos. Isso indica que esse modelo também não possui habilidade de previsão dentro dessa estação sem a aplicação da correção do viés climatológico.

Em relação às maiores correlações e menores RMSDs, exceto o GFDLaer04, os demais modelos apresentam resultados similares com correlação entre 0,45 e 0,62, enquanto o MME exibe correlação de e 0,45. Individualmente, os modelos CFSv2 e GEMNEMO mostram estatísticas que os destacam como melhores previsores na estação de SON na região SUL. Em geral, em nenhuma das estações o MME se destaca como melhor previsor, principalmente em termos de correlação e RMSD, comparado à alguns membros individuais (tabela 9). 
Tabela 9 - Coeficiente de correlação (r), Desvio Padrão (STD) e RMSD para os hindcasts (1982-2010) modelos para estações do ano da região SUL. Em negrito temos as correlações que possuem significância estatística para um valor de $\alpha=0.05$.

\begin{tabular}{lccccccccccccc}
\hline \multirow{2}{*}{ Modelo } & \multicolumn{4}{c}{ Correlação (r) } & \multicolumn{4}{c}{ Desv. Pad (STD) } & \multicolumn{4}{c}{ RMSD } \\
\cline { 2 - 13 } & DJF & MAM & JJA & SON & DJF & MAM & JJA & SON & DJF & MAM & JJA & SON \\
\hline CFSv2 & 0,32 & $\mathbf{0 , 4 3}$ & $\mathbf{0 , 6 2}$ & $\mathbf{0 , 6 2}$ & 0,44 & 0,44 & 0,56 & 0,50 & 1,05 & 1,18 & 0,74 & 0,96 \\
CCSM4 & 0,31 & $\mathbf{0 , 6 2}$ & $\mathbf{0 , 5 1}$ & $\mathbf{0 , 4 3}$ & 0,31 & 0,52 & 0,38 & 0,57 & 1,06 & 1,06 & 0,83 & 1,07 \\
GEMNEMO & 0,33 & $\mathbf{0 , 5 4}$ & $\mathbf{0 , 5 9}$ & $\mathbf{0 , 5 7}$ & 0,47 & 0,64 & 0,48 & 0,60 & 1,05 & 1,10 & 0,77 & 0,98 \\
NASA & 0,01 & $\mathbf{0 , 6 5}$ & $\mathbf{0 , 5 4}$ & $\mathbf{0 , 5 3}$ & 0,80 & 0,95 & 0,76 & 0,92 & 1,36 & 0,99 & 0,83 & 1,05 \\
GFDLaer04 & $-0,01$ & $\mathbf{0 , 6 4}$ & $\mathbf{0 , 4 5}$ & $-0,08$ & 0,37 & 0,44 & 0,17 & 0,34 & 1,17 & 1,08 & 0,89 & 1,26 \\
GFDLFLORa06 & $\mathbf{0 , 5 0}$ & $\mathbf{0 , 6 2}$ & $\mathbf{0 , 6 4}$ & $\mathbf{0 , 5 4}$ & 0,43 & 0,53 & 0,34 & 0,46 & 0,97 & 1,06 & 0,78 & 1,02 \\
GFDLFLORb01 & $\mathbf{0 , 4 4}$ & $\mathbf{0 , 6 4}$ & $\mathbf{0 , 6 2}$ & $\mathbf{0 , 4 5}$ & 0,38 & 0,46 & 0,40 & 0,48 & 1,00 & 1,07 & 0,77 & 1,06 \\
CanCM4i & 0,27 & $\mathbf{0 , 7 0}$ & $\mathbf{0 , 5 9}$ & $\mathbf{0 , 5 3}$ & 0,41 & 0,81 & 0,65 & 0,63 & 1,07 & 0,93 & 0,77 & 1,00 \\
MME & 0,27 & $\mathbf{0 , 6 0}$ & $\mathbf{0 , 5 7}$ & $\mathbf{0 , 4 5}$ & 0,45 & 0,60 & 0,47 & 0,56 & 1,09 & 1,06 & 0,80 & 1,05 \\
OBS & $\mathbf{1 , 0 0}$ & $\mathbf{1 , 0 0}$ & $\mathbf{1 , 0 0}$ & $\mathbf{1 , 0 0}$ & 1,13 & 1,32 & 0,97 & 1,21 & 0,00 & 0,00 & 0,00 & 0,00 \\
\hline
\end{tabular}

Pela figura 34, há para a maioria dos modelos tendência de subestimativa de chuva entre as estações FMA e SON e tendência de superestimativa entre as estações de OND e JFM. Como esperado da análise das figuras 32 e 33, entre FMA e SON, destaca-se o modelo GFDLaer04 (figura 33g) onde há maiores valores, em módulo, do erro relativo de chuva. Além disso, nas estações OND e JFM, nota-se que as maiores superestimativas da taxa de precipitação são encontradas nas previsões principalmente do modelo CCSM4 (figura 34a). 


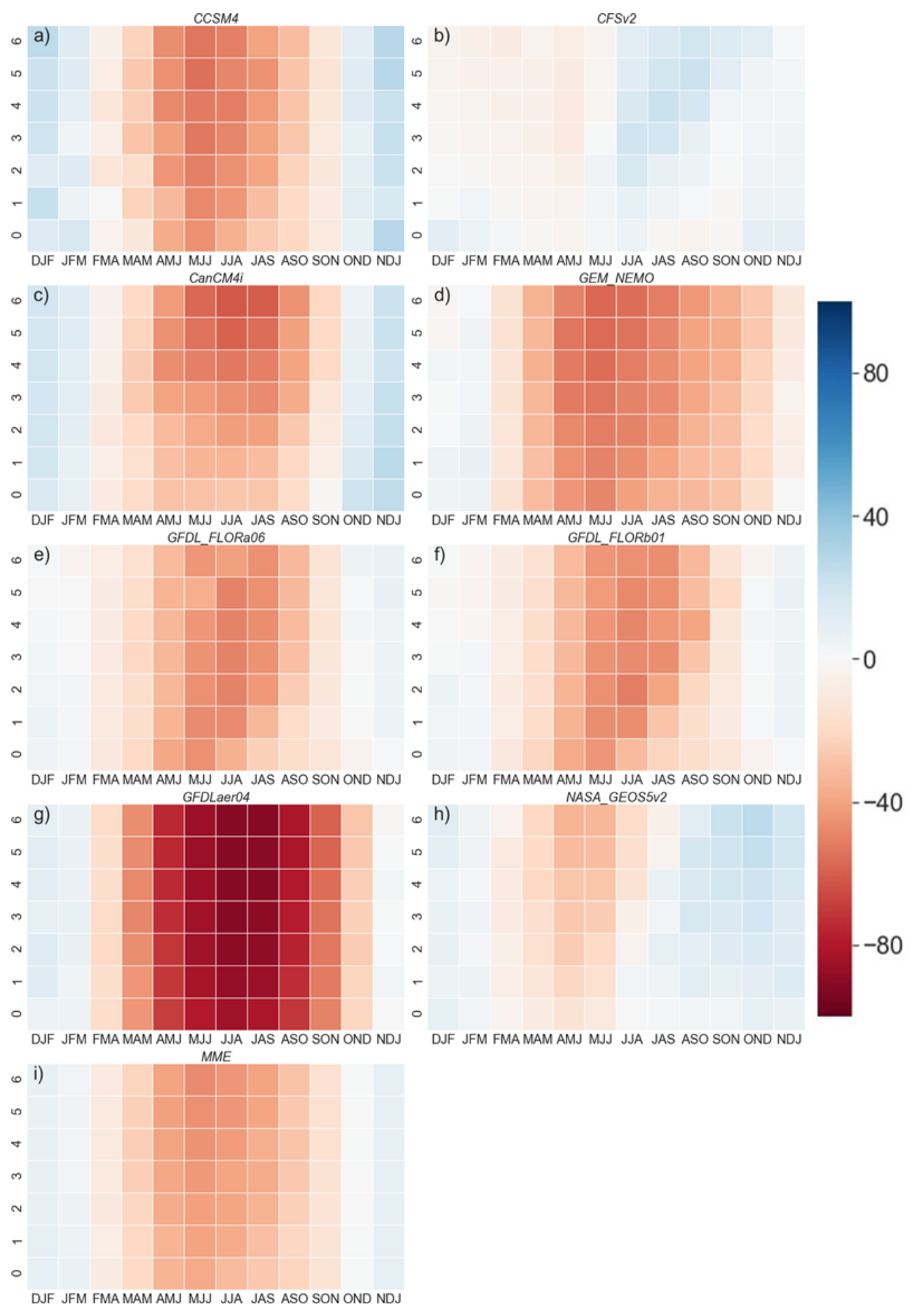

Figura 34 - Erro climatológico relativo (\%) do NMME para a chuva média trimestral na região SUL. O eixo Y representa os tempos de previsão (de 0 a 6), e o eixo $X$ os trimestres alvos.

A figura 35 mostra a relação dos modelos que atingem, na média do período de 2011 a 2018, os menores erros relativos à previsão da chuva trimestral em função dos tempos de previsão. Nota-se que nesse caso os melhores modelos tendem a superestimar a taxa de 
precipitação, sendo que as maiores superestimativa ocorrem principalmente entre AMJ e JAS (próximo ao período de inverno).

Considerando os tempos 0 e 1 de previsão, os modelos com maior frequência de ocorrência como melhores previsores são os da família do GFDL. Isso também é indicado pelos coeficientes de correlação mais elevados (principalmente para o GDFLFLORa06 e GFDLFLORb01, tabela 9) entre as estações DJF, MAM, JJA e SON, o que mostra maior habilidade de previsão desses modelos para essa região. A figura 34 também indica que até o tempo 6 os erros relativos na previsão da chuva trimestral são baixos e não ultrapassam $\pm 15 \%$.

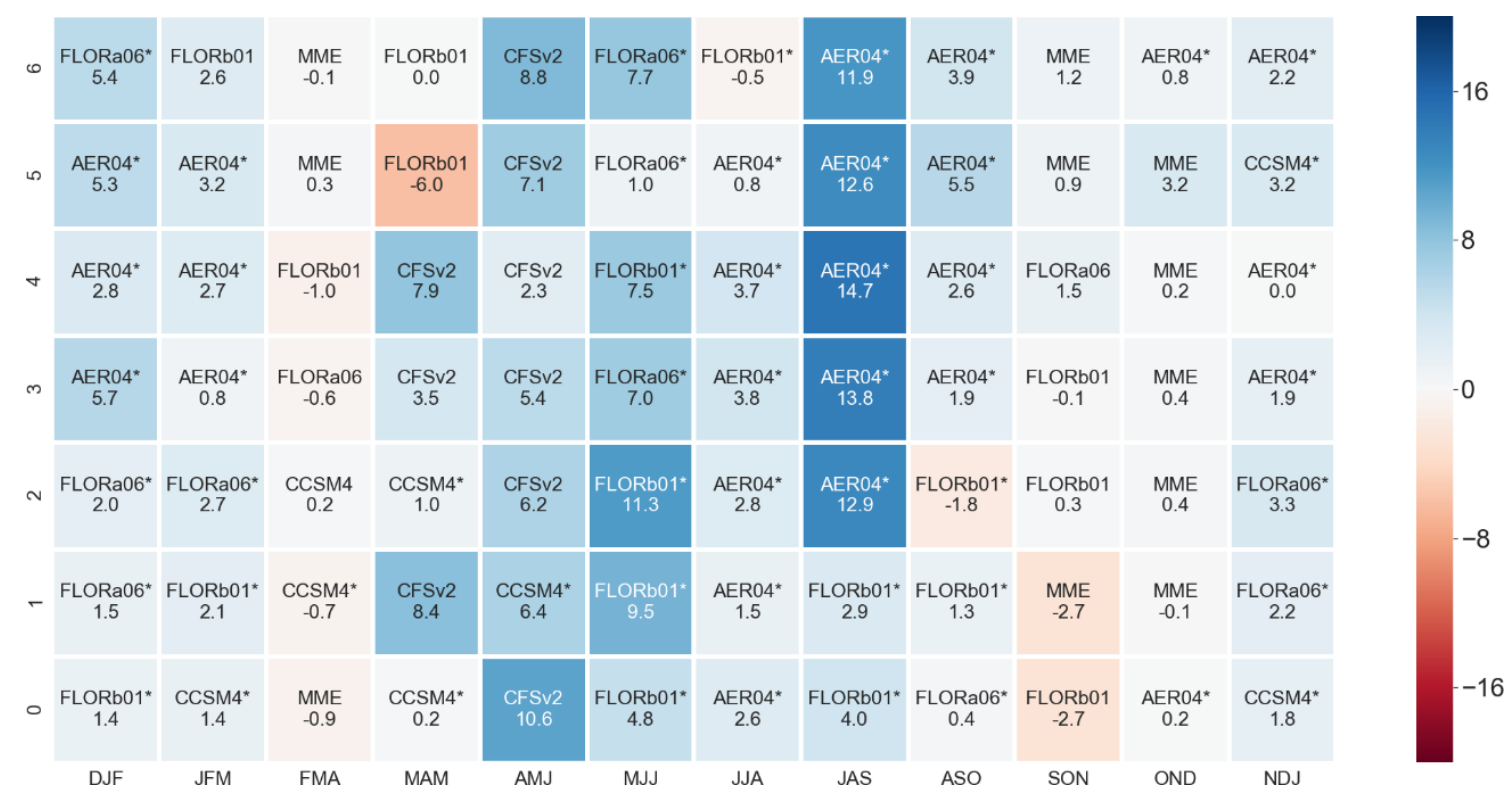

Figura 35 - Média dos erros relativos (\%) dos melhores modelos (menores erros em módulo) para as previsões entre as estações entre 2011 e 2018 para a região SUL. O símbolo “*” indica que o modelo foi corrigido pelo viés climatológico (figura 34).

Em relação aos piores modelos (figura 36), destaca-se a forte presença do viés climatológico do modelo GFDLaer04 que predomina em todos os tempos de previsão entre as estações de MAM e OND. Para as estações entre NDJ e FMA, o modelo com pior desempenho médio é o CCSM4 que também apresenta maiores valores para o viés climatológico (figura 34a). Entre JFM e FMA, o modelo CFSv2 e CFSv2* também aparecem com fraco desempenho entre os tempos 0 e 1 de previsão. 


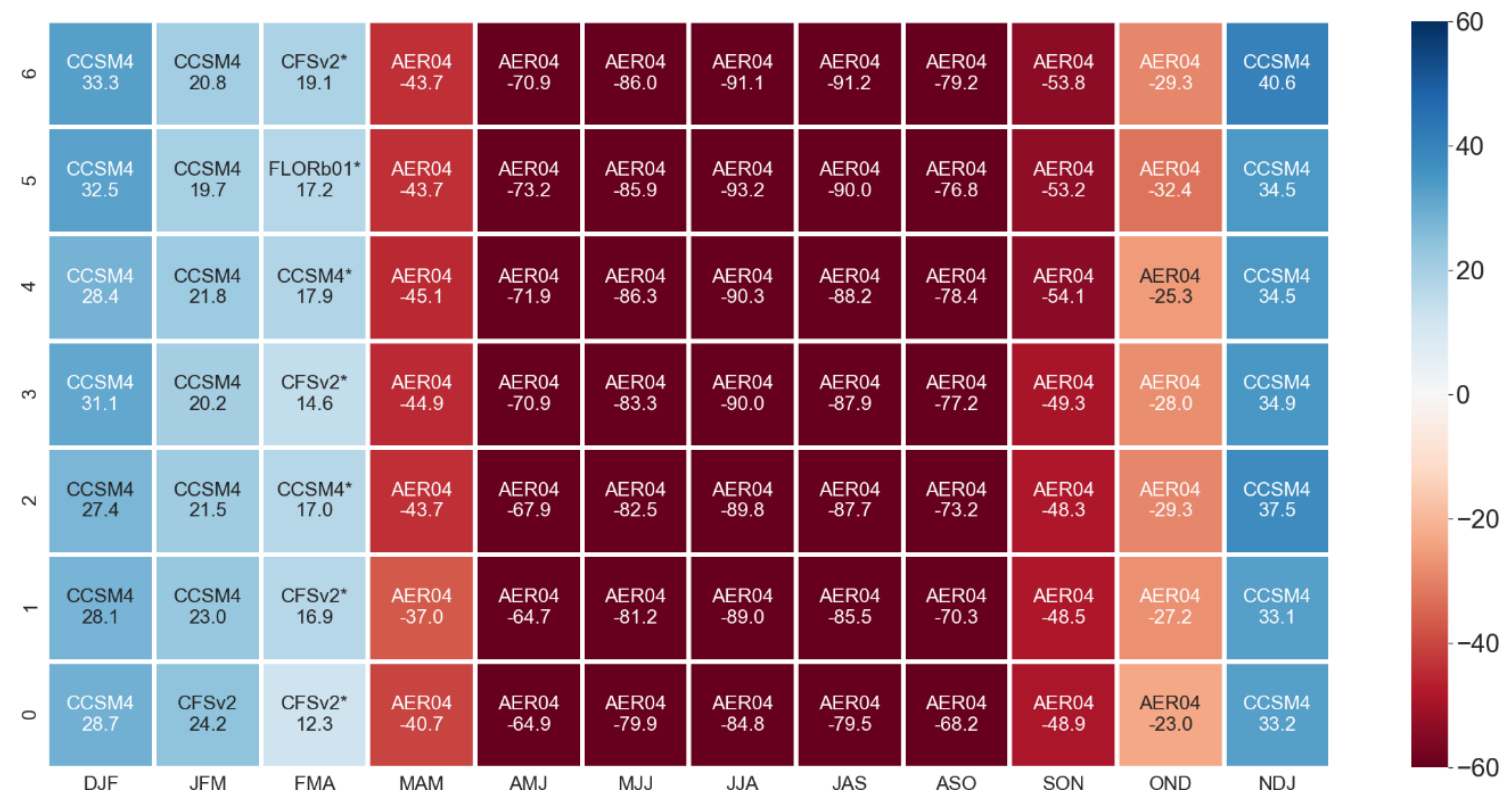

Figura 36 - Média dos erros relativos (\%) dos piores modelos (menores erros em módulo) para as previsões entre as estações entre 2011 e 2018 para a região SUL. O símbolo “*” indica que o modelo foi corrigido pelo viés climatológico (figura 34).

\subsection{Correlação entre as anomalias de precipitação previstas e observadas.}

Para avaliar a qualidade e habilidade das previsões sazonais de precipitação dos modelos estudados, é possível utilizar a correlação temporal de anomalias (CA) entre a base de dados prevista e observada durante o período de climatologia. Essa correlação dependerá da condição inicial e o tempo de previsão do mês/estação alvo. A partir dos mapas de correlações é possível afirmar que quanto mais próximo CA estiver de 1, mais perfeita será a previsão em relação a observação. Quanto mais próximo CA estiver de -1, também haverá uma correlação perfeita, porém em um sentido oposto. Para o valor de CA mais próximos ou igual a 0, não há correlações entre as bases de dados estudados. A seguir são discutidos os mapas de CA para cada modelo e para o MME para as estações principais (DJF, MAM, JJA e SON) considerando o tempo 1 de previsão. 


\subsubsection{Dezembro-Janeiro-Fevereiro (Tempo 1)}

Na estação de verão para o Hemisfério Sul, são esperados os maiores volumes acumulados de chuva sobre as regiões AMZ e SE, caracterizando uma importante estação de análise. É durante o verão austral, e estações próximas, que sistemas meteorológicos como as Zonas de Convergência do Atlântico Sul (ZCAS), por exemplo, se estabelecem e proporcionam a ocorrência de grandes volumes acumulados de chuva entre as regiões AMZ, BC e SE (Reboita et al., 2010).

Para as correlações de anomalias no verão (figura 37) os maiores valores positivos ocorrem principalmente entre a Argentina, Uruguai e RS e ao norte da região AMZ. Entre o sul da região $\mathrm{AMZ}$ e regiões $\mathrm{BC}$ e SE, há correlações com valores menores e com a maioria dos modelos convergindo para valores negativos. Apesar da correlação negativa entre áreas da região $\mathrm{AMZ}, \mathrm{BC}$ e SE, não há valores tão elevados quanto os positivos destacados ao norte da região AMZ e sul da região SUL. No entanto, valores negativos de correlação indicam baixa habilidade de previsão nessas áreas.

Embora o padrão espacial da correlação de anomalias apresente semelhanças entre os modelos, nota-se que: (a) alguns modelos individuais apresentam maiores áreas com correlações positivas e altas; (b) em função de alguns membros (NASAGEOS5, GEMNEMO e GFDL) as correlações na região SUL e NE diminuem no MME em comparação com membros individuais.

Como já apontavam as tabelas 5-9, em algumas regiões os modelos individuais apresentam correlações maiores com as observações na previsão de chuva de verão do que o MME. Isso ocorre no SUL do Brasil para os modelos CFSv2, GFDLFLORA06, GFDLFLORB01; nos modelos CFSv2, GEMNEMO e CanCM4 para as regiões AMZ e NE. 


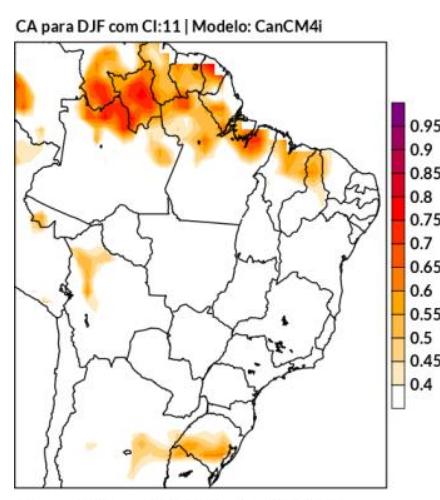

CA para DJF com Cl:11| Modelo: GFDLAER04

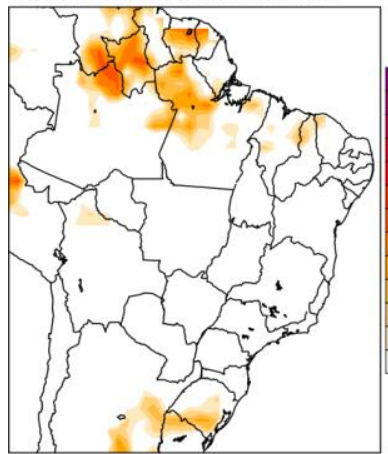

CA para DJF com Cl:11| Modelo: CCSM4

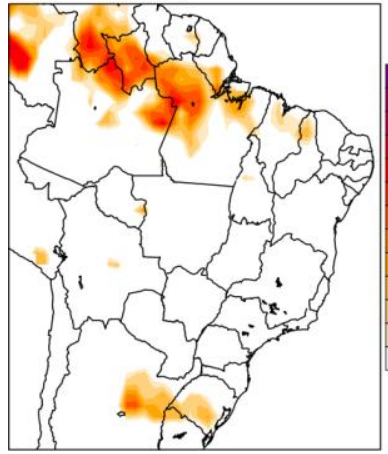

CA para DJF com Cl:11| Modelo: GEMNEMO

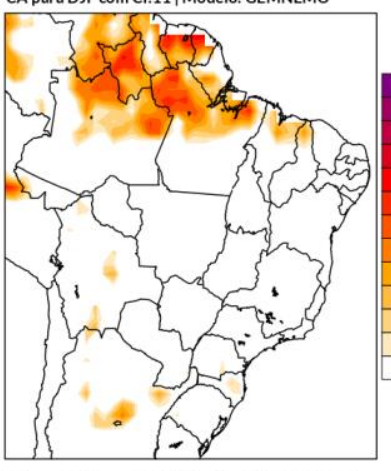

CA para DJF com Cl:11| Modelo: GFDLFLORA06

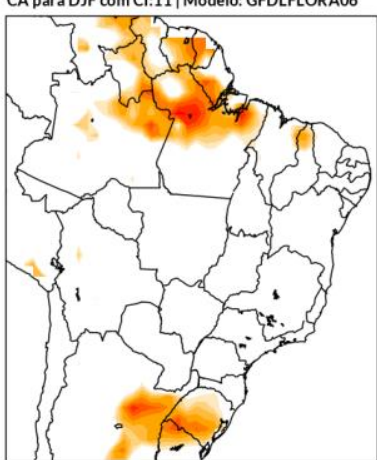

CA para DJF com Cl:11| Modelo: NASAGEOS5v2
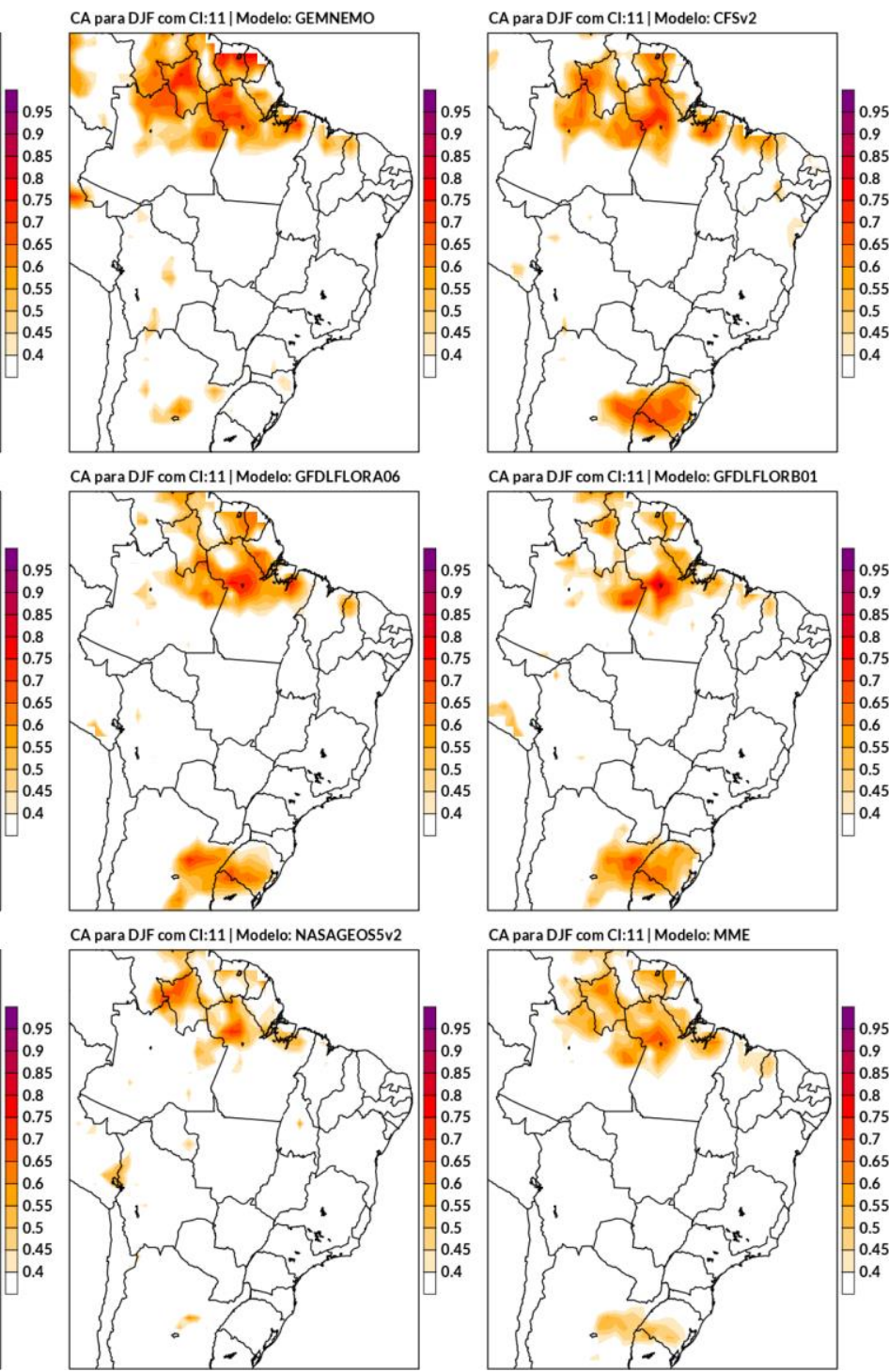

CA para DJF com Cl:11| Modelo: GFDLFLORB01

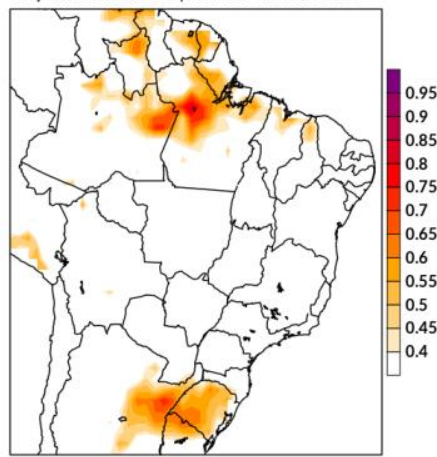

CA para DJF com Cl:11| Modelo: MME

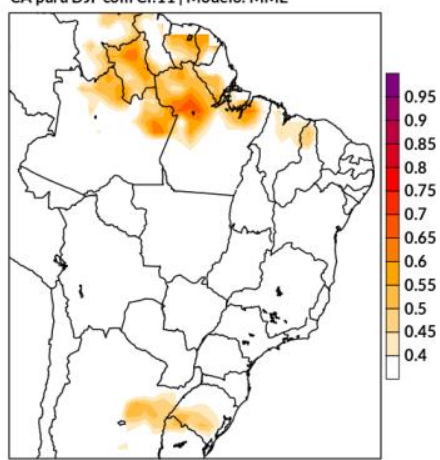

Figura 37 - Correlação de anomalia da taxa de precipitação prevista e observada para DJF- Tempo 1 com foco sobre o Brasil. Condição Inicial da previsão: Novembro. Áreas em branco não possuem significância estatística para a CA.

\subsubsection{Março-Abril-Maio (Tempo 1)}

MAM representa uma estação de transição entre o período úmido e seco em parte da AMZ e BC e SE, enquanto grande em parte do NE se estabelece a estação úmida. A figura 38 mostra as correlações de anomalias entre a taxa de precipitação prevista e observada para MAM. Em áreas da região NE (principalmente no centro-norte) e região SUL (principalmente em áreas do PR) nota-se os maiores valores positivos de correlação. As correlações sobre o PR são maiores do que nos demais setores do sul do Brasil na maioria dos modelos, com exceção dos GFDLaer04 e CFSv2. 
Para o centro-leste da AMZ e NE as correlações são altas e espacialmente homogêneas, exceto nos modelos NASAGEOS5v2 e CFSv2. A região SE apresenta valores negativos de correlação principalmente para os modelos NASAGEOS5v2, GFDLFLORA06 e GEMNEMO e com a média dos modelos (MME) indicando valores próximos à zero, o que não contribui como guia para previsão. Apenas o modelo CFSv2 apresenta correlações positivas e acima de 0,3 sobre a parte norte do SE, ou seja, no centro-norte de Minas Gerais. Um problema semelhante ocorre na região $\mathrm{BC}$, onde a maioria dos modelos indicam correlação negativa ou muito baixa. Na parte norte do BC, ou seja, no Mato Grosso. Um aumento nos valores de correlação também é encontrado em alguns modelos sobre o centro-norte do Tocantins e da Bahia.

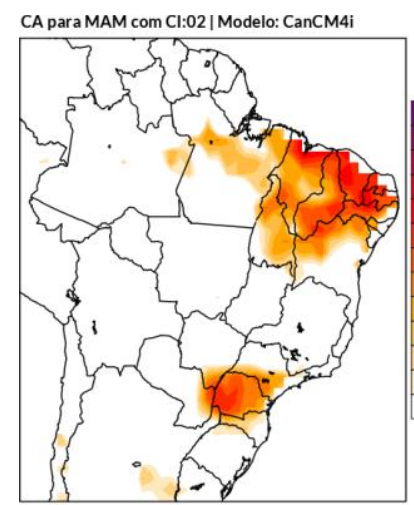

CA para MAM com Cl:02 | Modelo: GFDLAER04

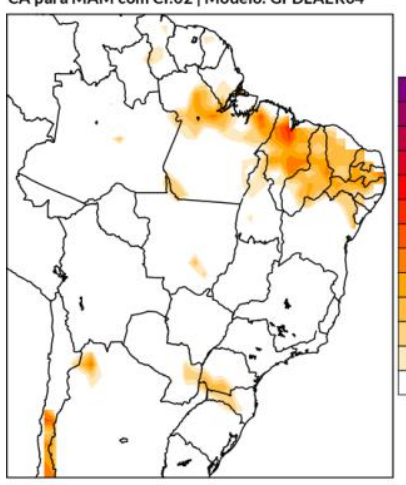

CA para MAM com Cl:02 | Modelo: CCSM4

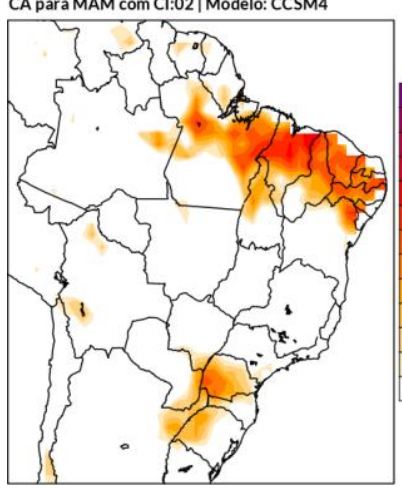

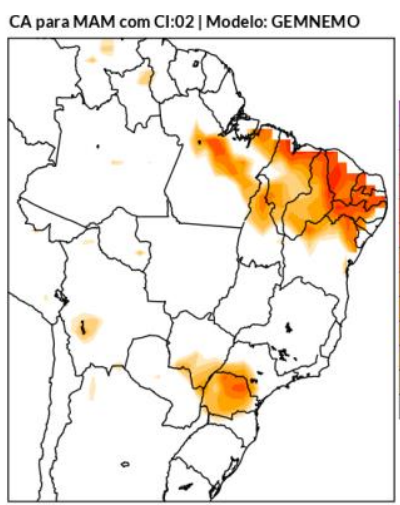

CA para MAM com Cl:02 | Modelo: GFDLFLORA06

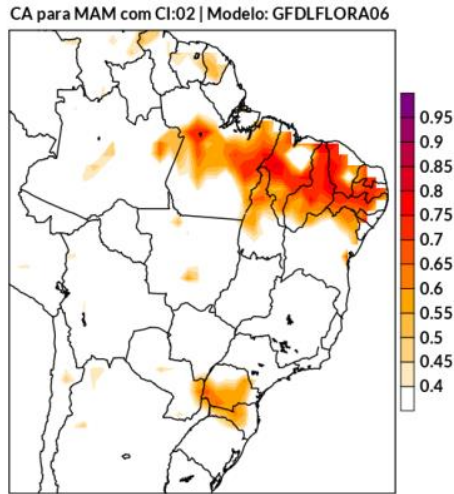

CA para MAM com Cl:02 | Modelo: NASAGEOS5v2

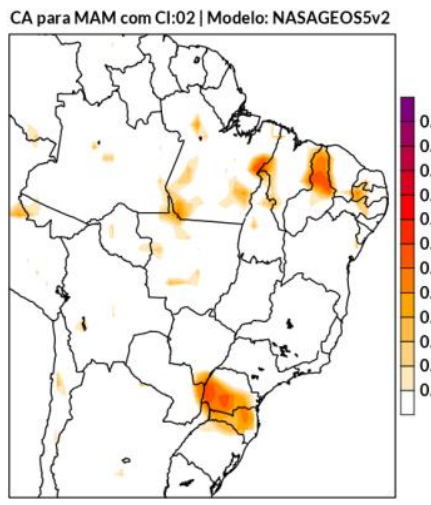

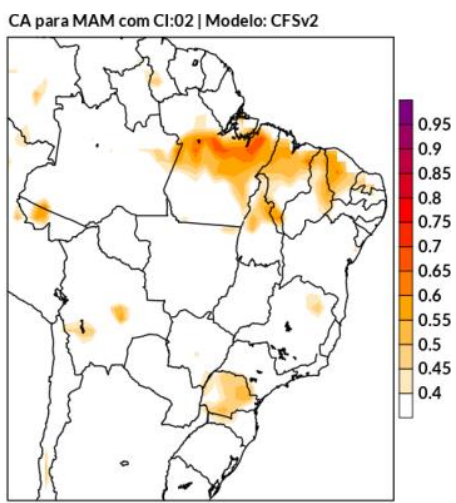

CA para MAM com Cl:02 | Modelo: GFDLFLORB01

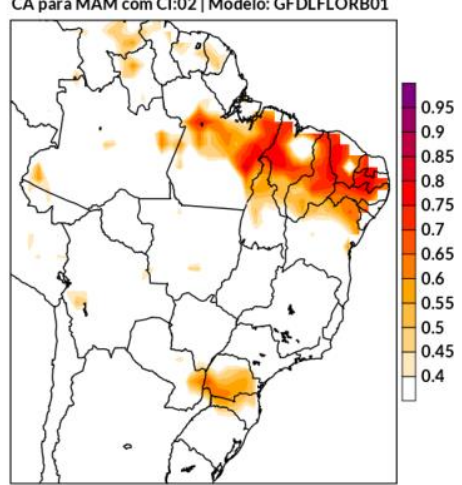

CA para MAM com Cl:02 | Modelo: MME

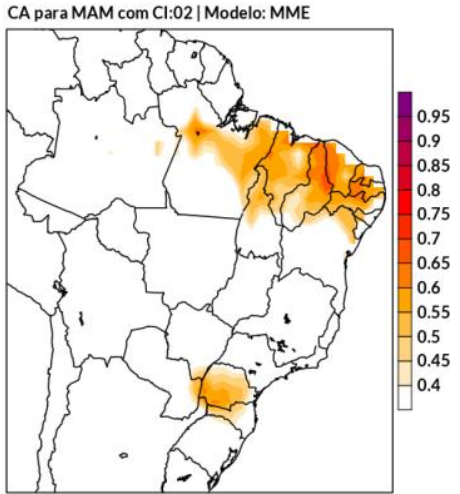

Figura 38 - Correlação de anomalia da taxa de precipitação prevista e observada para MAM- Tempo 1 com foco sobre o Brasil. Condição Inicial da previsão: Fevereiro. Áreas em branco não possuem significância estatística para a CA. 


\subsubsection{Junho-Julho-Agosto (Tempo 1)}

Para a estação de inverno do Brasil (figura 39), nota-se que há uma maior convergência entre os modelos para a ocorrência de maiores valores positivos de correlação entre áreas das regiões SE e SUL (PR, SP e MS).

Novamente, modelos individuais apresentam correlações positivas mais altas do que o MME em diversas regiões do Brasil. Sobre a região $B C$, também há uma convergência para valores intermediários (entre 0,5 e 0,6) positivos na maioria dos modelos, exceto para o GEMNEMO onde predomina correlações negativas.

Particularmente, se destacam os modelos CanCM4i e CFSv2 com correlações positivas e altas sobre o estado de São Paulo, onde normalmente as correlações entre previsão e observação de chuva são muito baixas ou negativas (Figuras 36, 37 e 39).

Na região BC as maiores correlações são encontradas no CanCM4i e no CFSv2 para o Mato Grosso do Sul (MS). No norte do NE se destacam as correlações positivas e altas ocupando uma área mais ampla da região no CCSM4 e NASA, e para o leste do NE o modelo CFSv2. Os modelos CanCM4i, CFSv2 e CCSM4 se destacam por apresentarem correlações positivas altas no centro-oeste e norte da região AMZ. Outro ponto de convergência entre os modelos é de valores altos positivos de correlação sobre a região dos Andes, entre a Argentina

e Chile. Nessas regiões as correlações positivas mais altas são encontradas no CCSM4i e GFDLFLORb01.

Na estação de inverno, temos uma redução das chuvas sobre áreas das regiões $\mathrm{AMZ}, \mathrm{BC}$, SE e NE, mas permanecendo com um padrão de chuvas sobre a região SUL (figura 9e). Dessa forma, em termos de correlações, maiores valores positivos sobre áreas da região SUL, MS e SP, indicando uma maior habilidade de previsão do que em outras estações do ano, como no verão e outono (Figuras 37-38). 


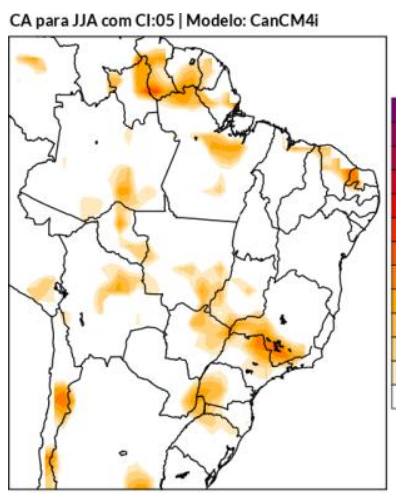

CA para JJA com Cl:05 | Modelo: GFDLAER04

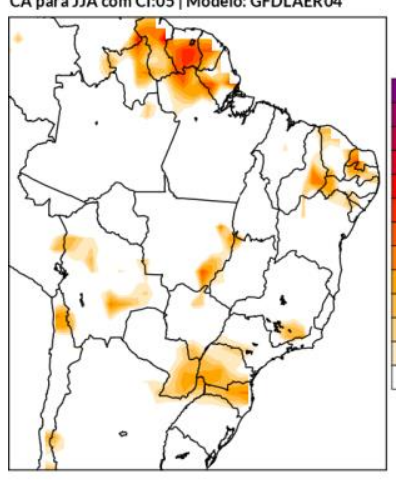

CA para JJA com Cl:05 | Modelo: CCSM4

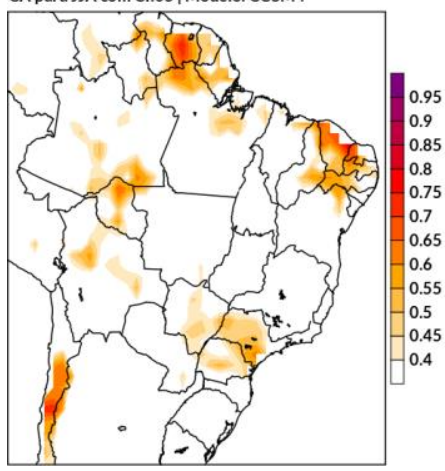

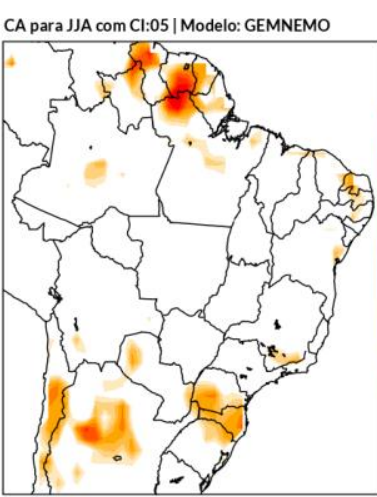

CA para JJA com Cl:05 I Modelo: GFDLFLORA06

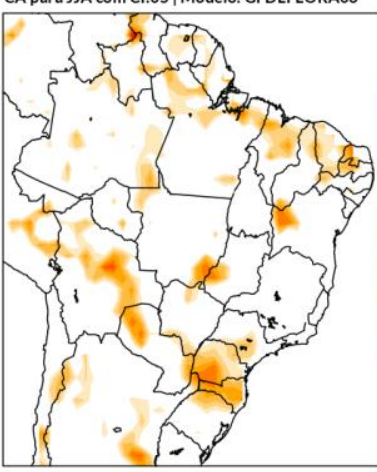

CA para JJA com Cl:05 | Modelo: NASAGEOS5v2

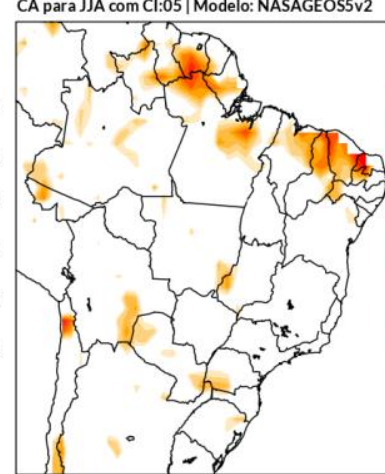

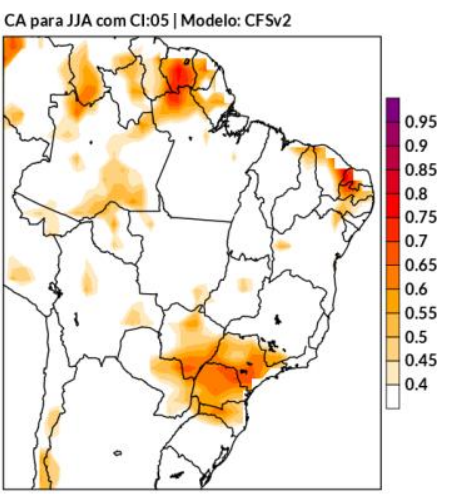

CA para JJA com Cl:05 | Modelo: GFDLFLORB01

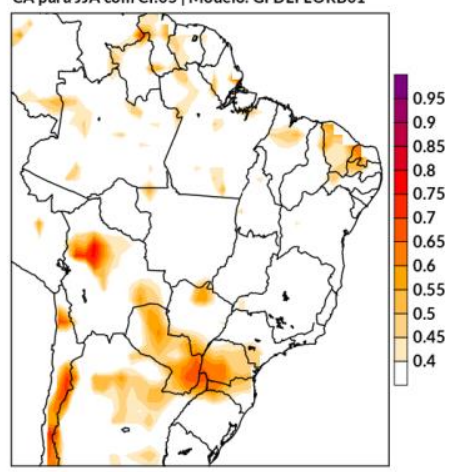

CA para JJA com Cl:05 | Modelo: MME

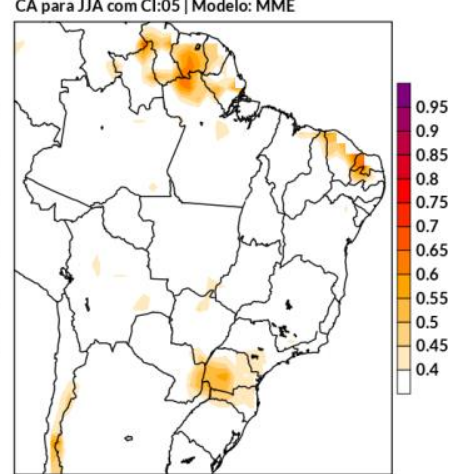

Figura 39 - Correlação de anomalia da taxa de precipitação prevista e observada para JJA- Tempo 1 com foco sobre o Brasil. Condição Inicial da previsão: Maio. Áreas em branco não possuem significância estatística para a CA.

\subsubsection{Setembro-Outubro-Novembro (Tempo 1)}

Para a estação de primavera do Hemisfério Sul (figura 40), os modelos possuem uma convergência para correlações positivas para a região SUL, exceto o modelo GFDLaer04 que indica predomínio de correlação negativa. Comparativamente os modelos GEMNEMO, GFDLFLORa06, GFDLFLORb01 apresentam maiores correlações sobre o SUL do que os demais. Sobre a região SE (principalmente em MG) também há uma maior convergência para valores positivos altos nos modelos GEMNEMO e CFSv2, com alguns modelos como CanCM4i 
e CCSM4 com predominância de correlações negativas. Sobre a região AMZ, as maiores correlações positivas são encontradas principalmente ao norte do PA em todos os modelos.

Para a região BC as correlações são positivas baixas ou então negativas. Predominância de correlações positivas e ligeiramente maiores são fornecidas pelos modelos NASA e CFSv2 na região BC. Novamente, também em SON nota-se que o MME tende a fornecer correlações menores do que modelos individuais em áreas específicas. O baixo skill da previsão em SON mostra que áreas do Brasil, Paraguai e Bolívia as correlações de anomalia do MME são em geral negativas, o que não ocorre nas demais estações já apresentadas.
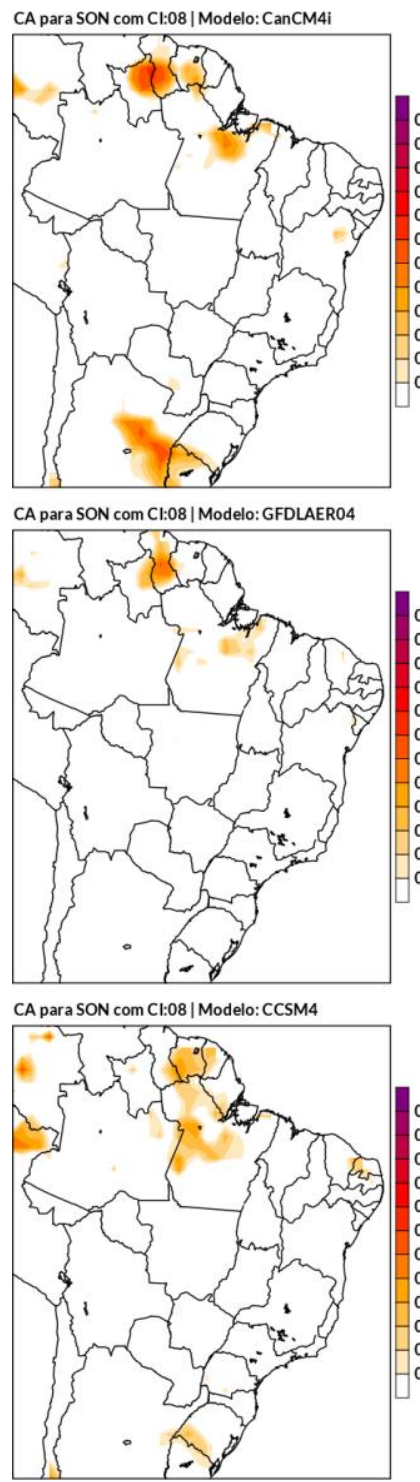

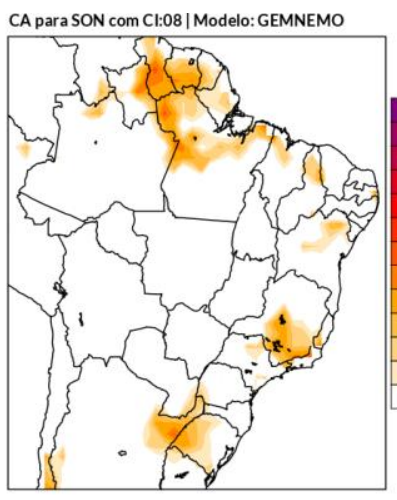

CA para SON com Cl:08| Modelo: GFDLFLORA06

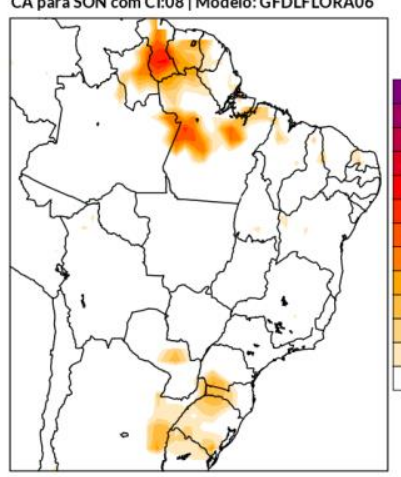

CA para SON com Cl:08 | Modelo: NASAGEOS5v2

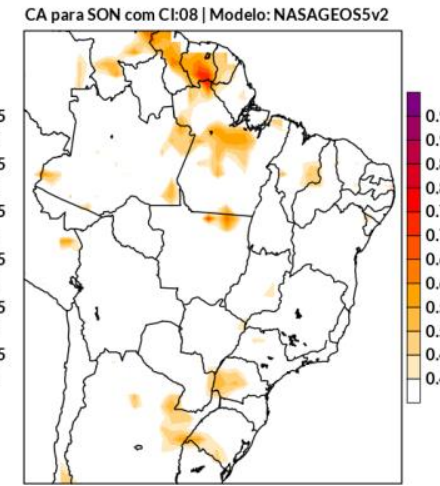

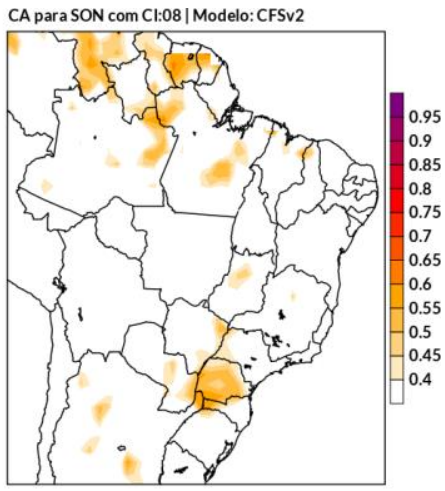

CA para SON com Cl:08 | Modelo: GFDLFLORB01

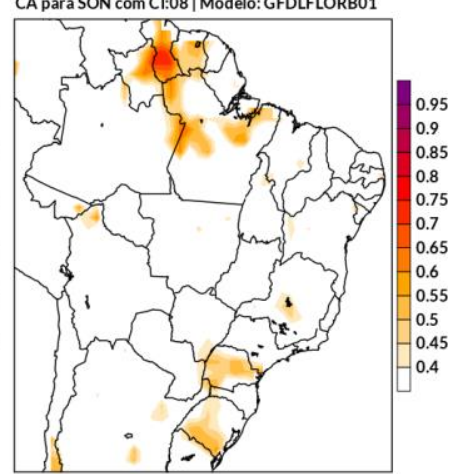

CA para SON com Cl:08 | Modelo: MME

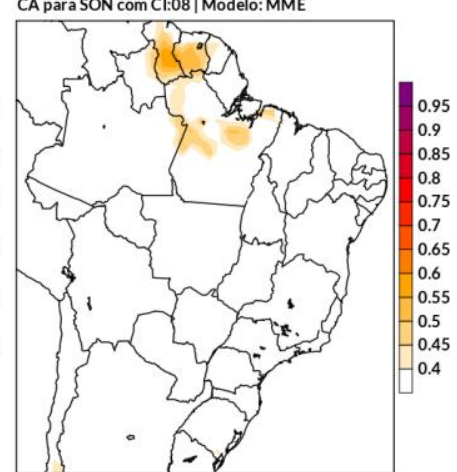

Figura 40 - Correlação de anomalia da taxa de precipitação prevista e observada para SON- Tempo 1 com foco sobre o Brasil. Condição Inicial da previsão: Agosto. Áreas em branco não possuem significância estatística para a CA. 


\subsection{Correlação entre as anomalias de precipitação previstas e a Temperatura da Superfície do Mar (TSM)}

Visto que os modelos numéricos do NMME são acoplados calculou-se a correlação entre a série temporal média na área da anomalia da taxa de precipitação prevista e a anomalia da TSM global para o período de hindcast de cada modelo. Com esses resultados, espera-se entender como a previsão de chuva sazonal para determinada região é ou não influenciada por processos oceânicos no período estudado. Tendo em vista os diferentes tempos de previsão para cada estação, além da região de estudo, essa correlação também dependerá da condição inicial e do tempo de previsão. Nessa seção, são apresentados apenas os resultados referentes às correlações do tempo 1 de previsão.

Perturbações oceânicas sobre áreas do Oceano Pacífico equatorial, são os principais iniciadores de padrões de teleconexão conhecidos e podem ser indicadores para possíveis sinais na anomalia de chuva em algumas regiões do Brasil (Coelho et al, 2002; Pezzi e Cavalcanti, 2001; Diaz et al, 1998). A Figura 41, mostra vários índices oceânicos que podem impactar a variabilidade climática em diferentes regiões do globo. Sobre áreas do Brasil, destacam-se os índices correspondentes ao padrão de teleconexão do El Niño e, por cobrir grande parte da costa do País, padrões como o dipolo do Atlântico também apresentam influências efetivas na variabilidade climática em regiões do Brasil (Moura et al, 2000; Salgueiro et al, 2016).

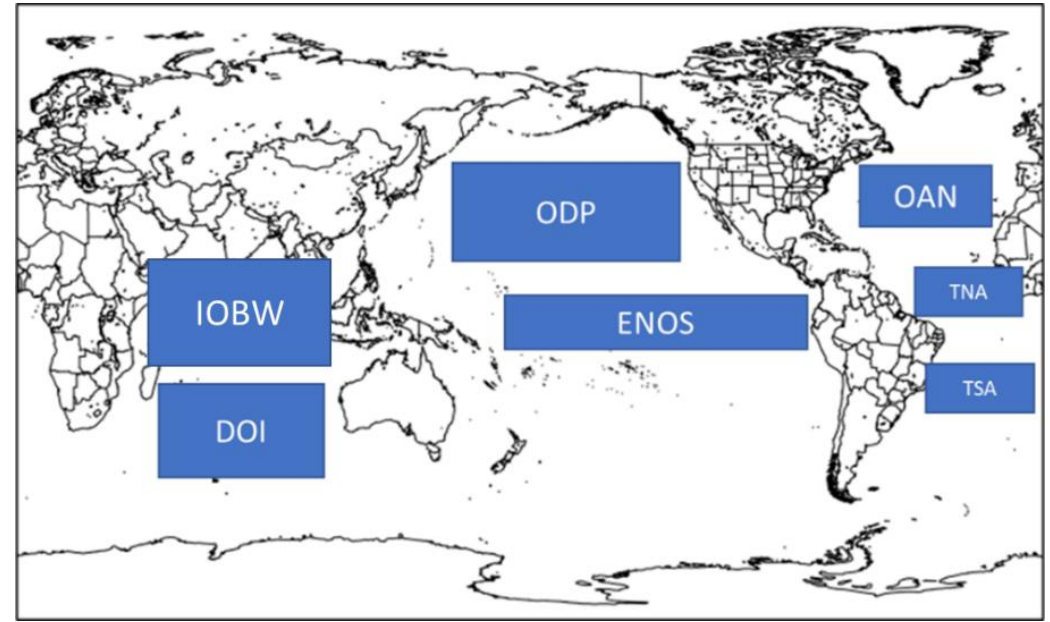

Figura 41 - Índices de teleconexão em diferentes bacias Oceânicas. ENOS: El Niño Oscilação Sul; ODP: Oscilação Decadal do Pacífico; IOBW: Indian Ocean Basin Warming; DOI: Dipolo do Oceano Índico; TSA e TNA: Dipolo do Oceano Atlântico; OAN: Oscilação do Atlântico Norte. 


\subsubsection{Dezembro-Janeiro-Fevereiro (Tempo 1)}

A figura 42 mostra que para região AMZ existem duas classes distintas entre os modelos. A primeira inclui os modelos (CFSv2, CCSM4, GFDLaer04, GFDLFLORa06, GFDLFLORb01 e NASA) que mostram forte correlação estatisticamente significativa entre a anomalia de chuva no verão e o fenômeno El Niño/La Niña no Pacífico tropical. As fortes correlações negativas com a TSM tropical do Pacífico indicam que anomalias positivas de TSM (El Niño) resultam em anomalias negativas de chuva na AMZ, como normalmente observado (Ropelewski e Halpert, 1987; Mason e Goddard, 2001). Sinais opostos ocorrendo em anos de La Niña. Um outro sinal comum à essa categoria de modelos é a presença de um dipolo de correlações estatisticamente significativas com a TSM no Atlântico Sul, o que poderia indicar influência do dipolo do Atlântico Sul na previsão de chuva da AMZ. Outra classe de modelos (CanCM4i, GEMNEMO, GFDLFLORb01 e MME) não apresenta correlações significativas entre as anomalias de chuva na AMZ e TSM global.
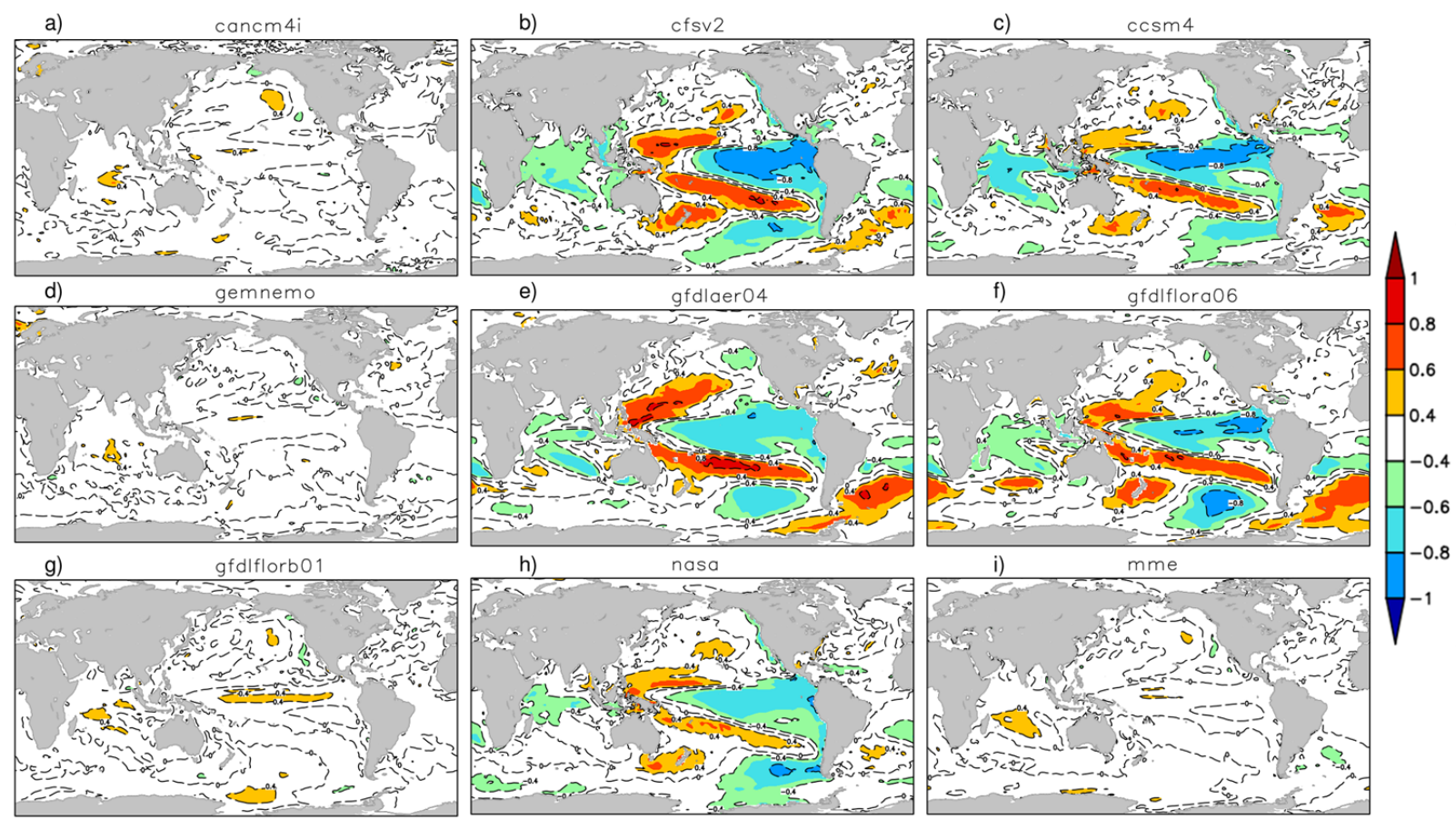

Figura 42 - Correlação temporal entre a anomalias de chuva previstas e anomalias de TSM para o tempo 1 de previsão para o hindcast de DJF para região AMZ: (a) CanCM4i, (b) CFSv2, (c) CCSM4, (d) GEMNEMO, (e) GFDLAER04, (f) GFDLFLORA06, (g) GFDLFLORB01, (h) NASA, (i) MME. Os valores em branco não apresentam significância estatística. 
Para a região BC (figura 43) o número de modelos (CFSv2 e GFDLFLORa06 e em menor grau o GFDLaer04) indicando influências remotas da TSM no Pacífico tropical e Atlântico Sul na anomalia chuva é menor do que na AMZ. E a existência desse sinal nestes modelos também não implica em maior habilidade de previsão de anomalias de chuva desde que as correlações temporais são próximas de zero (tabela 6). Outros modelos (GEMNEMO, NASA, CanCM4i e CCSM4) praticamente não indicam relações estatisticamente significativas entre a anomalia de chuva e a TSM global. No GFDLFLORb01 as correlações são positivas nas El Niño no Pacífico Central e TSM no Atlântico Sul equatorial, mas também não indicam impacto positivo na previsão de chuva que são fracamente correlacionadas com as observações (tabela 6).
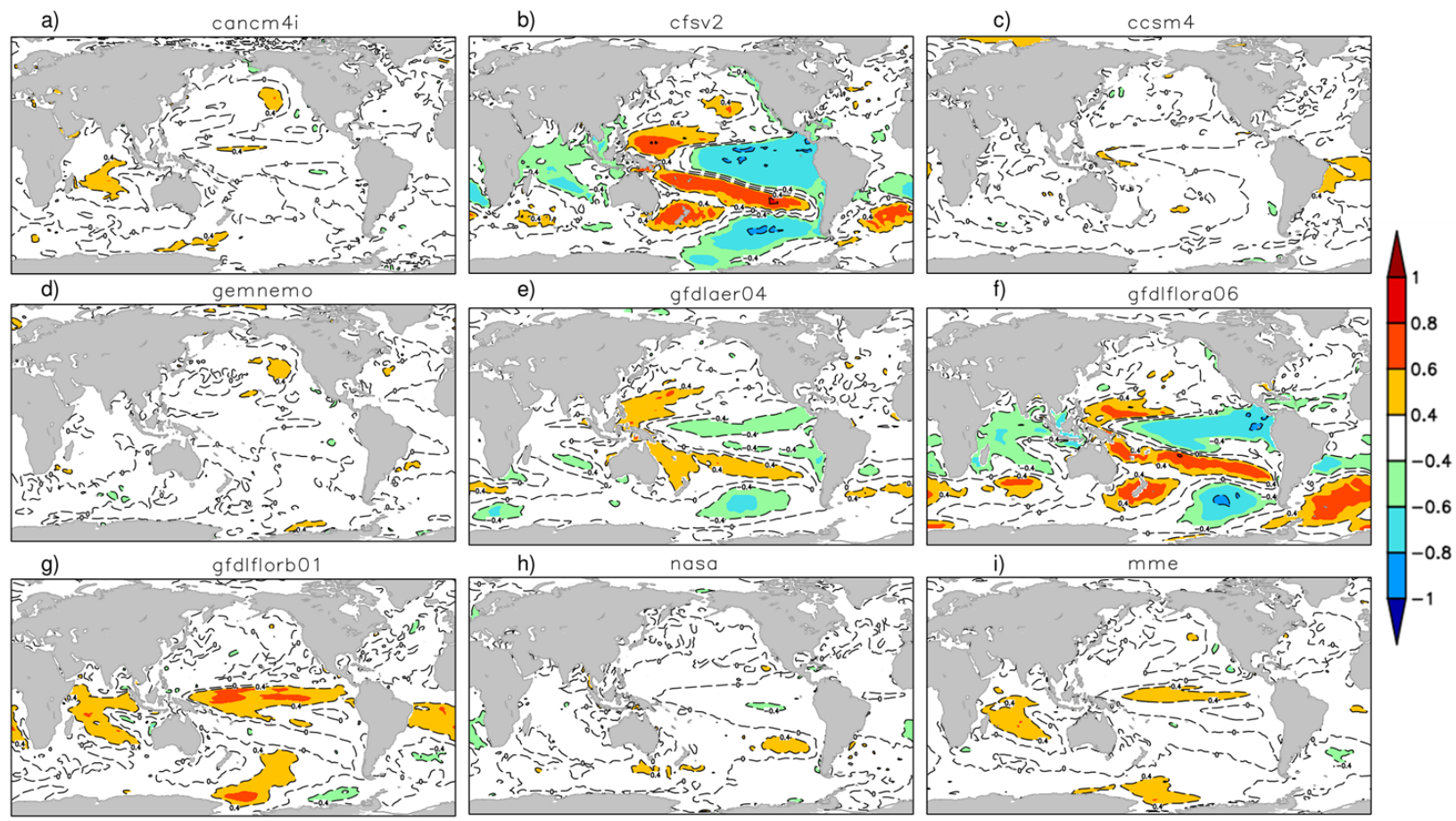

Figura 43 - Correlação temporal entre a anomalias de chuva previstas e anomalias de TSM para o tempo 1 de previsão para o hindcast de DJF para região BC: (a) CanCM4i, (b) CFSv2, (c) CCSM4, (d) GEMNEMO, (e) GFDLAER04, (f) GFDLFLORA06, (g) GFDLFLORB01, (h) NASA, (i) MME. Os valores em branco não apresentam significância estatística.

As anomalias de chuva e DJF na região NE também mostram padrões de correlação com a TSM global distintos entre os modelos (figura 44). Neste caso, dois modelos indicam correlação negativa com a região do El Niño no Pacífico equatorial (CFSv2 e GFDLFLORa06) e três indicam correlações negativas com a TSM no Atlântico tropical norte (GFDLFLORa06, 
CCSM4 e NASA). Como já discutido, as correlações entre anomalias de chuva previstas e observadas são baixas, exceto para o modelo da NASA $(+0,56)$ que indica relação mais forte, e estatisticamente significativas, entre as anomalias de chuva no NE e anomalias de TSM no Atlântico Norte tropical.
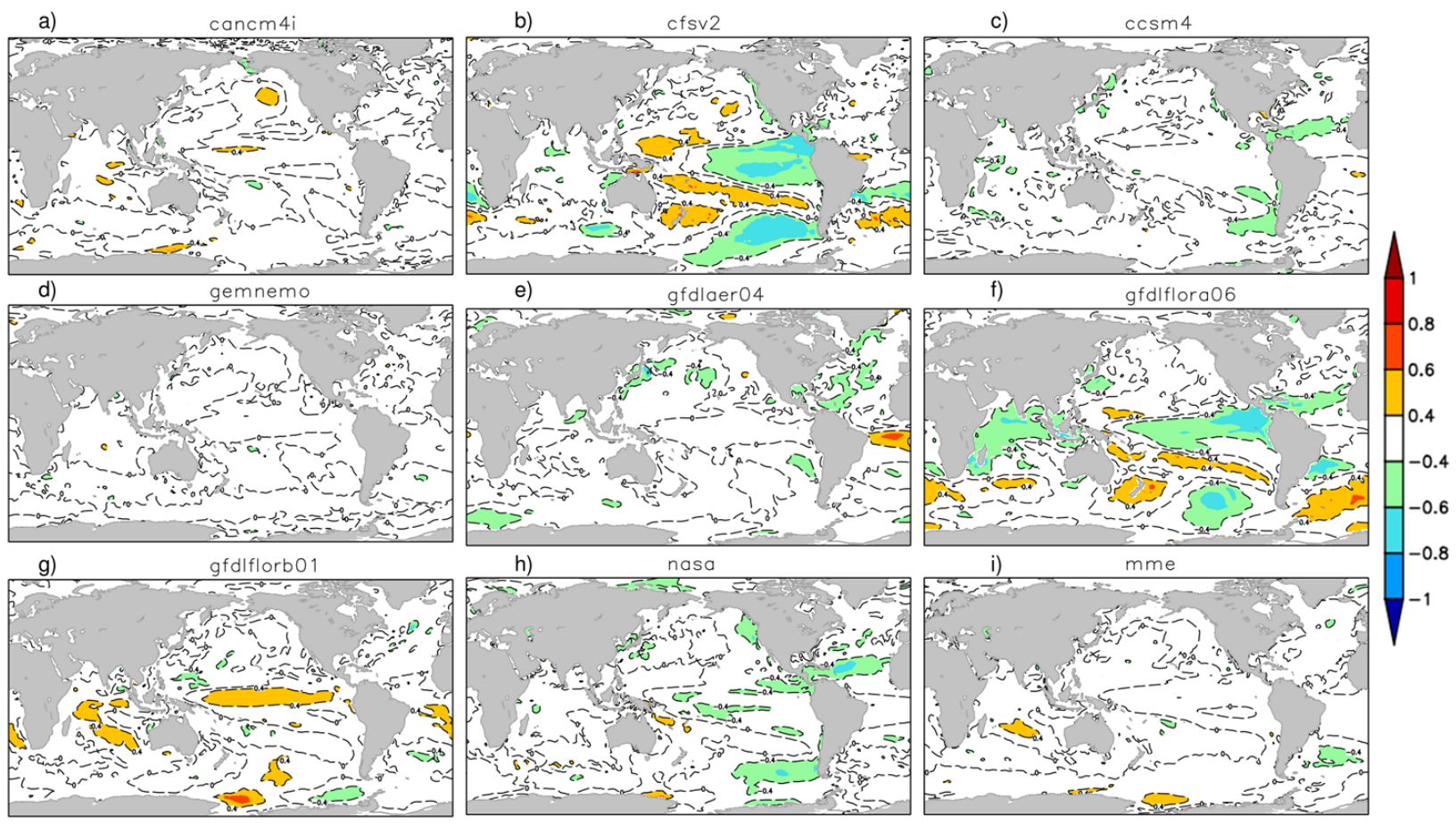

Figura 44 - Correlação temporal entre a anomalias de chuva previstas e anomalias de TSM para o tempo 1 de previsão para o hindcast de DJF para região NE: (a) CanCM4i, (b) CFSv2, (c) CCSM4, (d) GEMNEMO, (e) GFDLAER04, (f) GFDLFLORA06, (g) GFDLFLORB01, (h) NASA, (i) MME. Os valores em branco não apresentam significância estatística.

Vários modelos (CFSv2, GFDLFLORa06, GFDLFLORb01 e NASA) mostram padrões espaciais de correlação entre a anomalia de chuva na região SE e TSM global similares aos para a região BC (figura 43). O modelo GEMNEMO mostra um padrão de El Niño mais alongado na direção do Pacífico Central e o modelo CCSM4 um padrão de El Niño no Pacífico Central. No entanto, assim como para o BC, as correlações relativamente altas entre as anomalias de chuva no SE e a TSM Pacífico central-leste não se refletem na habilidade dos modelos em capturar a variabilidade interanual observada, já que as correlações entre anomalias de chuva prevista e observada são, em geral, negativas (exceto para o modelo GEMNEMO na tabela 9). 

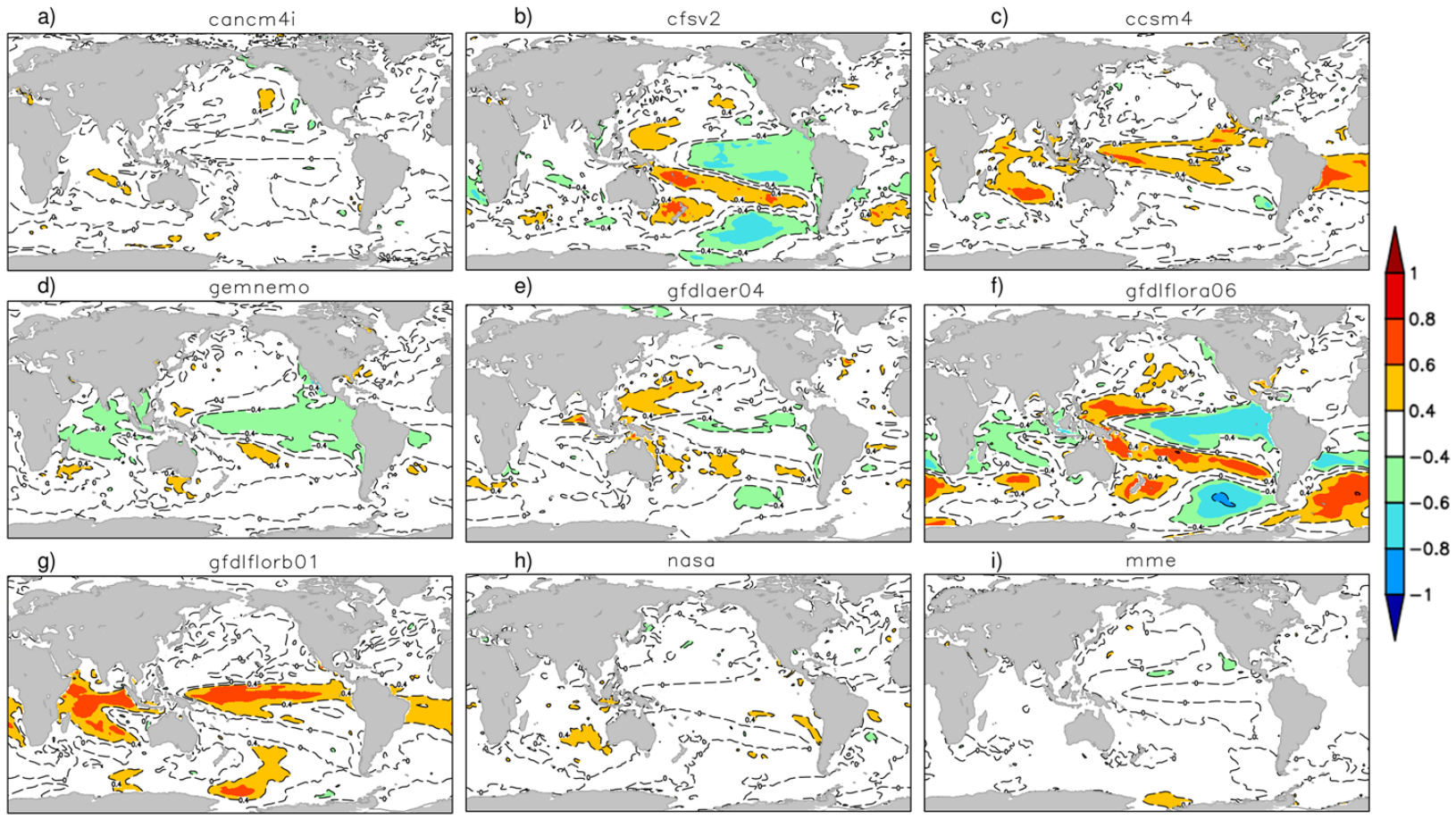

Figura 45 - Correlação temporal entre a anomalias de chuva previstas e anomalias de TSM para o tempo 1 de previsão para o hindcast de DJF para região SE: (a) CanCM4i, (b) CFSv2, (c) CCSM4, (d) GEMNEMO, (e) GFDLAER04, (f) GFDLFLORA06, (g) GFDLFLORB01, (h) NASA, (i) MME. Os valores em branco não apresentam significância estatística.

Para a região SUL, a figura 46 os modelos CFSv2 e GFDLFLORa06 mostram um padrão de El Niño no Pacífico tropical central-leste e um dipolo de anomalia no Atlântico Sul, enquanto na maioria dos modelos não existe um claro padrão de correlação entre as anomalias de chuva e de TSM global. No GFDLFLORa06 as correlações, tanto no Pacífico como no Atlântico Sul, são maiores do que no CFSv2 (figura 45), o que poderia explicar também a maior correlação entre a chuva prevista e observada (tabela 9). 

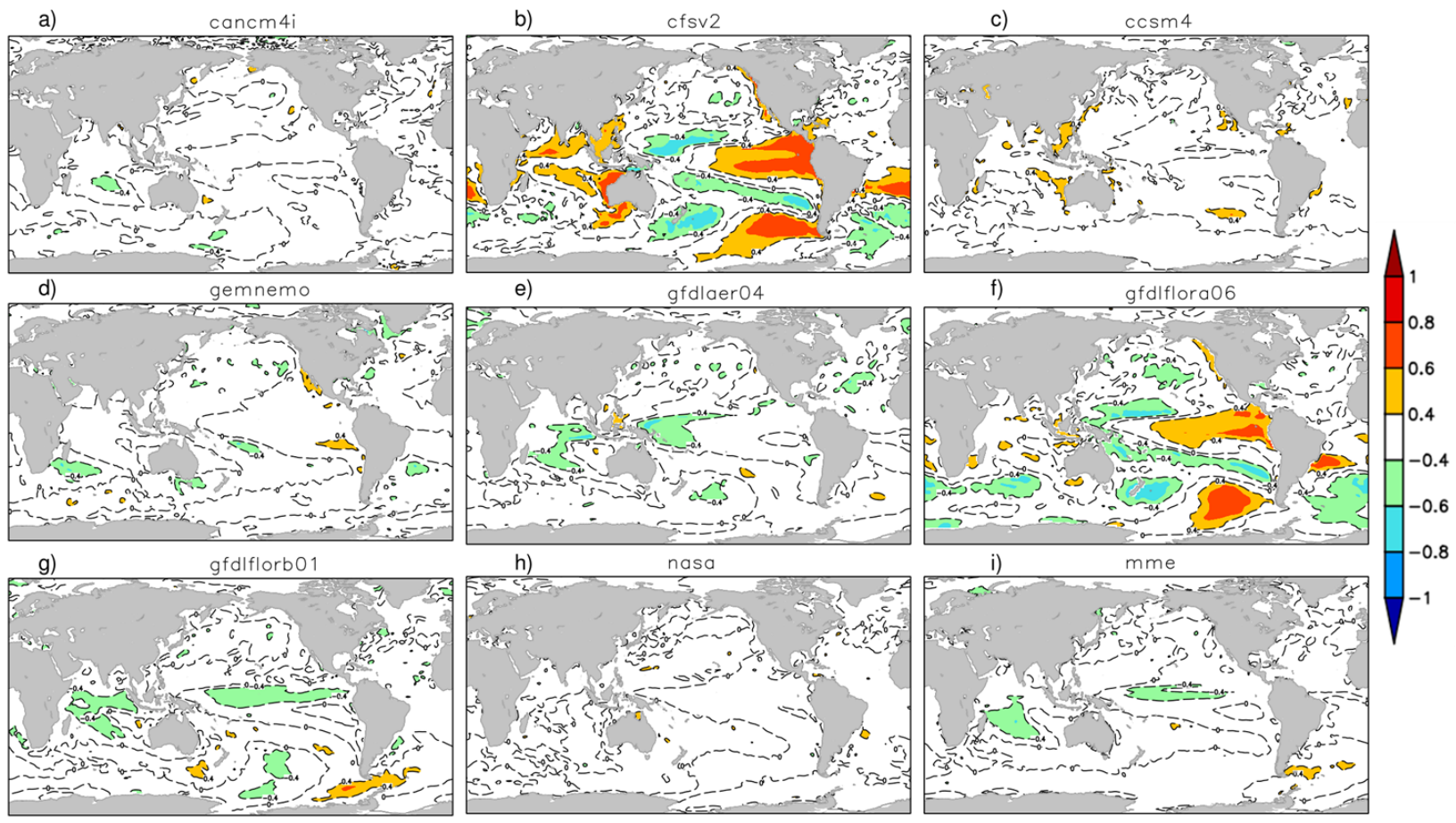

Figura 46 - Correlação temporal entre a anomalias de chuva previstas e anomalias de TSM para o tempo 1 de previsão para o hindcast de DJF para região SUL: (a) CanCM4i, (b) CFSv2, (c) CCSM4, (d) GEMNEMO, (e) GFDLAER04, (f) GFDLFLORA06, (g) GFDLFLORB01, (h) NASA, (i) MME. Os valores em branco não apresentam significância estatística.

Para os padrões de correlação entre a TSM e a chuva observada (figura 47), a região AMZ possui valores negativos em áreas do Pacífico Equatorial, de forma a convergir com o padrão simulado pelos modelos CFSv2, CCSM4, GFDLaer04, GFLFLORa06 e NASA para a estação de DJF. Para a região SUL, a figura 46 mostra correlações positivas principalmente em áreas mais a leste do Pacífico Equatorial (atingindo a região do Niño 1+2) que comparando com os padrões previstos (figura 46) nota-se uma convergência com os modelos CFSv2 e GFDLFLORa06.

Sobre áreas ao sul do Oceano Atlântico, observa-se que a região SUL apresenta uma correlação com áreas próximas ao litoral de SC e PR e que está de acordo com o estudo de Cataldi et al. (2010). Nessa região, os modelos que também apresentam correlações positivas são o CCSM4, CFSv2, GFLFLORa06 e NASA. 

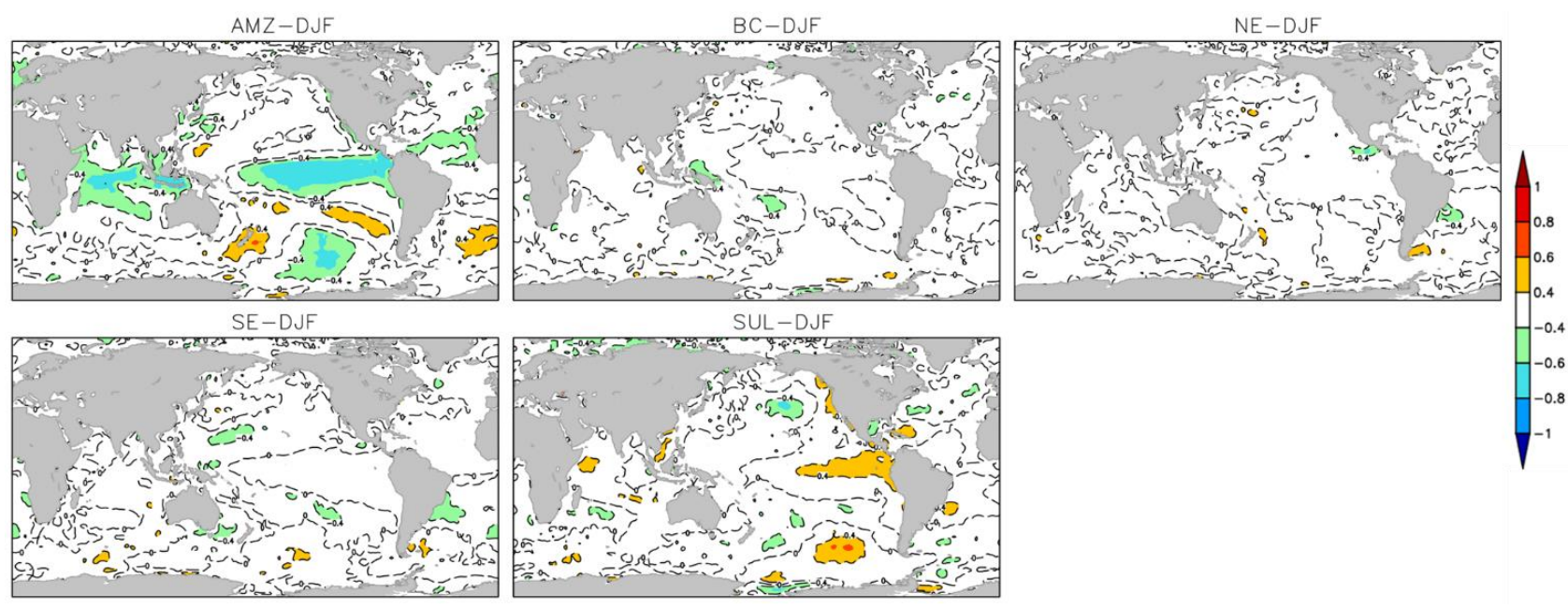

Figura 47 - Padrões de correlação para as anomalias de TSM e chuva observada para as regiões de estudo e para a estação de DJF. Os valores em branco não apresentam significância estatística.

Os padrões de correlação não indicam a atuação de nenhuma teleconexão importante entre as anomalias de chuva nas regiões BC e NE (Figura 47), como também é notado em algumas previsões (CanCM4, GENMENO e CCSM4 na BC e CanCM4i, GENMENO e NASA na NE). Para as anomalias de chuva observadas no SE também não se destaca nenhum padrão de teleconexão importante, apenas nota-se correlação negativa com a TSM no leste do sudeste do Brasil que não é previsto pelos modelos (Figura 45).

\subsubsection{Março-Abril-Maio (Tempo 1)}

Para a região AMZ e estação de MAM (figura 48), os modelos CFSv2, CCSM4, GFDLaer04, GFDLFLORb01, GFDLFLORa06 e NASA continuam apresentando correlações estatisticamente significativas principalmente em áreas do Oceano Pacífico. Nesses modelos, temos padrões similares com correlações positivas no Pacífico Norte, negativas no Pacífico Equatorial e positivas no Pacífico Sul. As correlações negativas na região do Pacífico Equatorial indicam que em anos de El Niño (La Niña) há uma tendência de previsão de anomalias negativas (positivas) de chuva na região AMZ.

Dentre as outras regiões do oceano, também há correlações negativas significativas em áreas ao norte do Oceano Atlântico para os modelos CFSv2, CCSM4, GFDLFLORa06 e NASA, 
enquanto na região sul do Oceano Atlântico tem-se correlações positivas principalmente para os modelos CCSM4, GFDLFLORa06 e NASA. Esses padrões de dipolo da correlação também podem indicar a influência do dipolo do Oceano Atlântico (TNA e TSA) na previsão de chuva da região AMZ na estação MAM.
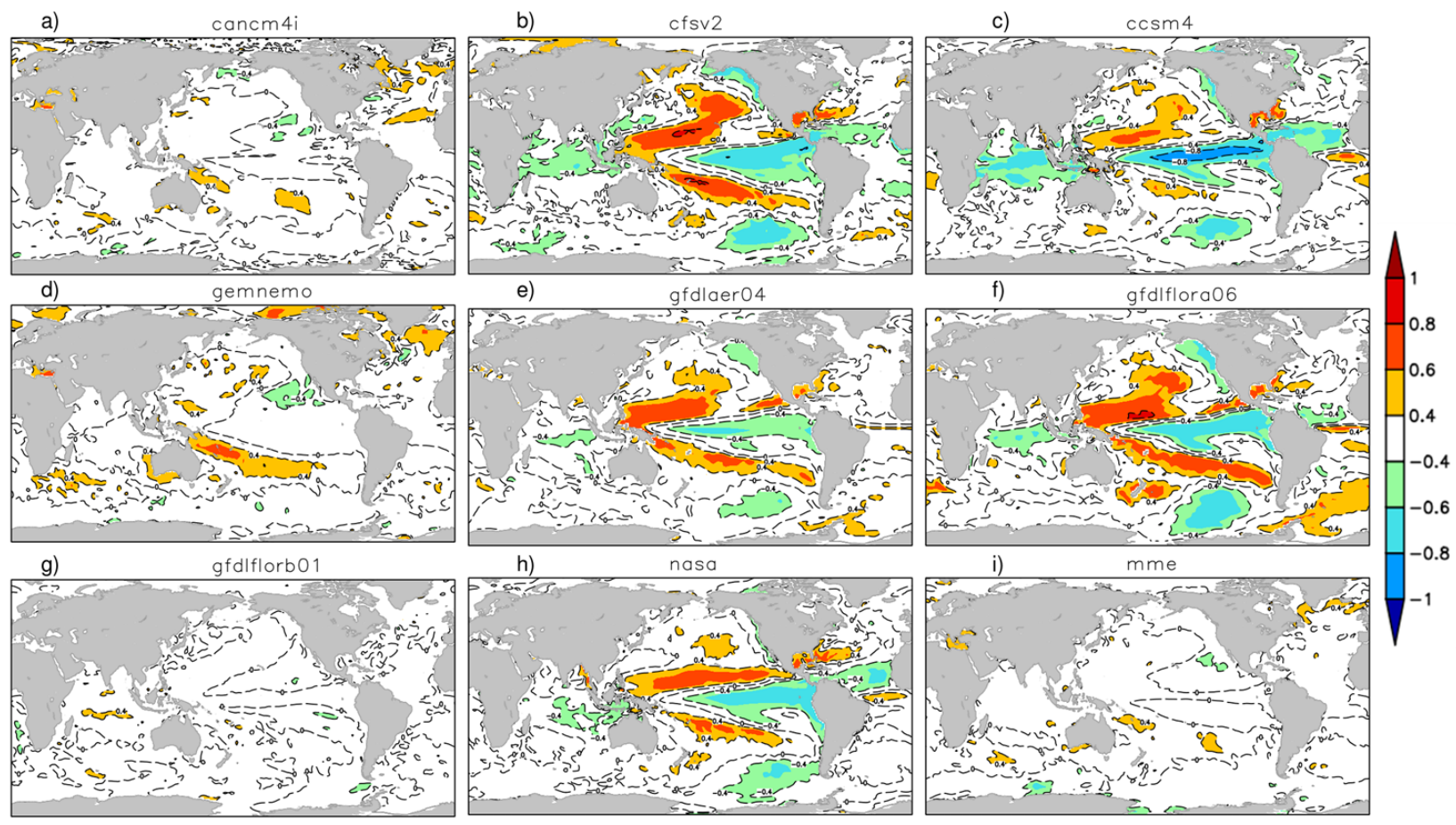

Figura 48 - Correlação temporal entre a anomalias de chuva previstas e anomalias de TSM para o tempo 1 de previsão para o hindcast de MAM para região AMZ: (a) CanCM4i, (b) CFSv2, (c) CCSM4, (d) GEMNEMO, (e) GFDLAER04, (f) GFDLFLORA06, (g) GFDLFLORB01, (h) NASA, (i) MME. Os valores em branco não apresentam significância estatística.

Em relação a região BC (figura 49), os modelos que apresentam correlações negativas mais significativas na região do Pacífico Equatorial são os GFDLaer04, GFDLFLORa06 e NASA, e com um sinal similar na região do Atlântico Norte. O modelo CCSM4, também apresenta correlações nessas áreas, porém em uma menor área. Essas correlações indicam que anomalias negativas (positivas) de TSM sobre essas regiões tendem a gerar anomalias de chuva positivas (negativas). Em relação aos demais modelos, não se observam valores estatisticamente significativos de correlação para essas regiões mencionadas. Sinais de correlação estatisticamente significativa negativa são notadas em três modelos sobre o Oceano 
Índico, que pode ser um indicativo para uma possível relação com o padrão de teleconexão IOBW (Indian Ocean Basin Warming).
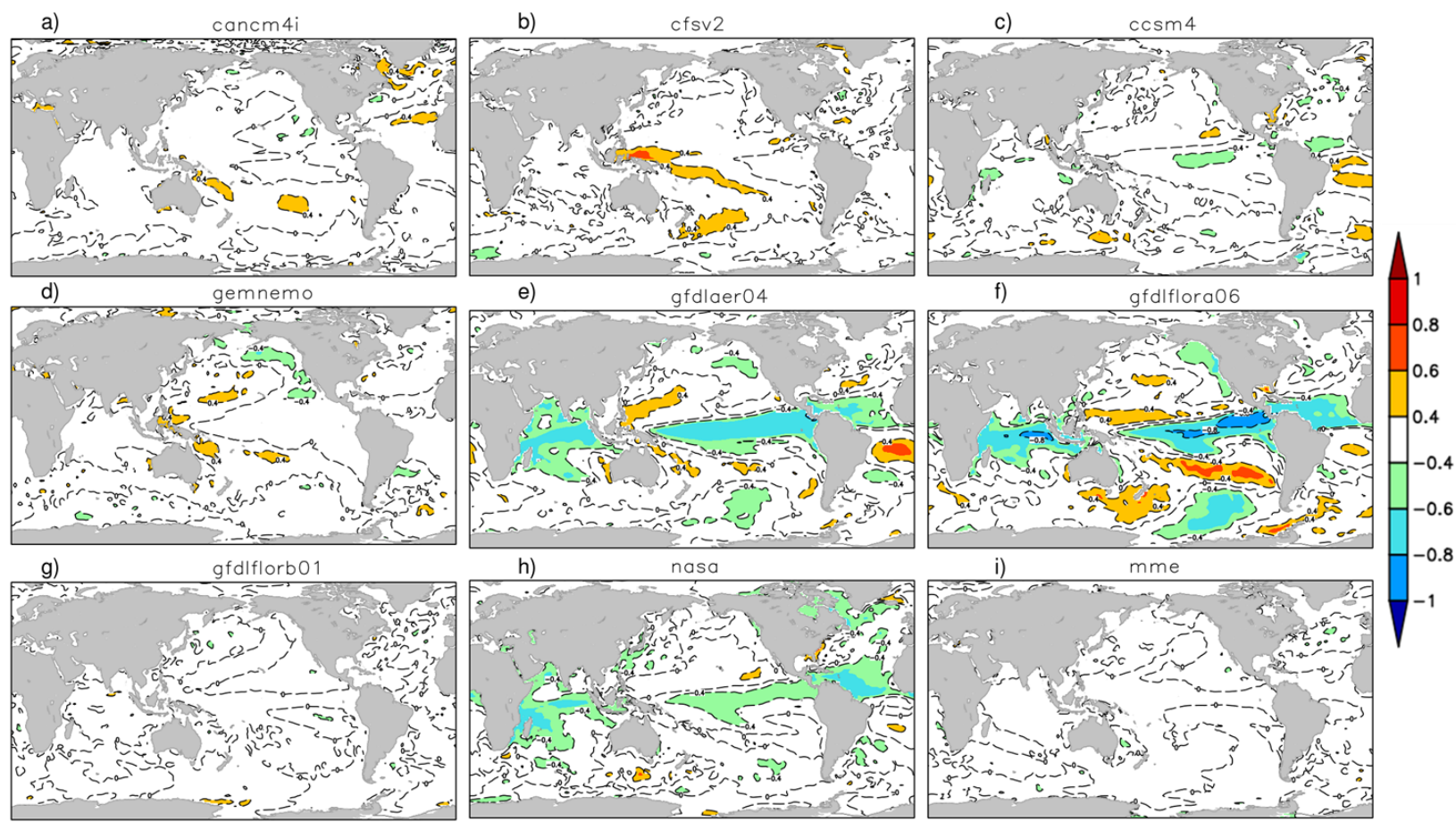

Figura 49 - Correlação temporal entre a anomalias de chuva previstas e anomalias de TSM para o tempo 1 de previsão para o hindcast de MAM para região BC: (a) CanCM4i, (b) CFSv2, (c) CCSM4, (d) GEMNEMO, (e) GFDLAER04, (f) GFDLFLORA06, (g) GFDLFLORB01, (h) NASA, (i) MME. Os valores em branco não apresentam significância estatística.

Para a região NE, a figura 50 continua mostrando anomalias negativas mais significativas em áreas do Oceano Pacífico Equatorial e para os modelos CFSv2, CCSM4, GFDLaer04, GFDLFLORa06 e NASA. Sobre o Oceano Índico, os modelos que mais se destacam com anomalias negativas são CCSM4 (principalmente em áreas mais ao norte), GFDLaer04 e GFDLFLORa06.

Sobre a região NE tem-se uma grande influência do Oceano Atlântico devido à proximidade entre ambos, com especial influência do dipolo do Atlântico tropical (Moura et al, 2000; Rodrigues et al, 2011; Harzalla et al, 1996). Sendo assim, vale destacar os modelos CFSv2, CCSM4, GFDLaer04, GFDLFLORa06 e NASA (figura 49) que, assim como em áreas do Pacífico Equatorial, também apresentam correlações significativas sobre o Atlântico (negativo 
ao norte e positivo ao sul), o que pode resultar em melhores previsões de chuva para a região NE. Além disso, vale destacar que todos os modelos citados possuem correlações positivas e com valores superiores a +0,66 em relação a precipitação observada (tabela 7).
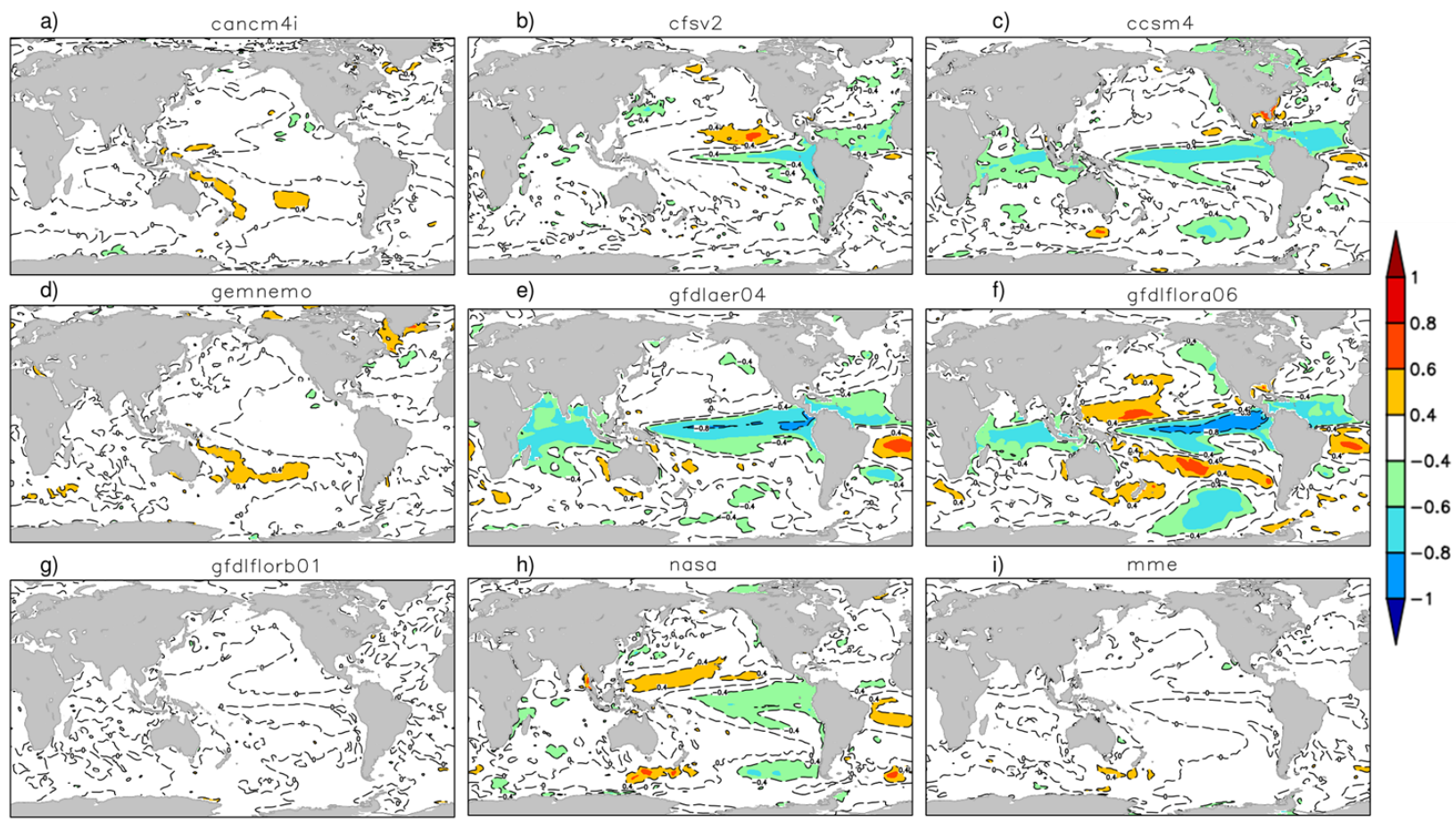

Figura 50 - Correlação temporal entre a anomalias de chuva previstas e anomalias de TSM para o tempo 1 de previsão para o hindcast de MAM para região NE: (a) CanCM4i, (b) CFSv2, (c) CCSM4, (d) GEMNEMO, (e) GFDLAER04, (f) GFDLFLORA06, (g) GFDLFLORB01, (h) NASA, (i) MME. Os valores em branco não apresentam significância estatística.

A figura 51, mostra os padrões de correlação para a região SE, no qual os três principais modelos indicam maiores valores na região do Pacífico Equatorial, mas com sinais invertidos, são CFSv2, GFDLaer04 e GFDLFLORa06. Ao contrário das demais regiões e estações já vistas, o modelo CFSv2 apresenta fortes correlações positivas sobre essa região do Pacífico (entre $+0,6$ e $+0,8)$, indicando que há uma tendência de que em fenômenos El Niño, resultaria na previsão de anomalias positivas de precipitação na SE. Este sinal é oposto aos dos modelos GFDLaer04 e GFDLFLORa06. Resultados similares aos do Pacífico equatorial também são notados no CFSv2 em áreas do Oceano Índico.

Para o Oceano Atlântico, notam-se áreas próximas à costa da região NE com valores altos de correlações estatisticamente significativas e positivas para os resultados dos modelos 
CFSv2, CCSM4 e GFDLaer04. Destaca-se que vários modelos (CanCM4i, GEMNEMO, GFDLFLORb01 e MME) não indicam influência da TSM remota na chuva da região SE, enquanto o modelo da NASA indica influência do setor subtropical Atlântico Sul.
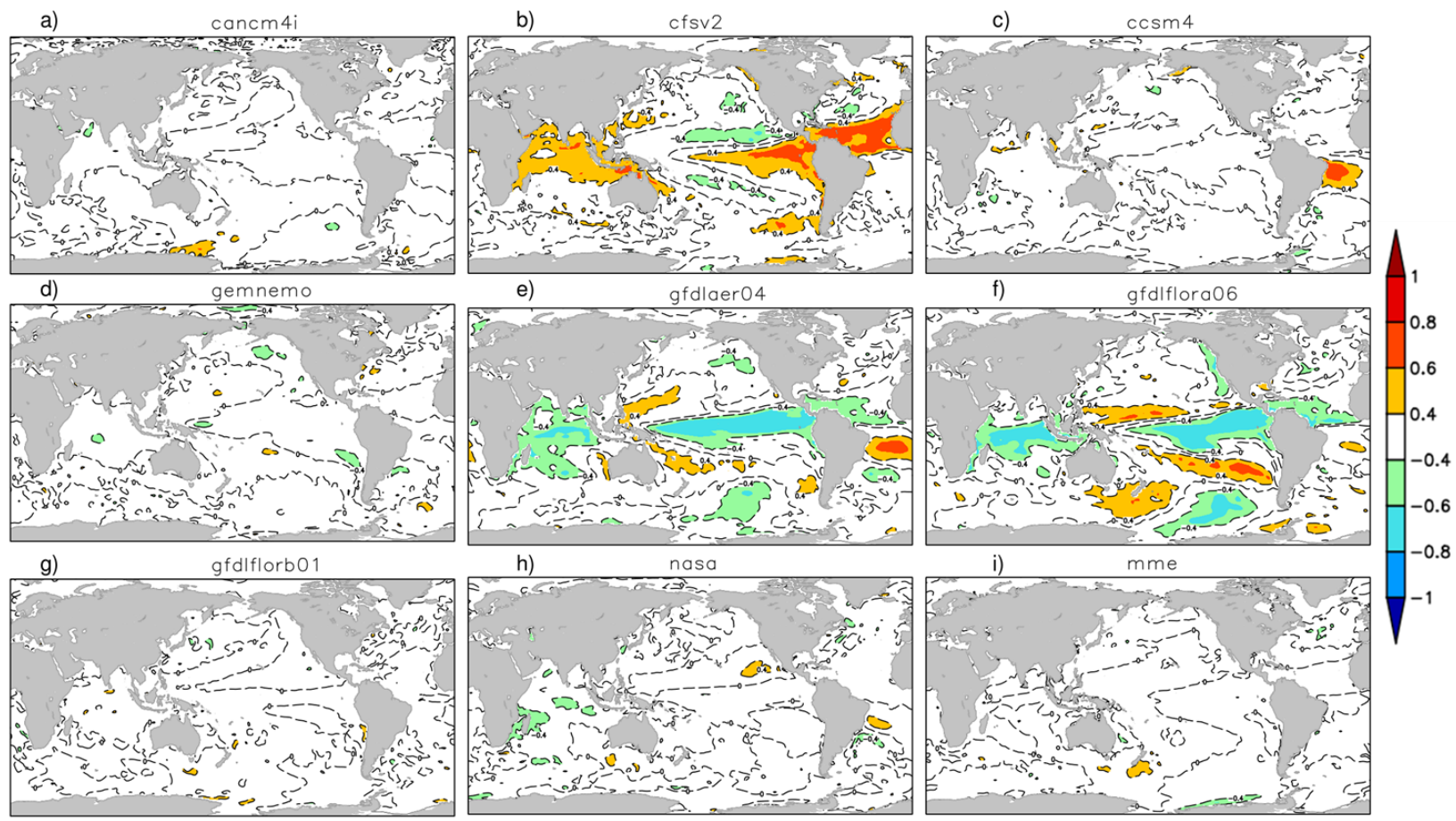

Figura 51 - Correlação temporal entre a anomalias de chuva previstas e anomalias de TSM para o tempo 1 de previsão para o hindcast de MAM para região SE: (a) CanCM4i, (b) CFSv2, (c) CCSM4, (d) GEMNEMO, (e) GFDLAER04, (f) GFDLFLORA06, (g) GFDLFLORB01, (h) NASA, (i) MME. Os valores em branco não apresentam significância estatística.

Para a região SUL (figura 52) uma forte correlação positiva é encontrada nos modelos CFSv2, CCSM4, GFDLaer04, GFDLFLORa06 e NASA para áreas da região do Pacífico Equatorial, sendo os valores maiores, em módulo, em comparação com as demais regiões. Esses maiores valores de correlação são um indicativo de que o fenômeno ENSO possui uma forte influência na previsão de chuva sobre essa região. Além disso, valores positivos de correlação também estão presentes na região do Oceano Índico e Oceano Atlântico tropical norte (principalmente para o modelo CFSv2). 

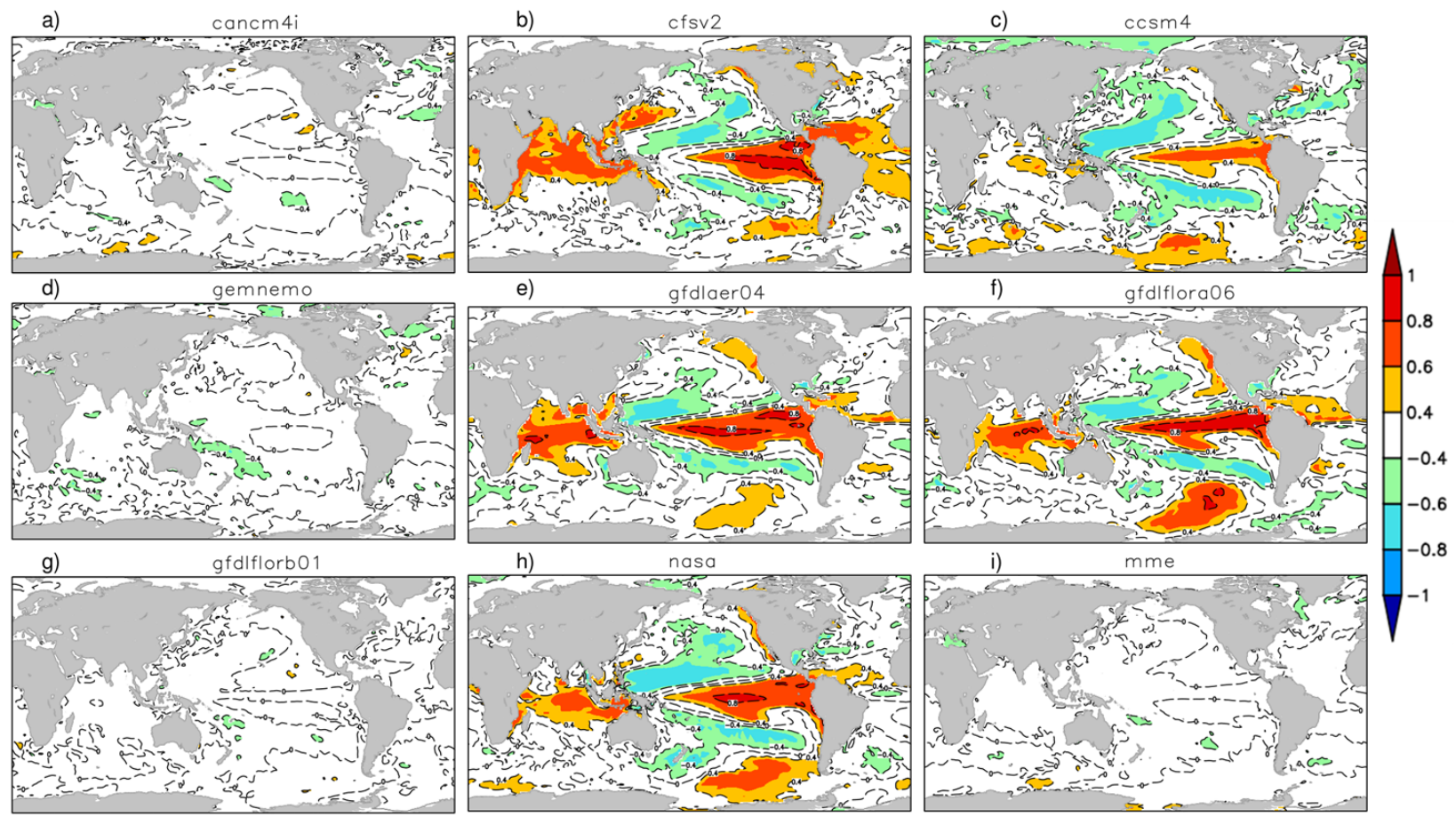

Figura 52 - Correlação temporal entre a anomalias de chuva previstas e anomalias de TSM para o tempo 1 de previsão para o hindcast de MAM para região SUL: (a) CanCM4i, (b) CFSv2, (c) CCSM4, (d) GEMNEMO, (e) GFDLAER04, (f) GFDLFLORA06, (g) GFDLFLORB01, (h) NASA, (i) MME. Os valores em branco não apresentam significância estatística.

Vale destacar que assim como na estação de DJF, a média dos membros (MME) não apresenta correlações estatisticamente significativas nas principais áreas mencionadas do Oceano (Pacífico, Índico e Atlântico) na estação de MAM. Isto mostra que a utilização de modelos separados tende a revelar padrões de TSM e chuva previstos mais correlacionados, e podem ser indicativos para melhores previsões.

Em relação aos padrões observados de correlação, valores estatisticamente significativos ocorrem para as regiões AMZ, NE e SUL (Figura 53). Destaca-se principalmente correlações com a região do Pacífico Equatorial, indicando que, assim como nos modelos, essa região possui uma forte influência nas anomalias de chuva sobre as áreas AMZ, NE e SUL do Brasil. Como para a estação de DJF, as regiões AMZ e SUL seguem com correlações negativas e positivas, respectivamente, e a região NE passa a apresentar correlações negativas. Além disso, sobre a região do Oceano Atlântico Equatorial, também há um padrão de correlação negativo (áreas mais ao norte) e positivo (áreas mais ao sul) simulado pelos modelos para as regiões NE e AMZ (figura 49). A região SE continua a indicar correlação negativa entre as anomalias de 
chuva e a TSM no leste do sudeste do Brasil, que é parcialmente reproduzido pelo modelo GEMNEMO (figura 50). Para a região BC não se nota nenhum padrão de teleconexão definido, como também ocorre nas previsões do CanCM4i, GEMNEMO E GFDLFLORb01 (figura 49).
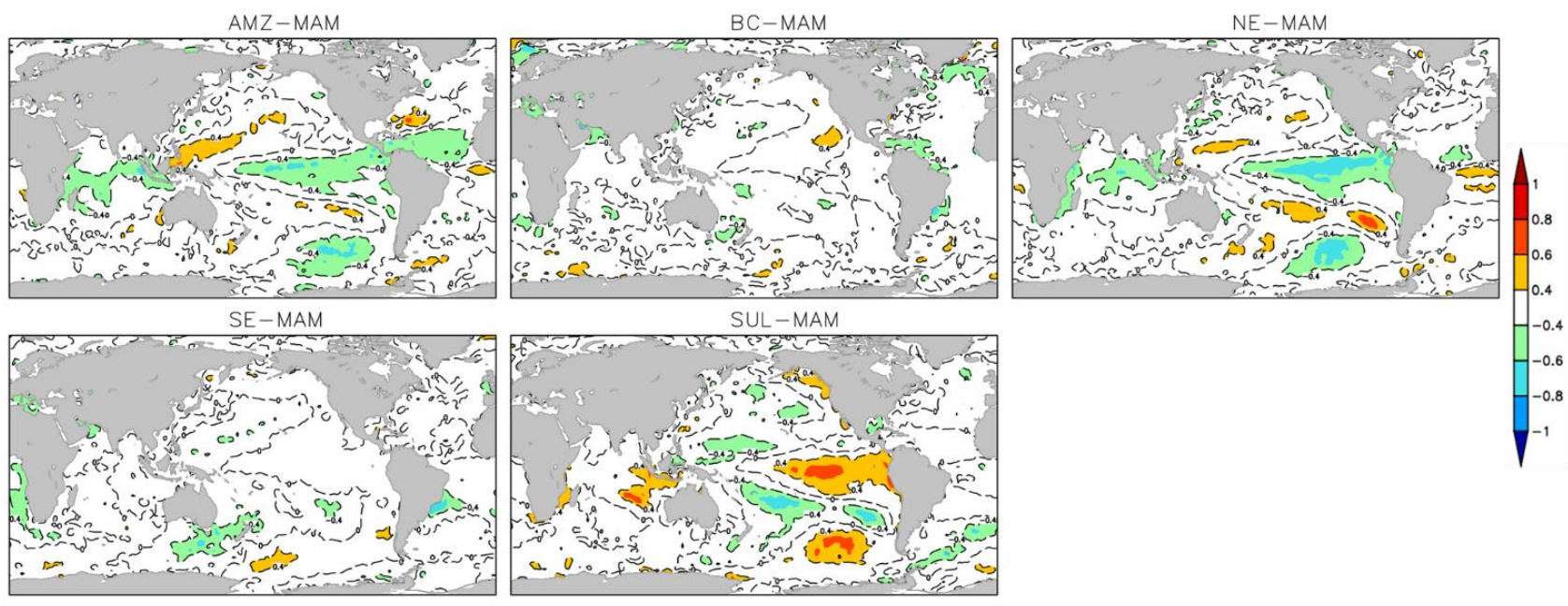

Figura 53 - Padrões de correlação para as anomalias de TSM e chuva observada para as regiões de estudo e para a estação de MAM. Os valores em branco não apresentam significância estatística.

\subsubsection{Junho-Julho-Agosto (Tempo 1)}

Para as correlações de anomalia prevista para o tempo 1 de previsão da estação de inverno sobre o Brasil (JJA), nota-se que, para a região AMZ (figura 54) os modelos CFSv2, CCSM4, GFDLaer04 e NASA apresentam maiores valores negativos na região Pacífico equatorial. Estas correlações indicam que quando há previsões de anomalias positivas de TSM sobre a região do ENSO, há uma tendência destes modelos simularem anomalias negativas de precipitação. Entre estes, os modelos CFSv2, NASA e CCSM4 também indicam forte influência negativa do Atlântico tropical norte chuva e são os que apresentam maiores correlações entre a chuva prevista e observada em JJA, como mostrado na tabela 5. Os demais modelos ou não indicam influência (GFDLFLOR01 e MME) da TSM na chuva ou mostram padrões não tão definidos (CanCM4i, GEMNEMO e GFDLFLORa06) GFDL em termos de atuação de sistemas remotos na chuva de JJA na AMZ. 

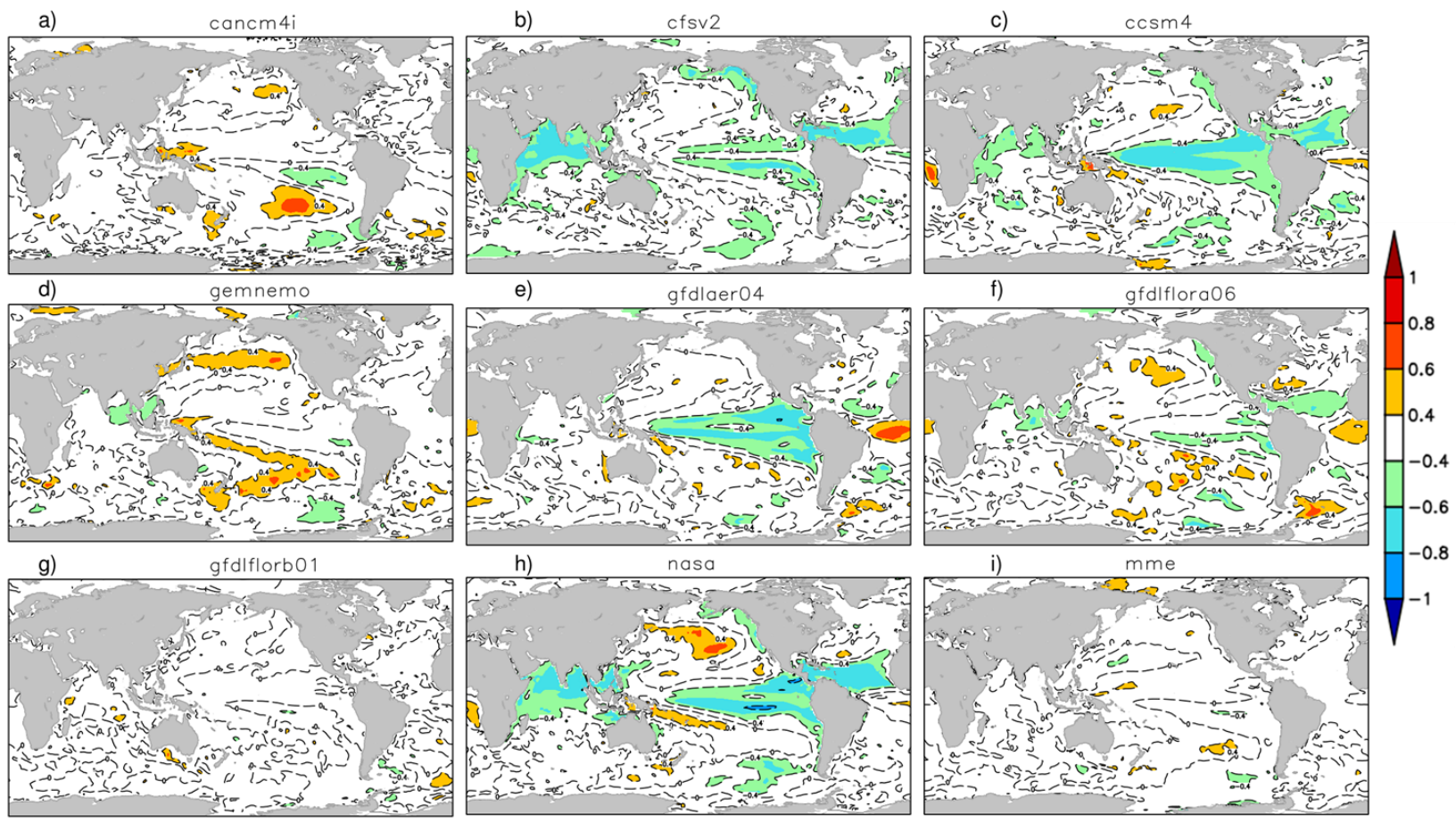

Figura 54 - Correlação temporal entre a anomalias de chuva previstas e anomalias de TSM para o tempo 1 de previsão para o hindcast de JJA para região AMZ: (a) CanCM4i, (b) CFSv2, (c) CCSM4, (d) GEMNEMO, (e) GFDLAER04, (f) GFDLFLORA06, (g) GFDLFLORB01, (h) NASA, (i) MME. Os valores em branco não apresentam significância estatística.

Para a região BC (figura 55), o padrão de correlação é o contrário em comparação a região AMZ (figura 54) para a região do Pacífico equatorial. Nesse caso, há uma correlação positiva principalmente para os modelos CFSv2, CCSM4, GFDLaer04, GFDLFLORa06 e NASA. Dessa forma, esse sinal de correlação indica que em episódios de El Niño (La Niña) há uma tendência de previsão de anomalias positivas (negativas) de chuva. Ainda sobre o Oceano Pacífico, o sinal de anomalias positivas em áreas mais a leste pelo modelo CanCM4i (figura 55a) e mais ao sul no MME (figura 55i) mostram menores valores de correlação e em uma menor área em comparação aos demais modelos. Além disso, praticamente não se observam sinais remotos de correlações nos modelos GEMNEMO e GFDLFLORb01 (Figuras 55 d, g).

Cruzando esses os padrões de correlação entre TSM e chuva com os valores de correlação da chuva prevista e observada para a região BC em JJA (tabela 6), tem-se que as maiores correlações estatisticamente significativas são encontradas para os modelos CFSv2, CCSM4 e GFDLFLORa06. Isso pode ser um indicativo de que a anomalia de TSM possui certo controle dinâmico nestes modelos nos padrões de teleconexão influenciando a chuva observada em JJA 
no BC. No entanto, o mesmo não ocorre no GFDLFLORb01 e CanCM4i que também apresentam correlações altas entre a chuva prevista e observada em JJA (tabela 6).
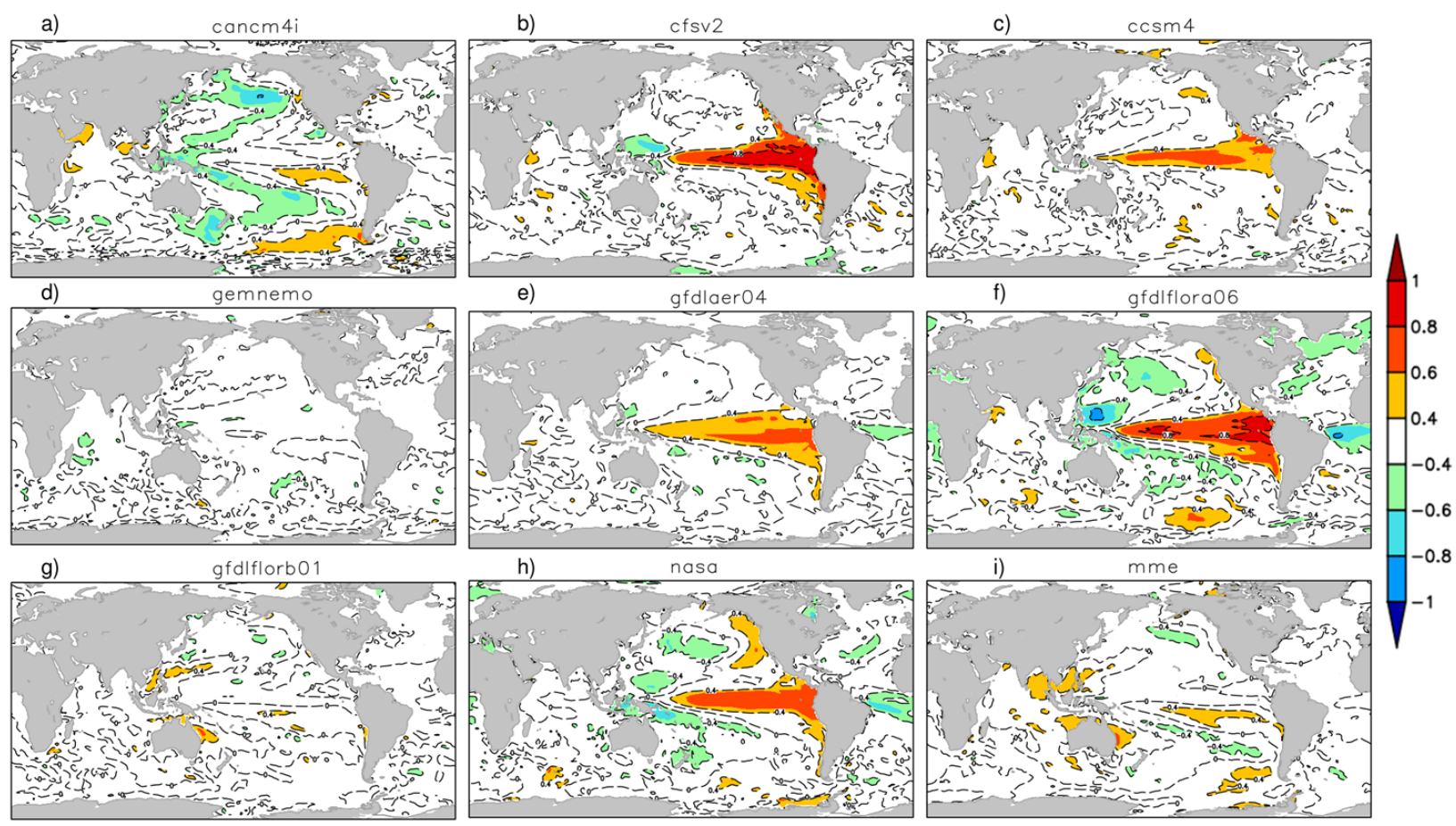

Figura 55 - Correlação temporal entre a anomalias de chuva previstas e anomalias de TSM para o tempo 1 de previsão para o hindcast de JJA para região BC: (a) CanCM4i, (b) CFSv2, (c) CCSM4, (d) GEMNEMO, (e) GFDLAER04, (f) GFDLFLORA06, (g) GFDLFLORB01, (h) NASA, (i) MME. Os valores em branco não apresentam significância estatística.

Em relação à região NE (figura 56), os modelos CFSv2, CCSM4, GFDLaer04, GFDLFLORa06 e NASA continuam mostrando maiores valores de correlação, em módulo, sobre áreas equatoriais do Pacífico. O sinal negativo das correlações indica uma relação oposta entre as previsões de TSM e precipitação, ou seja, anomalias negativas de TSM estariam associadas com anomalias positivas de chuva e vice-versa. Para essa região, há ainda correlações estatisticamente significativas no Oceano Atlântico tropical, principalmente para os modelos GFDLaer04, GDLFLORa06 e NASA, e com uma convergência entre esses modelos fornecendo valores negativos de correlação em áreas do Atlântico tropical ao norte. Já para áreas mais ao sul do Oceano Atlântico e próximo a região equatorial, os valores de correlação tendem a ser positivos, principalmente para os modelos GFDLFLORa06 e GFDLaer04. 
Sobre o Oceano Índico, não há correlações estatisticamente significativas para a maioria dos modelos, exceto para os modelos CFSv2 e NASA, que mostram correlações negativas em áreas mais ao norte e próximo à costa da África e Ásia.

Nos modelos GFDLFLORb01 e GEMNEMO não se nota um padrão de influência claro entre as anomalias de chuva em JJA no NE e as anomalias de TSM ao redor do globo (figura 56).

Em JJA as correlações entre anomalias de chuva observadas e previstas são relativamente altas e estatisticamente significativas (tabela 7). Isso ocorre tanto nos modelos com padrão de teleconexão bem definido, como por exemplo o CCSM4, como para aqueles com onde isto não ocorre, como no CanCM4i.
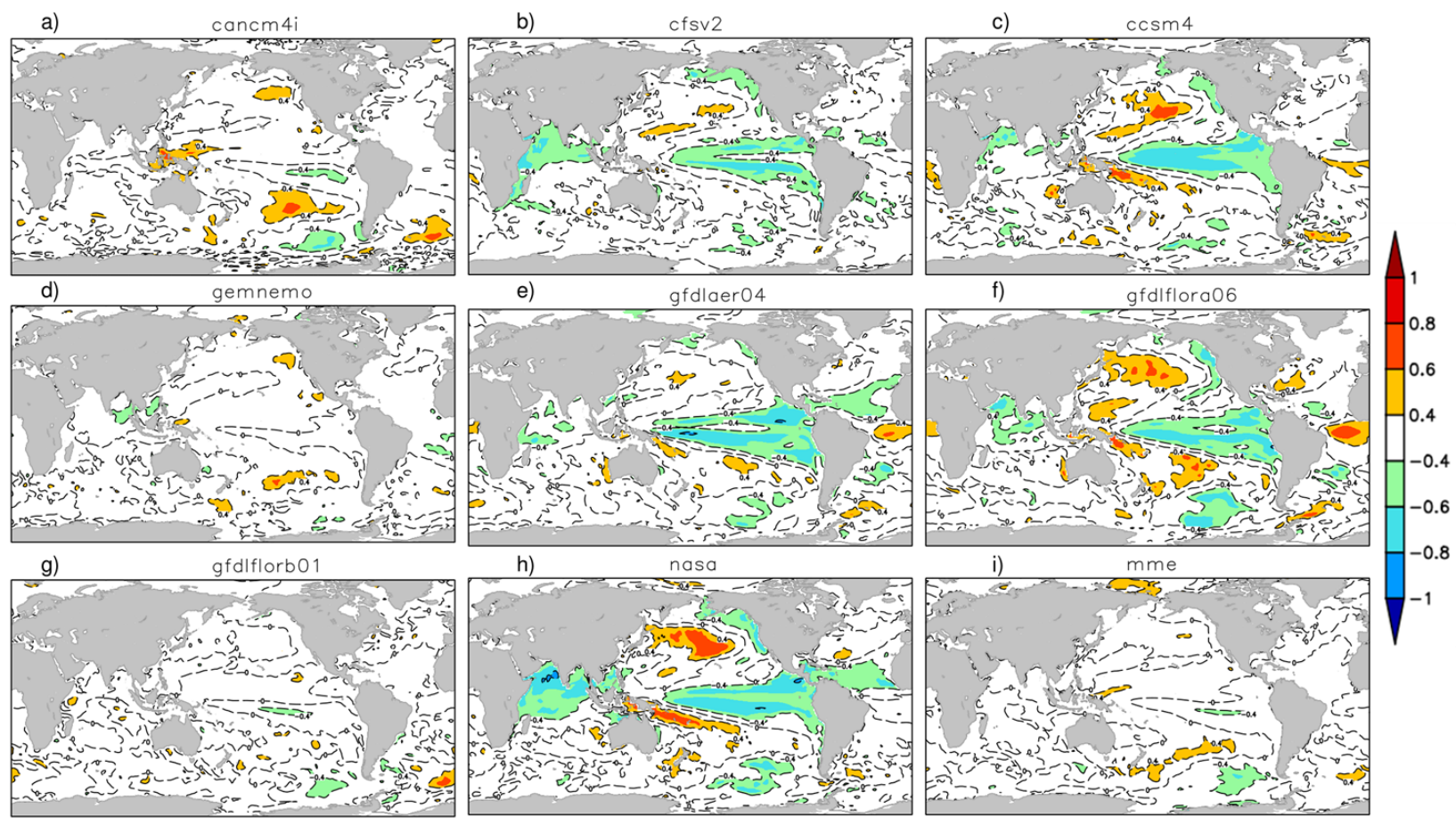

Figura 56 - Correlação temporal entre a anomalias de chuva previstas e anomalias de TSM para o tempo 1 de previsão para o hindcast de JJA para região NE: (a) CanCM4i, (b) CFSv2, (c) CCSM4, (d) GEMNEMO, (e) GFDLAER04, (f) GFDLFLORA06, (g) GFDLFLORB01, (h) NASA, (i) MME. Os valores em branco não apresentam significância estatística..

Para a região SE (figura 57) destacam-se os modelos CFSv2, GFDLFLORb01 e NASA que mostram correlações positivas entre anomalias de chuva e a TSM em áreas do Pacífico 
Equatorial. Nos demais modelos, não há significância estatística para as correlações de chuva e TSM sobre essas áreas. Vale ressaltar que para o modelo CFSv2, onde as correlações são maiores (entre $+0,8$ e $+0,9$ ) também há uma correlação significativa entre a chuva prevista e observada dentro em JJA, conforme é indicado na tabela 8.
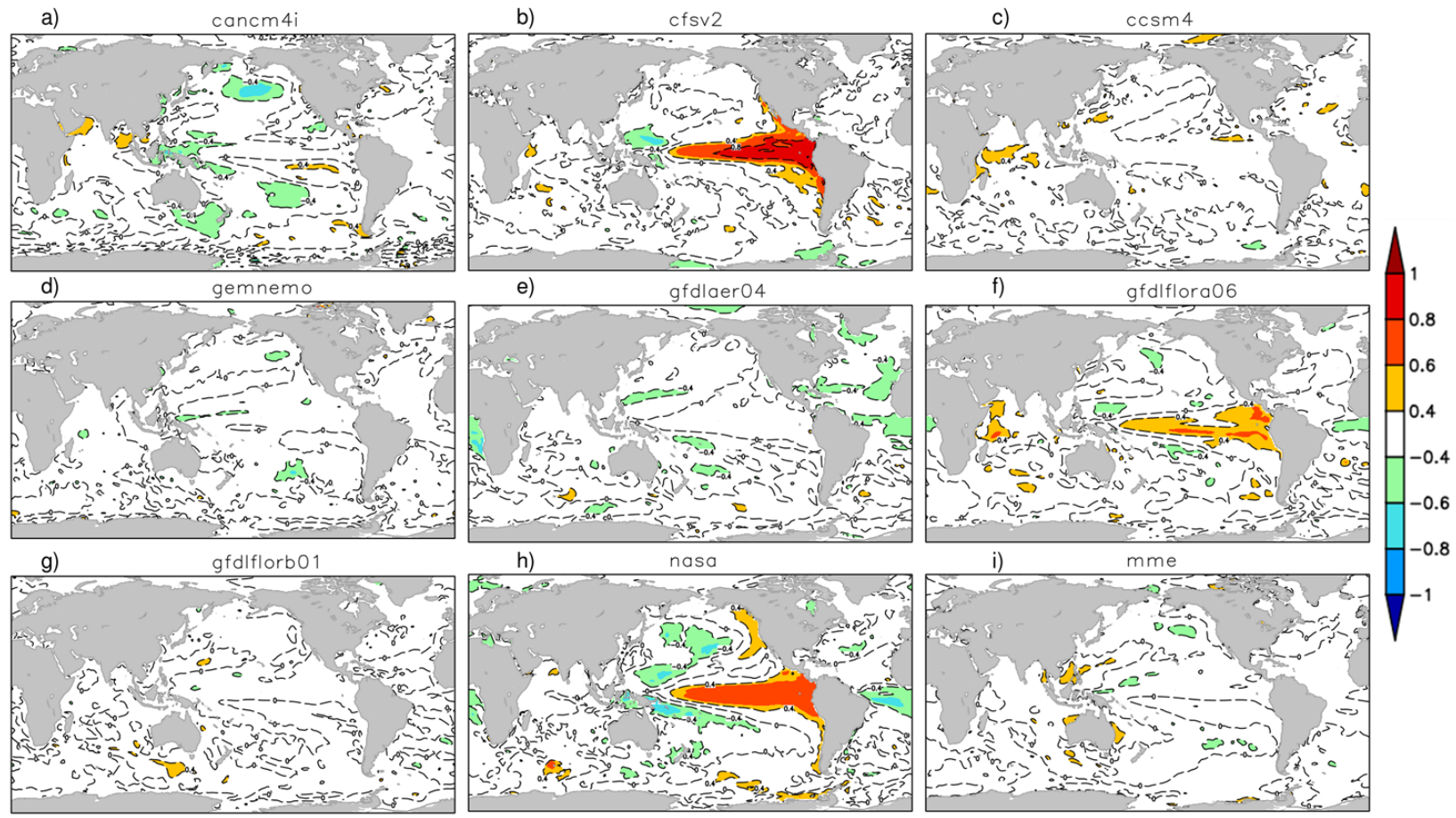

Figura 57 - Correlação temporal entre a anomalias de chuva previstas e anomalias de TSM para o tempo 1 de previsão para o hindcast de JJA para região SE: (a) CanCM4i, (b) CFSv2, (c) CCSM4, (d) GEMNEMO, (e) GFDLAER04, (f) GFDLFLORA06, (g) GFDLFLORB01, (h) NASA, (i) MME. Os valores em branco não apresentam significância estatística.

Na região SUL (figura 58), correlações positivas e significativas sobre áreas da região do Pacífico Equatorial e a chuva são fornecidas pelos modelos CFSv2, CCSM4, GFDLaer04, GFDLFLORa06, NASA. Os maiores valores de correlação são encontrados nos modelos CFSv2 (principalmente mais a leste) e NASA (em áreas mais centrais). Para os modelos CanCM4i e MME, também há indicação de menores valores de correlação positiva e estatisticamente significativa, mas em áreas mais ao sul da região Equatorial do Oceano Pacífico. 

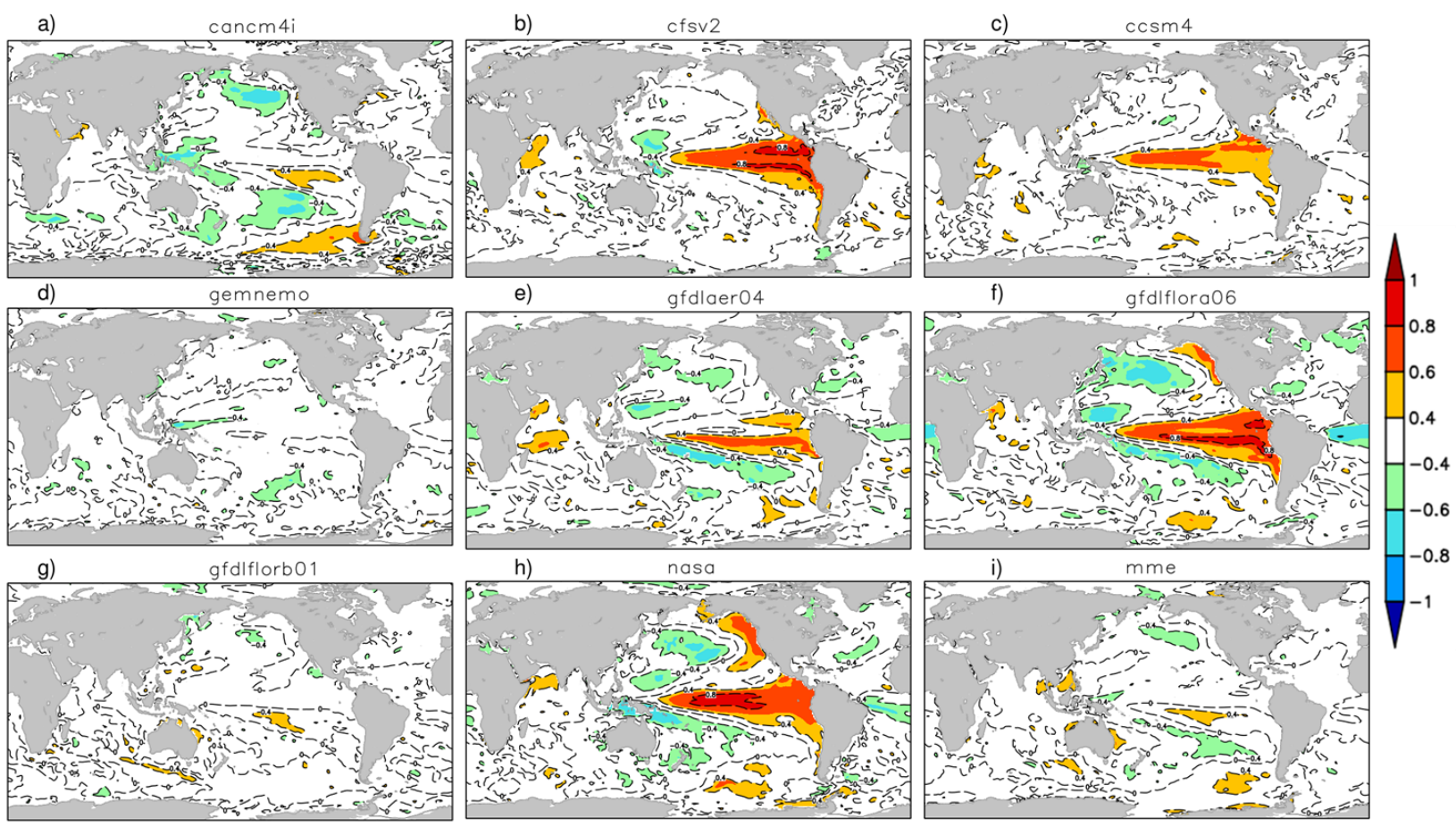

Figura 58 - Correlação temporal entre a anomalias de chuva previstas e anomalias de TSM para o tempo 1 de previsão para o hindcast de JJA para região SUL: (a) CanCM4i, (b) CFSv2, (c) CCSM4, (d) GEMNEMO, (e) GFDLAER04, (f) GFDLFLORA06, (g) GFDLFLORB01, (h) NASA, (i) MME. Os valores em branco não apresentam significância estatística.

De uma forma geral, nessa região e estação do ano, tem-se o destaque para áreas da região Equatorial do Pacífico, onde os modelos CFSv2, CCSM4, GFDLaer04, GFDLFLORa06 e NASA apresentam maiores correlações significativas entre as anomalias de chuva e TSM previstas dentre as regiões estudadas.

O padrão de correlação observado (figura 59) continua indicando valores negativos para as regiões AMZ e NE, e positivos para a região SUL com a região do Pacífico Equatorial, mas principalmente em áreas mais a leste (atingindo áreas do Nino 1+2). Comparando com as correlações das anomalias previstas (figuras 54 a 58), nota-se um padrão semelhante para os modelos com significância estatística sobre a região Equatorial do Pacífico, porém nas previsões se estendem por uma maior área nas previsões. Em relação às regiões BC e SE não se notam padrões estatisticamente significativos de correlação sobre a região Equatorial do Pacífico. Para a região SE isto está de acordo com a maioria das previsões (figura 57), enquanto 
para a região SUL a maioria das previsões indicam forte relação com a região do El Niño (figura 58).
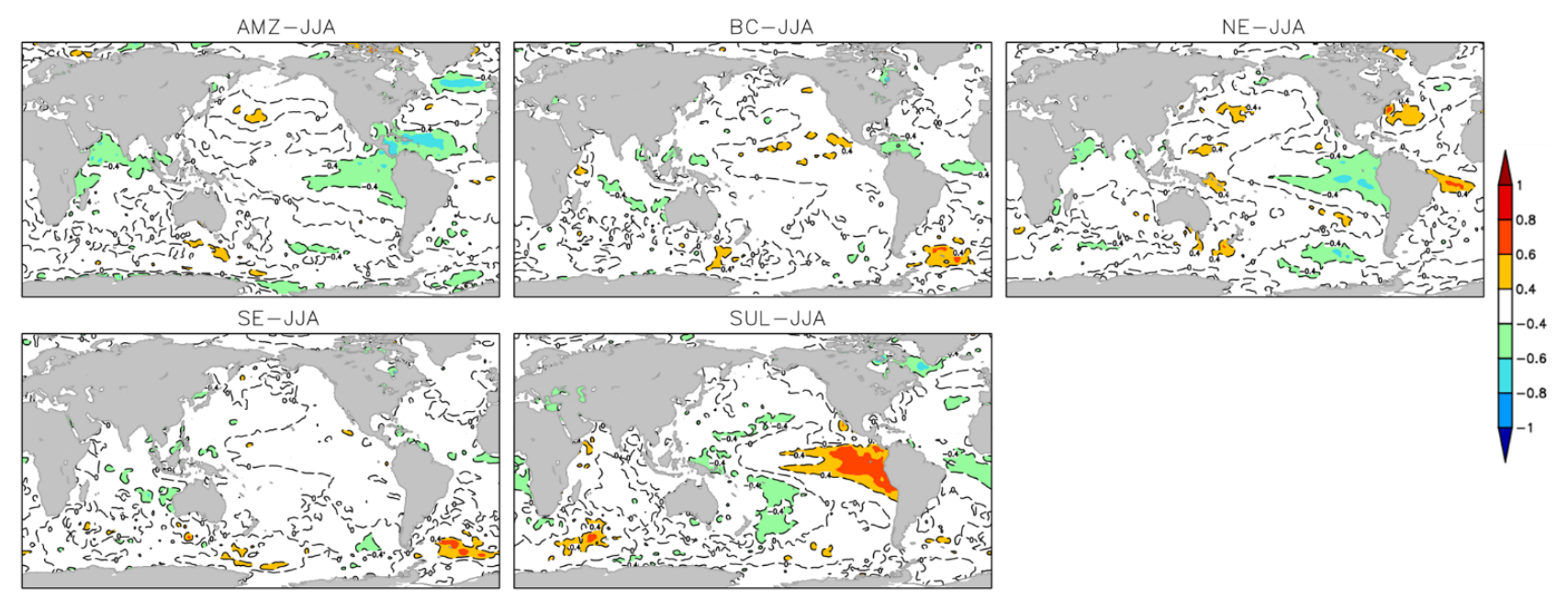

Figura 59 - Padrões de correlação para as anomalias de TSM e chuva observada para as regiões de estudo e para a estação de MAM. Os valores em branco não apresentam significância estatística.

\subsubsection{Setembro-Outubro-Novembro (tempo 1)}

Em relação a estação de SON, a região AMZ (figura 60) mostra uma grande área de correlação com significância estatística sobre a região do Pacífico Equatorial, sendo os modelos CCSM4, GFDLaer04 e GFDLFLORa06, os que apresentam os maiores valores, em módulo, de correlações negativas. Um sinal semelhante é simulado, principalmente nos membros do modelo GFDL (aer04 e FLORa06), onde há correlações positivas em áreas mais ao sul do Pacífico Equatorial, seguido de correlações negativas em latitudes mais altas, o que pode ser o indicativo de padrões de ondas atmosféricas correlacionadas com as chuvas previstas sobre a região AMZ.

Em áreas do Oceano Atlântico, há novamente uma forte correlação pelos membros do modelo GFDL (aer04 e FLORb01), com valores positivos em áreas equatoriais e ao norte e negativos em áreas mais a sul e próximo à costa da região Sudeste do Brasil. 

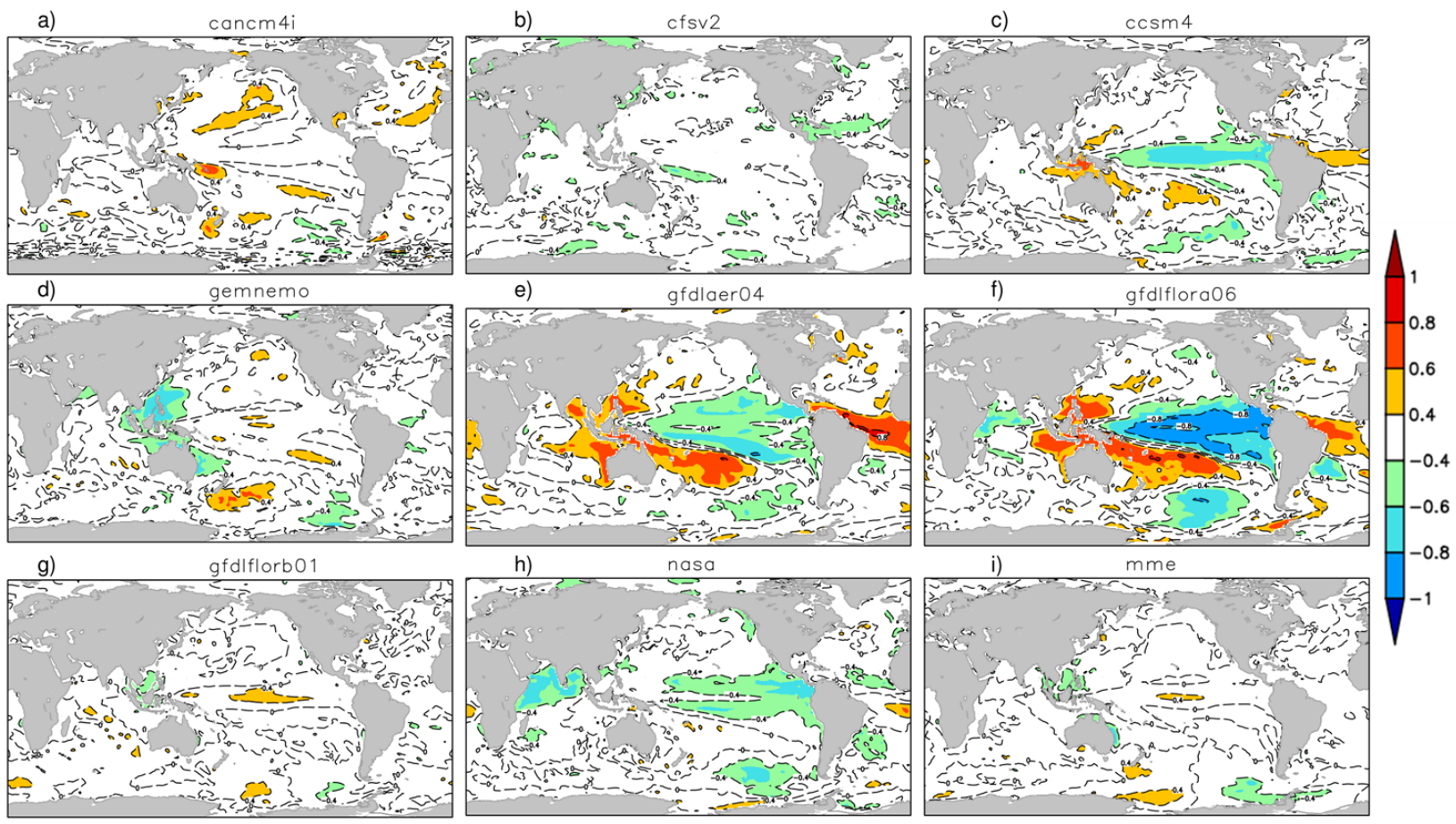

Figura 60 - Correlação temporal entre a anomalias de chuva previstas e anomalias de TSM para o tempo 1 de previsão para o hindcast de SON para região AMZ: (a) CanCM4i, (b) CFSv2, (c) CCSM4, (d) GEMNEMO, (e) GFDLAER04, (f) GFDLFLORA06, (g) GFDLFLORB01, (h) NASA, (i) MME. Os valores em branco não apresentam significância estatística.

Para a região BC (figura 61), três modelos apresentam uma maior correlação com a região do Pacífico Equatorial: CFSv2, com correlações positivas (principalmente sobre áreas mais a leste) e GFDLaer04 e GFDLFLORa06, com correlações negativas. Para esses membros do GFDL, o padrão é similar ao visto na região $A M Z$, de correlações negativas em áreas equatoriais, positivas mais ao sul e novamente negativas em latitudes mais altas.

Outro modelo que também apresenta correlações maiores e significativas é o CCSM4 (figura 61c), mas em áreas mais ao sul do Pacífico Equatorial e com valores positivos. Além disso, também há correlações positivas e significativas sobre o Oceano Atlântico (principalmente na porção norte) para esse modelo. 

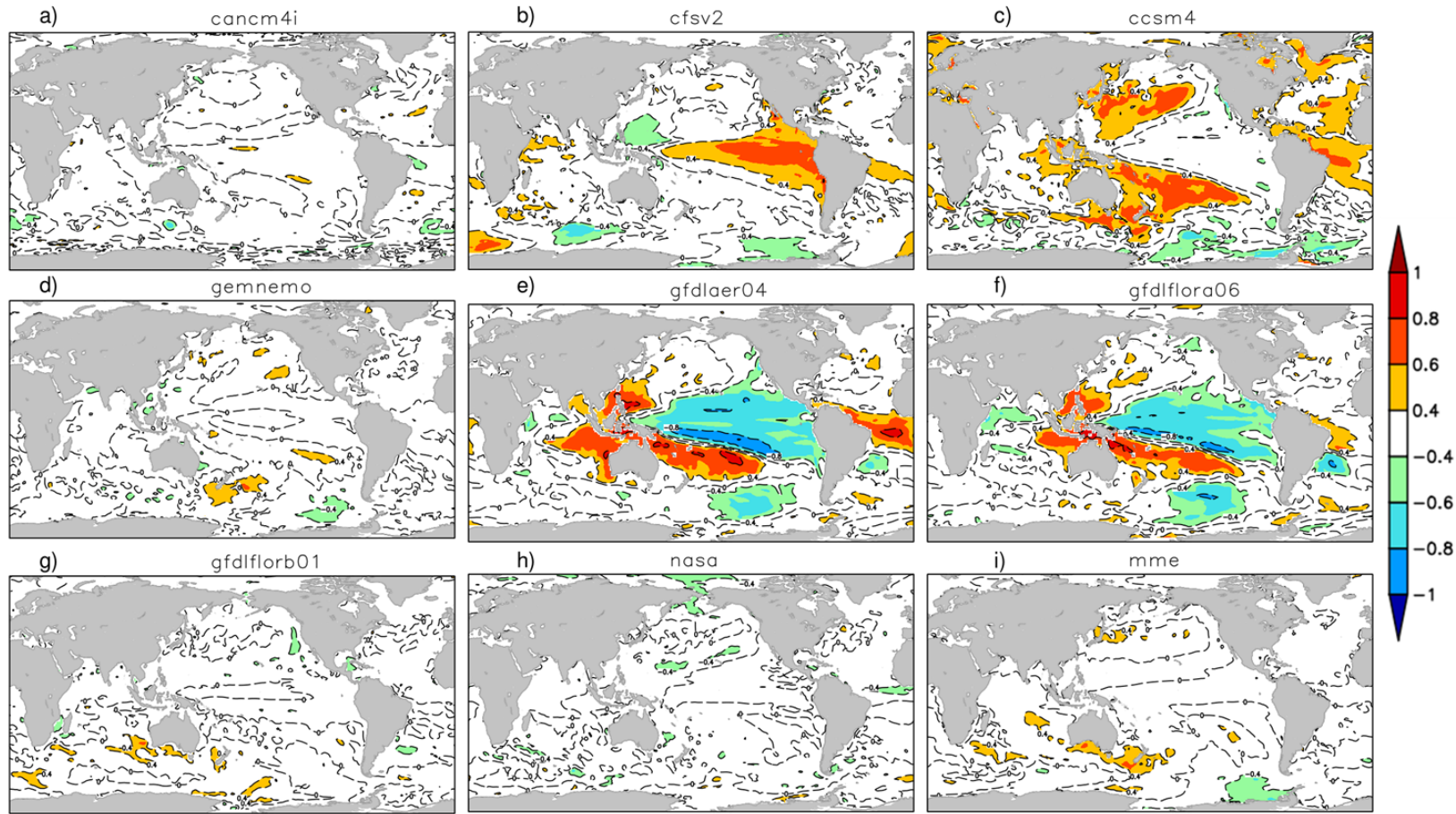

Figura 61 - Correlação temporal entre a anomalias de chuva previstas e anomalias de TSM para o tempo 1 de previsão para o hindcast de SON para região BC: (a) CanCM4i, (b) CFSv2, (c) CCSM4, (d) GEMNEMO, (e) GFDLAER04, (f) GFDLFLORA06, (g) GFDLFLORB01, (h) NASA, (i) MME. Os valores em branco não apresentam significância estatística.

Com relação a região NE (figura 62), correlações positivas e significativas são mostradas pelo modelo CanCM4i e negativos para os modelos CCSM4, GFDLaer04 e GFDLFLORa06 na região do Pacífico Equatorial.

Vale destacar que no modelo CCSM4 (figura 62c), as correlações negativas significativas estão presentes principalmente em áreas mais a leste da região Equatorial do Pacífico, e, assim como na região $\mathrm{BC}$, com valores positivos em áreas mais ao sul dessa região. Além disso, também continuam mostrando valores positivos de correlação em áreas centrais e ao norte do Oceano Atlântico. 

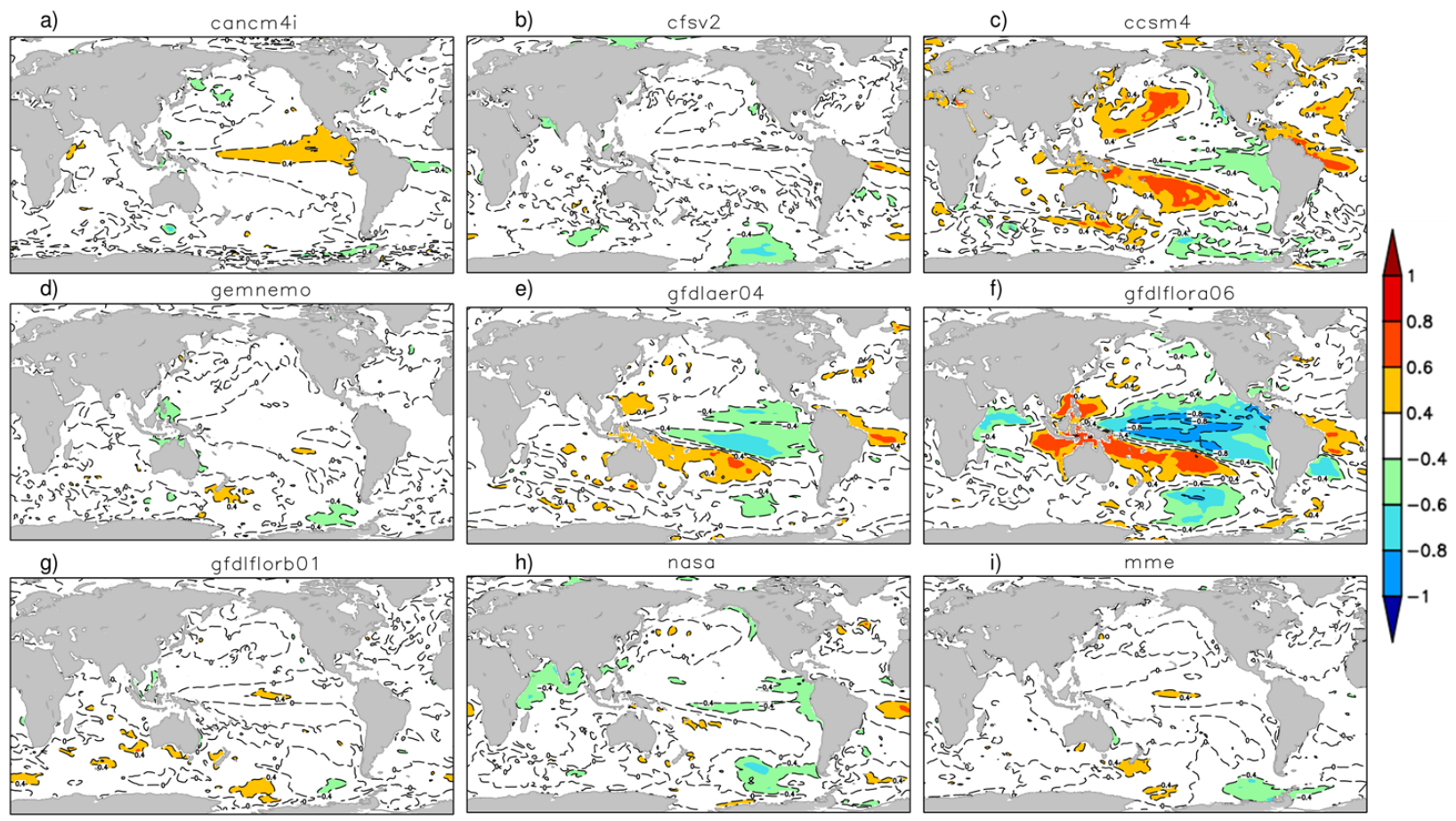

Figura 62 - Correlação temporal entre a anomalias de chuva previstas e anomalias de TSM para o tempo 1 de previsão para o hindcast de SON para região NE: (a) CanCM4i, (b) CFSv2, (c) CCSM4, (d) GEMNEMO, (e) GFDLAER04, (f) GFDLFLORA06, (g) GFDLFLORB01, (h) NASA, (i) MME. Os valores em branco não apresentam significância estatística.

Para a região SE (figura 63), correlações significativas positivas ocorrem na região do Pacífico Equatorial no modelo CFSv2 (principalmente entre áreas centrais e a leste), enquanto nos modelos GFDLaer04 e GFDLFLORa06 as correlações são negativas e alongadas leste-oeste. Nesses modelos, também há correlações positivas significativas em áreas mais ao sul do Oceano Pacífico e sobre o norte do Oceano Índico. Para o modelo CCSM4, também há correlações negativas significativas, porém, com valores menores (entre - $-0,4$ e -0,6) e com um padrão similar ao de correlações positivas presentes nos modelos GFDLaer04 e GFDLFLORa06.

Em áreas do Oceano Atlântico, as correlações continuam significativas nos modelos GFDLaer04 e GFDLFLOR06, sendo os valores positivos em áreas centrais e próximo à costa da região NE e negativos próximo à costa da região SE. Para o modelo CCSM4, também há correlações positivas, porém na porção norte do Oceano Atlântico Sul. 
Para os demais modelos, a região SE apresenta correlações significativas com a TSM em algumas áreas do globo, porém, sem apresentar os valores altos e com padrões menos definidos do que nos modelos CFSv2, GDLaer04, GDLFLORa06 e CCSM4.
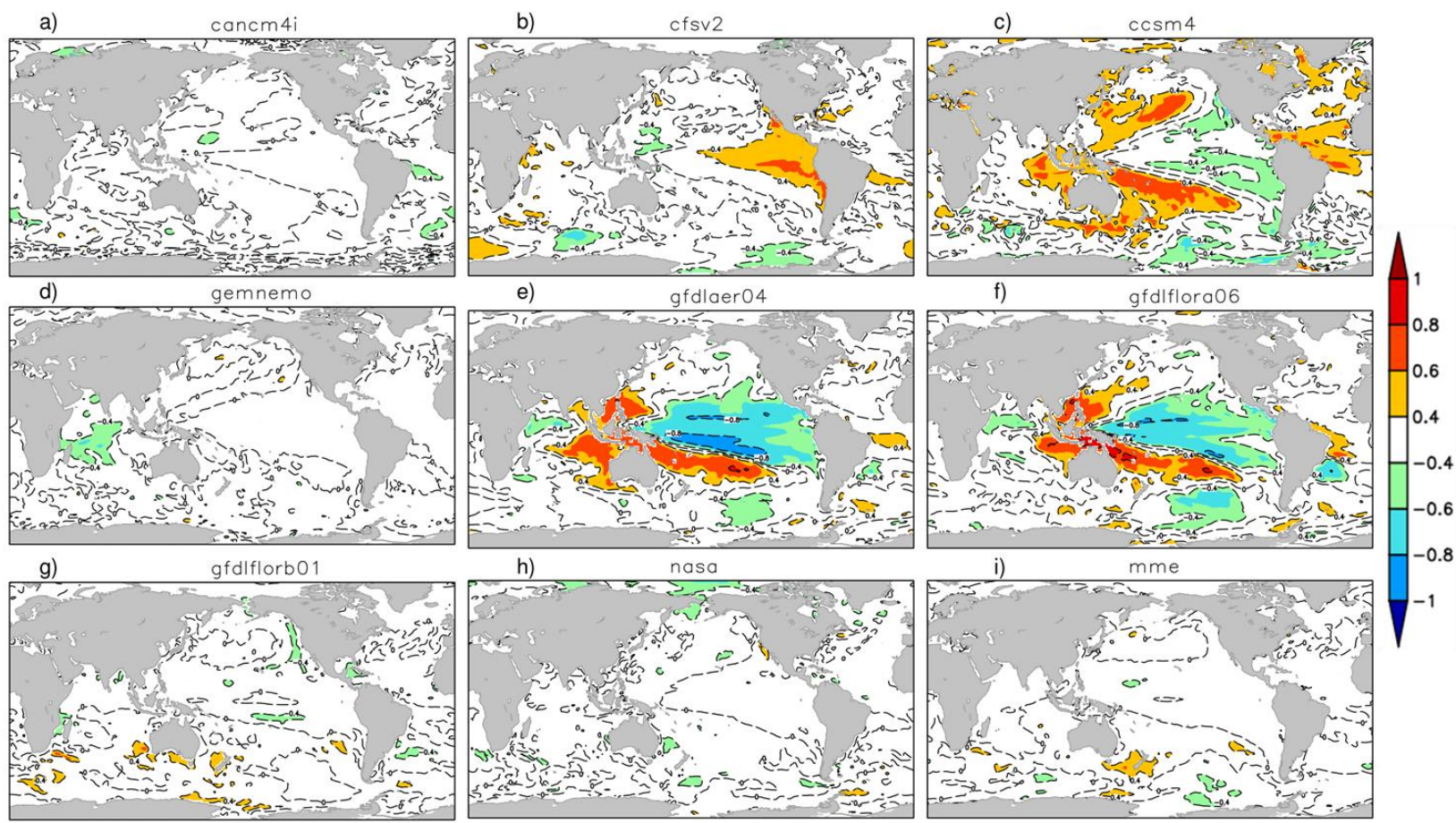

Figura 63 - Correlação temporal entre a anomalias de chuva previstas e anomalias de TSM para o tempo 1 de previsão para o hindcast de SON para região SE: (a) CanCM4i, (b) CFSv2, (c) CCSM4, (d) GEMNEMO, (e) GFDLAER04, (f) GFDLFLORA06, (g) GFDLFLORB01, (h) NASA, (i) MME. Os valores em branco não apresentam significância estatística.

Na região SUL (figura 64), nota-se uma maior convergência entre os modelos CFSv2, CCSM4, GFDLFLORa06 e NASA que indicam fortes correlações positivas (acima de $+0,6)$ com áreas do Pacífico Equatorial. Portanto, para esses modelos as previsões de anomalias positivas (negativas) de TSM tendem a ocasionar previsões de volumes de precipitação acima (abaixo) da climatologia. O sinal desses modelos é similar ao que é observado durante episódios típicos de El Niño e La Niña, o que leva a uma maior confiabilidade em suas previsões. Em outros modelos (CanCM4i, NASA, GFDLaer04, GFDLFLORb01 e MME) os padrões de correlação são bastante indefinidos como mostrado na figura 64. 

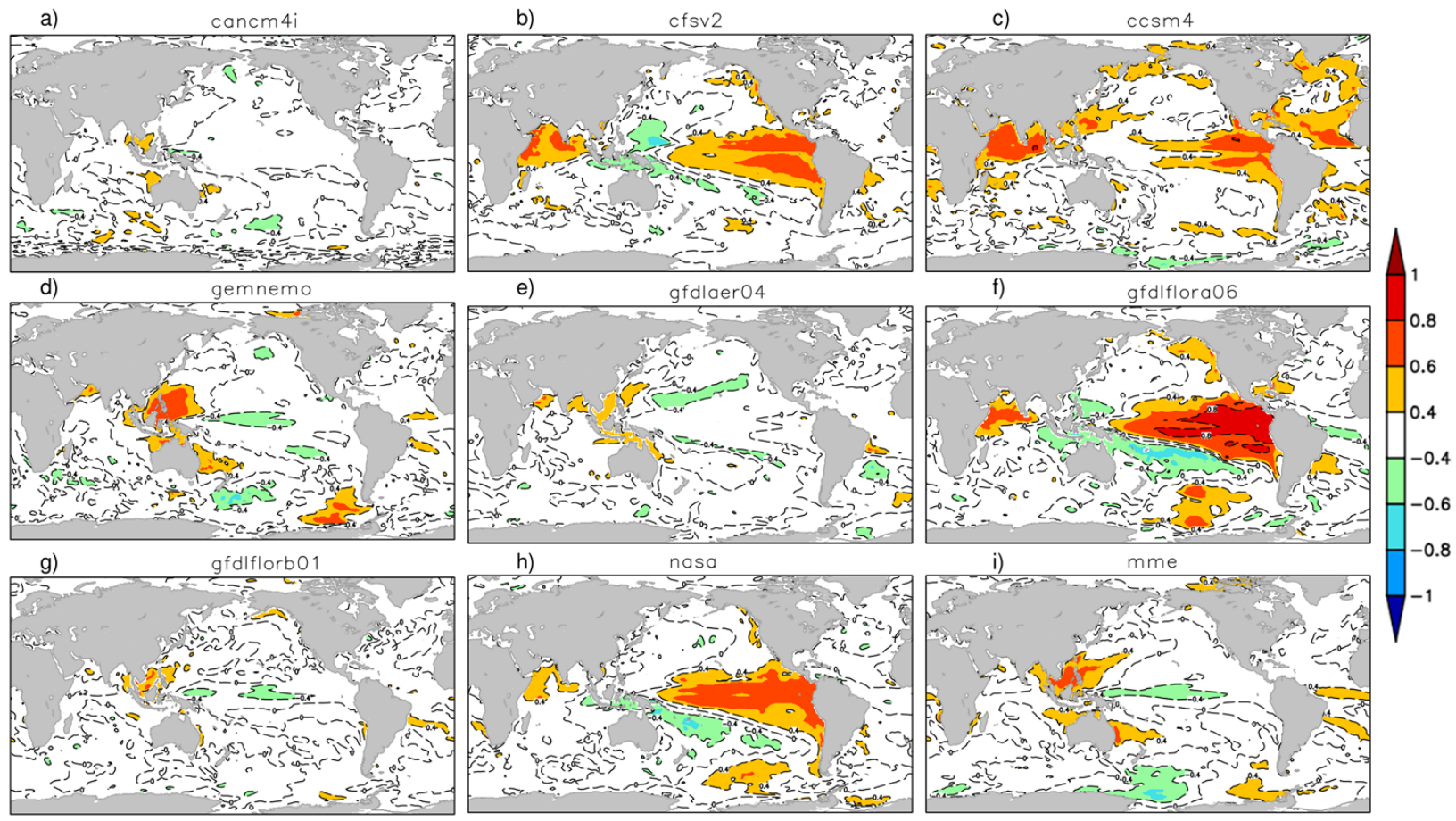

Figura 64 - Correlação temporal entre a anomalias de chuva previstas e anomalias de TSM para o tempo 1 de previsão para o hindcast de SON para região SUL: (a) CanCM4i, (b) CFSv2, (c) CCSM4, (d) GEMNEMO, (e) GFDLAER04, (f) GFDLFLORA06, (g) GFDLFLORB01, (h) NASA, (i) MME. Os valores em branco não apresentam significância estatística.

Para os padrões de anomalias observadas em SON (figura 65) um maior destaque é notado principalmente para a região SUL, que apresenta valores positivos e significativos de correlação com a região Equatorial do Pacífico (principalmente a leste). Além disso, como observado para a estação de DJF (figura 46) notam-se correlações positivas sobre áreas do Oceano Atlântico, próximas à costa do PR e SP.

Para as demais regiões (AMZ, NE, BC e SE), não se observa correlações significativas sobre áreas equatoriais do Pacífico que destaquem uma forte influência de episódios de ENSO nos regimes de chuva. Coelho et al. (2002) estudou a influência do ENSO sobre áreas do Brasil, e notou que nas regiões BC e SE há a presença de regiões de transições que possuem uma baixa previsibilidade de precipitação. De acordo com as figuras 61 e 63 os modelos indicam padrões semelhantes para as regiões BC e SE durante SON e 5 dos 9 membros concordam com as observações (figura 65) ao não identificar nenhum padrão de teleconexão definido entre anomalias de chuva e TSM. 

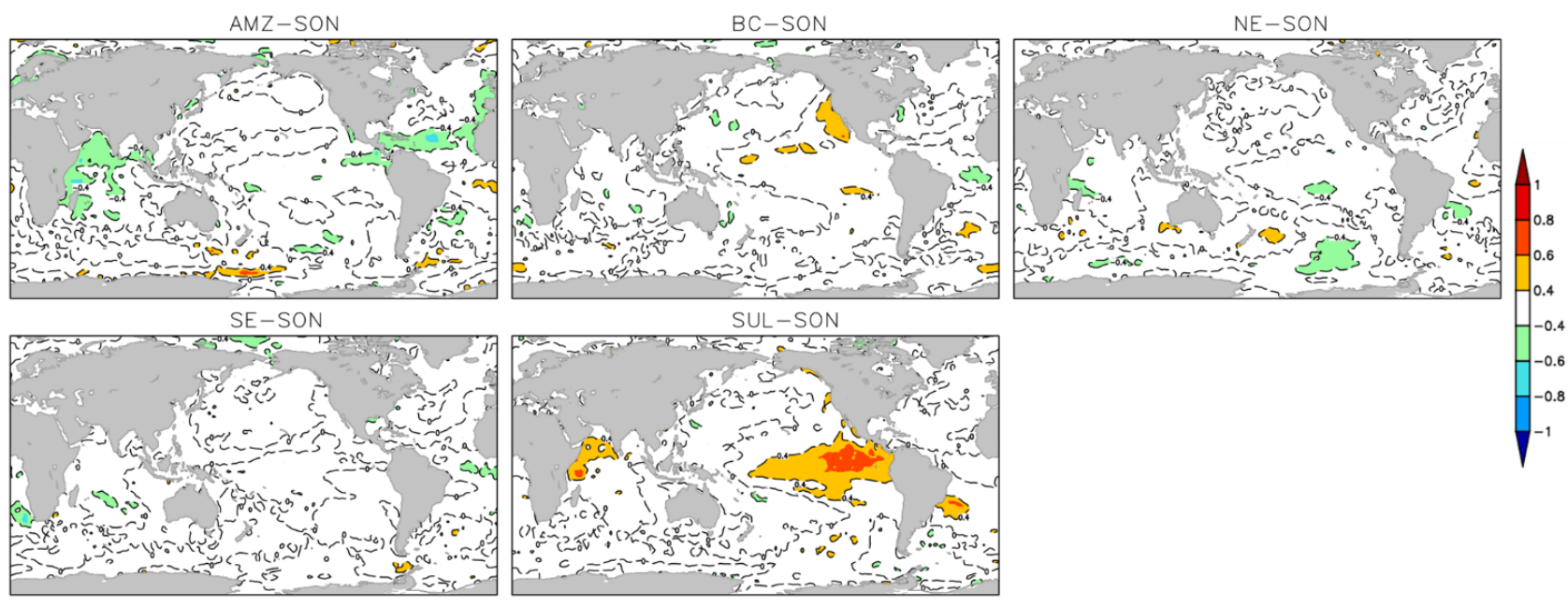

Figura 65 - Padrões de correlação para as anomalias de TSM e chuva observada para as regiões de estudo e para a estação de MAM. Os valores em branco não apresentam significância estatística.

De uma forma geral, as correlações de anomalias de TSM e precipitação previstas pelos modelos tendem a mostrar padrões estatisticamente significativos principalmente com áreas da região do Pacífico Equatorial (Lat: 5N - 5S; Lon: 160W - 80W) ao longo de todas as regiões e estações estudadas, mostrando que essa região interfere nas previsões de chuva desses modelos.

A tabela 10 mostra os modelos que possuem as maiores correlações estatisticamente significativas entre a anomalia de TSM na região do Pacífico Equatorial e precipitação previstas em cada uma das regiões. Nota-se, que os modelos CFSv2 (b), CCSM4 (c), GFDLaer04 (e), GFDLFLORb01 (g) e NASA (h) na maioria das estações e regiões apresentam valores negativos de correlação. Os modelos CanCM4i (a), GEMNEMO (d), GFDLFLORa06 (f) e MME (i), por outro lado, aparecem pontualmente em algumas estações do ano. Vale ressaltar que a média dos modelos (MME) não apresenta correlações estatisticamente significativas, sendo os maiores valores, em módulo, nas regiões BC e SUL e principalmente para as estações DJF e SON. 
Tabela 10 - Média na área da região Equatorial do Pacífico das correlações entre as anomalias de TSM e precipitação previstas para as estações do ano e regiões de estudo. (a) CanCM4i, (b) CFSv2, (c) CCSM4, (d) GEMNEMO, (e) GFDLaer04, (f) GFDLFLORa06, (g) GFDLFLORb01, (h) NASA, (i) MME e observação. Em vermelho temos as correlações positivas e em azul as negativas. Em branco temos as correlações sem significância estatística.

\begin{tabular}{|c|c|c|c|c|c|c|c|c|c|c|}
\hline & \multicolumn{9}{|c|}{ Modelos } & \multirow[b]{2}{*}{ obs } \\
\hline & $\mathbf{a}$ & $\mathbf{b}$ & c & d & e & f & g & h & i & \\
\hline \multicolumn{11}{|l|}{ AMZ } \\
\hline DJF & 0,15 & $-0,85$ & $-0,83$ & 0,21 & $-0,70$ & $-0,79$ & 0,35 & $-0,73$ & 0,26 & $-0,67$ \\
\hline MAM & $-0,05$ & $-0,67$ & $-0,76$ & $-0,20$ & $-0,54$ & $-0,67$ & 0,17 & $-0,68$ & 0,02 & $-0,50$ \\
\hline JJA & 0,09 & $-0,38$ & $-0,61$ & $-0,02$ & $-0,55$ & $-0,26$ & 0,08 & $-0,57$ & 0,08 & $-0,41$ \\
\hline SON & 0,15 & $-0,15$ & $-0,62$ & 0,22 & $-0,43$ & $-0,84$ & 0,32 & $-0,50$ & 0,23 & $-0,33$ \\
\hline \multicolumn{11}{|l|}{ BC } \\
\hline DJF & 0,22 & $-0,78$ & $-0,10$ & $-0,01$ & $-0,43$ & $-0,75$ & 0,50 & $-0,34$ & 0,38 & 0,18 \\
\hline MAM & 0,01 & 0,00 & $-0,39$ & $-0,22$ & $-0,68$ & $-0,73$ & 0,15 & $-0,41$ & 0,10 & $-0,01$ \\
\hline JJA & $-0,06$ & 0,83 & 0,60 & $-0,22$ & 0,58 & 0,78 & $-0,05$ & 0,70 & $-0,10$ & 0,31 \\
\hline $\mathrm{SON}$ & 0,30 & 0,64 & $-0,32$ & 0,00 & $-0,62$ & $-0,63$ & $-0,02$ & 0,12 & 0,18 & 0,13 \\
\hline \multicolumn{11}{|l|}{ NE } \\
\hline DJF & 0,25 & $-0,56$ & $-0,32$ & 0,21 & 0,12 & $-0,59$ & 0,44 & $-0,37$ & 0,30 & $-0,17$ \\
\hline MAM & $-0,12$ & $-0,51$ & $-0,64$ & $-0,12$ & $-0,75$ & $-0,76$ & 0,09 & $-0,52$ & $-0,01$ & $-0,60$ \\
\hline JJA & 0,14 & $-0,43$ & $-0,60$ & 0,03 & $-0,50$ & $-0,51$ & 0,04 & $-0,57$ & 0,01 & $-0,39$ \\
\hline $\mathrm{SON}$ & 0,45 & 0,09 & $-0,40$ & 0,19 & $-0,44$ & $-0,79$ & 0,24 & $-0,32$ & 0,26 & $-0,24$ \\
\hline \multicolumn{11}{|l|}{ SE } \\
\hline DJF & 0,12 & $-0,55$ & 0,38 & $-0,53$ & $-0,39$ & $-0,69$ & 0,55 & 0,36 & 0,15 & 0,27 \\
\hline MAM & $-0,17$ & 0,55 & 0,07 & $-0,28$ & $-0,65$ & $-0,62$ & 0,21 & $-0,26$ & $-0,05$ & 0,19 \\
\hline JJA & $-0,15$ & 0,82 & 0,20 & $-0,18$ & 0,27 & 0,48 & $-0,12$ & 0,72 & $-0,17$ & 0,28 \\
\hline SON & 0,13 & 0,54 & $-0,40$ & $-0,24$ & $-0,63$ & $-0,60$ & $-0,11$ & 0,21 & $-0,13$ & $-0,04$ \\
\hline \multicolumn{11}{|l|}{ SUL } \\
\hline$\overline{\mathrm{DJJ}}$ & $-0,15$ & 0,56 & 0,02 & 0,23 & $-0,25$ & 0,55 & $-0,41$ & $-0,08$ & $-0,35$ & 0,42 \\
\hline MAM & $-0,03$ & 0,74 & 0,62 & $-0,07$ & 0,74 & 0,81 & $-0,08$ & 0,75 & $-0,11$ & 0,53 \\
\hline JJA & $-0,15$ & 0,75 & 0,57 & $-0,18$ & 0,31 & 0,69 & $-0,15$ & 0,78 & $-0,18$ & 0,52 \\
\hline $\mathrm{SON}$ & $-0,26$ & 0,61 & 0,54 & $-0,32$ & $-0,03$ & 0,85 & $-0,28$ & 0,71 & $-0,31$ & 0,58 \\
\hline
\end{tabular}




\section{Conclusão}

O presente trabalho avaliou a habilidade dos modelos climáticos que compõem o projeto North America Multi-Model Ensemble (NMME) para previsões sazonais sobre o Brasil, focando em cinco sub regiões: Amazônia (AMZ), Central (BC), Nordeste (NE), Sudeste (SE) e Sul (SUL). Devido à vasta quantidade de tempos de previsão e inicializações, as análises concentraram-se nas previsões para as estações de verão (Dezembro, Janeiro e Fevereiro), outono (Março, Abril e Maio), inverno (Junho, Julho e Agosto) e primavera (Setembro, Outubro, Novembro) do Hemisfério Sul. As previsões do NMME foram avaliadas através de comparações com a análise de chuva do CPC (Climate Prediction Center). Dois períodos distintos foram definidos para avaliar as previsões sazonais dos modelos do NMME: hindcast (1981/1982 - 2010) e forecast (2011 - 2018). Vários índices estatísticos (correlação e sua significância estatística obtida através do teste T-Student, desvio padrão e raiz quadrada do erro médio quadrático, viés relativo etc.) foram utilizados na avaliação das previsões do NMME.

O período de climatologia do modelo (hindcasting) permitiu identificar a presença do erro climatológico médio (viés climatológico) para as diversas regiões do Brasil. A comparação entre as regiões, mostrou que a região AMZ possui um maior viés climatológico absoluto ao longo de todas as estações do ano, enquanto para as regiões NE, BC e SE, os maiores erros absolutos foram encontrados próximos ao período de verão. Na região SUL, notou-se a presença do erro climatológico ao longo de todas as estações do ano, sendo esses erros ligeiramente menores nos meses DJFM. Em outras áreas da América do Sul, destaca-se a região dos Andes, onde há um forte viés climatológico positivo em todos os modelos do NMME e estações do ano. Em termos de viés relativos, os modelos do NMME, de um modo geral, apresentaram viéses positivos durante o período úmido e negativos durante o período seco, sendo que há uma maior dependência do erro em função da estação do ano (relativamente maiores nos meses mais secos do ano) do que do tempo (tempo de antecedência) da previsão.

A utilização do coeficiente de correlação de Pearson entre previsões e observações identificou áreas onde há uma maior habilidade (maiores correlações) de previsão da anomalia de chuva sazonal. Visto o acoplamento oceano-atmosfera dos modelos de previsão climática 
do NMME, também foram avaliados os padrões de teleconexão através dos mapas de correlações entre as anomalias de TSM e de chuva. Isto permitiu identificar quais modelos preveem padrões de teleconexão semelhantes aos observados.

Uma área de destaque entre as correlações de TSM e chuva, é a região do Pacífico Equatorial que, tanto para os padrões observados, quanto para os previstos, mostraram uma maior área de correlação, mostrando uma forte influência do fenômeno ENSO nos padrões de chuva do Brasil principalmente para as regiões AMZ, NE e SUL.

Em escala espacial regionalizada, as principais conclusões das avaliações dos períodos climatologia (1981/82 - 2010) e previsão (2011 - 2018) para cada um dos subdomínios estão sintetizadas a seguir.

\section{Região AMZ}

Para a região $\mathrm{AMZ}$, obteve-se que ao longo de todas as estações do ano valores de correlação positivos entre as precipitações previstas e observadas. Além disso, essa região mostra uma forte correlação negativa com os padrões de teleconexão que ocorrem em áreas da região do Pacífico Equatorial, que caracterizam o fenômeno de ENSO.

Na estação DJF, as maiores correlações (acima de +0,64) entre chuva prevista e observada foram as dos modelos CFSv2 e os membros do GFDL (aer04, FLORa06 e FLORb01), sendo que espacialmente há uma maior habilidade de previsão de chuva principalmente no setor mais ao norte da AMZ.

Para MAM, os modelos CFSv2, GFDLaer04 e GFDLFLORa06 continuam apresentando maiores correlações, porém, com uma maior habilidade de previsão sobre áreas ao norte do PA e TO. Nessa estação se destacam padrões de teleconexão com o Pacífico Equatorial e com o Atlântico tropical norte. Em JJA, há uma maior influência de áreas mais a leste do Pacífico Equatorial (região do Nino 1+2), sendo os modelos CFSv2, CCSM4, NASAGEOS5v2 e GFDLFLORa06 os que simulam padrões de TSM previstas similares aos observados, e as maiores correlações entre chuva prevista e observada, principalmente no setor oeste da região AMZ. 
Na estação de SON, os modelos CFSv2, CCSM4, NASAGEOS5v2, GFDLFLORa06 e CanCM4i apresentam as maiores correlações e uma melhor habilidade de previsão da chuva. As correlações são maiores ainda para áreas mais ao norte da região AMZ. Além disso, vale destacar que não foram encontradas influências dos padrões de TSM da região do Pacífico Equatorial, o que também ocorre nas previsões do CFSv2, CanCM4i e GEMNEMO.

\section{Região BC}

Em relação a região $\mathrm{BC}$, notou-se que os padrões de correlação entre a TSM e a chuva observada, não indicam uma forte influência da região Equatorial do Oceano Pacífico em todas as estações do ano Isso mostra uma baixa habilidade de previsão para essa região onde as observações não indicam qualquer influência remota na anomalia de chuva sazonal. Ao longo de todos os tempos de previsão e estações do ano obteve-se a presença de um viéses climatológico negativo nos modelos (exceto para o CFSv2), sendo que os maiores erros são encontrados durante as estações próximas à de inverno JJA, mostrando a necessidade de aplicar a correção do viéses climatológico nos resultados de previsão de chuva. Os modelos do NMME não apresentam correlações estatisticamente significativas entre a precipitação prevista e observada em DJF. As correlações de anomalias são baixas, em módulo, e indicam predominância de valores negativos em áreas mais ao sul da região BC (sobre áreas do MS) e positivas em áreas mais ao norte (sobre áreas do MT). Desta forma, não se identifica habilidade de nenhum dos modelos do NMME para a previsão da variabilidade interanual de chuva em DJF.

Para MAM, o modelo CCSM4 apresentou correlação um pouco maior e significativa entre as anomalias de chuva observadas e previstas, com valor de +0.45 . Nas áreas entre o sul do MS e PR, e sobre o MT encontram-se os maiores valores de correlação positivas e significativas na maioria dos modelos (exceto CFSv2 e GEMNEMO). As previsões para SON mostram comportamento similar às previsões de MAM (correlações baixas e com divergência entre os modelos para valores positivos e negativos). Contudo, destaca-se o modelo NASAGEOS5v2 que apresentou correlação de +0,58 entre anomalias de chuva previstas e observadas, indicando maior habilidade de previsão principalmente sobre o sul do MS. 
Em comparação com as demais estações do ano, JJA apresenta correlações maiores positivas e estatisticamente significativas entre a precipitação prevista e observada. Destacamse os modelos CFSv2, CCSM4, GFDLFLORa06 e FLORb01 com maiores correlações (acima de +0.49). Além disso, as correlações de anomalias de chuva para essa estação também são positivas e maiores principalmente sobre áreas do MS, indicando uma maior habilidade de previsão sobre esse local.

\section{Região NE}

Na região NE, obteve-se viés climatológico positivo (superestimativa da chuva) entre as estações de primavera e verão para os modelos CFSv2, GEMNEMO e NASAGEOSv5, e viés negativo (subestimativa da chuva) entre as estações de outono e inverno em praticamente todos os modelos (exceto para o modelo NASAGEOS5v2). Isto indica a necessidade de aplicar a correção de viés climatológico nas previsões de chuva. Em relação aos padrões de TSM observados, nota-se que a região do Pacífico Equatorial não apresenta correlações significativas com a chuva observada em DJF e SON, enquanto em MAM e JJA as correlações são negativas e significativas. Além disso, nessa região notou-se uma maior influência dos padrões de TSM do Oceano Atlântico tropical, o que evidencia a influência dos padrões de teleconexão TNA e TSA na chuva observada.

Tanto para o verão como primavera, a maioria dos modelos do NMME indicam padrão de correlações baixas entre as anomalias de chuva previstas e observadas, com raras exceções. Entre essas exceções destacam-se em DJF o modelo CCSM4, com correlação de +0,54, e em SON o modelo GFDLFLORa06 com correlação de +0,43. As correlações de anomalias em DJF mostram que há uma habilidade ligeiramente superior de previsão dos modelos ao norte dessa região. Esses resultados indicam que no período que antecede a estação chuvosa da maior parte do NE (DJF) há baixa correlação entre previsão e observação, indicando fraca habilidade de previsão. Comportamento similar ocorre na estação seca (SON) do NE. 
A habilidade dos modelos do NMME para a previsão de chuva aumenta consideravelmente em MAM e JJA. Em MAM os valores de correlação são positivos e elevados (acima de +0.66), indicando forte relação entre as chuvas previstas e observadas, com destaques para os modelos CCSM4, GEMNEMO, GFLFLORa06 e FLORb01. Esse aumento nos valores de correlação também se reflete nos padrões de habilidade de previsão de anomalias em algumas áreas específicas, como o norte da BA. Para JJA, as correlações entre chuva prevista e observada continuam altas (acima de +0,68), sendo os modelos CFSv2, CCSM4, NASAGEOS5v2 e CanCM4i os que apresentam maiores valores. As correlações de anomalia continuam com valores significativos em áreas mais ao norte da BA na maioria dos modelos (exceto o GEMNEMO).

Vale lembrar que diferente das estações SON e DJF, MAM e JJA mostraram maiores correlações entre a chuva prevista e observada, o que pode ser um indicativo para a influência dos padrões de teleconexão da região do Pacífico Equatorial, uma vez que em MAM e JJA há correlações estatisticamente significativas.

\section{Região SE}

Para a região SE, predomina viés climatológico negativo para a maioria dos modelos (exceto para o CFSv2 e NASAGEOS5v2) entre as estações de MAM e SON, sendo que o GFDLaer04 se destaca com maior viés em módulo. Em relação aos padrões de TSM observados nota-se que não há uma forte influência direta da região do Pacífico Equatorial, e consequentemente dos fenômenos ENSO, em todas as estações (DJF, MAM, JJA e SON). Em comparação com as demais regiões, poucos modelos apresentam correlações significativas entre chuva prevista e observada, indicando baixa habilidade de previsão da chuva sazonal. Em termos de habilidade de previsão, as correlações de anomalia de chuva mostram durante o verão (DJF) predominância de valores negativos, exceto o GEMNEMO onde a correlação é positiva $(+0,21)$ mas não estatisticamente significativa. Na primavera (MAM), alguns sinais das correlações mais significativas positivas são encontrados em áreas ao sul de SP, porém, nas demais áreas dessa região os valores tendem a ser baixos e até negativos. Em termos médios na região SE destaca-se o CFSv2 com correlação de $+0,43$. Durante a estação de JJA, nota-se um 
aumento nas correlações em todos os modelos, sendo que os maiores valores são positivos e concentrados nos setor sul do SE (principalmente em áreas de SP), indicando um pequeno aumento na habilidade de previsão sobre essas áreas. Nessa estação, destaca-se o modelo CFSv2 com maiores valores de correlação $(+0,43)$ estatisticamente significativa. Diferente das demais estações, SON apresenta um aumento da habilidade de previsão sobre áreas de MG em todos os modelos, destacando-se as correlações médias na área maiores no GEMNEMO $(+0,57)$ e CanCM4i $(+0,48)$.

\section{Região SUL}

Em relação a região SUL, nota-se um forte viés climatológico negativo entre as estações de outono e inverno em praticamente todos os modelos (exceto o CFSv2) e um viés positivo nas estações próximas da primavera e verão. A presença do viés negativo entre o outono e inverno é mais evidente no hindcast do modelo GFDLaer04. Isso indica a necessidade de aplicar a correção de viés nas previsões de chuva desse modelo para remover previsões enviesadas.

Para as influências dos padrões de TSM na precipitação, a região SUL apresenta correlação positiva e alta (acima de +0.42) em estações do ano para o padrão do ENSO no Pacífico equatorial. E esse padrão é simulado pela maioria dos modelos (principalmente CFSv2, CCSM4, GFDLFLORa06 e NASAGEOS5v2) e estações do ano. Dessa forma, além de evidenciar a influência do fenômeno ENSO sobre o a chuva nessa região, também mostra que os modelos simulam sinais de anomalias de precipitação condizentes com os esperados quando da ocorrência de El Niño ou La Niña.

A habilidade de previsão do NMME é relativamente boa no SUL. Durante as estações de DJF e SON, os maiores coeficientes de correlação são positivos e presentes sobre áreas do RS (principalmente ao sul), enquanto nas demais estações (MAM e JJA) há um deslocamento mais a norte, de forma a atingir principalmente áreas do PR e sul do MS. De uma forma geral, destaca-se a presença de uma forte correlação positiva entre as anomalias de chuva previstas e observadas sobre áreas do PR na maior parte do ano, indicando uma maior habilidade de previsão sobre essas áreas e durante todo ano. 


\section{Habilidade de previsão do NMME}

Uma conclusão geral e importante é que durante todas as estações do ano e subdomínios as previsões fornecidas pela média dos modelos (MME ou conjunto) não se sobressaiu como o melhor previsor quando comparado com a média de modelos específicos. Esse resultado aponta que melhores previsões sazonais, principalmente para a previsão de anomalias sazonais, a utilização de previsões obtidas de membros específicos do NMME pode resultar em previsões com menores erros para determinada região e estação do ano. Portanto, a figura 65 sintetiza para as quatro principais estações do ano os melhores e os piores modelos previsores da anomalia sazonal de chuva em cada subdomínio. As regiões SUL e AMZ se destacam pela presença de um maior número de modelos com potencial para serem utilizados para previsão sazonal na maior parte do ano, enquanto o oposto ocorre para as regiões SE e BC. Por outro lado, a região NE situa-se em uma posição intermediária, com vários modelos indicando potencial de previsibilidade em MAM e JJA, enquanto o número de modelos com potencial de previsão em SON e DJF diminui consideravelmente.
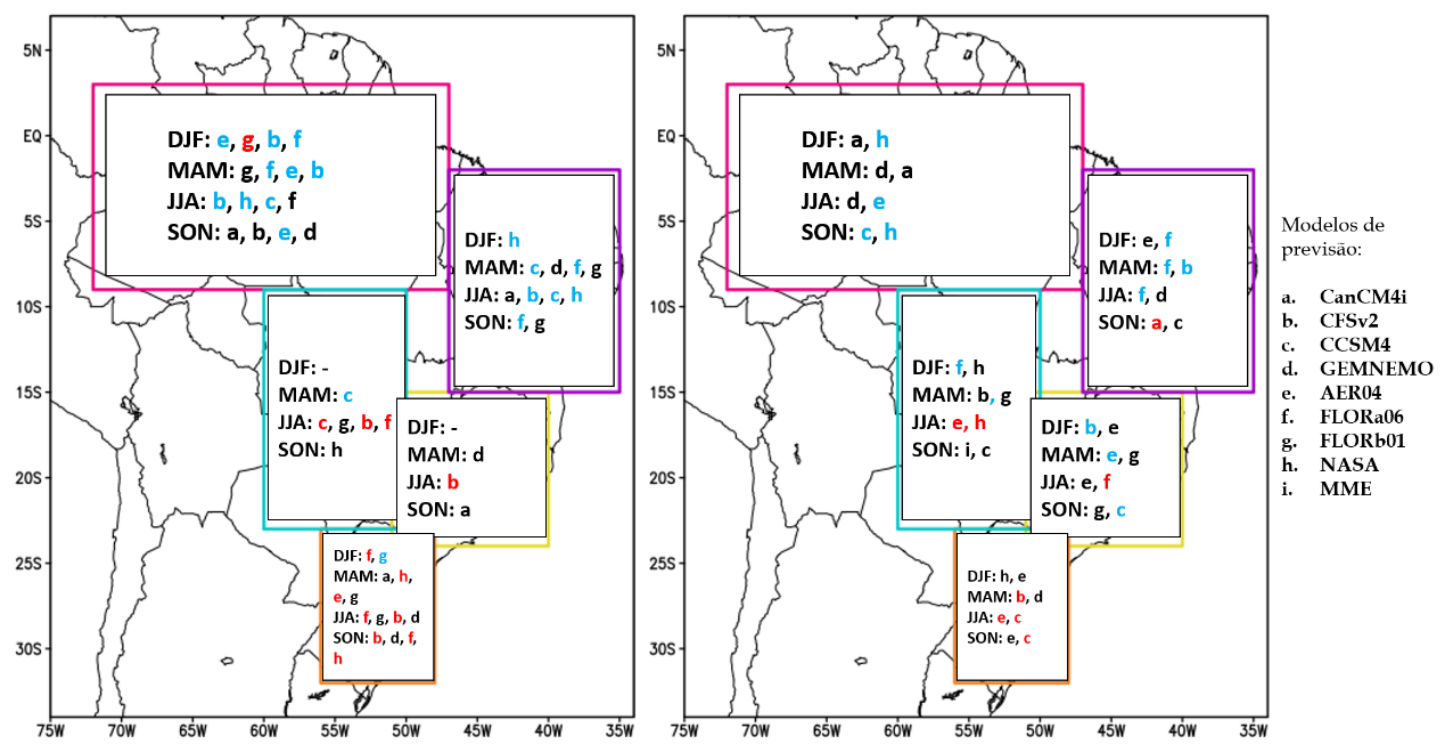

Figura 66 - Relação de até quatro melhores (a esquerda) e piores (a direita) modelos do NMME para previsão, considerando os valores de correlação entre a precipitação prevista e observada estatisticamente significativa. A ordem dos modelos (letras) indica a ordem das maiores para as menores correlações. A cor das letras mostra se determinado modelo possui correlação negativa (azul) ou positiva (vermelho) com a região do Pacífico Equatorial. 


\section{Perspectivas para trabalhos futuros}

Os conhecimentos obtidos nesse trabalho podem ser aprofundados e abordados em outros temas como:

- avaliar os membros individuais de cada modelo;

- gerar uma previsão de precipitação sazonal composta por um ensemble com os melhores modelos de cada região e estação do ano;

- realizar uma previsão probabilística considerando os quantis superiores e inferiores de chuva;

- avaliar as previsões de TSM com os padrões de teleconexão conhecidos;

- avaliar as previsões de temperatura da superfície que também é fornecido por esses modelos;

- estudar se as previsões dos modelos possuem assertividade para casos de extremo; 


\section{Referências}

Amorim, A. C., Chaves, R., and Santos e Silva, C. (2014). Influence of the tropical Atlantic Ocean's sea surface temperature in the eastern northeast Brazil precipitation. Atmospheric and Climate Sciences, 04:874-883.

Andrade, F., Coelho, C., and Cavalcanti, I. (2019). Global precipitation hindcast quality assessment of the Subseasonal to Seasonal (S2S) prediction project models. Climate Dynamics, 52.

Anochi, J. and Campos Velho, H. (2019). Neural network for seasonal climate precipitation prediction on the Brazil.

Becker, E. and Dool, H. (2015). Probabilistic seasonal forecasts in the north American MultiModel Ensemble: A baseline skill assessment. Journal of Climate, 29: 151210144222001.

Becker, E., Dool, H., and Zhang, Q. (2014). Predictability and forecast skill in NMME. Journal of Climate, 27:5891-5906.

Becker, E., Kirtman, B., and Pegion, K. (2020). Evolution of the north American Multi-Model Ensemble (NMME). Geophysical Research Letters, 47.

Bombardi, R. J., Trenary, L., Pegion, K., Cash, B., DelSole, T., and Kinter, J. L. (15 Oct. 2018). Seasonal predictability of summer rainfall over south America. Journal of Climate, 31 (20): $8181-8195$.

Borovikov, A., Cullather, R., Kovach, R., Marshak, J., Vernieres, G., Vikhliaev, Y., Zhao, B., and $\mathrm{Li}, \mathrm{Z}$. (2019). Geos-5 seasonal forecast system. Climate Dynamics, 53:1-27.

Bustamante, J., Gomes, J., and Chou, S. C. (2012). 5- Year ETA Model Seasonal forecast climatology over South America.

Cataldi, M., Assad, L. P. d. F., Torres Junior, A. R., and Alves, J. L. D. (2010). Estudo da influência das anomalias da TSM do Atlântico Sul extratropical na região da Confluência Brasil-Malvinas no regime hidrometeorológico de verão do Sul e Sudeste do Brasil. Revista Brasileira de Meteorologia, 25: 513 - 524.

Chaves, R. and Nobre, P. (2004). Interactions between Sea Surface Temperature over the South Atlantic Ocean and the South Atlantic Convergence Zone. Geophys. Res. Lett., 31. 
Chen, M., Shi, W., Xie, P., Silva, V., Kousky, V., Higgins, W., and Janowiak, J. (2008). Assessing objective techniques for gauge-based analyses of global daily precipitation. Journal of Geophysical Research (Atmospheres), 113: 4110.

Cheung, K. (2001). A review of ensemble forecasting techniques with a focus on tropical cyclone forecasting. Meteorological Applications, 8:315 - 332.

Coelho, C., Firpo, M., and Andrade, F. (2018). A verification framework for South American sub-seasonal precipitation predictions. Meteorologische Zeitschrift, 27.

Coelho, C., Prestrelo de Oliveira, C., Ambrizzi, T., Reboita, M., Carpenedo, C., Campos, J., Tomaziello, A. C., Pampuch, L., Custodio, M., Dutra, L., Rocha, R., and Reh- bein, A. (2015). The 2014 southeast Brazil austral summer drought: Regional scale mechanisms and teleconnections. Clim. Dyn., pages 1-1.

Coelho, C., Uvo, C., and Ambrizzi, T. (2002). Exploring the impacts of the tropical pacific SST on the precipitation patterns over south America during ENSO periods. Theoretical and Applied Climatology, 71: 185-197.

Danabasoglu, G. (2020). Introducing to the Community Earth System Model (CESM). NCAR/UCAR.

Delworth, T., Broccoli, A., Rosati, A., Ronald, S., Balaji, V., Beesley, J., Cooke, W., Dixon, K., Dunne, J., Dunne, K., Durachta, J., Findell, K., Ginoux, P., Gnanadesikan, A., Gordon, C., Griffies, S., Gudgel, R., Harrison, M., Held, I., and Zhang, R. (2006). GFDL's, CM2 global coupled climate models. part i: Formulation and simulation characteristics. Journal of Climate, 19:643-674.

Delworth, T., Rosati, A., Anderson, W., Adcroft, A., Balaji, V., Benson, R., Dixon, K., Griffies, S., Lee, H., Pacanowski, R., Vecchi, G., Wittenberg, A., Zeng, F., and Zhang, R. (2011). Simulated climate and climate change in the GFDL CM2.5 high-resolution coupled climate model. J. Clim., 25

DeWitt, D. G. (2005). Retrospective forecasts of Interannual Sea Surface Temperature anomalies from 1982 to present using a directly coupled atmosphere-Ocean general circulation model. Monthly Weather Review, 133 (10): 2972 - 2995.

Diaz, A., Studzinski, C., and Mechoso, C. (1998). Relationships between precipitation anomalies in Uruguay and southern Brazil and Sea Surface Temperature in the Pacific and Atlantic Oceans. Journal of Climate, 11: 251-271.

Drumond, A. and Ambrizzi, T. (2008). The role of the south Indian and Pacific Oceans in south American monsoon variability. Theoretical and Applied Climatology, 94: 125-137. 
Edwards, P. N. (2011). History of climate modeling. WIREs Climate Change, 2 (1) :128- 139.

Gimeno, L. (2013). Grand challenges in atmospheric science. Frontiers in Earth Science, 1.

Goddard, L., Mason, S., Zebiak, S., Ropelewski, C., Basher, R., and Cane, M. (2001). Current approaches to seasonal to interannual climate predictions. International Journal of Climatology, 21 (9): 1111-1152.

Grimm, A. M. and Ambrizzi, T. (2009). Teleconnections into South America from the Tropics and Extratropics on Interannual and Intraseasonal Timescales. Springer Netherlands, pages 159-191. Dordrecht.

Guimarães, B. S., Coelho, C. A. S., Woolnough, S. J., Kubota, P. Y., Bastarz, C. F., Figueroa, S. N., Bonatti, J. P., and de Souza, D. C. (2020). Configuration and hind- cast quality assessment of a Brazilian global sub-seasonal prediction system. Quarterly Journal of the Royal Meteorological Society, 146 (728): 1067-1084.

Harzallha, A., Rocha de Aragão, J.O., and Sadourny, R (1996). Interannual rainfall variability in north-east Brazil: Observation and model simulation. International Journal of Climatology, 16 (8): 861-878.

Herring, S., Hoerling, M., Kossin, J., Peterson, T., and Stott, P. (2015). Introduction to explaining extreme events of 2014 from a climate perspective. Bulletin of the American Meteorological Society, 96: S1-S4.

Infanti, J. M. and Kirtman, B. P. (2014). Southeastern U.S. rainfall prediction in the north American Multi-Model ensemble. Journal of Hydrometeorology, 15 (2): 529 - 550.

Kalnay, E. (2002). Atmospheric Modeling, Data Assimilation and Predictability. Cambridge University Press.

Kirtman, B. P. and Min, D. (2009). Multi-Model ensemble ENSO prediction with CCSM and CFS. Monthly Weather Review, 137 (9): 2908 - 2930.

Kirtman, B. P., Min, D., Infanti, J. M., Kinter, J. L., Paolino, D. A., Zhang, Q., van den Dool, H., Saha, S., Mendez, M. P., Becker, E., Peng, P., Tripp, P., Huang, J., DeWitt, D. G., Tippett, M. K., Barnston, A. G., Li, S., Rosati, A., Schubert, S. D., Rienecker, M., Suarez, M., Li, Z. E., Marshak, J., Lim, Y.-K. Tribbia, J., Pegion, K., Merryfield, W. J., Denis, B., and Wood, E. F. (01 Apr. 2014). The north American Multi-Model ensemble: Phase-1 Seasonal-toInterannual prediction; phase- 2 toward developing Intraseasonal prediction. Bulletin of the American Meteorological Society, 95 (4): 585 - 601.

Klingaman, N. P., Young, M., Chevuturi, A., Guimaraes, B., Guo, L., Woolnough, S. J., Coelho, C. A. S., Kubota, P. Y., and Holloway, C. E. (2021). Subseasonal prediction performance 
for austral summer south American rainfall. Weather and Forecasting, 36 (1): 147 - 169.

Larson, S. M. and Kirtman, B. P. (2014). The pacific meridional mode as an ENSO precursor and predictor in the north American Multi-Model ensemble. Journal of Climate, 27 (18): $7018-7032$.

Leith, C. E. (1974). Theoretical skill of Monte Carlo forecasts. Monthly Weather Review, 102 (6): $409-418$.

Li, W., Li, L., Fu, R., Deng, Y., and Wang, H. (2011). Changes to the north Atlantic subtropical high and its role in the intensification of summer rainfall variability in the southeastern United States. Journal of Climate - J. Climate, 24: 1499-1506.

Lin, H., Merryfield, W., Muncaster, R., Smith, G., Markovic, M., Dupont, F., Roy, F., Lemieux, J.-F., Dirkson, A., Kharin, V., Lee, W.-S., Charron, M., and Erfani, A. (2020). The Canadian Seasonal to Interannual prediction system version 2 (CANSIPSv2). Weather and Forecasting, 35.

Machado, R. and Rocha, R. (2011). Seasonal climatic forecast over Brazil: evaluation of the RegCM3 model nested to the CPTEC/COLA global model. Revista Brasileira de Meteorologia, 26: 121-136.

Mason, S. and Goddard, L. (2001). Probabilistic precipitation anomalies associated with ENSO. Bulletin of the American Meteorological Society, 82: 619-638.

Merryfield, W., Lee, W.-S., Boer, G., Kharin, V., Scinocca, J., Flato, G., Ajayamohan, R., Fyfe, J., Tang, Y., and Polavarapu, S. (2013). The Canadian Seasonal to Interannual prediction system. part I: Models and initialization. Monthly Weather Review, 141.

Mo, K. and Lyon, B. (2015). Global meteorological drought prediction using the north America Multi-Model Ensemble. Journal of Hydrometeorology, 16: 150310071054006.

Molod, A., Hackert, E., Vikhliaev, Y., Zhao, B., Barahona, D., Vernieres, G., Borovikov, A., Kovach, R., Marshak, J., Schubert, S., Li, Z., Lim, Y.-K., Andrews, L., Cullather, R., Koster, R., Achuthavarier, D., Carton, J., Coy, L., Freire, J., and Pawson, S. (2020). GEOS-S2s version 2: The GMAO high resolution coupled model and assimilation system for seasonal prediction. Journal of Geophysical Research: Atmospheres, 125.

Moura, G., Oribe, J., Aragão, R., Lacerda, F., and Passavante, J. (2000). Relação entre a precipitação no setor leste do nordeste do Brasil e a temperatura da superfície nos Oceanos Atlântico e Pacífico. Revista Brasileira de Engenharia Agrícola e Ambiental, 4. 
Palmer, T. N., Alessandri, A., Andersen, U., Cantelaube, P., Davey, M., Délécluse, P., Déqué, M., Díez, E., Doblas-Reyes, F. J., Feddersen, H., Graham, R., Gualdi, S., Guérémy, J.-F., Hagedorn, R., Hoshen, M., Keenlyside, N., Latif, M., Lazar, A., Maisonnave, E., Marletto, V., Morse, A. P., Orfila, B., Rogel, P., Terres, J.-M., \& Thomson, M. C. (2004). Development of a European Multi-Model ensemble system for Seasonal-to-Interannual prediction (DEMETER). Bulletin of the American Meteorological Society, 85 (6): 853 - 872.

Pezzi, L. and Cavalcanti, I. (2001). The relative importance of ENSO and tropical Atlantic sea surface temperature anomalies for seasonal precipitation over south America. Clim. Dyn, 17.

Reboita, Michelle Simões, Dias, Cássia Gabriele, Dutra, Lívia Márcia Mosso, Rocha, Rosmeri Porfírio da, e Llopart, Marta (2018). Seasonal climate forecast to Brazil obtained through global and regional climate models. Revista Brasileira de Meteorologia, 33:207 - 224.

Reboita, M., Gan, M., Rocha, R., and Ambrizzi, T. (2010). Regimes de precipitação na América do Sul: Uma revisão bibliográfica. Revista Brasileira de Meteorologia, 25: 185- 204.

Rodrigues, R., Haarsma, R., Campos, E., and Ambrizzi, T. (2011). The impacts of inter-El Niño Variability on the tropical Atlantic and Northeast Brazil climate. Journal of Climate, 24.

Ropelewski, C. F. and Halpert, M. S. (1987). Global and regional scale precipitation patterns associated with the El Niño/Southern oscillation. Monthly Weather Review, 115 (8): $1606-1626$.

Saha, S., Moorthi, S., Wu, X., Wang, J., Nadiga, S., Tripp, P., Behringer, D., Hou, Y.-T., Chuang, H.-Y., Iredell, M., Ek, M., Meng, J., Yang, R., Peña, M., Dool, H., Zhang, Q., Wang, W., Chen, M., and Becker, E. (2014a). The NCEP Climate Forecast System Version 2. Journal of Climate, 27:2185-2208.

Salgueiro, J., Montenegro, S., Pinto, E., Silva, B. B., Souza, W., and Oliveira, L. (2016). Influence of Oceanic-atmospheric interactions on extreme events of daily rainfall in the subbasin 39 located in northeastern Brazil. RBRH, 21.

Sampaio, G. and Silva Dias, P. (2014). Evolução dos modelos climáticos e de previsão de tempo e clima. Revista USP, página 41.

Shukla, S., Khan, S., AghaKouchak, A., Guan, K., and Funk, C. (2015). Temperature impacts on the water year 2014 drought in California. Geophysical Research Letters, 42.

Smith, D., Scaife, A., Boer, G., Caian, M., Guemas, V., Hawkins, E., Hazeleger, W., Hermanson, L., Ho, C., Ishii, M., Kharin, V., Kimoto, M., Kirtman, B., Lean, J., Matei, , Merryfield, W., Muller, W., Pohlmann, H., Rosati, A., and Wyser, K. (2012). Real-time Multi-Model decadal climate predictions. Climate Dynamics, 41. 
Souza, P. and Cavalcanti, I. (2009). Atmospheric centers of action associated with the Atlantic ITCZ position. International Journal of Climatology, 29.

Tian, D., Martinez, C., Graham, W., and Hwang, S. (2014a). Statistical downscaling MultiModel forecasts for seasonal precipitation and surface temperature over the southeastern United States. Journal of Climate, 27: 8384-8411.

Tian, D., Martinez, C. J., Graham, W. D., and Hwang, S. (2014b). Statistical downscaling Multi-Model forecasts for seasonal precipitation and surface temperature over the southeastern United States. Journal of Climate, 27 (22): 8384 - 8411.

Toth, Z. and Kalnay, E. (1993). Ensemble forecasting at NMC: The generation of perturbations. Bulletin of the American Meteorological Society, 74 (12): 2317 - 2330.

Toth, Z., Talagrand, O., Candille, G., and Zhu, Y. (2003). Probability and ensemble forecasts. Chapter 7.

Uvo, C., Repelli, C., Zebiak, S., and Kushnir, Y. (1998). The relationships between tropical pacific and Atlantic SST and northeast Brazil monthly precipitation. Journal of Climate - J. Climate, 11: 551-562.

Wilks, D. S. (2011). Statistical methods in the atmospheric sciences. Elsevier Academic Press, Amsterdam; Boston.

Xie, P., Yatagai, A., Chen, M., Hayasaka, T., Fukushima, Y., Liu, C., and Yang, S. (2007). A gauge-based analysis of daily precipitation over east Asia. Journal of Hydrometeorology - J. Hydrometeorol, 8. 